\title{
Experimental studies of electromagnetic signals to enhance radio imaging method (RIM)
}

\author{
William D. Monaghan \\ West Virginia University
}

Follow this and additional works at: https://researchrepository.wvu.edu/etd

\section{Recommended Citation}

Monaghan, William D., "Experimental studies of electromagnetic signals to enhance radio imaging method (RIM)" (2007). Graduate Theses, Dissertations, and Problem Reports. 1860.

https://researchrepository.wvu.edu/etd/1860

This Thesis is protected by copyright and/or related rights. It has been brought to you by the The Research Repository @ WVU with permission from the rights-holder(s). You are free to use this Thesis in any way that is permitted by the copyright and related rights legislation that applies to your use. For other uses you must obtain permission from the rights-holder(s) directly, unless additional rights are indicated by a Creative Commons license in the record and/ or on the work itself. This Thesis has been accepted for inclusion in WVU Graduate Theses, Dissertations, and Problem Reports collection by an authorized administrator of The Research Repository @ WVU. For more information, please contact researchrepository@mail.wvu.edu. 


\title{
EXPERIMENTAL STUDIES OF ELECTROMAGNETIC SIGNALS TO ENHANCE RADIO IMAGING METHOD (RIM)
}

\author{
William D. Monaghan
}

Thesis submitted to the College of Engineering and Mineral Resources

West Virginia University

In partial fulfillment of requirements for the degree of

\section{Master of Science \\ In \\ Mining Engineering}

Yi Luo, Ph. D.

Keith A. Heasley, Ph. D.

Syd S. Peng, Ph. D.

\section{Department of Mining Engineering \\ Morgantown, West Virginia \\ 2007}

Keywords: Electromagnetic, Radio Imaging Method (RIM), RADAR, Attenuation, Geologic Anomalies, Physical Model, Longwall Mining 


\title{
ABSTRACT \\ EXPERIMENTAL STUDIES OF ELECTROMAGNETIC SIGNALS TO ENHANCE RADIO IMAGING METHOD (RIM)
}

\author{
William D. Monaghan
}

Safety and production of coal mining operations could be greatly affected by geologic anomalies such as faults, sandstone intrusions, dykes, fracture zones, sudden thinning and severe undulation of the coal seam. Since most of these geologic anomalies in coal seams effect the attenuation rate of electromagnetic signal that passes through them, the radio imaging method (RIM), using a signal in the kilohertz range, is capable of locating the zones of geologic anomalies in underground coal mines with the help of tomographic reconstruction programs. RIM technology is a promising geophysical tool for exploring the geologic anomalies ahead of modern longwall faces, which are normally wider than 1,000 $\mathrm{ft}$. When multiple geologic anomalies co-exist in an area, it is very difficult for RIM technology to differentiate the contributions of each individual anomalous factor. Other problems with RIM technology are the angular spreading and moisture content is not taken into consideration of the surveyed area. To increase the accuracy of RIM technology, spatial spreading testing and a scaled physical model were employed to investigate the capabilities and limitations of RIM technology. To simulate the RIM technology, a Ground Penetration RADAR (GPR) system was modified and a higher frequency signal was used in the scaled physical model. One of the problems using the GPR was that data collected was represented in counts and formulae had to be developed in order to convert the data into volts. Laboratory testing was conducted to assure proper similarities between the actual longwall panel and the scaled physical model. These model tests were done to gain a better quantitative understanding of the propagation of EM signals in the physical model. The testing procedure and data results are presented and quantified. 


\section{DEDICATION}

This Master thesis is dedicated to my great grandfather, Patrick John Monaghan (1866 - 1949) and my father Patrick David Monaghan (1934 - 2000). My father was my best friend, my greatest hero, and a great mentor. He always encouraged me to do my best and to treat others with respect. My father told me about my great grandfather's life as a coal miner. My great grandfather was a coal miner in the early 1900's in Dravosburg, PA, and placed his life in harm's way every day when he worked in the coal mines. I received my great grandfather's coal mining pick as a gift on Aug 19, 2006 at the annual Monaghan $57^{\text {th }}$ family reunion held in South Park, PA. I now treasure his coal mining pick with great pride and honor.

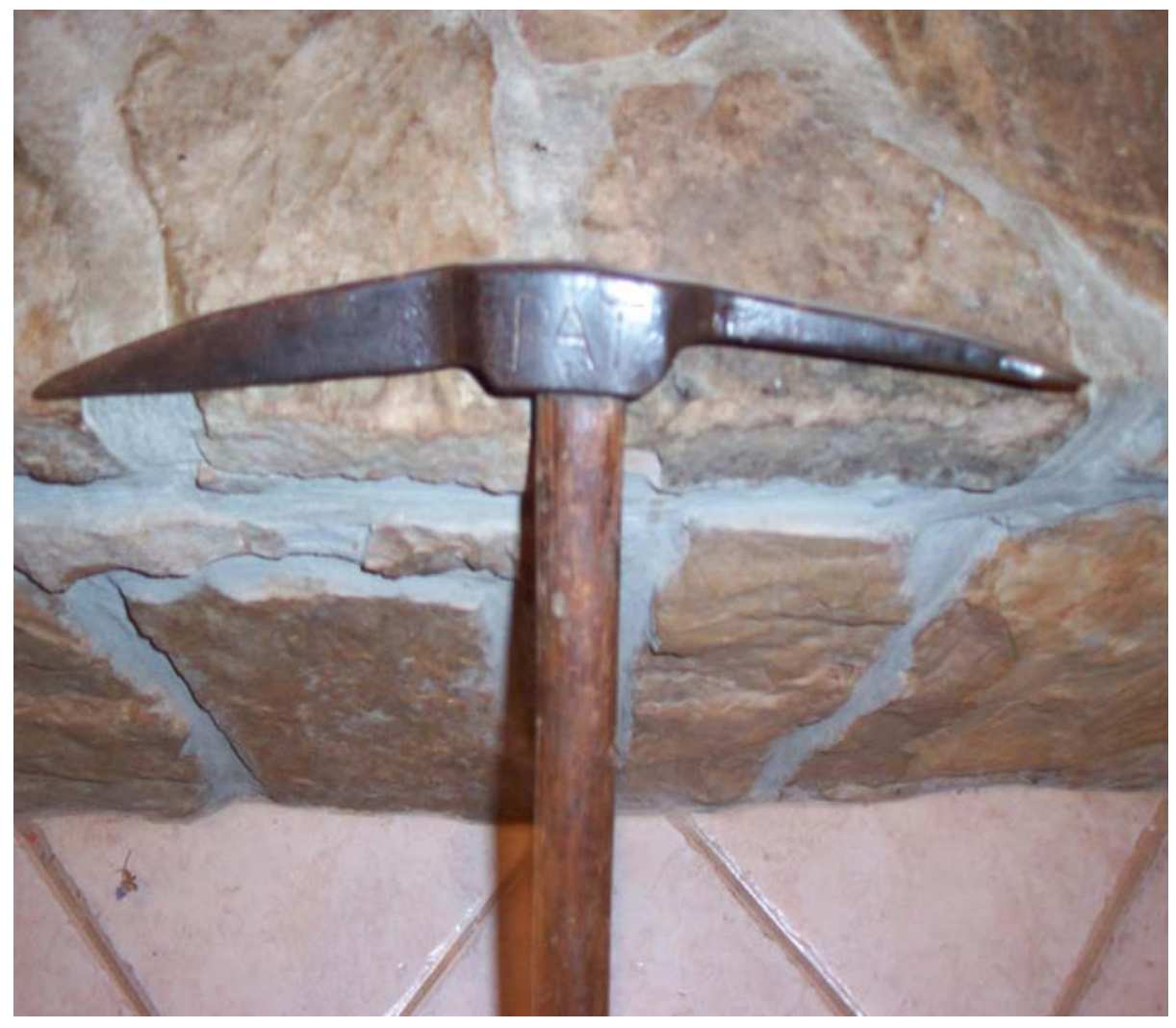




\section{ACKNOWLEDGEMENT}

The author wishes to thank those of the Department of Mining Engineering for being members of my committee, who have contributed to the preparation and completion of this thesis. A debt of gratitude is owed to Dr. Yi Luo (my Advisor) for his encouragement and guidance in my studies at West Virginia University. Special appreciation is also given to Dr. Syd S. Peng, for his support and valuable suggestions during this research work. I would also like to thank Dr. Keith Heasley for being on my committee and for his friendship. In addition, thanks goes out to Dr. Chris Bise for taking a vested interest and offering valuable information and assistance in the pursuit of my advanced degree.

The author also wishes to express his thanks to his fellow students and the staff of CEMR during this program. Thanks are extended with admiration and respect to Jun $\mathrm{Lu}, \mathrm{Ph}$. D. graduate student for his invaluable partnership in conducting this complex research and more importantly, his friendship. This research would never have been possible without the efforts of Jun Lu. Jun Lu spent many hours determining the proper size, proper materials and constructing the physical model. Jun Lu willingly addressed all of my concerns and always participated in many lengthy tests performed.

I would also like to thank Alex Smith, Jerry Finfinger, Jürgen Brune, and Gerrit Goodman. Alex Smith, who is my manager, always went that extra mile to help me in any way he could. Alex is a diehard WVU fan. In addition appreciation is owed to Gary Mowrey, Mike Trevits and Liming Yuan my fellow coworkers at NIOSH for their support and encouragement.

I am also grateful for my good friend Tom Rebottini (Rebo), who is currently working as a coal miner at Foundation's Emerald Mine. Rebo has many years of experience around the longwall face area and was an invaluable source of information during my studies at WVU.

Finally, sincere thanks to my wife, Pamela, daughter, Meghan and son, William, for their support

and tolerating me while I was studying at home in the evenings and on the weekends and allowing me to achieve this goal at the family's expense. Pam provided me the love, support and encouragement I needed to complete this goal. 


\section{TABLE OF CONTENTS}

ABSTRACT
DEDICATION
ACKNOWLEDGEMENT
TABLE OF CONTENTS
LIST OF FIGURES TABLES
LIST OF ABBREVIATIONS

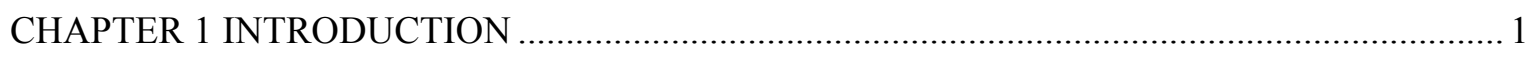

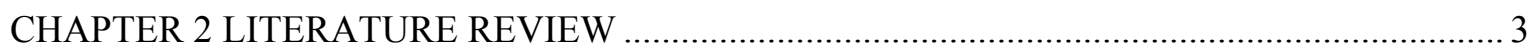

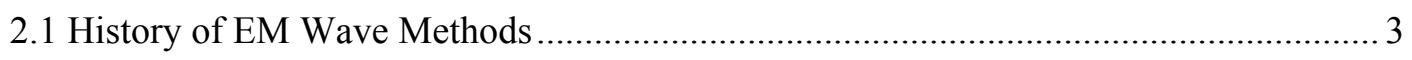

2.2 EM Terminology, Definitions and Examples ….................................................. 3

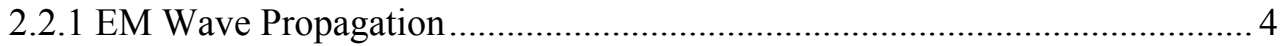

2.2.2 Electrical and Magnetic Properties of Rock, Soils and Fluids......................... 4

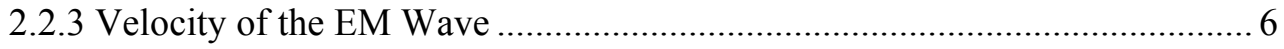

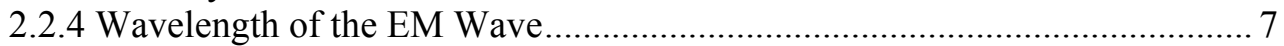

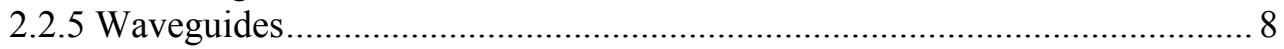

2.2.6 Attenuation, Resistivity, Conductivity ...................................................... 9

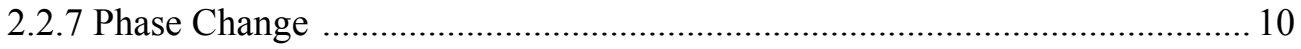

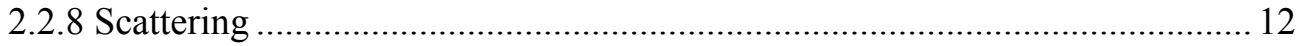

2.3 Applications and Limitations of RIM Technology for Modern Longwall Mining ......... 12

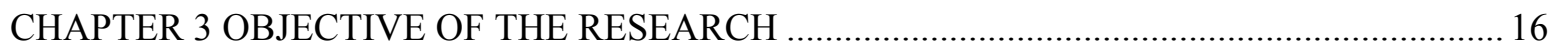

CHAPTER 4 METHODODOLOGY OF THE RESEARCH .................................................... 17

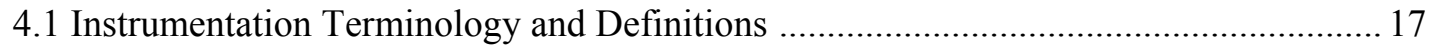

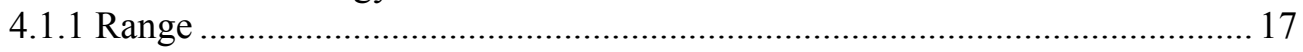

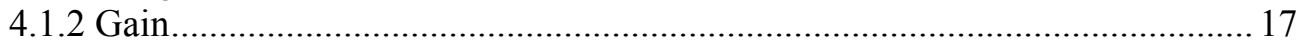

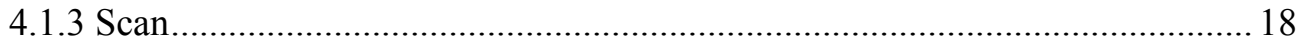

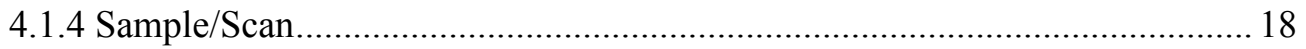

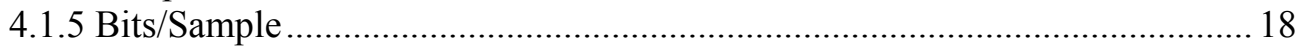

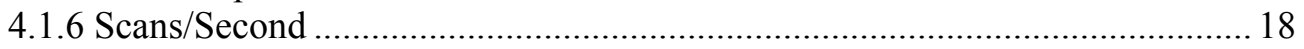

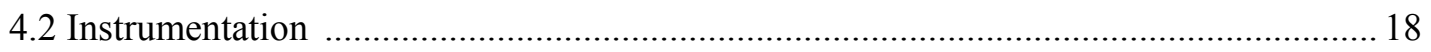

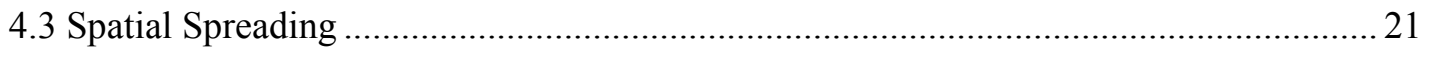

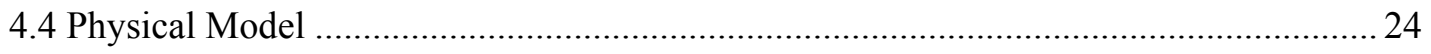




\section{TABLE OF CONTENTS (Continued)}

CHAPTER 5 DATA COLLECTION AND PREPARATIONS …................................................... 27

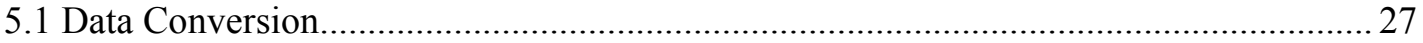

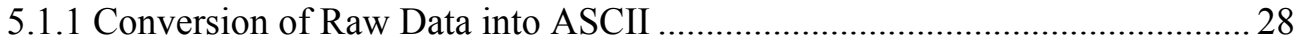

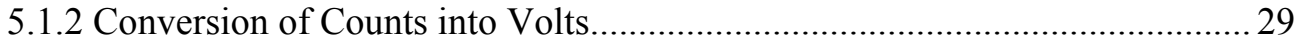

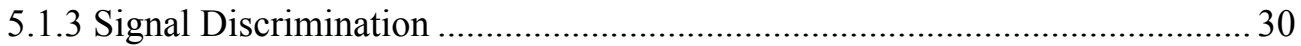

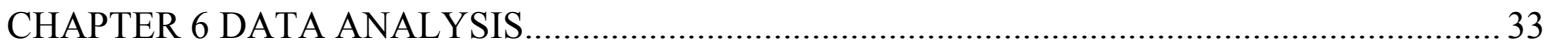

6.1 Signal Strength Reduction as Spatial Spreading Data Analysis ..................................... 34

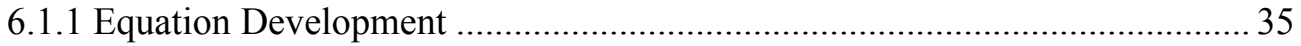

6.1.2 Signal Strength Reduction Development for the Equation in the

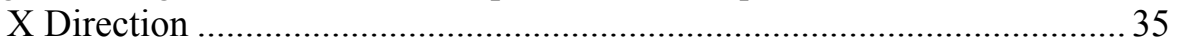

6.1.3 Signal Strength Reduction Development for the Equation in the

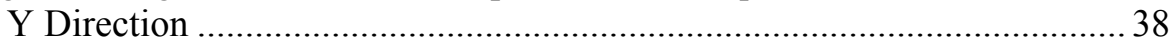

6.1.4 Measured Radiation Distribution in the Y Direction ..................................... 39

6.1.5 Signal Strength Reduction Development for the Equation in the

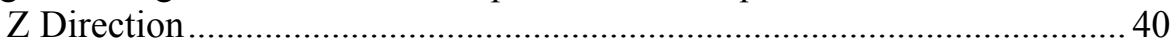

6.16 Measured Radiation Distribution in the Z Direction ..................................... 41

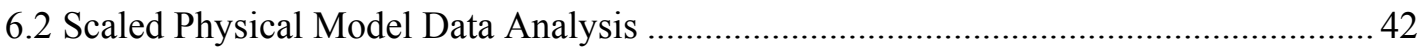

6.2.1 Procedure to Determine the Voltage Attenuation Rate in the Scaled Physical

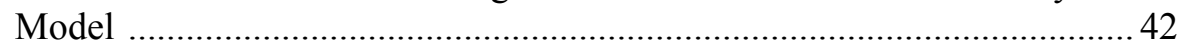

6.2.2 Reconnaissance Survey Scaled Physical Model ............................................ 44

6.2.3 Distribution of EM Signal Attenuation of the Dry and Wet Physical Model . 44

6.2.4 Reconnaissance Survey of the Dry Physical Model ..................................... 45

6.2.5 Reconnaissance Survey of the Wet Physical Model ....................................... 56

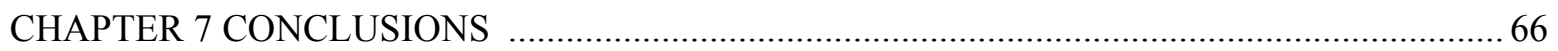

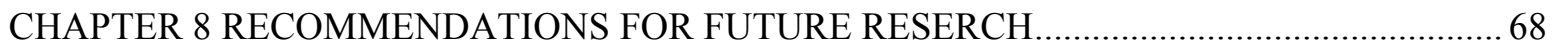

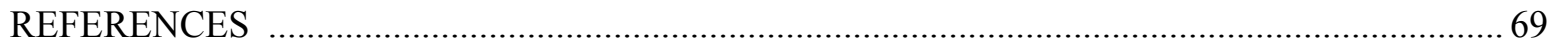

APPENDIX A

APPENDIX B

APPENDIX C

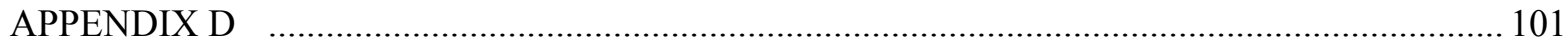




\section{LIST OF FIGURES}

$\underline{\text { Figure \# }}$

$\underline{\text { Page \# }}$

1.1 RIM imagining instrumentation 1

2.1 Moisture effects on the dielectric constant at different moisture levels for a coal sample from the Sewickley seam 5

2.2 Moisture effects on the attenuation rate at different moisture levels for a coal sample from the Sewickley seam 5

2.3 Cross section of a coal seam showing EM wave flow. 8

2.4 Attenuation increase in a coal seam... 11

Natural waveguide anomalies in coal seams.

Typical RIM survey setup for a longwall panel...... 


\section{LIST OF FIGURES (Continued)}

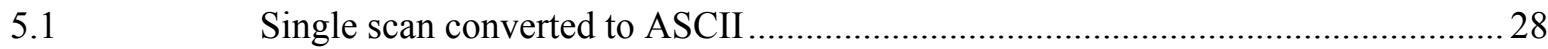

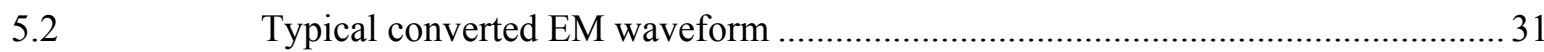

Example of measured signal strength in the physical model ................................ 34

Example of signal strength reduction and spreading in air ................................... 35

Center spreading points used to determine the $\mathrm{X}$ equation.................................... 36

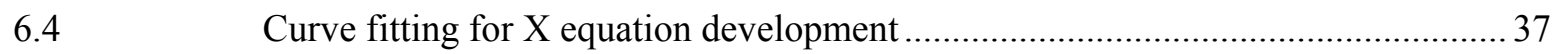

Curve fitting for Y equation development ...................................................... 39

Measured radiation distributions in the $\mathrm{Y}$ direction............................................. 40

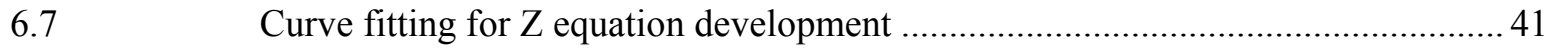

6.8 Measured radiation distributions in the $\mathrm{Z}$ direction .......................................... 42

6.9 Example of determining signal attenuation rate in the scaled physical model ........ 43

6.10 Total signal strength attenuation distribution in dry physical model .................... 44

6.11 Total signal strength attenuation distribution in wet physical model ....................45

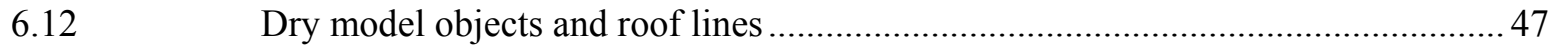

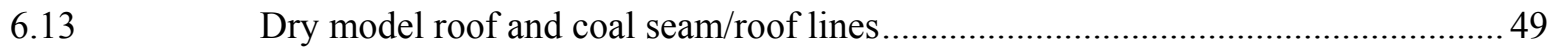

6.14 Dry model coal seam/roof and coal seam lines................................................... 51

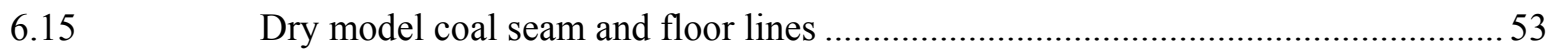

Image of wet physical model with survey lines (L1-L5) ....................................... 56

Image of wax paper and crack in wet physical model ......................................... 57

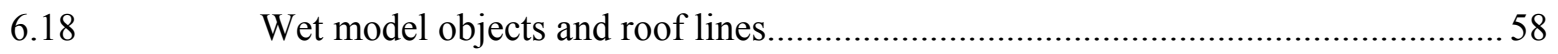

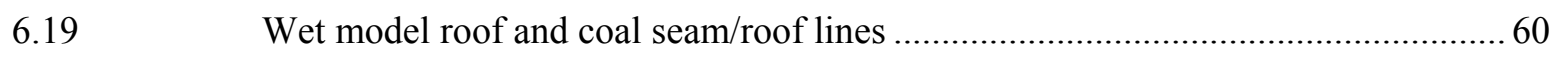




\section{LIST OF FIGURES (Continued)}

Figure \#

$\underline{\text { Page \# }}$ 


\section{LIST OF TABLES}

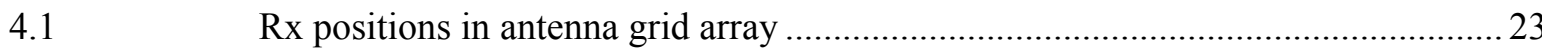

G.1 Gain factors, voltage scaling factors and counts scaling factors......................... 32

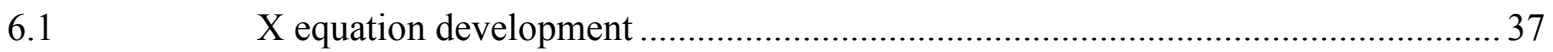

6.2 Spatial spreading testing $\mathrm{Tx}$ and $\mathrm{Rx}$ in the horizontal position $(\mathrm{Y}) \ldots \ldots \ldots \ldots \ldots \ldots \ldots . . . . . . . . . . . .38$

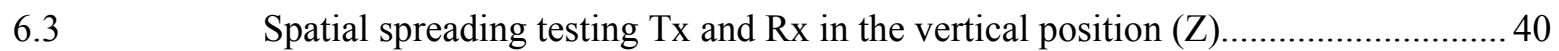

6.4 Reconnaissance survey dry physical model line 5 objects ................................... 48

Reconnaissance survey dry physical model line 4 roof ..................................... 50

6.6 Reconnaissance survey dry physical model line 3 coal seam/roof ....................... 52

Reconnaissance survey dry physical model line2 coal seam ................................ 54

Reconnaissance survey dry physical model line1 floor ....................................... 55

Reconnaissance survey wet physical model line 5 objects .................................. 59

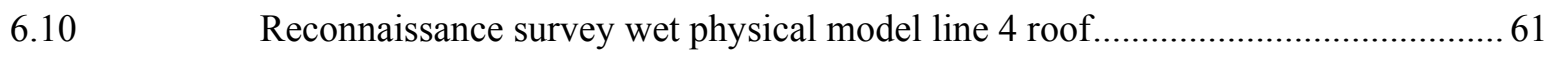

Reconnaissance survey wet physical model line 3 coal seam/roof........................ 62

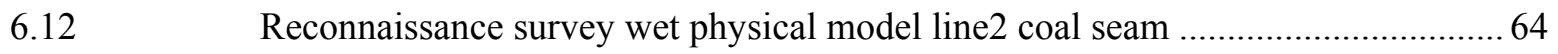

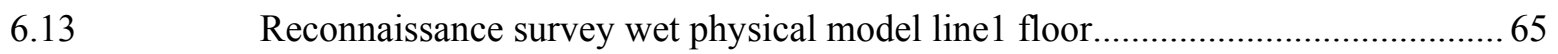




\section{ABBREVIATIONS OF UNITS}

$\mathrm{dB}-$ decibels

$\mathrm{ft}-\mathrm{feet}$

$\mathrm{Hz}$ - cycle/second

in - inches

$\mathrm{m}$ - meters

ns - nanoseconds

$\mathrm{s}-$ seconds

$\mu \mathrm{V}-$ microvolts

$\mu \mathrm{W}-$ microwatts

V - volts

W - watts 


\section{CHAPTER 1}

\section{INTRODUCTION}

Electromagnetic (EM) waves can propagate via highly resistive layers in the earth. A waveguide (boundaries capable of guiding electromagnetic waves) can be formed by a coal seam bounded by conducting rock (Wait, 1976). The Radio Imaging Method (RIM), which was developed about twenty years ago, shows promise in being able to locate geologic anomalies ahead of the longwall face and is based on Wait's findings. These geologic anomalies in the coal seam may be caused by faults, sandstone intrusions, dykes, fracture zones, sudden thinning and severe undulation of coal seams and can cause difficult mining conditions, loss of production and safety issues.

RIM technology is based on the EM wave properties, velocity and attenuation in the coal seam. Geologic anomalies in the coal seam affect the velocity (electromagnetic wave propagation described by the speed of light) usually presented in meter per second $(\mathrm{m} / \mathrm{s})$ and attenuation rate (the rate of reduction of the average power with respect to distance along a transmitting path) usually presented in decibels per meter $(\mathrm{dB} / \mathrm{m})$. From these changes in the EM wave it is possible to generate tomographic imaging (similar to a medical CAT scan) of the coal seam showing the geologic anomalies within the seam.

Figure 1.1 illustrates a RIM instrumentation setup on a longwall panel. This instrumentation consists of a transmitter (Tx) antenna, which is typically positioned on the headgate side of the longwall panel, and a receiving ( $\mathrm{Rx})$ antenna, which is usually positioned on the tailgate side. The theory of operation for the RIM technology is that the transmitted EM wave travels along a path in the coal seam and is received by the receiver antenna. As the EM wave encounters anomalies in the coal seam the EM wave changes in velocity and magnitude.

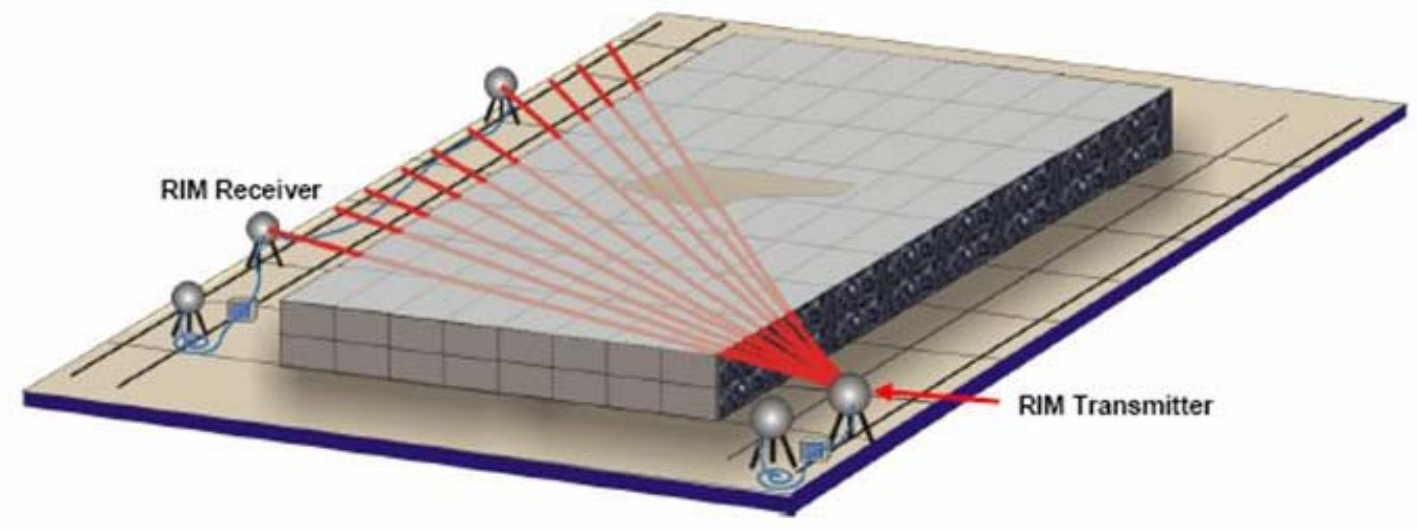

Figure 1.1 RIM imaging instrumentation (Stolarczyk and Peng, 2003) 
The objective of this research is to increase the accuracy of the RIM technology by studying the EM wave properties on a scaled physical model of a longwall panel and quantifying the data collected. When multiple geologic anomalies co-exist in an area, it is very difficult for RIM technology to differentiate the contributions of each individual anomalous factor. Other problems with RIM technology are the angular spreading and moisture content is not taken into consideration of the surveyed area.

As mentioned earlier, the RIM instrumentation uses two antennas (one transmitter and one receiver) that are physically separated. In a typical RADAR system, one antenna is used for both the transmitter and receiver. This was a problem with the GPR system, provided by the National Institute for Occupational Safety and Health (NIOSH) used in this research. The GPR system was modified using a specialized antenna break-out-box, to allow the separation of the transmitter and receiver antenna. Another one of the problems using the GPR was that data collected was represented in counts and formulae had to be developed in order to convert the data into volts.

Prior to the EM surveys on the physical model, spatial spreading tests were performed in air inorder to understand the EM wave signal strength and to develop the generation of angular and center spreading equations. In the physical model, the coal seam, floor, roof strata and geologic anomalies were simulated with properly mixed materials. The physical model was tested at different times to demonstrate the effect of aging and moisture content. The physical model EM test data was post-processed in several steps to quantify the data with known physical parameters of the model. This processed data was used to generate individual EM line scans and contour maps that in turn were compared with the embedded geologic anomalies. The end results demonstrate the various attenuations for each EM signal scan. These tests provide a better understanding of the propagation and signal characteristics of the EM signals that can be used to improve RIM. 


\section{CHAPTER 2}

\section{LITERATURE REVIEW}

\subsection{History of EM Wave Methods}

The first survey using EM wave methods was performed in 1929 to sound the depth of a glacier (Stern, 1929, 1930). This EM wave method did not become popular until the late 1950's when the United States Air Force planes RADAR were seeing through ice as they tried to land in Greenland, but the pilots misread the altitude and crashed into the ice. This started the investigation of EM waves to see into the subsurface not only for ice sounding but also for mapping of subsoil properties and water tables (Cook, 1960). In 1967, a system was proposed and then built and flown as the surface electrical properties experiments on Apollo 17 to the moon.

After 1972, an explosion of applications, publications and research started in the field of EM wave technologies for geologic surveys by Geological Survey of Canada, United States Army Cold Regions Research and Engineering Laboratory (CRREL), Ohio State University (OSU), United States Bureau of Mines (USBM), Colorado School of Mines, Stolar Horizon Inc., and others (Olhoeft, 2003). Over 300 patents have been issued around the world based on EM wave technologies to detect and map geological conditions. In addition, many institutions, including West Virginia University, are performing research to further enhance the understanding of the complex propagation mechanism of the EM signals in geological formations for underground geological mapping.

The mining industry has shown a growing interest in non-invasive technologies for detecting and mapping geological conditions for several decades. Since the Quecreek mining accident that occurred on July 24, 2002, the Pennsylvania state government established the Governor's Commission on Mine Voids and Mine Safety to investigate and document hazards regarding accurate location of voids and avoidance of other hazards associated with mining (Commonwealth of Pennsylvania, 2002). One of the Commission's recommendations was to continue research, development and refinement of the various geophysical methods and to enable these techniques to be applied separately or in conjunction with drilling to provide more positive results pertaining to the location of and definition of mine voids (PA DEP, 2002).

\subsection{EM Terminology, Definitions and Examples}

The common terminology and definitions associated with EM wave theory are presented in this section in order to give the reader a more comprehensive understanding of this science. 


\subsubsection{EM Wave Propagation}

Maxwell's Equations describe the propagation of an electromagnetic field. The patterns of EM wave propagation and scattering can be used to locate and quantitatively identify changes in electrical and magnetic properties in the ground (Olhoeft, 1980). Understanding the interaction between the electric and magnetic fields and the properties of matter can provide quantitative information.

\subsubsection{Electrical and Magnetic Properties of Rocks, Soils and Fluids}

In the early 1960's, Watt performed experiments to examine the electrical properties of the Earth's crust (Watt et al., 1963). He found that the propagation of the EM waves through different geological material is not only frequency dependent, but also depends on the electrical properties of the rocks under investigation. Several conclusions were reached in this research. The conductivity of the water in the rock fractures affects the electrical characteristics. Pressure at the time when the rock was formed affects the electrical characteristics. Temperature and the depth of the rock affect the electrical characteristics.

The electrical and magnetic properties of rocks, soils and fluids control the speed of propagation of EM waves and their amplitudes. In most cases, the electrical properties are much more important than the magnetic properties. At RADAR frequencies, in range of $1 \mathrm{MHz}-1.0 \mathrm{GHz}$, electrical properties are dominantly controlled by rock or soil density, and by the chemistry, state (liquid/gas/solid), distribution (pore space connectivity) and content of water (Olhoeft, 1980; Stillman, 2006).

Electrical properties come in two basic types: one that describes energy dissipation and the other that describes energy storage (Roberts, 1988). Electrical dissipation occurs as the result of charge motion (or transport) called conduction. Electrical conductivity is the ability of a material to transport charge through the process of conduction, normalized by geometry to describe a material property. Dissipation (or energy loss) results from the conversion of electrical energy to thermal energy (Joule heating) through momentum transfer during collisions as the charges move. Electrical storage is the result of chargestoring energy when the application of an external force moves the charge from some equilibrium position and there is a restoring force trying to move the charge back. This process is called dielectric polarization (Olhoeft, 1981).

The EM properties of geological material depend on many factors. For coal measure rocks, the most important of them are the moisture content, mineral composition, orientation of planes of weakness, and crystalline structure, etc. (Parkhomenko, 1967). Boykov in 2006, performed electrical experiments on coal samples for the Sewickley coal seam and found that the moisture content of the coal sample has the greatest affect on the electrical properties: dielectric constant (Figure 2.1) and attenuation rate (Figure 2.2). 


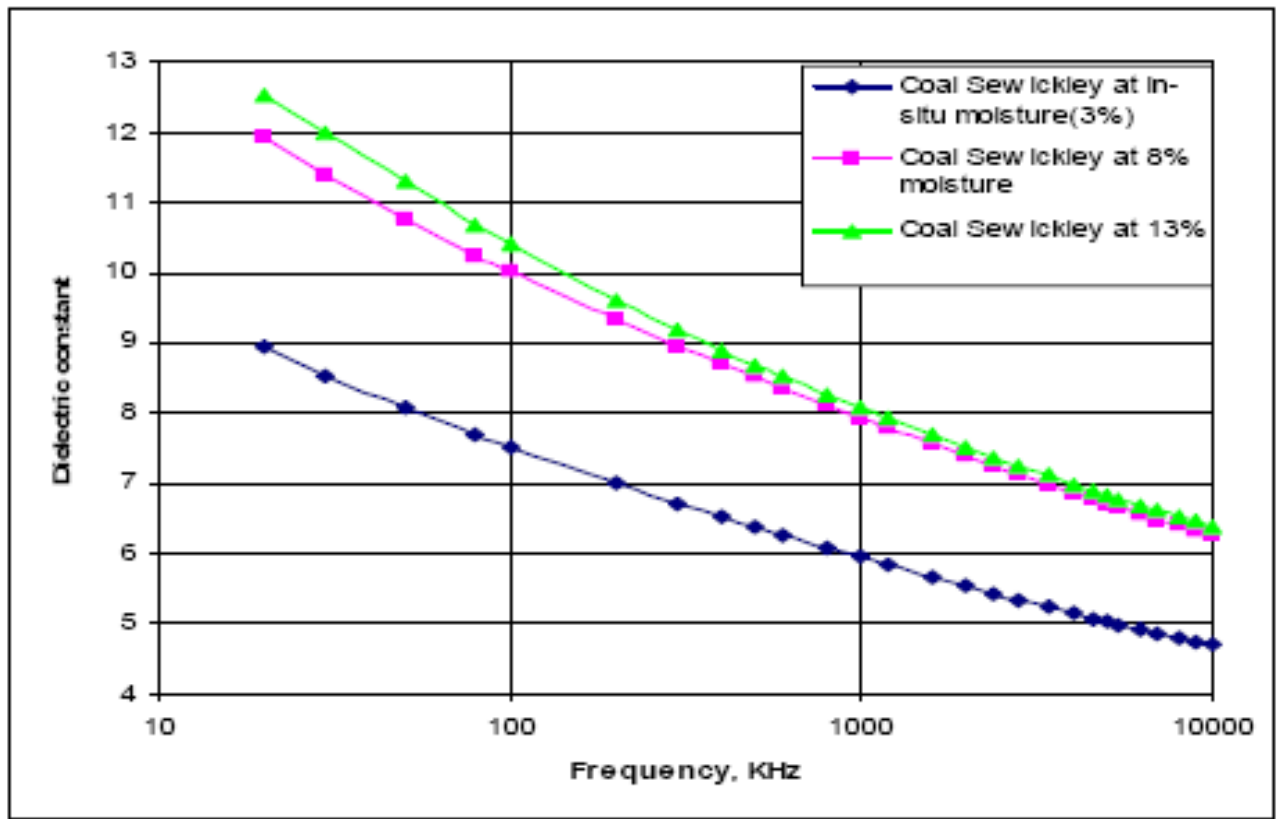

Figure 2.1 Moisture effects on the dielectric constant at different moisture levels for a coal sample from the Sewickley seam (Boykov, 2006)

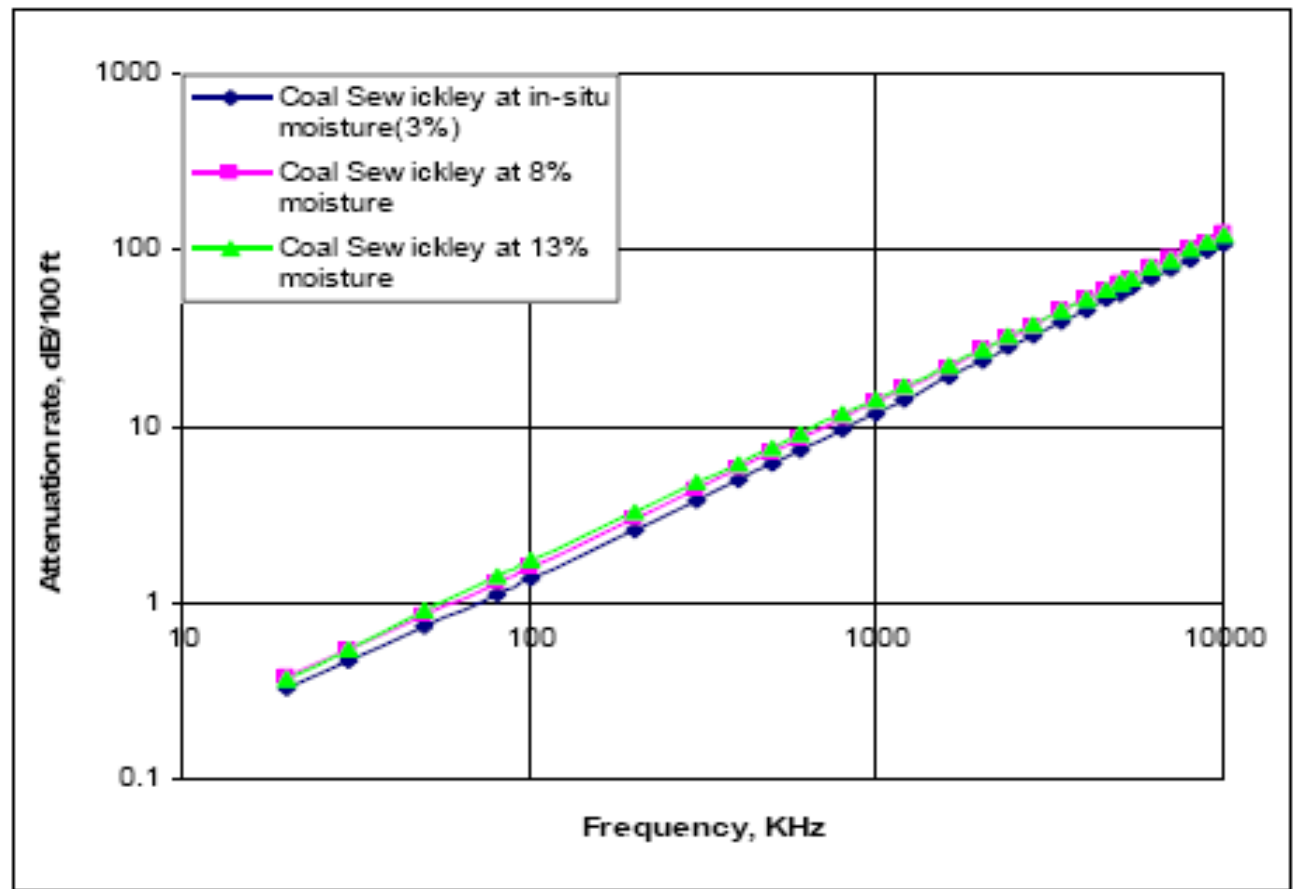

Figure 2.2 Moisture effects on the attenuation rate at different moisture levels for a coal sample from the Sewickley seam (Boykov, 2006) 


\subsubsection{Velocity of the EM Wave}

The velocity of EM wave propagation in a material is defined by the speed. The EM wave propagation in a material is always slower than the velocity of light in vacuum (or free space). The velocity is controlled by the ability of the material to store energy by pushing back against an externally applied force. In electromagnetism, this is described by dielectric permittivity and magnetic permeability polarization properties (Olhoeft, 2003). The dielectric constant affects the velocity of propagation of the EM pulse. The dielectric constant ranges from 1 for air (fastest propagation) to 81 for water (slowest propagation). In rocks and minerals, dielectric properties are primarily a function of mineralogy, porosity, water saturation, frequency, and depending on the lithology, component geometries, and electrochemical interactions (Monaghan, 2003). Some approximate dielectric constant values for rock materials are: dry coal $=4.5$, dry limestone $=5.5$ and wet sandstone 6.0. Table 2.1 shows some approximate dielectric constants for various materials

In low loss, nonmagnetic materials, the velocity of EM wave propagation in the material is equal to the speed of light in vacuum (c), divided by the square root of the dielectric constant $(\varepsilon)$. This formula is presented as follows:

$$
v=c / \sqrt{\varepsilon}
$$

Where: $v=[\mathrm{m} / \mathrm{s}]$ is the velocity of the EM wave;

$C=3 \times 10^{8}[\mathrm{~m} / \mathrm{s}]$ is the velocity of light in a vacuum. 
Table 2.1 Approximate dielectric constants for various materials

\begin{tabular}{lrlr}
\multicolumn{1}{c}{ Material } & $\begin{array}{r}\text { Dielectric } \\
\text { Constant }\end{array}$ & \multicolumn{1}{c}{ Material } & $\begin{array}{r}\text { Dielectric } \\
\text { Constant }\end{array}$ \\
\hline Air & 1 & Wet Granite & 6.5 \\
Snow Firn & 1.5 & Travertine & 8 \\
Dry Loamy/Clayey Soils & 2.5 & Wet Limestone & 8 \\
Dry Clay & 4 & Wet Basalt & 8.5 \\
Dry Sands & 4 & Tills & 11 \\
Ice & 4 & Wet Concrete & 12.5 \\
Coal & 4.5 & Volcanic Ash & 13 \\
Asphalt & 5 & Wet Sands & 15 \\
Dry Granite & 5 & Wet Sandy Soils & 23.5 \\
Frozen Sand \& Gravel & 5 & Dry Bauxite & 25 \\
Dry Concrete & 5.5 & Saturated Sands & 25 \\
Dry Limestone & 5.5 & Wet Clay & 27 \\
Dry Sand \& Gravel & 5.5 & Peats & 61.5 \\
Potash Ore & 5.5 & Organic Soils & 64 \\
Dry Mineral/Sandy Soils & 6 & Sea Water & 81 \\
Dry Salt & 6 & Water & 81 \\
Frozen Soil/Permafrost & 6 & & \\
Syenite Porphyry & 6 & & \\
Wet Sandstone & 6 & &
\end{tabular}

\subsubsection{Wavelength of the EM Wave}

The wavelength is the spatial distance traversed by one period (or cycle) of the propagating EM wave. The wavelength is the velocity of propagation in the material divided by the frequency of the propagating wave. The formula is presented as follows:

$$
\lambda=v / f
$$

Where: $\lambda=[\mathrm{m}]$ wavelength;

$v=[\mathrm{m} / \mathrm{s}]$ is the velocity of the EM wave;

$f=[\mathrm{c} / \mathrm{s}]$ is the frequency. 


\subsubsection{Waveguides}

Under the right circumstances of geometry and EM property difference, EM propagating waves may be trapped and guided along paths specified by the geometries. Stolarczyk and Fry showed that in coal-bearing formations, seams are constrained by sedimentary layers of mudstone, claystone or shale and when the electrical conductivity of the surrounding sediment layers is greater than the conductivity of a seam, a natural parallel-plate waveguide forms in the strata (Stolarczyk and Fry, 1990). The waveguide in the coal seam is well presented when there is a difference of at least one order of magnitude in the dielectric constant between the coal seam and its bounding sedimentary rocks. When the natural waveguide exist in the coal seam, the EM wave can be transmitted through the coal more easily since more energy stays in the boundary of the waveguide. Figure 2.3 shows the EM wave's flow in coal seams.

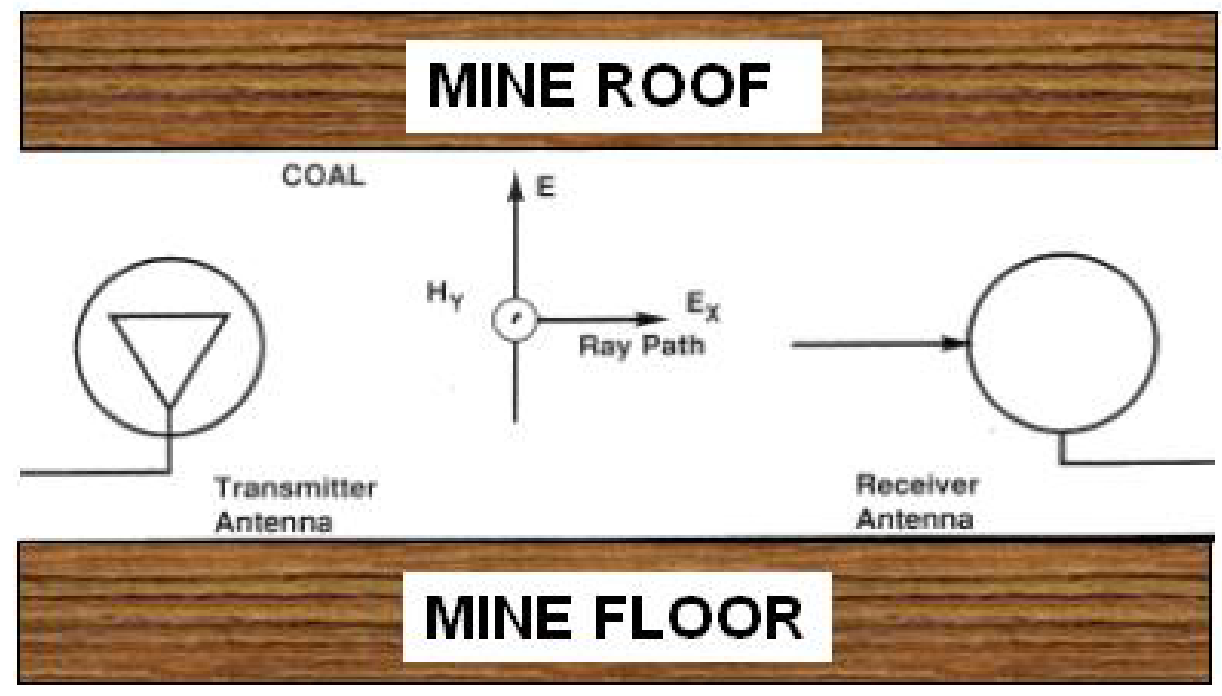

Figure 2.3 Cross section of a coal seam showing EM wave flow (Stolarczyk and Fry, 1990)

In Figure 2.3, the electric field is polarized between the mudstone and the claystone sediment layers. This means the electric field is a vector pointing in a particular direction. Generally, the magnetic field is perpendicular to the electric field, and the direction of propagation is perpendicular to both electric and magnetic field directions. There is a small electric field component (Ex) aligned in the direction of propagation. The magnetic (Hy) field component is directed into the page. The horizontal EM wave will travel in the coal seam between the Tx and Rx antennas. 


\subsubsection{Attenuation, Resistivity, Conductivity}

The attenuation is dependent upon the resistivity/conductivity of the media through which the EM signal is propagating, as well as the frequency of the EM signal itself. The depth of penetration of the EM signal in the strata is known to be inversely proportional to the wave attenuation (Reynold, 2003). If geologic anomalies such as faults, sandstone intrusions, sudden thinning and severe undulation of the coal seam are along the EM path, the EM signal will be significantly attenuated. The formula to calculate attenuation rate is presented as follows (Boykov, 2006):

$$
\alpha=8.68 \omega \sqrt{\frac{\mu_{0} \varepsilon_{0} \varepsilon_{r}}{2}\left[\sqrt{1+(\tan \delta)^{2}}-1\right]}
$$

Where: $\alpha=[\mathrm{dB} / 100 \mathrm{ft}]$ attenuation;

$\omega=2 \pi \mathrm{f}$ where $\mathrm{f}$ is the frequency $(\mathrm{Hz})$;

$\mu_{0}=4 \pi 10^{-7}[$ Henry $/ \mathrm{m}]$ permeability of free space;

$\varepsilon_{0}=(1 / 36) \pi 10^{-9}[$ Farads $/ \mathrm{m}]$ permittivity of free space;

$\varepsilon_{r}=$ dielectric constant of material;

$\varepsilon_{r}=\varepsilon^{\prime}=$ real part of the dielectric constant;

$\varepsilon^{\prime \prime}=$ complex part of the dielectric constant;

$\tan \delta=$ the loss tangent, which is the ratio of $\varepsilon^{\prime \prime} / \varepsilon^{\prime}$.

The resultant attenuation losses are exhibited as temperature rises, but also may be used (as apparent attenuation) to describe energy that is lost through geometric effects. Such apparent losses are the result of geometric spreading, surface and volume scattering, waveguides and multipathing (propagating waves leave the transmit antenna and travel to the receive antenna by multiple different paths). In multipathing, the energy is not transformed to heat and is still EM, but it is following a path 
that is no longer useful or observable (Olhoeft, 1993). Figure 2.4 shows an attenuation increase in a coal seam and due to energy being dissipated as heat.

The electrical resistivity (or electric resistance) is a measure of how strong the material opposes the flow of electric current. The electrical conductivity is a measure of a materials ability to conduct an electrical current. Conductivity is the reciprocal (inverse) of electrical resisitivity. The formula to calculate the resistivity of rocks is presented as follows (Boykov, 2006):

$$
R=\frac{1}{2 \pi \varepsilon_{r} \tan \delta\left(8,854 \times 10^{-12}\right)}
$$

Where: $R=[\mathrm{ohm}-\mathrm{m}]$ resistivity.

The formula to calculate the conductivity is presented as follows:

$$
\sigma=1 / R
$$

Where: $\sigma=[$ Seimems per meter $]$ conductivity.

\subsubsection{Phase Change}

When the electromagnetic (EM) signal travels through the subsurface media it is modified relative to that which travels through the air. The receiver EM signal will differ in both phase and amplitude relative to the unmodulated field that was generated by the transmitter. The degree to which the receiving EM signal differs provides important information about the geometry, size and electrical properties of the earth material. 


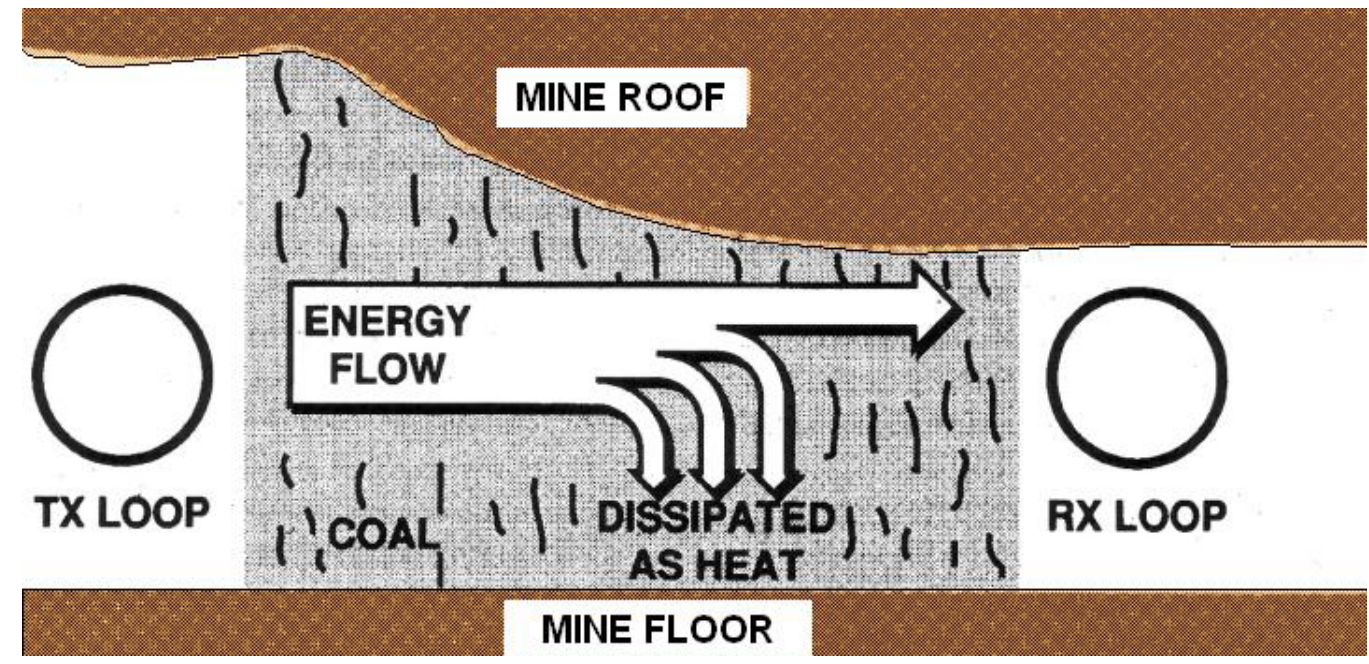

Figure 2.4 Attenuation increase in a coal seam

As mentioned before, various types of geologic anomalies can exist in coal seams. Figure 2.5 shows an example of some of these geologic anomalies (Stolarczyk and Fry, 1990).

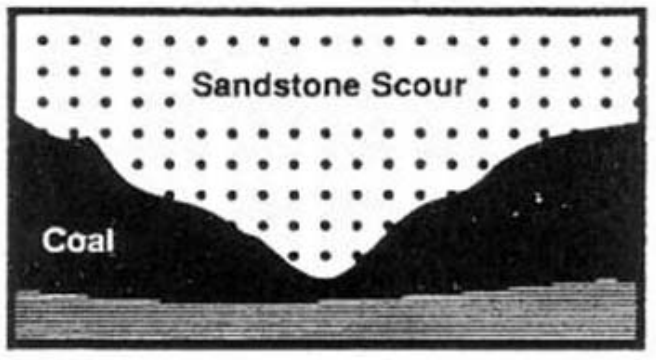

\section{Washout}

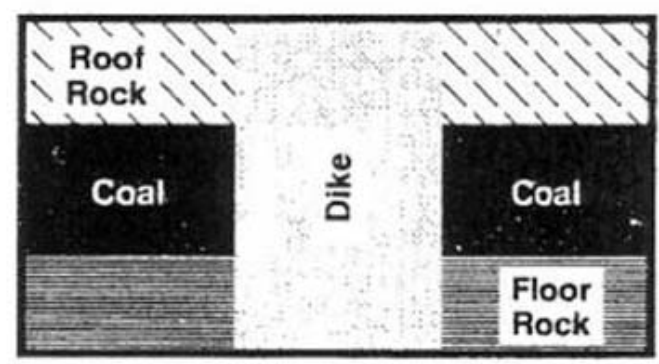

Dike

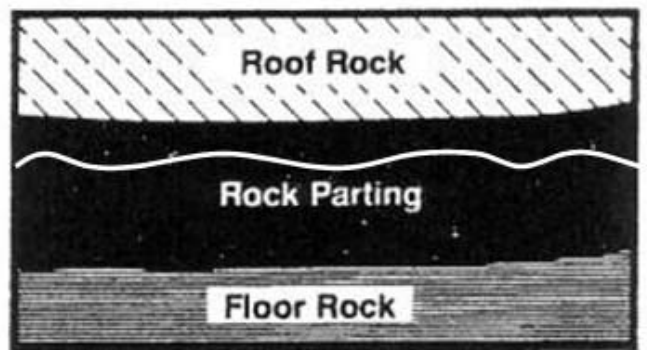

Interbedding

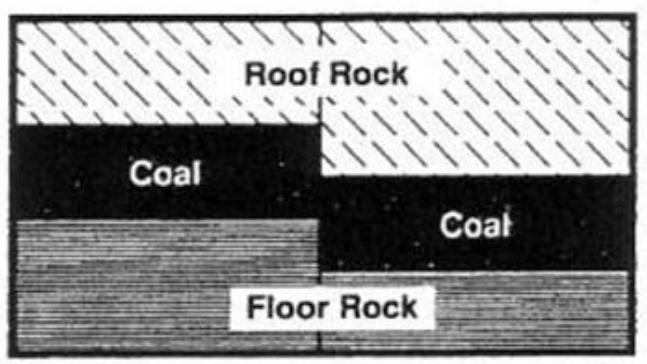

Fault

Figure 2.5 Natural waveguide anomalies in coal seams 


\subsubsection{Scattering}

Scattering results when a propagating electromagnetic wave encounters a significant change in electrical or magnetic material properties (anomaly). Scattering creates secondary waves in the seam waveguide.

\subsection{Applications and Limitation of RIM Technology for Modern Longwall Mining}

Stolar Horizon, Inc. has developed instrumentation, survey procedures, and they have licensed a program from an Australian company to image the geological structure in front of longwall face. The survey is conducted in the gate roads of the longwall panel usually with the transmitter (Tx) antenna in the headgate and the receiver $(\mathrm{Rx})$ antenna in the tailgate. Survey marks are typically placed at $20 \mathrm{ft}$ increments and are referred to as survey measurement stations. A typical RIM survey setup for a longwall panel is shown in Figure 2.5.

As the EM wave, which is generated by the Tx antenna, encounters an anomalous geologic disturbance zone in the coal seam, the EM wave propagation constants (amplitude attenuation and phase) change and energy is scattered which creates secondary waves in the coal seam waveguide. A typical EM wave showing energy scattered is shown in Figure 2.6.

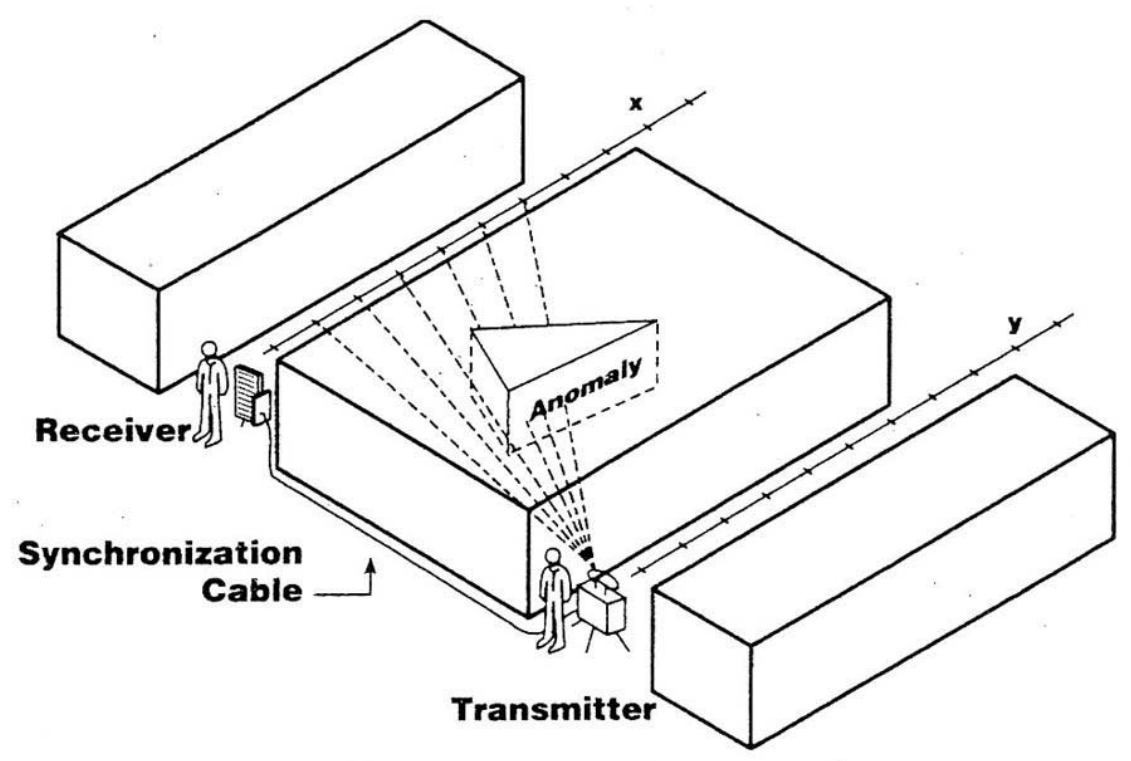

Figure 2.6 Typical RIM survey setup for a longwall panel (Stolarczyk and R.C. Fry, 1989) 


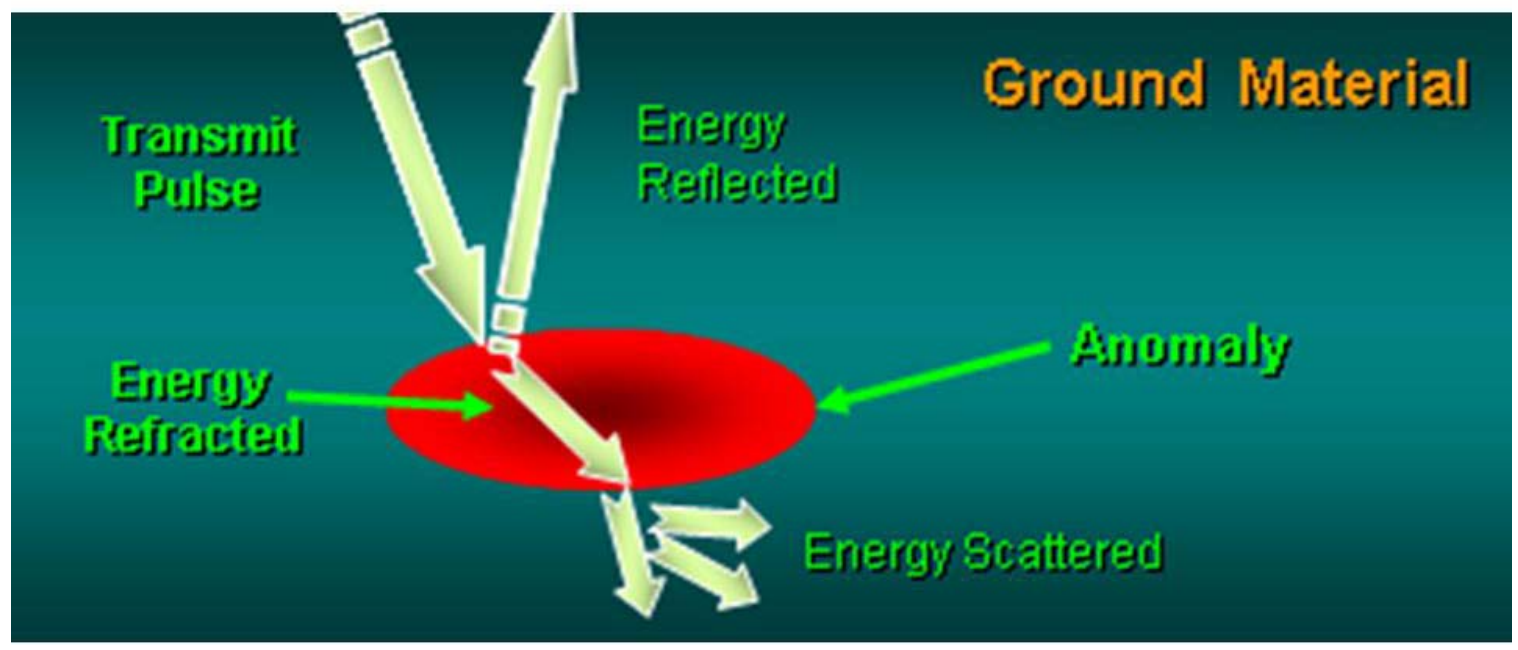

Figure 2.7 Energy scatter from an anomalous geologic disturbance zone

In Figure 2.8, an example of the transmitted sinusoidal radio wave at the headgate and the received sinusoidal radio wave at the tailgate are shown. The radio wave received at the tailgate is attenuated and shifted in phase by $(\theta)$ electrical degrees. When the ray pass distance is known, the attenuation rate $(\alpha)$ in decibels per $\mathrm{ft}$ can be determined. This attenuation rate can be used as the baseline for the coal seam assuming there are no geologic anomalies encountered in the ray path. When the Tx antenna and Rx antenna are moved to various measuring stations and the attenuation rate increases, it is assumed that changes are a result from geologic anomalies ahead of the longwall face.
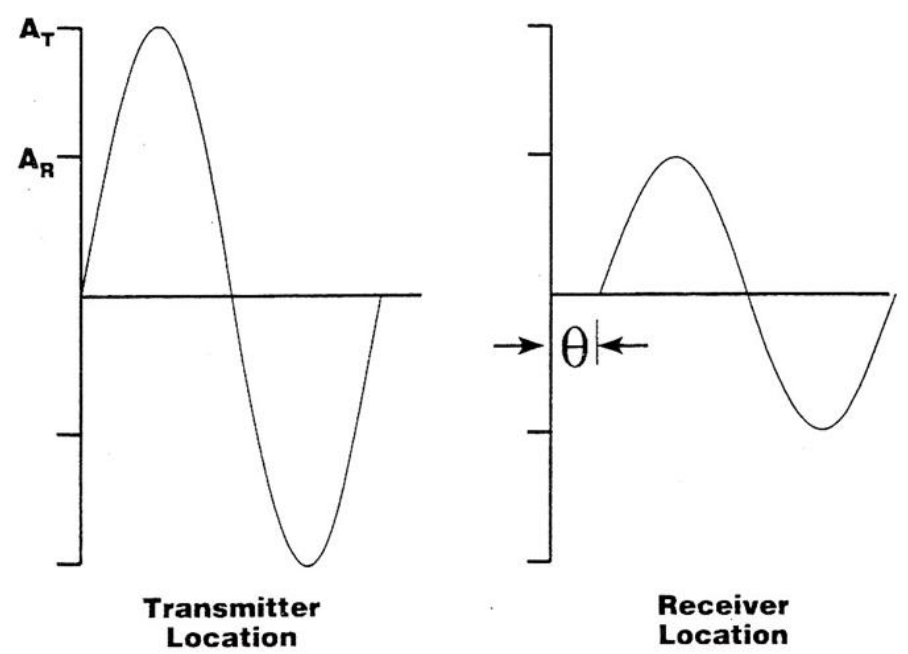

Figure 2.8 Sinusoidal radio wave signals along a ray path (Stolarczyk and R.C. Fry, 1989) 
When a tomographic survey is performed through a rectangular block of coal, the Tx antenna and the Rx antenna move alternately at the predefined measurement stations located on the opposite sides of the block. After a complete RIM survey, hundreds of transmission ray paths from the Tx antenna to the Rx antenna at various measurement stations are formed. The received signal strength and the total attenuated energy for each ray path are determined and recorded. In the data analysis phase, the surveyed block is divided into small rectangular pixels. The rate of energy attenuation within a pixel is assumed to be the same. When a EM signal penetrates through a pixel, the energy attenuated by the pixel is the product of the attenuation rate and the distance through the pixel. The total energy attenuation along a ray path is the summation of the attenuations through the pixels on the path. Sophisticated tomographic reconstruction algorithms are employed to back-calculate the attenuation rates in the pixels. By systematically changing the attenuation rates for the pixels, the calculated and measured total energy attenuations can be matched with reasonable accuracy. The resulting attenuation rates are then plotted to show the distribution of the attenuation rate within the survey block which in turn is used as the indicators of geologic anomalies.

A typical tomographic image from a short section of an actual longwall panel is shown in Figure 2.9. In this image, the hottest color (red being the highest value) represents the areas with the highest attenuation rate (lower signal strength) and the cool color (blue being the lowest value) represents the areas with the lowest attenuation rate (higher signal strength).

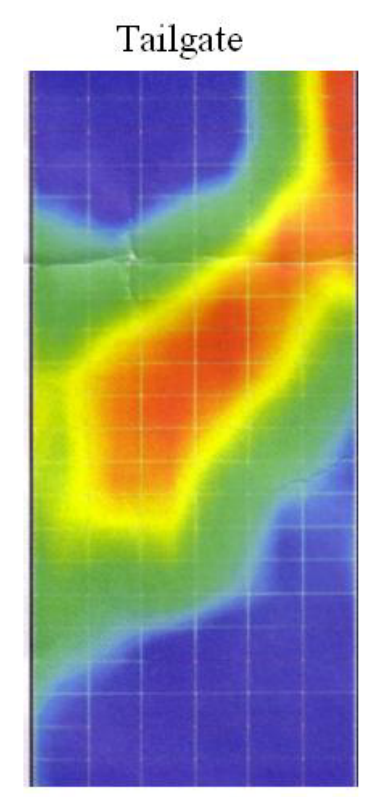

Headgate

Figure 2.9 Example of signal attenuation rate tomogram 
It should be noted that longwall panels were approximately $500 \mathrm{ft}$. wide in the earlier 1980's. While today the widest longwall panel is about $1500 \mathrm{ft}$. wide. The National Mining Association (NMA) and the U.S. Department of Energy (DOE's) Industry of the Future Mining program provided research and development funds to extend the operating range of the RIM instrumentation to greater than 3,000 feet.

Stolar Horizon, Inc. has done considerable research to develop approaches and methodologies for improving the RIM range and detection accuracy of geologic anomalies. This variety of past research indicates the importance of further understanding angular spreading, material moisture content, increasing the range, understanding the influences of multiple geologic anomalies when they co-exist in a longwall panel and increasing the accuracy of the RIM method. 


\section{CHAPTER 3}

\section{OBJECTIVE OF THE RESEARCH}

The overall objective of this research is to increase the accuracy of the RIM technology by studying the EM wave properties on a scaled physical model of a longwall panel and quantifying the data collected. The properties of interest are the EM signal attenuation rates caused from interfaces between the roof, seam, floor and targets (simulated geologic anomalies). The interfaces are those that cause a significant reduction (attenuation) in the EM signal received at the $\mathrm{Rx}$ antenna. There are many factors that effect the EM ray path between the Tx and Rx antennas and often it is difficult to understand the changes of the received signal strength and waveform at the Rx antenna. Simply identifying a received signal at an Rx antenna measuring station does not necessarily provide sufficient information about the ray path. It is of the utmost importance to know: the geometry of the surveyed area, the positions and contact points of the Tx and Rx antennas, the center and angular spreading of the Tx EM signal, and the electrical characteristics of the coal measure rocks to accurately image the area surveyed. Therefore this research focus is on identifying the effects of the roof, seam, floor and targets (geologic anomalies) on the EM signal in a scaled physical model. This research, which used a scaled model, can be used to: further define the characteristics of EM signals during an actual longwall panel RIM survey, provide insight in the design and development for software programs used for post processing the raw EM signal data, and provide insight in the design and development for software programs used for tomographic reconstruction. 


\section{CHAPTER 4}

\section{METHODOLOGY OF THE RESEARCH}

This research was conducted to increase the accuracy of the RIM technology. An off-the-shelf Geophysical Survey System, Inc. (GSSI) SIR ${ }^{\circledR}$ (Subsurface Interface RADAR) II GPR system was modified to allow the separation between the Tx and Rx antenna. This separation was necessary since the GPR system work on the principle of reflective electromagnetic methodology. The Tx and Rx antennas are housed in one box that are separated by a precise distance. As mentioned before, the RIM system works on the principle of penetrative electromagnetic methodology and it uses two antennas located on the opposite sides of the investigated object.

The first stage of this research was to determine the signal strength reduction as spatial spreading. In spatial spreading the signal energy level is reduced as it travels through air space. In the next stage, EM surveys were conducted at various times and under different conditions on a scaled physical model. Methods were then developed to process the collected data. This was done by analyzing the contributions of the spatial spreading, analyzing the contributions of the geologic anomalies in the model, determining the attenuation rate of the each received signal, and contour mapping reconstruction of the model.

\subsection{Instrumentation Terminology and Definitions}

The common terminology and definitions associated with the instrumentation used in this research are presented in this section in order to give the reader a more comprehensive understanding of this science.

\subsubsection{Range}

The range parameter is a time value and tells the Geophysical Survey System how long to record a received signal after the systems sends out a transmit pulse. The range can be set. Any portion of the transmitted pulse that can reach the Rx antenna within the set range can be recorded or displayed. For a given antenna frequency, there is always a maximum depth that the signal can penetrate. There is a maximum range for any given situation beyond which you will get no received signal.

\subsubsection{Gain}

The signal received at the Rx antenna is very low amplitude and must be amplified by the system for viewing in its display screen and subsequent interpretation. Adjusting the gain factor in the Geophysical Survey System does this. The amount of amplification applied depends on the material 
attenuation rate between the $\mathrm{Tx}$ and $\mathrm{Rx}$. The amount of amplification generally increases when the distance between the Tx and $\mathrm{Rx}$ is increased. The gain factor is expressed in the units of $\mathrm{dB}$.

\subsubsection{Scan}

A scan is the data that is recorded or displayed for a single received signal within the set range.

\subsubsection{Samples/Scan}

The numbers of data points taken per scan.

\subsubsection{Bits/Sample}

Bits/Sample is the resolution of the data taken at a data point. Typically bits/sample can be set to 8 or 16 . The resolution of the data is determined by the 2 to the power of bits/sample. For example 8 bit data would have a resolution of $2^{\wedge} 8$ or 256 and 16 bit data would have a resolution of $2^{\wedge} 16$ or 65536 .

\subsubsection{Scans/Second}

Scan/Second is the number of scans taken in one second.

\subsection{Instrumentation}

The tests were conducted using a modified GSSI SIR ${ }^{\circledR}$ II model number DC-2 control unit, two $900 \mathrm{MHz}$ antennas (Figure 4.1), with a specialized antenna breakout box built by GSSI. Figure 4.2 shows a close-up view of the antenna breakout box. A higher frequency (shorter wavelength) EM signal was used in the physical model testing versus a lower frequency (in the kilohertz range) which is used in an actual Stolar Horizon, Inc. RIM system. This was necessary due to the small size of the physical model to ensure the "similarity" between the actual longwall panel and the scaled model.

The control unit generates an electromagnetic pulse that is transmitted by the Tx antenna and is received by the Rx antenna. The power output of the $900 \mathrm{MHz}$ Tx antenna is $-24 \mathrm{~dB}$ and the transmitted energy of the pulse is radiated in a conical pattern (Figure 4.3). The received signal provides information on the attenuation characteristics (signal strength) associated with the material and the travel time. 


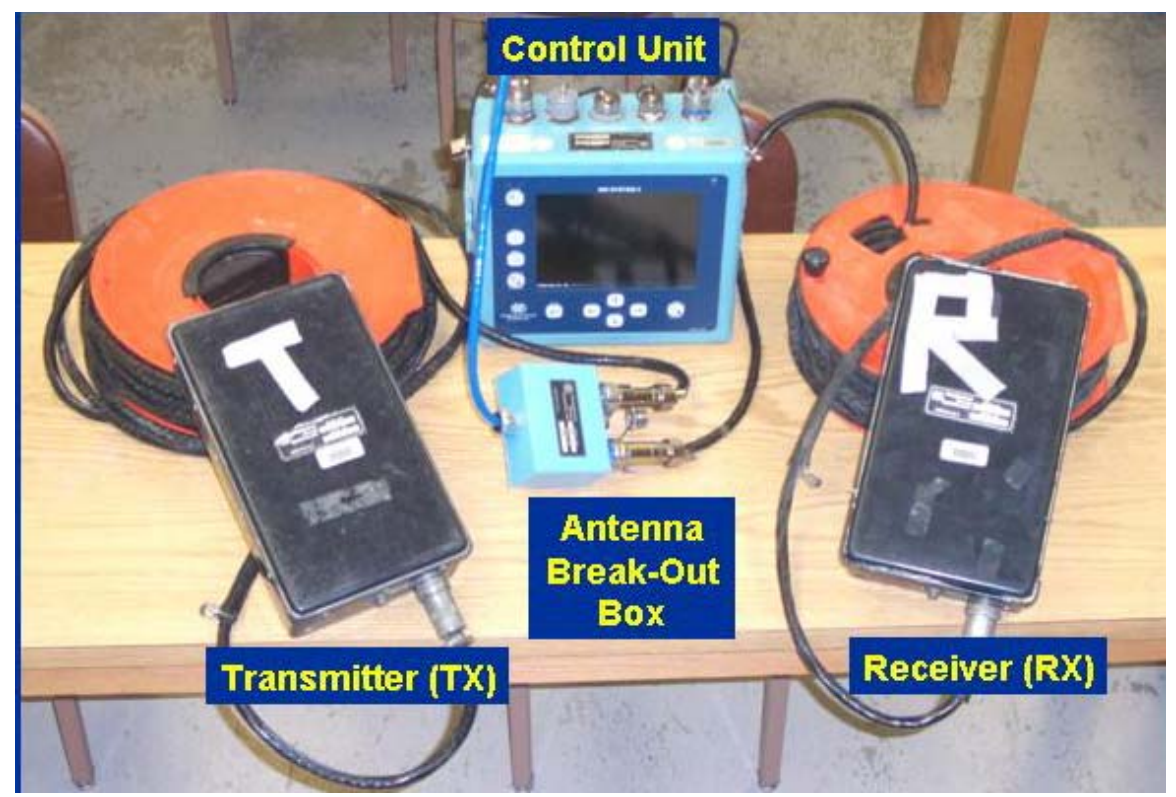

Figure 4.1 GSSI SIR II GPR system with antenna breakout box

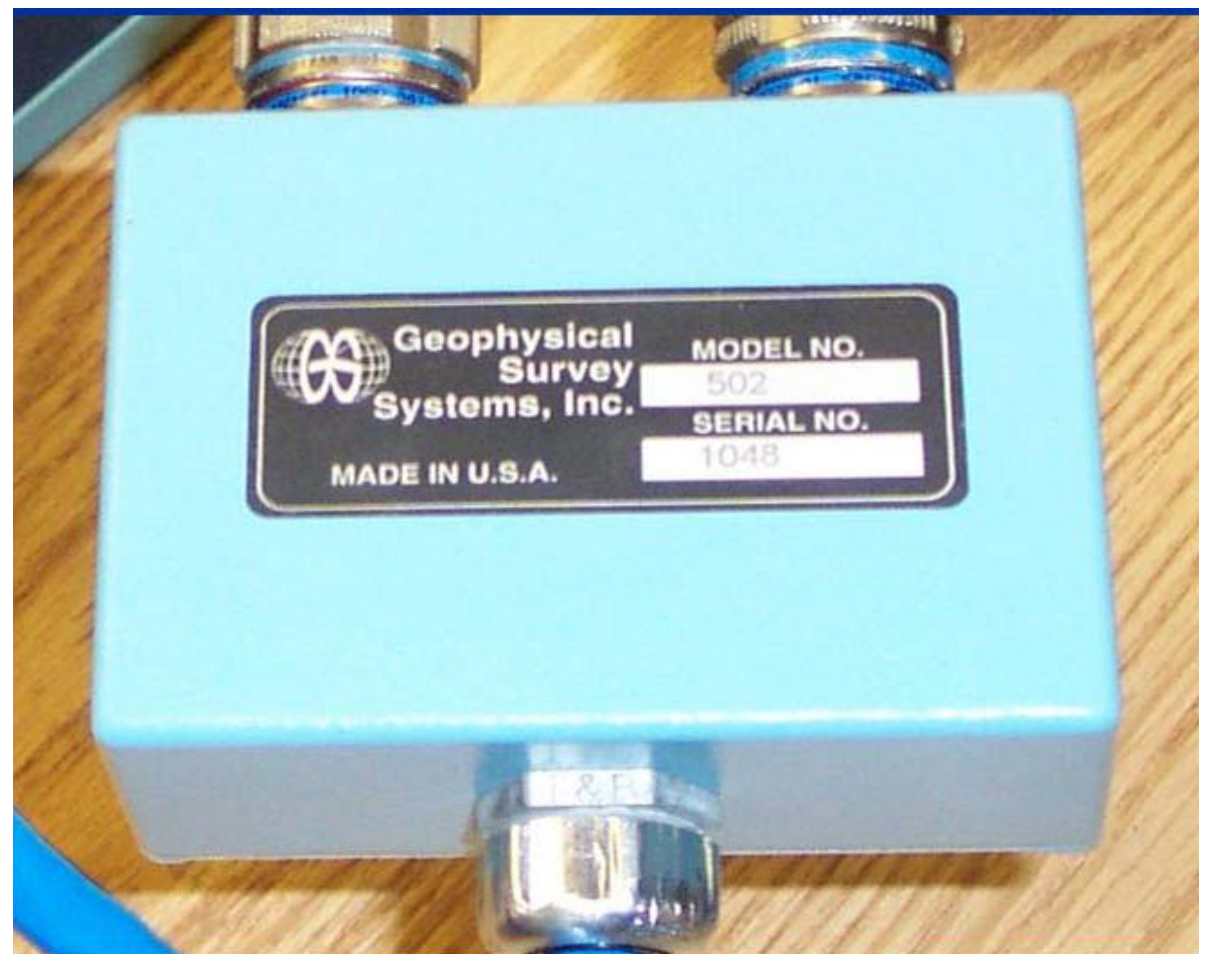

Figure 4.2 Close-up of antenna breakout box 


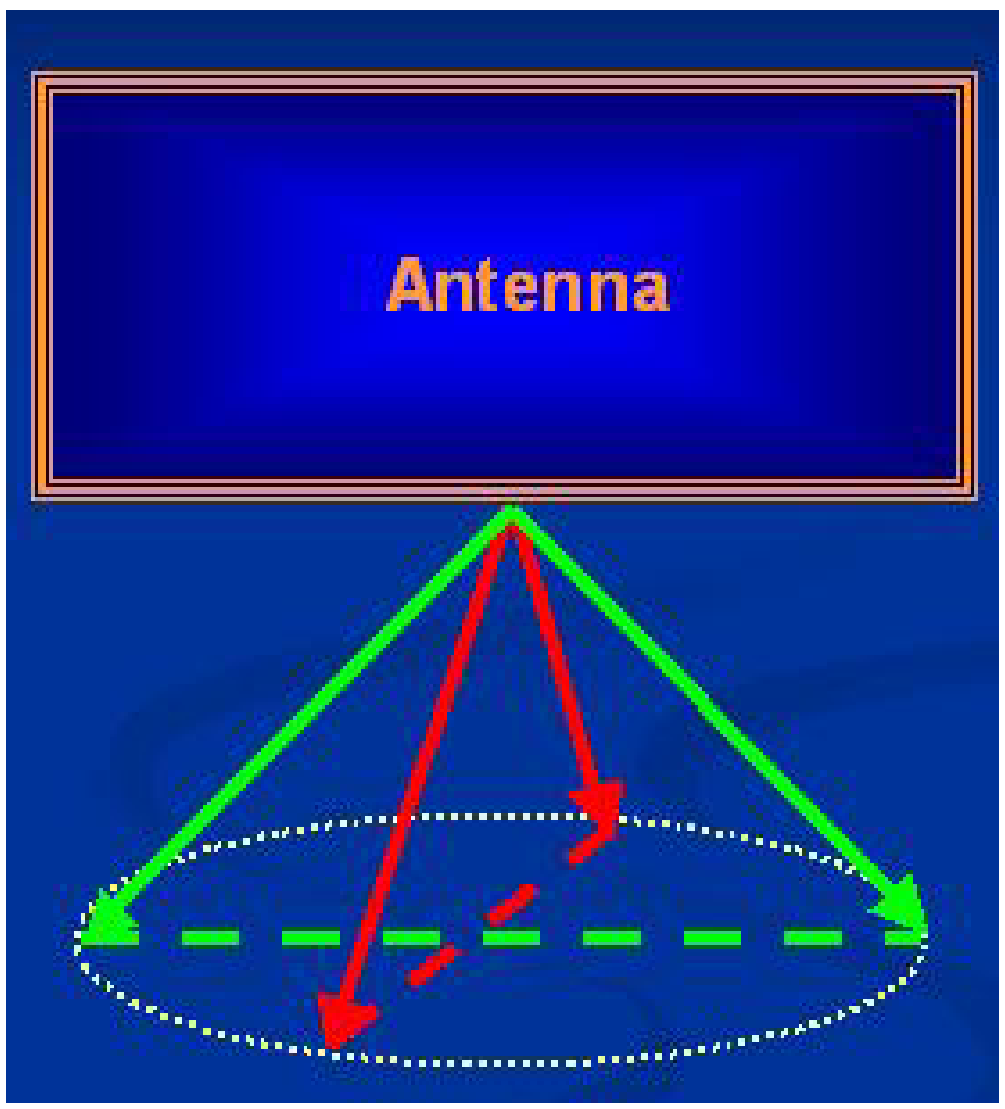

Figure 4.3 Tx antenna radiated energy pattern

The limitations of the system depend on two electrical properties of the geological materials under investigation: dielectric constant and electrical conductivity. The dielectric constant affects the velocity of propagating EM pulse as indicated by Eq. 2.1. The dielectric constant ranges from 1 for air (fastest propagation) to 81 for water (slowest propagation). As mentioned before, the electrical conductivity (measure of a material's ability to conduct electric current, Eq. 2.5) controls the depth of pulse penetration. The lower the conductivity of the material, the deeper the pulse can penetrate. The depth of penetration of the EM pulse also depends on the antenna frequency. Higher frequency antennas have a shallow penetration and lower frequency antennas have deeper penetration. 


\subsection{Spatial Spreading}

The signal strength measured at the Rx antenna will depend on the relative position of that antenna with respect to the Tx antenna. It is therefore necessary to define the Rx antenna position and signal strength in relationship to the XYZ Cartesian coordinate system (Figure 4.4) to develop equations. The emitting point of the Tx antenna is located at the origin and points to the $\mathrm{X}$-axis of the coordinated system. It should be noted that the signal received at a point (xyz) from the transmitter is weaker then that at the emitting point. The difference in signal strength is due to two parts: the signal spatial spreading and the attenuation by media on the path. In order to obtain the total attenuation between points, the reduced signal strength at point (xyz) due to spatial spreading should be know first.

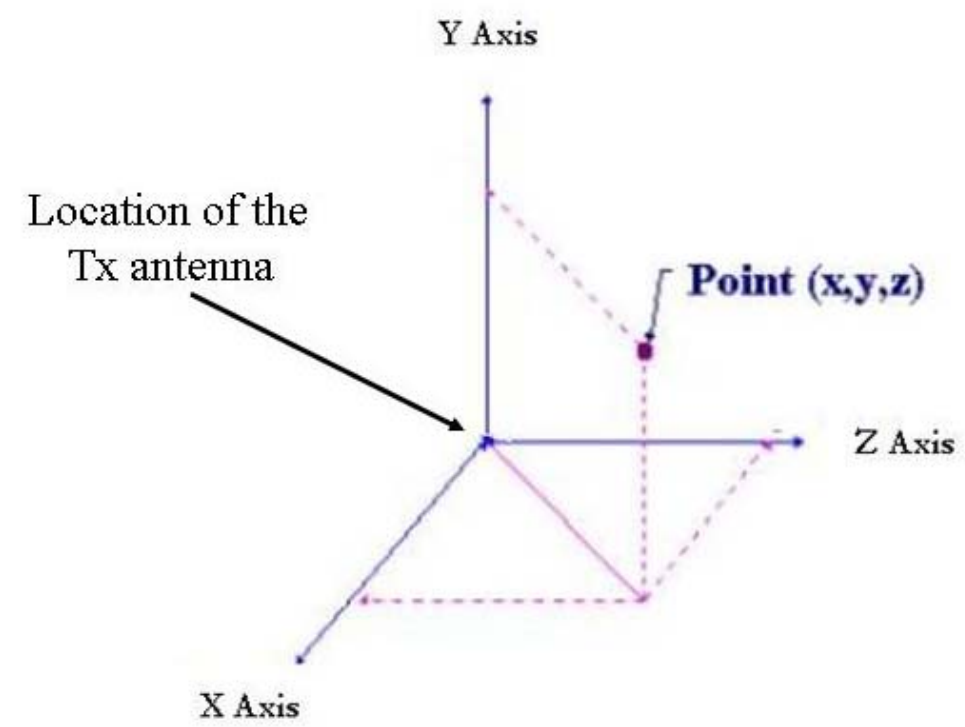

Figure 4.4 Three dimensional Cartesian coordinate system

In the development of the equations to represent the spatial spreading of EM signal in air an antenna grid array was utilized as shown in Figure 4.5. Data for signal strength reduction as spatial spreading were obtained in July, August, and December of 2005 and again in February of 2007. 


\section{Spatial Spreading Testing}

Line 4

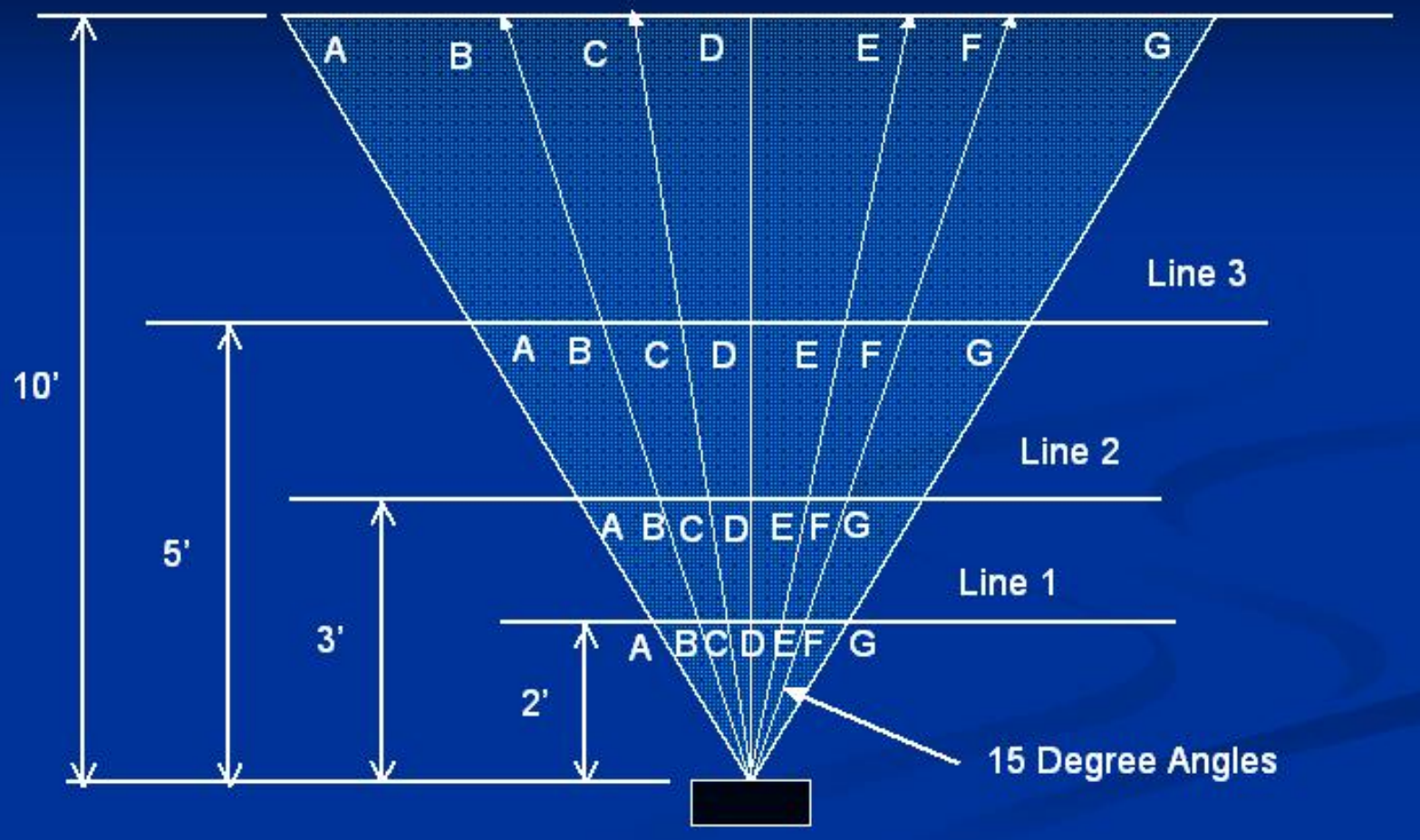

TX Antenna

Figure 4.5 Antenna grid array

The Tx and Rx antennas were placed in the horizontal/side lying position (Figure 4.6). The Tx antenna was stationary while the Rx antenna was moved at the grid points. A data set was obtained on Line 1 - Line 4, A - G to generate the data for the Y-axis. The complete data set consisted of 28 data points. Then, the Tx and Rx antennas were rotated by 90 degrees to the vertical/upright position and another data set was obtained for the Z-axis (Figure 4.7). The X-axis data was obtained from the center points or $\mathrm{D}\left(0^{\circ}\right)$. The $\mathrm{Rx}$ antenna locations are provided in Table 4.1 . 
Table 4.1 Rx positions in antenna grid array

\begin{tabular}{|c|c|c|c|c|c|c|c|c|}
\hline \multicolumn{2}{|c|}{} & \multicolumn{7}{|c|}{ Distance from Emitting Point } \\
\hline Line & $\begin{array}{c}\text { Distance } \\
\mathrm{ft}\end{array}$ & $\begin{array}{c}\mathrm{A}(-45) \\
\mathrm{ft}\end{array}$ & $\begin{array}{c}\mathrm{B}(-30) \\
\mathrm{ft}\end{array}$ & $\begin{array}{c}\mathrm{C}(-15) \\
\mathrm{ft}\end{array}$ & $\begin{array}{c}\mathrm{D}(0) \\
\mathrm{ft}\end{array}$ & $\begin{array}{c}\mathrm{E}(15) \\
\mathrm{ft}\end{array}$ & $\begin{array}{c}\mathrm{F}(30) \\
\mathrm{ft}\end{array}$ & $\begin{array}{c}\mathrm{G}(45) \\
\mathrm{ft}\end{array}$ \\
\hline \hline 1 & 2 & 2.83 & 2.31 & 2.07 & 2 & 2.07 & 2.31 & 2.83 \\
\hline 2 & 3 & 4.24 & 3.46 & 3.11 & 3 & 3.11 & 3.46 & 4.24 \\
\hline 3 & 5 & 7.07 & 5.77 & 5.18 & 5 & 5.18 & 5.77 & 7.07 \\
\hline 4 & 10 & 14.14 & 11.55 & 10.35 & 10 & 10.35 & 11.55 & 14.14 \\
\hline
\end{tabular}

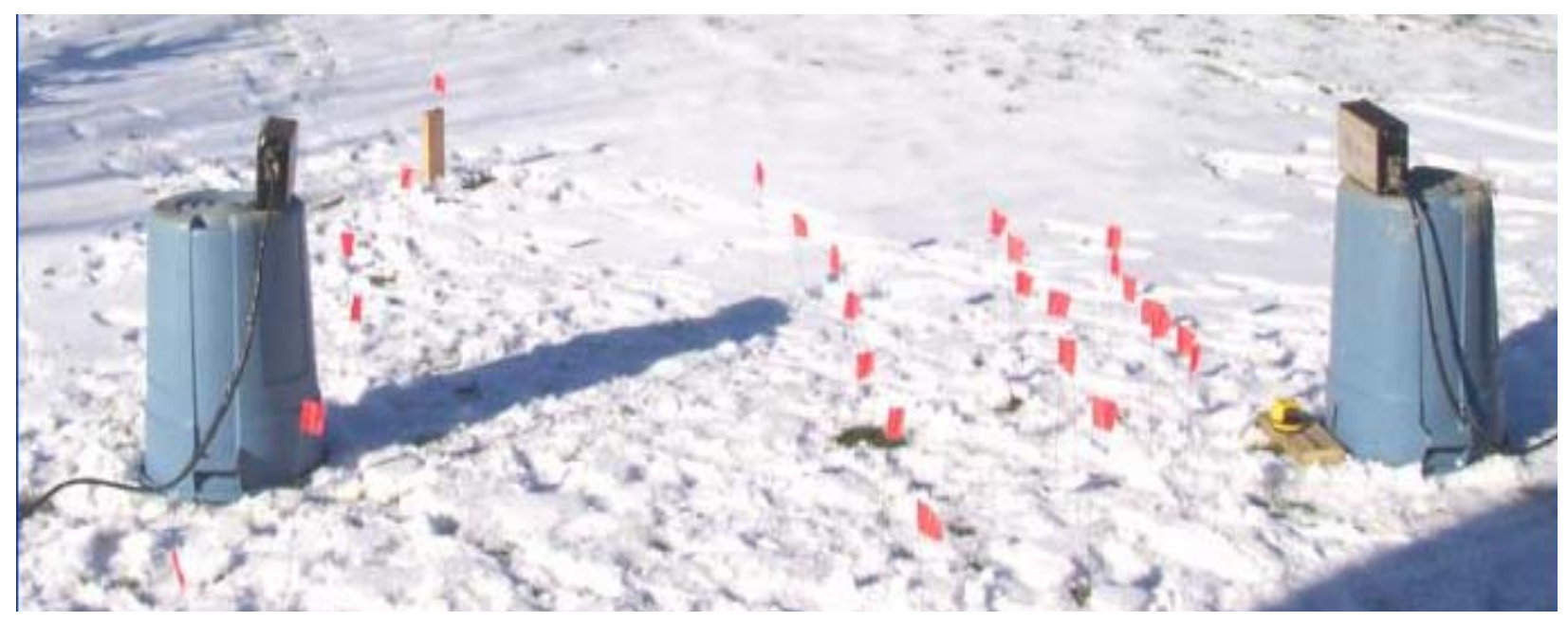

Figure 4.6 Antennas horizontal position (Y-axis)

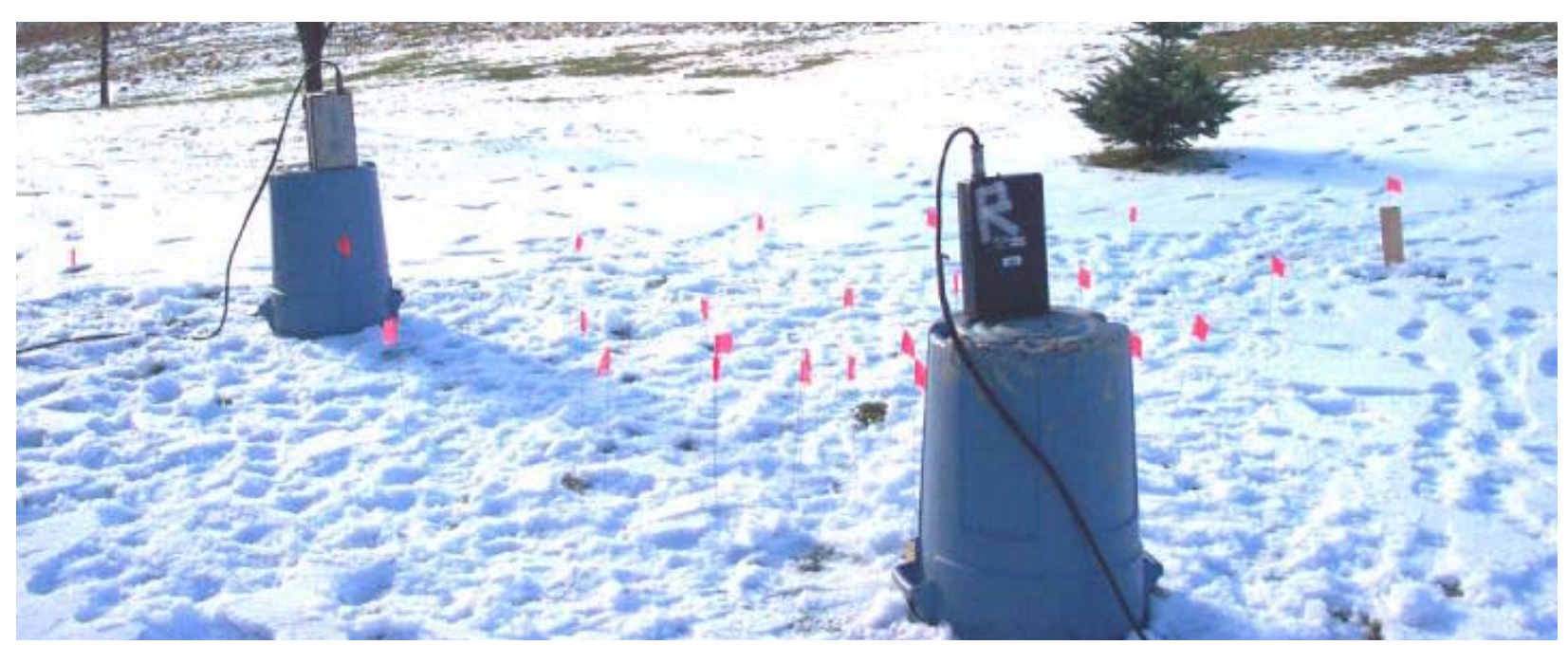

Figure 4.7 Antennas vertical position (Z-axis) 


\subsection{Physical Model}

In the scale model (Figure 4.8), the coal seam, floor, roof strata, and geologic anomalies are simulated with mixed sand, cement, gypsum, coal powder, and iron powder. Different ratios of sand, gypsum, and cement were used to build the floor and roof strata. A mixture of coal powder and gypsum were used to simulate the coal seam. Due to the relatively small size of the physical model, a highfrequency $900 \mathrm{MHz}$ EM signal had to be used in the model testing to ensure the "similarities" between the actual longwall panels and the scaled model. Using this frequency allowed approximately 2 EM waves to travel through the model when the Tx and $\mathrm{Rx}$ antennas were positioned for reconnaissance surveys, as shown in Figure 4.9. EM reconnaissance surveys (Tx and Rx antennas are aligned without vertical or horizontal offset) were conducted in February 2006, April 2006, February 2007, and April 2007. Data points were obtained every 2-inch. on 5 different lines: L1 Floor, L2 Coal Seam, L3 Coal Seam/Roof, L4 Roof, L5 Objects as shown in Figure 4.10. The actual physical model is shown in Figure 4.11 .

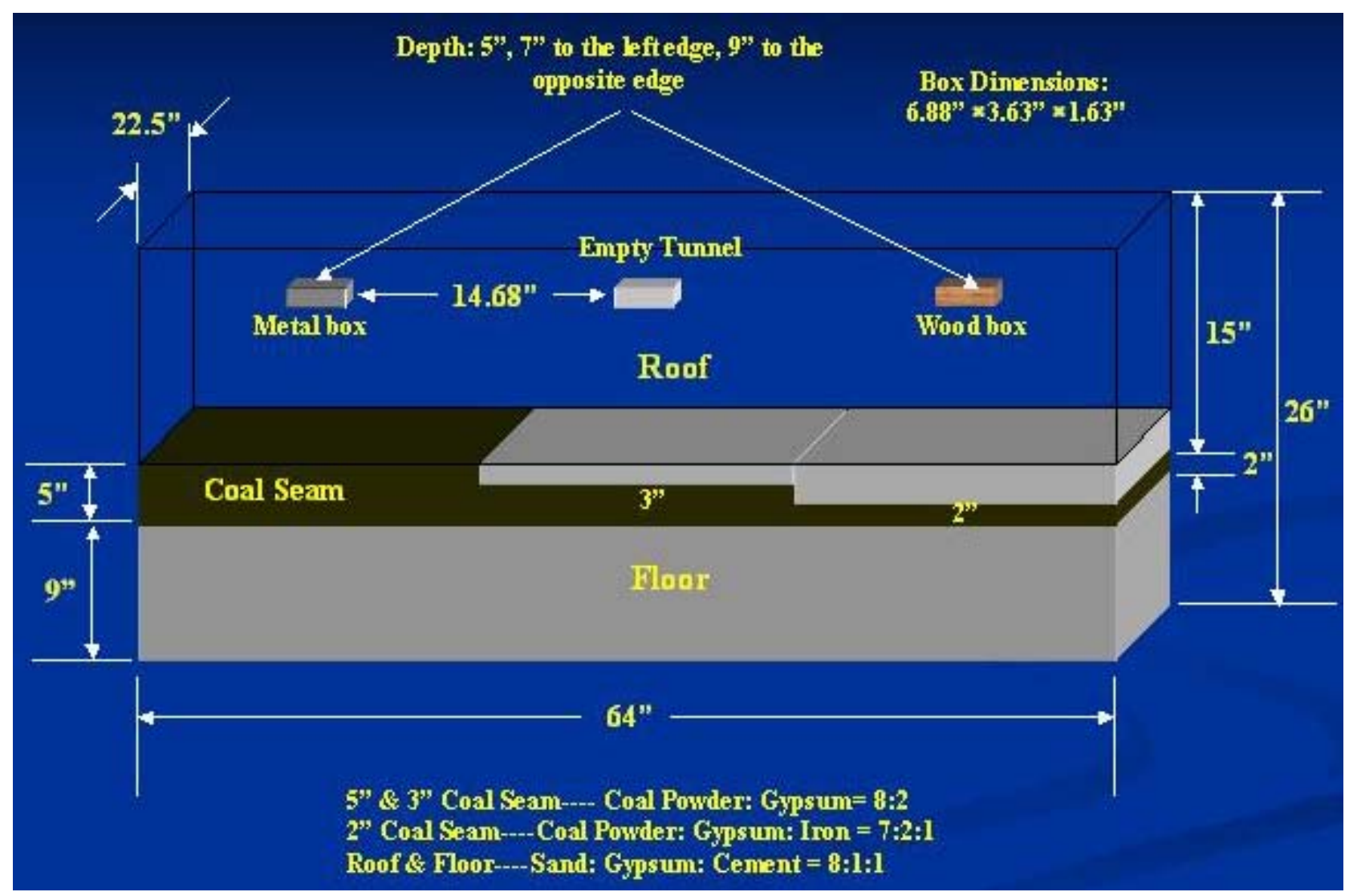

Figure 4.8 Scaled physical model dimensions 


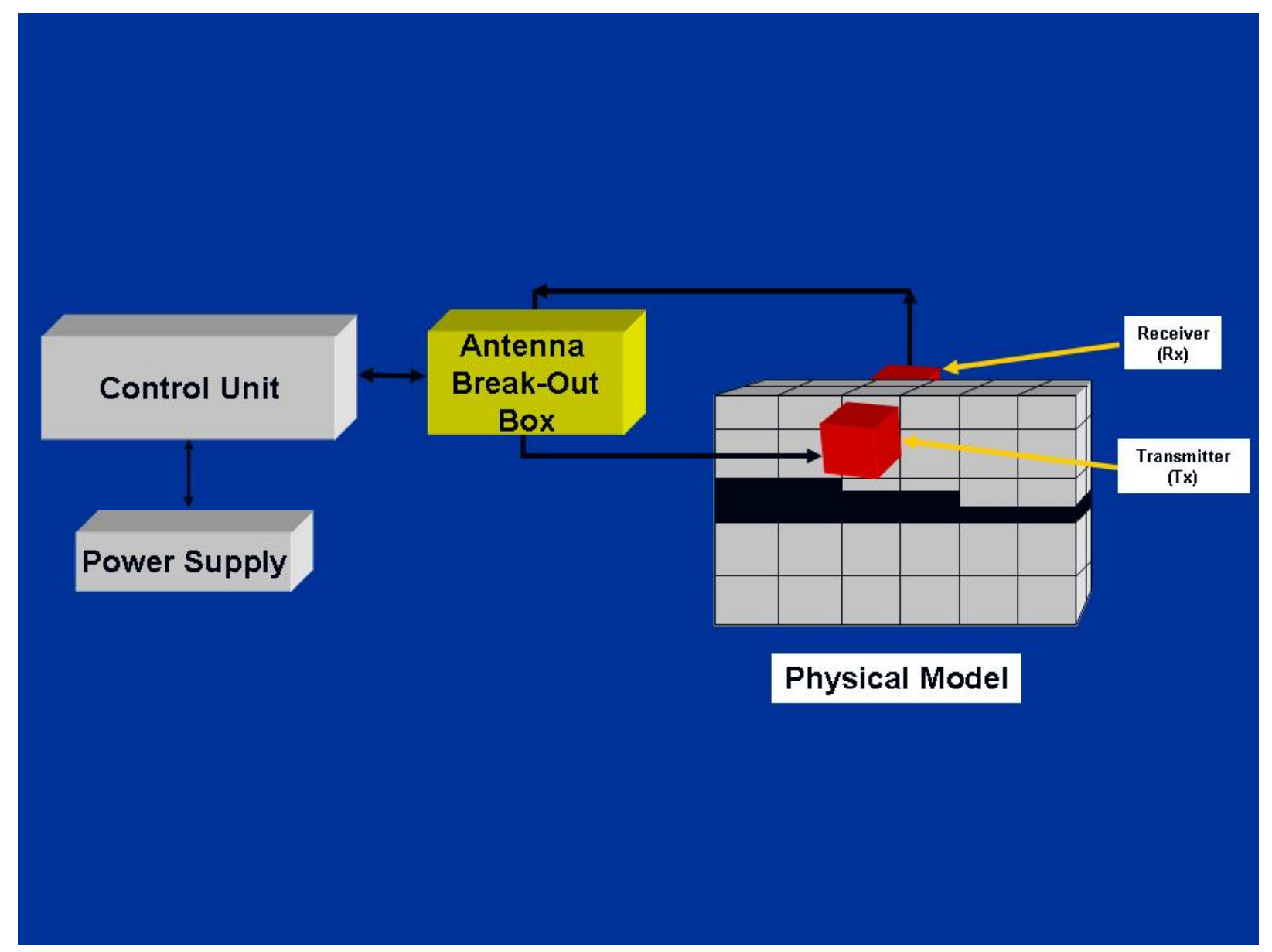

Figure 4.9 EM reconnaissance survey setup

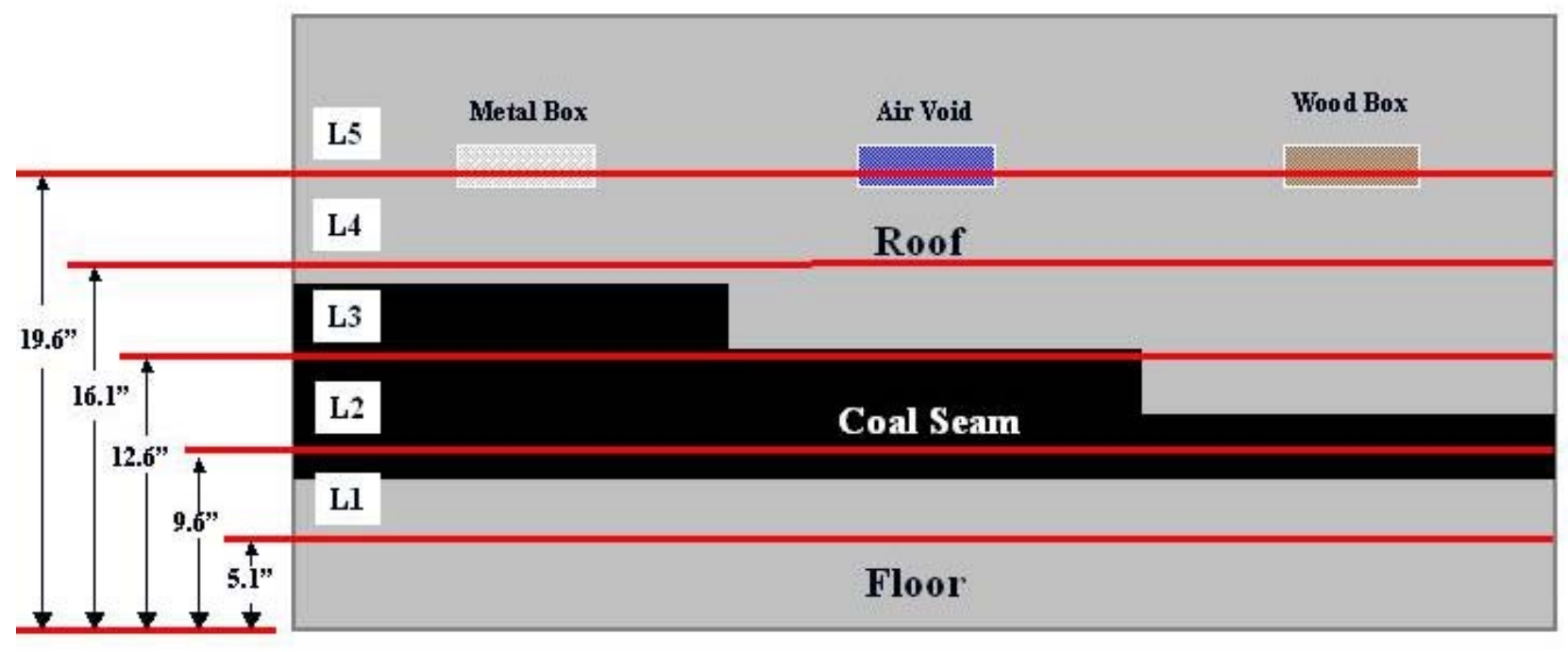

Figure 4.10 Scaled physical model reconnaissance survey lines 


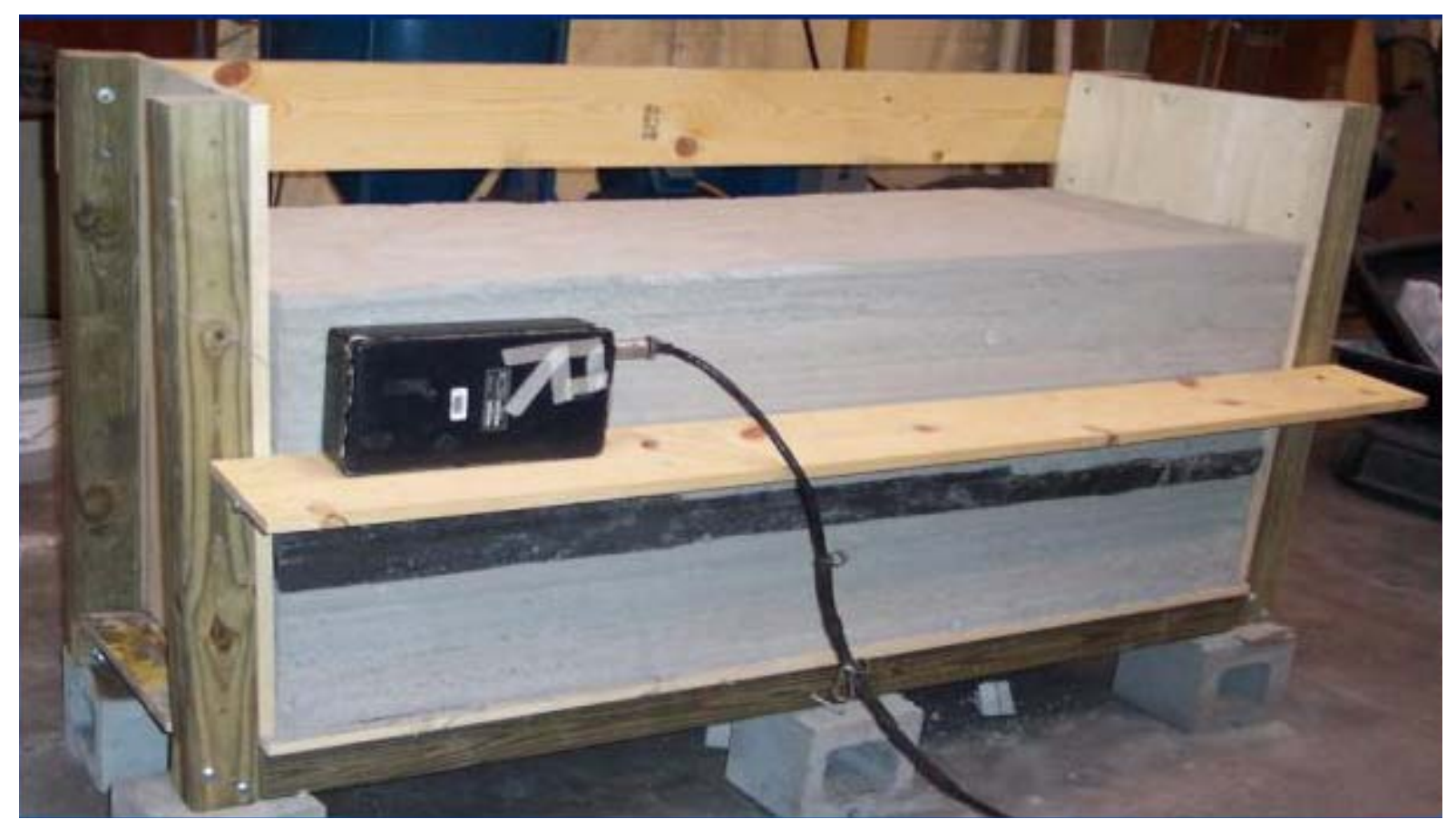

Figure 4.11 Scaled physical model 


\section{CHAPTER 5}

\section{DATA COLLECTION AND CONVERSION}

The first step of this research was to determine the spatial spreading of the EM signal (reduction of energy level as it travels through air space). In the next stage, EM reconnaissance surveys were conducted at various times and under different conditions on a scaled physical model.

The data collected from the spatial spreading tests and physical model tests were recorded on the modified GPR instrumentation. A series of tests were conducted, generally 28 data points for the spatial spreading testing, and 155 data points for the reconnaissance physical model testing.

The data was prepared for analysis initially by downloading the raw data from the modified GPR instrumentation to a computer. In order to facilitate the handling and analysis of the data, several programs were utilized. These programs included: the GSSI data transfer utility, GSSI RADAR Data Analyzer (RADAN), GSSI RADAN to ASCII conversion, Microsoft Excel, CurveExpert and Golden Software Surfer.

The data was collected in terms of signal amplitude (counts) and time (samples). A typical waveform consists of 512 samples. A sample is a memory location, which stores five integers. The first two samples contain the header information about the signal waveform. This information includes: time, date, range, gains points and, resolution. The remaining 510 samples contain the signal amplitudes for the complete waveform. The time per sample can be determined by taking the range, which is set in the instrumentation, divided by 510 . The formula is presented as follows:

$$
\text { Time per sample }=\text { range } / 510
$$

As an example:

$$
\begin{aligned}
& \text { range }=15 \mathrm{~ns} ; \\
& \text { time per sample }=29.41 \rho \mathrm{s} .
\end{aligned}
$$

\subsection{Data Conversion}

A number of data analysis techniques were used to convert the raw data into ASCII format and then into voltages, taking into consideration the relationship between the gain factors in $\mathrm{dB}$, scaling factors for volts, and the scaling factor for counts. To generate the spatial spreading equations, the CurveExpert program was used. For the reconstruction of the attenuation signal strength distribution contour maps, the Surfer program was used. 


\subsubsection{Conversion of Raw Data into ASCII}

The raw data generated in the GSSI instrumentation is in a proprietary format file (*.DZT). In order to further post process the raw data, the DZT files were converted to ASCII (American Standard Code for Information) using a RADAN to ASCII conversion utility program. As mention earlier, each scan has a total of 512 memory locations and the first two memory locations contain the header information which is not needed for the final data analysis. The resolution of each memory location is 65,536 absolute counts. The counts can range from +32768 to -32768 . An example of single scan data converted to ASCII then imported into a Microsoft Excel spreadsheet is shown in Figure 5.1.

\section{Raw Data}

single scan/sample 512 memory locations

\begin{tabular}{|c|c|c|}
\hline \multicolumn{2}{|c|}{ Arial } & - \\
\hline & 11 & $\nabla$ \\
\hline & A & $B$ \\
\hline 1 & 32767 & \\
\hline 2 & -32768 & \\
\hline 3 & 0 & \\
\hline 4 & 2 & \\
\hline 5 & 6 & \\
\hline 6 & 11 & \\
\hline 7 & 15 & \\
\hline 8 & 17 & \\
\hline 9 & 22 & \\
\hline 10 & 29 & \\
\hline 11 & 41 & \\
\hline 12 & 57 & \\
\hline 13 & 80 & \\
\hline 14 & 116 & \\
\hline 15 & 142 & \\
\hline 16 & 160 & \\
\hline 17 & 188 & \\
\hline 18 & 232 & \\
\hline 19 & 291 & \\
\hline 20 & 379 & \\
\hline 21 & 497 & \\
\hline 22 & 621 & \\
\hline
\end{tabular}

\section{header information}

(time, date, range,gains, resolution)

\section{memory locations maximum value of 32768 minimum value of $\mathbf{- 3 2 7 6 8}$}

Figure 5.1 Single scan converted to ASCII 


\subsubsection{Conversion of Counts into Volts}

As mentioned earlier, the raw data signal strength from the collected data is represented in counts with an absolute maximum count of 65,536. Typically signal strength is expressed in units of power (W), voltage $(\mathrm{V})$, or decibels $(\mathrm{dB})$. In order to make the data more understandable the absolute signal strength was converted into volts. This conversion was accomplished by using following basic equations (UNSW, 2007):

$$
\begin{aligned}
& d B=10 \log \left(\frac{P_{2}}{P_{1}}\right) \\
& d B=20 \log \left(\frac{v_{2}}{v_{1}}\right)
\end{aligned}
$$

Where:

$P_{1}, P_{2}$ - the reference and actual power, $\mu \mathrm{W} ;$
$v_{1}, v_{2}$ - the reference and actual voltage, $\mu \mathrm{V}$.

The $900 \mathrm{MHz}$ Tx antenna used in the tests emits a maximum signal strength of $4 \mu \mathrm{W}$ or $63 \mu \mathrm{V}$. Since $1 \mathrm{~mW}$ is equivalent to $0 \mathrm{~dB}$, the maximum signal strength emitted for the Tx antenna is $-24 \mathrm{~dB}$. The data collected in the tests used different gain factors in order to make the signal scan waveforms more easily visible on the instrumentation control panel display. The data obtained in the various tests using different gain factors had to be scaled to a level of $0 \mathrm{~dB}$. If the signal strength is expressed in volts, the relationship between the scaling factors for volts is $S_{v}$. The relationship between the voltage scaling factor and the gain factor are shown in the following equations:

By using equation 5.3, and substituting in the $900 \mathrm{MHz}$ maximum signal strength, the scaling factor for volts $S_{v}$, can be derived

$$
\begin{aligned}
& d B=20 \log \left(\frac{v_{2}}{v_{1}}\right) \\
& -24+G=20 \log \left(\frac{63 S_{v}}{1000}\right)
\end{aligned}
$$




$$
\begin{aligned}
& (-24+G) / 20=\log \left(\frac{63 S_{v}}{1000}\right) \\
& 10^{(-24+\mathrm{G}) / 20}=\left(\frac{63 \mathrm{~S}_{\mathrm{v}}}{1000}\right) \\
& 63 \mathrm{~S}_{\mathrm{v}}=1000 \times 10^{(-24+\mathrm{G}) / 20} \\
& \mathrm{~S}_{\mathrm{v}}=(15.8730) \times 10^{(-24+\mathrm{G}) / 20}
\end{aligned}
$$

Where:

$S_{v}$ - scaled factor for volts;

G - Gain (dB).

If the uncorrected signal strength is in counts, the scaling factor for count $S_{c}$ is determined by the following equation:

$$
S_{c}=\frac{2^{16}}{63} \times S_{v}
$$

Where:

$$
\begin{aligned}
& S_{c} \text { - scaled factor for counts; } \\
& S_{v} \text { - scaled factor for voltage. }
\end{aligned}
$$

The relationship between volts $(\mathrm{uV})$, and $S_{c}$ (scaled counts) is determined by the following equation:

$$
V=\text { counts } / S_{c}
$$

Where:

$$
\mathrm{V} \text { - Voltage }(\mu \mathrm{V}) \text {. }
$$

\subsubsection{Signal Discrimination}

A typical EM waveform converted into ASCII and then plotted in Excel is shown in Figure 5.2. The $\mathrm{Y}$-axis represents the signal strength maximum and minimum in counts and the $\mathrm{X}$-axis represent 
samples. As mentioned earlier, the waveform consists of 510 samples on the X-axis and each sample can be converted to a time as indicated by Eq. 5.1.

This research was focused on the analysis of the first received maximum and minimum amplitudes. A recommended area for future research is to understand the signal characteristics after the first received maximum and minimum amplitudes. It should be noted that with multiple reflections in the waveform, signal discrimination techniques have been developed that consider the velocity of the EM waveform. The logic used is as follows:

1. Determine the relaxation pulse.

2. Determine the first maximum and minimum counts after the relaxation pulse.

3. Take the absolute value of the maximum and minimum counts.

4. Convert the absolute value of counts into user-friendly units of volts.

5. Use the relaxation pulse to determine the first arrival time.

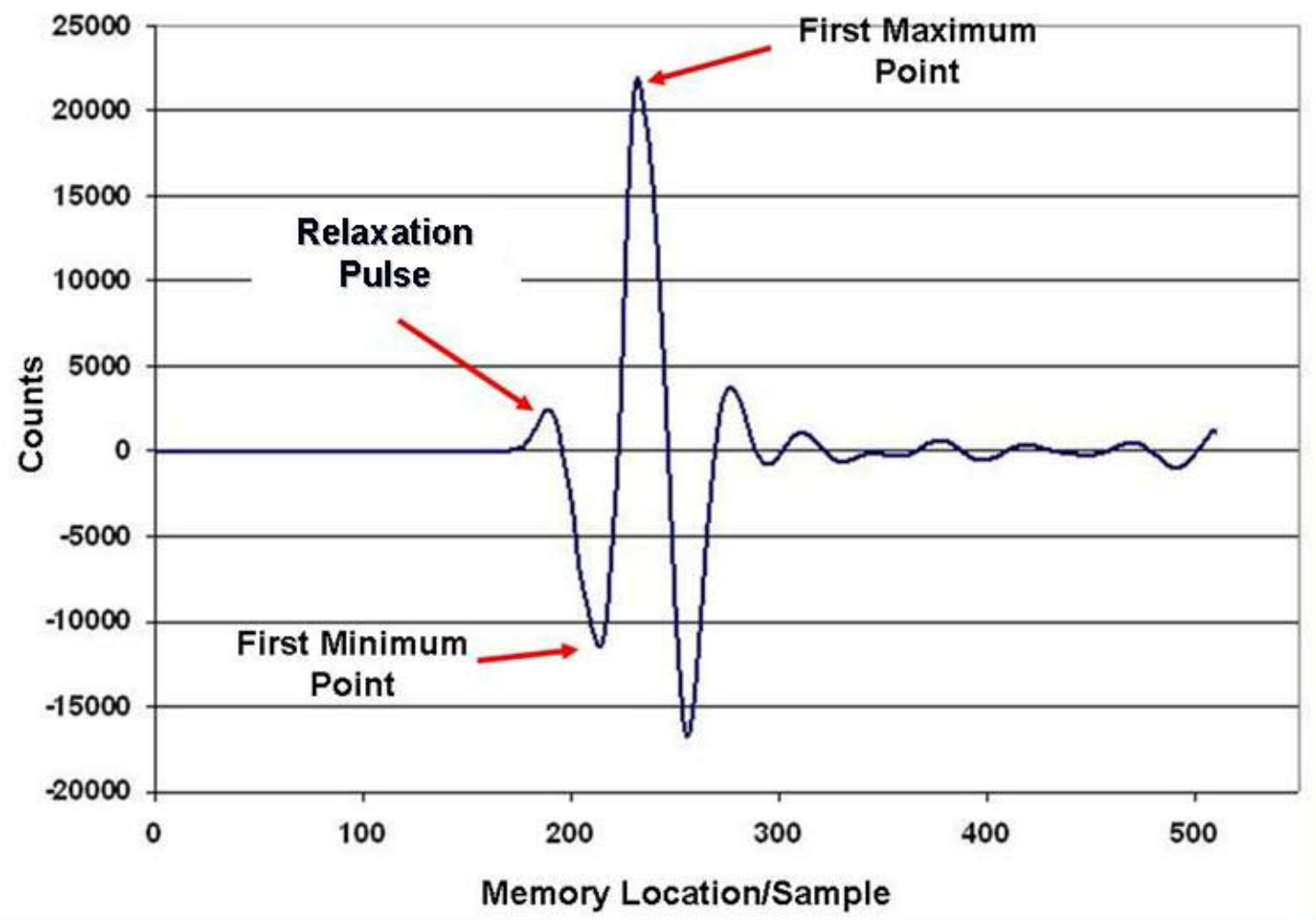

Figure 5.2 Typical converted EM waveform 
The scaling factors $\left(S_{v}, S_{c}\right)$ for a range of gain factors $(0$ to $40 \mathrm{~dB})$ are shown in Table 5.1.

Table 5.1 Gain factors $(\mathrm{G})$, voltage scaling factors $\left(S_{v}\right)$ and counts scaling factors $\left(S_{c}\right)$

\begin{tabular}{|c|c|c|c|c|}
\hline $\begin{array}{l}\text { Gain Factor } \\
\text { G(dB) }\end{array}$ & \multicolumn{2}{|c|}{$\begin{array}{l}\text { Scaling Factor } \\
\text { Applied to uV }\end{array}$} & \multicolumn{2}{|c|}{$\begin{array}{l}\text { Scaling Factor } \\
\text { Applied to Counts }\end{array}$} \\
\hline & Sv & $1 / \mathrm{Sv}$ & Sc & 1/Sc \\
\hline 0 & 1.0015 & 0.9985 & 1041.83 & 0.0009598 \\
\hline 1 & 1.1237 & 0.8899 & 1168.96 & 0.0008555 \\
\hline 2 & 1.2608 & 0.7931 & 1311.59 & 0.0007624 \\
\hline 3 & 1.4147 & 0.7069 & 1471.63 & 0.0006795 \\
\hline 4 & 1.5873 & 0.6300 & 1651.20 & 0.0006056 \\
\hline 5 & 1.7810 & 0.5615 & 1852.67 & 0.0005398 \\
\hline 6 & 1.9983 & 0.5004 & 2078.73 & 0.0004811 \\
\hline 7 & 2.2421 & 0.4460 & 2332.38 & 0.0004287 \\
\hline 8 & 2.5157 & 0.3975 & 2616.97 & 0.0003821 \\
\hline 9 & 2.8227 & 0.3543 & 2936.29 & 0.0003406 \\
\hline 10 & 3.1671 & 0.3157 & 3294.57 & 0.0003035 \\
\hline 11 & 3.5535 & 0.2814 & 3696.57 & 0.0002705 \\
\hline 12 & 3.9871 & 0.2508 & 4147.62 & 0.0002411 \\
\hline 13 & 4.4736 & 0.2235 & 4653.70 & 0.0002149 \\
\hline 14 & 5.0195 & 0.1992 & 5221.54 & 0.0001915 \\
\hline 15 & 5.6320 & 0.1776 & 5858.67 & 0.0001707 \\
\hline 16 & 6.3192 & 0.1582 & 6573.53 & 0.0001521 \\
\hline 17 & 7.0902 & 0.1410 & 7375.63 & 0.0001356 \\
\hline 18 & 7.9554 & 0.1257 & 8275.59 & 0.0001208 \\
\hline 19 & 8.9261 & 0.1120 & 9285.36 & 0.0001077 \\
\hline 20 & 10.0152 & 0.0998 & 10418.35 & 0.0000960 \\
\hline 21 & 11.2372 & 0.0890 & 11689.58 & 0.0000855 \\
\hline 22 & 12.6084 & 0.0793 & 13115.92 & 0.0000762 \\
\hline 23 & 14.1468 & 0.0707 & 14716.31 & 0.0000680 \\
\hline 24 & 15.8730 & 0.0630 & 16511.97 & 0.0000606 \\
\hline 25 & 17.8098 & 0.0561 & 18526.73 & 0.0000540 \\
\hline 26 & 19.9829 & 0.0500 & 20787.34 & 0.0000481 \\
\hline 27 & 22.4212 & 0.0446 & 23323.77 & 0.0000429 \\
\hline 28 & 25.1570 & 0.0398 & 26169.71 & 0.0000382 \\
\hline 29 & 28.2267 & 0.0354 & 29362.89 & 0.0000341 \\
\hline 30 & 31.6708 & 0.0316 & 32945.71 & 0.0000304 \\
\hline 31 & 35.5353 & 0.0281 & 36965.69 & 0.0000271 \\
\hline 32 & 39.8712 & 0.0251 & 41476.19 & 0.0000241 \\
\hline 33 & 44.7362 & 0.0224 & 46537.05 & 0.0000215 \\
\hline 34 & 50.1949 & 0.0199 & 52215.43 & 0.0000192 \\
\hline 35 & 56.3196 & 0.0178 & 58586.67 & 0.0000171 \\
\hline 36 & 63.1916 & 0.0158 & 65735.33 & 0.0000152 \\
\hline 37 & 70.9022 & 0.0141 & 73756.25 & 0.0000136 \\
\hline 38 & 79.5535 & 0.0126 & 82755.87 & 0.0000121 \\
\hline 39 & 89.2605 & 0.0112 & 92853.62 & 0.0000108 \\
\hline 40 & 100.1520 & 0.0100 & 104183.47 & 0.0000096 \\
\hline
\end{tabular}




\section{CHAPTER 6 \\ DATA ANALYSIS}

As mentioned earlier, the overall goal of this research is to increase the accuracy of the RIM technology by studying the EM wave properties on a scaled physical model of a longwall panel and quantifying the data collected. This was accomplished by performing spatial spreading testing in air and EM reconnaissance surveys on a scaled physical model. After analyzing the data from the spatial spreading testing, an understanding was gained on the signal strength reduction in the $\mathrm{X}, \mathrm{Y}$ and $\mathrm{Z}$ directions and an equation was developed. This was needed since simply identifying a received signal at an Rx antenna in an EM survey does not necessarily provide all sufficient information about the signal.

In a scaled physical model the geometry of the area being surveyed, locations of the geologic anomalies, thickness of the roof and coal seam, and the contact points of the Tx and Rx antennas were all known. These parameters are important since they were needed in the data analysis of the EM surveys performed on the scaled physical model. Surveys on the physical model were performed at different times to gain an understanding of how the moisture content effects the EM signal characteristics. It was possible to determine the attenuation rate of the EM signal in the scaled physical model. The total attenuation rate is determined by taking the difference between the signal strength measured in air and the measured signal strength in the physical model. Figure 6.1 shows the voltage differences caused by media at three different points (V1, V2, and V3) in a model. V(a) is the measured strength (volts) in air and $\mathrm{V}(\mathrm{m})$ is the measured signal strength (volts) in the model. The following equation shows how to determine the actual voltage drop due to the model at different points.

$$
\mathrm{V}_{\mathrm{i}}=\mathrm{V}(\mathrm{a})-\mathrm{Vm}_{\mathrm{i}}
$$

Where:

$$
\begin{aligned}
& V_{i}=\text { actual voltage of model at point } i \\
& V(a)=\text { air voltage; } \\
& \mathrm{Vm}_{\mathrm{i}}=\text { measured voltage of the model at point } i .
\end{aligned}
$$

The voltage attenuation rate at point $\mathrm{i}$ can be determined by dividing the actual voltage of the model by the distance between the Tx and Rx antennas. This is shown in the following equation.

$$
\text { Attenuation Rate }=\mathrm{V}_{\mathrm{i}} / \mathrm{L}
$$

Where: $\mathrm{L}=$ distance. 


\section{Equations are needed to determine the center and angular spreading}

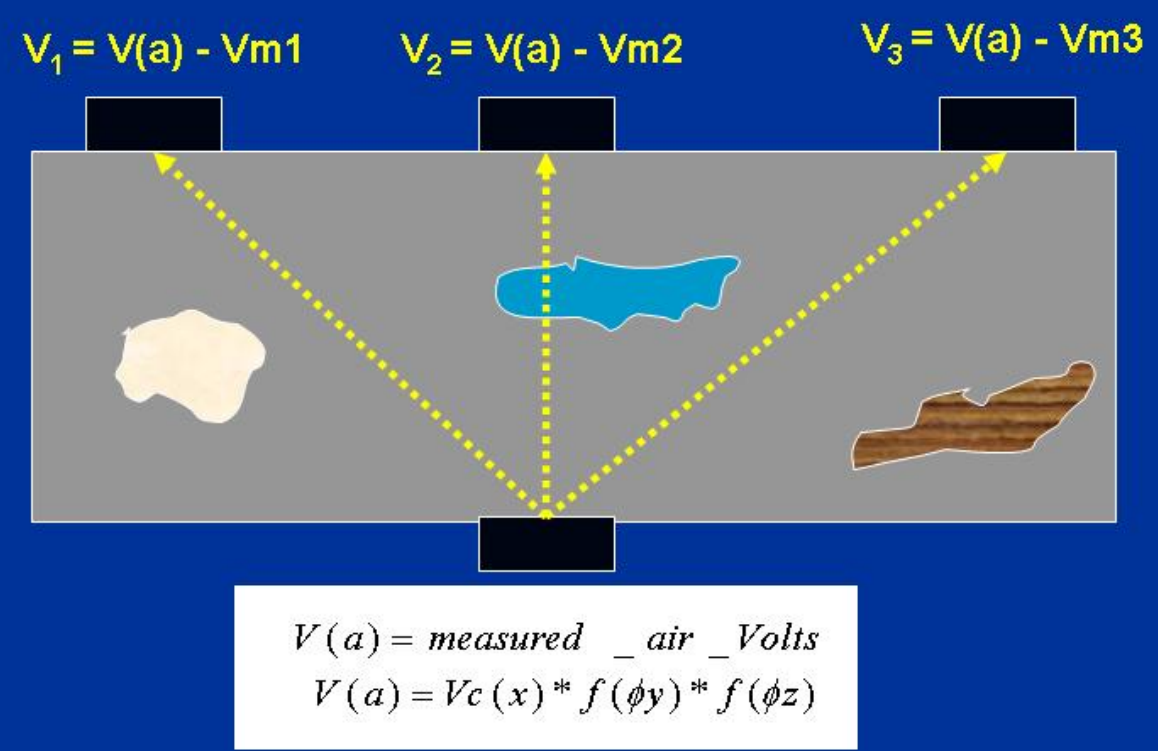

$$
\mathrm{Vm}=\text { measured model Volts }
$$

Figure 6.1 Example of measured signal strengths in the physical model

\subsection{Signal Strength Reduction as Spatial Spreading Data Analysis}

As mentioned earlier, the transmitted energy of the pulse for the Tx antenna is radiated in a conical pattern as shown in Figure 6.2. As the energy travels through space, it spreads and the signal strength is reduced. Spatial spreading testing was performed in air to generate an equation that can be used to determine this signal strength reduction in the XYZ coordinate plane. Additional data on spatial spreading is located in Appendix A. 


\section{TX Antenna}

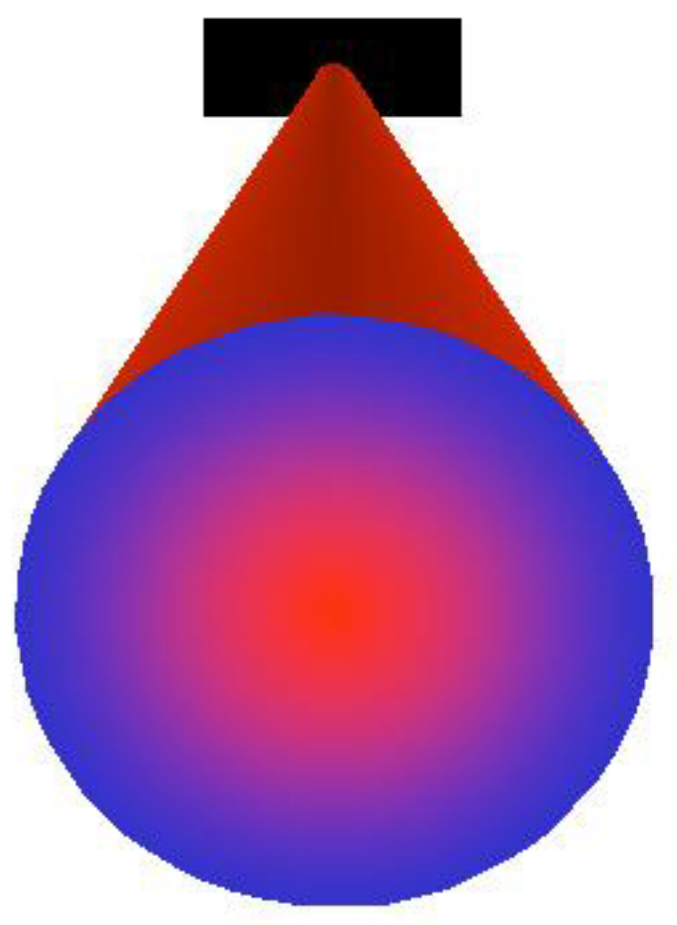

Figure 6.2 Example of signal strength reduction and spreading in air

\subsubsection{Equation Developed}

The follow equation was developed to determine the signal strength $V(a)$ at a given point (xyz). The Tx antenna is at the origin of the XYZ coordinate system and the Rx antenna is located at some point in the XYZ coordinate plane (Figure 4.4).

$$
V(a)=V c(x) * f(\phi y) * f(\phi z)
$$

The derivation for each part of this equation as a function of the antennas orientation is presented below.

\subsubsection{Signal Strength Reduction Development for the Equation in the X Direction}

Finding the maximum signal strength at point $\mathrm{D}$, lines $1-4$ for several data sets, was the method used for the development of the $\mathrm{X}$ part of the equation. Figure 6.3 shows point $\mathrm{D}$ for lines $1-4$. 


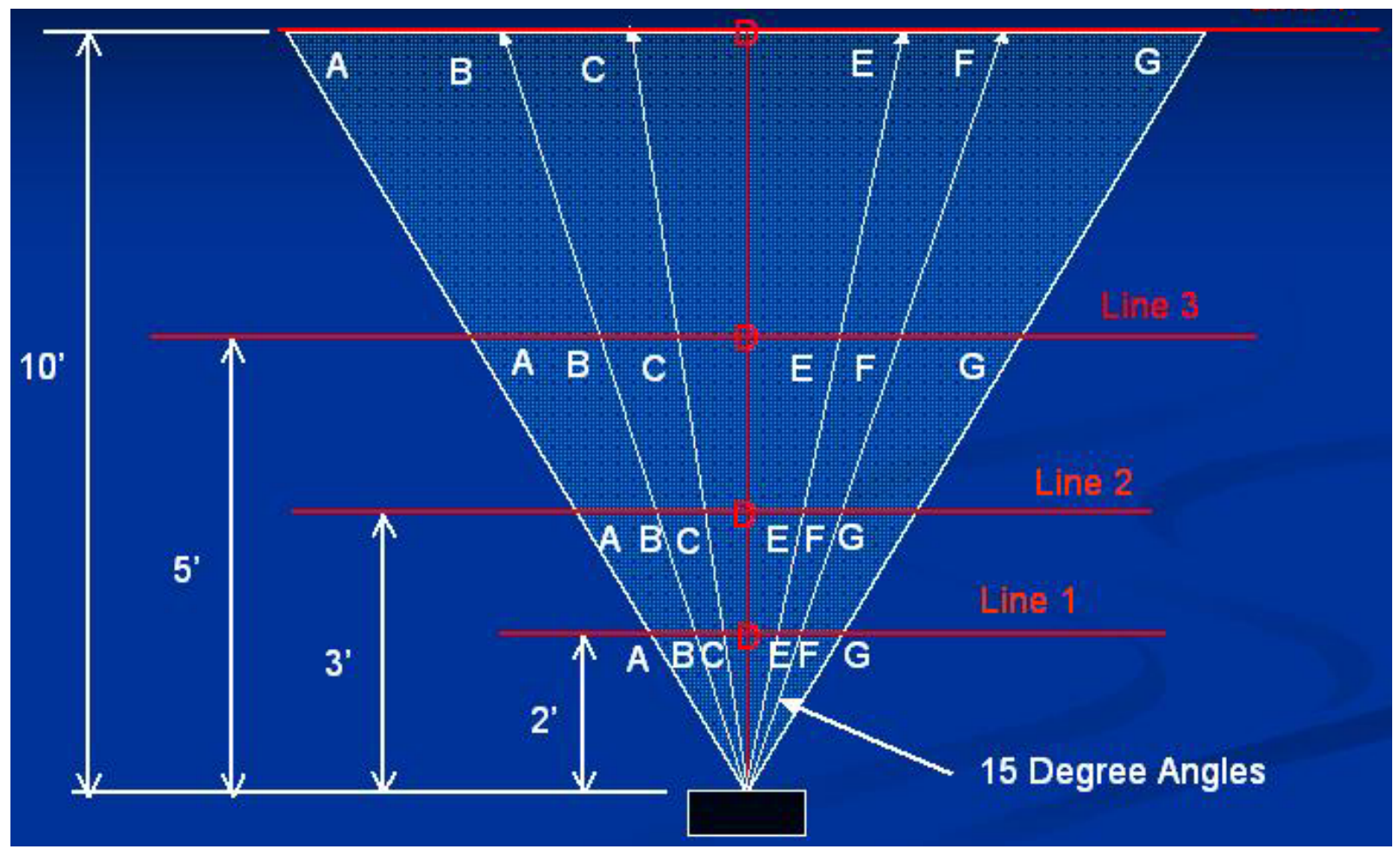

Figure 6.3 Center spreading points used to determine the $\mathrm{X}$ equation

Data from four different spatial spreading tests were used in the development of the $\mathrm{X}$-axis equation. The data is shown in Table 6.1. Data values were then plotted in CurveExpert as shown in Figure 6.4. The equation developed for the $\mathrm{X}$-axis is as follows.

$$
\operatorname{Vc}(x)=1 /\left(a+b x^{c}\right)
$$

Where:

$$
\begin{aligned}
& a=-0.090073 \\
& b=0.1454967 \\
& c=0.5395678
\end{aligned}
$$

With the development of this equation, the center spreading signal strength in air at a fixed distance can be determined. 
Table 6.1 X equation development

\begin{tabular}{||c|c|c|c||}
\hline Line & Point & $\begin{array}{c}\text { Distance } \\
\mathrm{ft}\end{array}$ & $\begin{array}{c}\text { Volts } \\
\mathrm{uV}\end{array}$ \\
\hline \hline 1 & $\mathrm{D}$ & 2.00 & 8.40 \\
\hline 1 & $\mathrm{D}$ & 2.00 & 8.10 \\
\hline 1 & $\mathrm{D}$ & 2.00 & 8.20 \\
\hline 1 & $\mathrm{D}$ & 2.00 & 8.60 \\
\hline 2 & $\mathrm{D}$ & 3.00 & 5.30 \\
\hline 2 & $\mathrm{D}$ & 3.00 & 5.20 \\
\hline 2 & $\mathrm{D}$ & 3.00 & 5.60 \\
\hline 2 & $\mathrm{D}$ & 3.00 & 5.50 \\
\hline 3 & $\mathrm{D}$ & 5.00 & 4.30 \\
\hline 3 & $\mathrm{D}$ & 5.00 & 4.50 \\
\hline 3 & $\mathrm{D}$ & 5.00 & 4.40 \\
\hline 3 & $\mathrm{D}$ & 5.00 & 4.50 \\
\hline 4 & $\mathrm{D}$ & 10.00 & 2.14 \\
\hline 4 & $\mathrm{D}$ & 10.00 & 2.10 \\
\hline 4 & $\mathrm{D}$ & 10.00 & 2.30 \\
\hline 4 & $\mathrm{D}$ & 10.00 & 2.10 \\
\hline
\end{tabular}

\section{Warris Model}

\section{-}

info Please press the right mouse button for the graphing features menu. Press F1 for help.

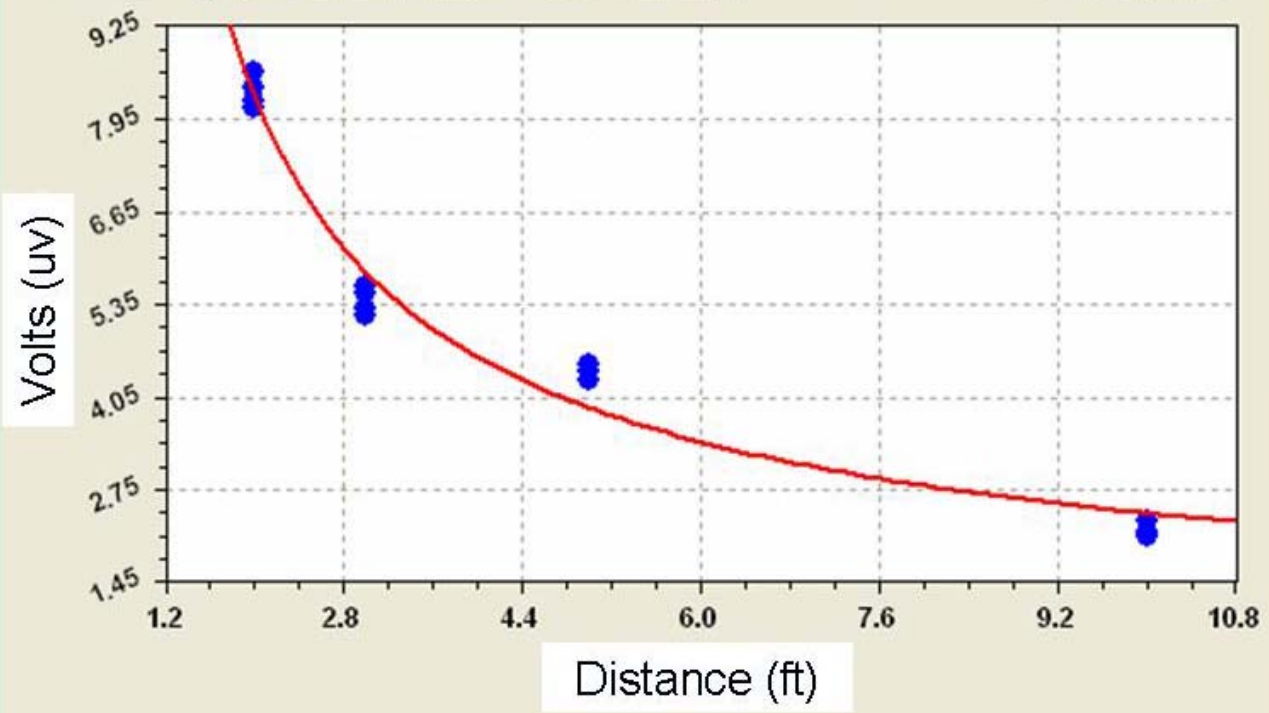

Figure 6.4 Curve fitting for $\mathrm{X}$ equation development 


\subsubsection{Signal Strength Reduction Development for the Equation in the Y Direction}

From the spatial spreading tests, the Tx and Rx antenna were positioned as shown in Figure 4.6. The data was collected from lines $1-4$, points $A-G$, as shown in Figure 6.3. The following data was obtained and is shown in Table 6.2.

1. $\quad$ Rx position and angle with respect to the Tx as shown in Figure 6.3.

2. Memory locations, counts, and arrival times.

3. Absolute magnitude of the memory counts.

4. Velocity of wave.

5. $\quad$ Air volts, derived from the gain and scaling factor as shown in Table 5.1.

6. Normalized magnitudes that are used for equation development.

Data values were then plotted in CurveExpert as shown in Figure 6.5.

Table 6.2 Spatial spreading testing Tx and $\mathrm{Rx}$ in the horizontal position (Y)

\begin{tabular}{|c|c|c|c|c|c|c|c|c|c|c|c|c|c|c|}
\hline \multicolumn{15}{|c|}{ Tx=90 Rx=90, File \# 1010-1037, Range 20(ns), Gain 15 (dB), Sv=5.6320, Sc=5858.7, Offset -1.67(ns), February 5, 2007 } \\
\hline Rx Point & Distance, $\mathrm{ft}$ & Angle, deg & Memory & $\operatorname{Max}$ & time & Memory & Min & time & Ave. time & Abs & First Arrival & Velocity & Air Volts & Normalized \\
\hline & receiver & & Location & Count & $\mathrm{ns}$ & Location & Count & $\mathrm{ns}$ & $\mathrm{ns}$ & & \begin{tabular}{|c|}
$\mathrm{ns}$ \\
\end{tabular} & $\mathrm{ft} / \mathrm{ns}$ & (uV) & \\
\hline L1-A & 2.83 & -45 & 50 & 10624 & 1.96 & 36 & -8832 & 1.41 & 1.69 & 19456 & 2.63 & 1.08 & 3.3209 & 0.40 \\
\hline L1-B & 2.31 & -30 & 38 & 18304 & 1.49 & 24 & -14464 & 0.94 & 1.22 & 32768 & 2.16 & 1.07 & 5.5930 & 0.68 \\
\hline L1-C & 2.07 & -15 & 35 & 24448 & 1.37 & 21 & -18816 & 0.82 & 1.10 & 43264 & 2.04 & 1.01 & 7.3846 & 0.90 \\
\hline L1-D & 2.00 & 0 & 33 & 26496 & 1.29 & 19 & -21632 & 0.74 & 1.02 & 48128 & 1.96 & 1.02 & 8.2148 & 1.00 \\
\hline L1-E & 2.07 & 15 & 31 & 24496 & 1.22 & 18 & -20864 & 0.71 & 0.96 & 45360 & 1.89 & 1.10 & 7.7423 & 0.94 \\
\hline L1-F & 2.31 & 30 & 39 & 18048 & 1.53 & 25 & -15488 & 0.98 & 1.25 & 33536 & 2.20 & 1.05 & 5.7241 & 0.70 \\
\hline L1-G & 2.83 & 45 & 52 & 12416 & 2.04 & 37 & -9600 & 1.45 & 1.74 & 22016 & 2.71 & 1.04 & 3.7578 & 0.46 \\
\hline L2-A & 4.24 & -45 & 81 & 7296 & 3.18 & 66 & -4992 & 2.59 & 2.88 & 12288 & 3.85 & 1.10 & 2.0974 & 0.38 \\
\hline L2-B & 3.46 & -30 & 60 & 13184 & 2.35 & 46 & -10368 & 1.80 & 2.08 & 23552 & 3.02 & 1.14 & 4.0200 & 0.72 \\
\hline L2-C & 3.11 & -15 & 54 & 16560 & 2.12 & 41 & -12800 & 1.61 & 1.86 & 29360 & 2.79 & 1.12 & 5.0114 & 0.90 \\
\hline L2-D & 3.00 & 0 & 52 & 18560 & 2.04 & 38 & -14208 & 1.49 & 1.76 & 32768 & 2.71 & 1.11 & 5.5930 & 1.00 \\
\hline L2-E & 3.11 & 15 & 58 & 16384 & 2.27 & 43 & -13056 & 1.69 & 1.98 & 29440 & 2.94 & 1.06 & 5.0250 & 0.90 \\
\hline L2-F & 3.46 & 30 & 62 & 13184 & 2.43 & 48 & \begin{tabular}{|l|l|}
-10880 \\
\end{tabular} & 1.88 & 2.16 & 24064 & 3.10 & 1.12 & 4.1074 & 0.73 \\
\hline L2-G & 4.24 & 45 & 82 & 9600 & 3.21 & 68 & -6528 & 2.67 & 2.94 & 16128 & 3.88 & 1.09 & 2.7528 & 0.49 \\
\hline L3-A & 7.07 & -45 & 160 & 5760 & 6.27 & 145 & -4224 & 5.68 & 5.98 & 9984 & 6.94 & 1.02 & 1.7041 & 0.35 \\
\hline L3-B & 5.77 & -30 & 126 & 10368 & 4.94 & 112 & -8064 & 4.39 & 4.66 & 18432 & 5.61 & 1.03 & 3.1461 & 0.65 \\
\hline L3-C & 5.18 & -15 & 109 & 14848 & 4.27 & 96 & -11520 & 3.76 & 4.02 & 26368 & 4.94 & 1.05 & 4.5007 & 0.94 \\
\hline L3-D & 5.00 & 0 & 109 & 16000 & 4.27 & 96 & -12160 & 3.76 & 4.02 & 28160 & 4.94 & 1.01 & 4.8065 & 1.00 \\
\hline L3-E & 5.18 & 15 & 110 & 15104 & 4.31 & 96 & -11520 & 3.76 & 4.04 & 26624 & 4.98 & 1.04 & 4.5444 & 0.95 \\
\hline L3-F & 5.77 & 30 & 122 & 10136 & 4.78 & 109 & -9344 & 4.27 & 4.53 & 19480 & 5.45 & 1.06 & 3.3250 & 0.69 \\
\hline L3-G & 7.07 & 45 & 158 & 7040 & 6.19 & 143 & -5760 & 5.61 & 5.90 & 12800 & 6.86 & 1.03 & 2.1848 & 0.45 \\
\hline L4-A & 14.14 & -45 & 342 & 2688 & 13.41 & 330 & -2176 & 12.94 & 13.17 & 4864 & 14.08 & 1.00 & 0.8302 & 0.31 \\
\hline L4-B & 11.55 & -30 & 284 & 5760 & \begin{tabular}{|l|}
11.13 \\
\end{tabular} & 269 & -3968 & \begin{tabular}{|l|}
10.54 \\
\end{tabular} & 10.84 & 9728 & 11.80 & 0.98 & 1.6604 & 0.62 \\
\hline L4-C & 10.35 & -15 & 246 & 7808 & \begin{tabular}{|l|}
9.64 \\
\end{tabular} & 232 & -5504 & \begin{tabular}{|l|}
9.09 \\
\end{tabular} & 9.37 & 13312 & 10.31 & 1.00 & 2.2722 & 0.85 \\
\hline L4-D & 10.00 & 0 & 239 & 9088 & 9.37 & 224 & -6528 & 8.78 & 9.07 & 15616 & 10.04 & 1.00 & 2.6654 & 1.00 \\
\hline L4-E & 10.35 & 15 & 246 & 8320 & 9.64 & 232 & -6016 & 9.09 & 9.37 & 14336 & 10.31 & 1.00 & 2.4470 & 0.92 \\
\hline L4-F & 11.55 & 30 & 285 & 6016 & 11.17 & 271 & -4224 & 10.62 & 10.90 & 10240 & 11.84 & 0.98 & 1.7478 & 0.66 \\
\hline L4-G & 14.14 & 45 & 346 & 3456 & 13.56 & 332 & -2176 & 13.01 & 13.29 & 5632 & 14.23 & 0.99 & 0.9613 & 0.36 \\
\hline
\end{tabular}




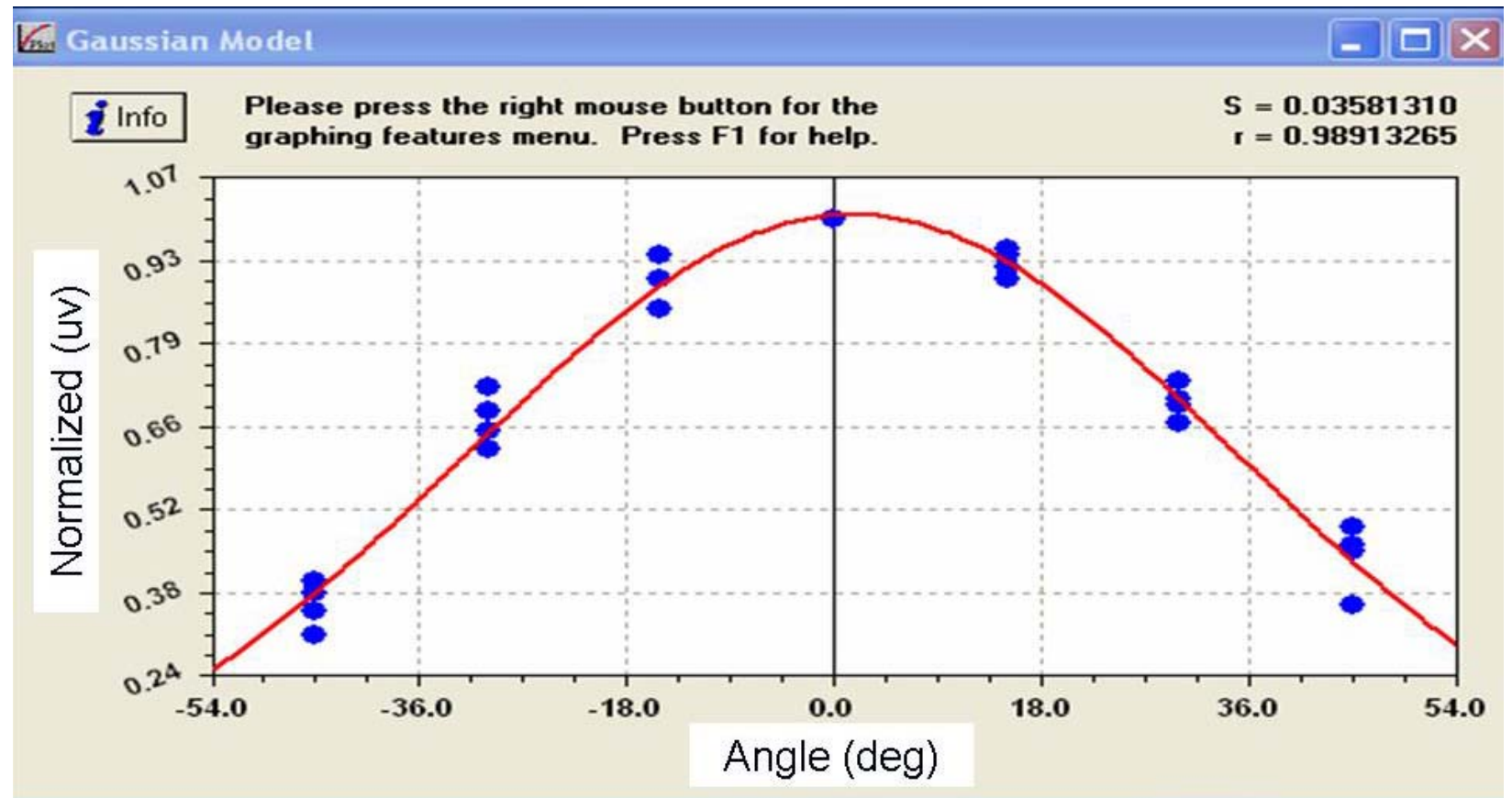

Figure 6.5 Curve fitting for $\mathrm{Y}$ equation development

The equation developed for the Y-axis is as follows.

$$
f\left(\phi_{y}\right)=a e^{\frac{-\phi y^{2}}{2 c^{2}}}
$$

Where:

$$
\begin{aligned}
& a=1.008668 ; \\
& c=33.37539 .
\end{aligned}
$$

\subsubsection{Measured Radiation Distribution in the Y Direction}

The measured radiation distributions for the $\mathrm{Y}$ direction are shown in Figure 6.6. In this figure, the hotter color (red) represent higher signal strengths and the cooler color (blue) represent lower signal strengths. The numerical values in the contour mapping are volts that were derived from the absolute magnitude counts. 


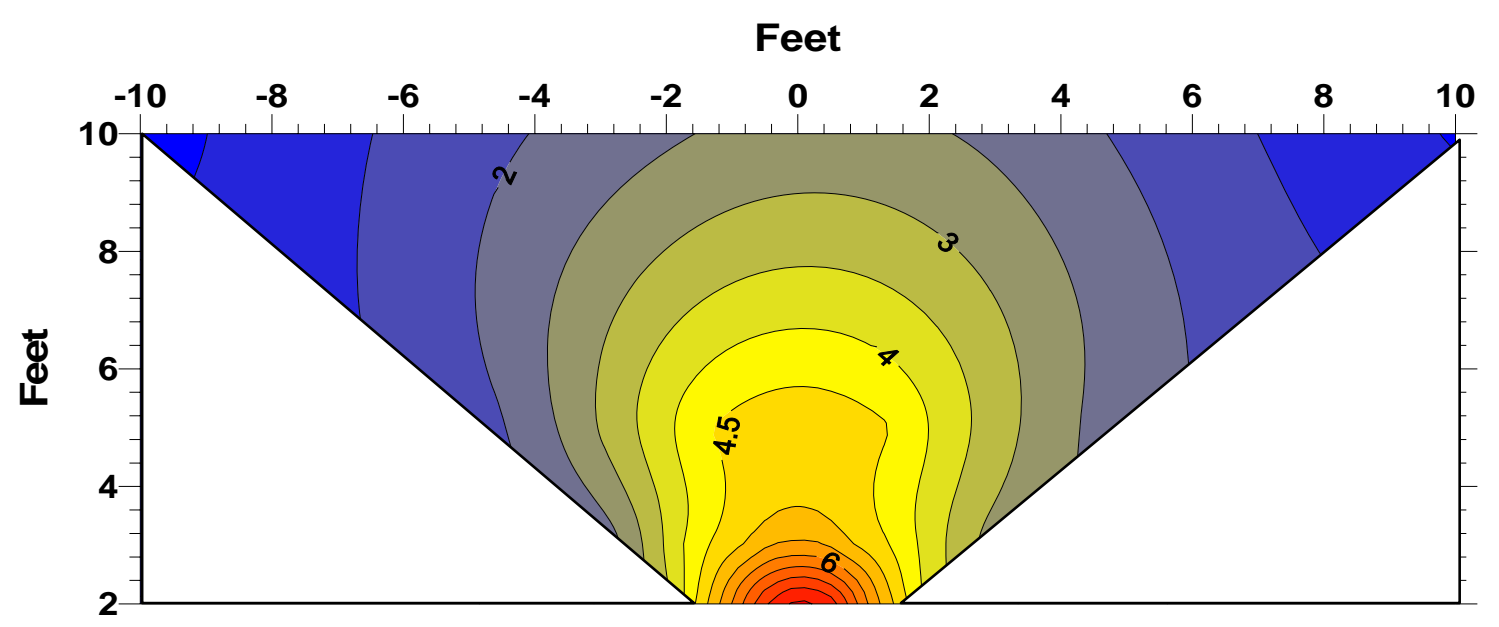

Figure 6.6 Measured radiation distribution in the $\mathrm{Y}$ direction

\subsubsection{Signal Strength Reduction Development for the Equation in the Z Direction}

From the spatial spreading tests, the Tx and Rx antenna were repositioned as shown in Figure 4.7. The data was collected from lines $1-4$, points $A-G$, as shown in Figure 6.3. The testing procedure was identical to the testing perform in the $\mathrm{Y}$ direction with the exception of the Tx and Rx antennas being rotated by $90 \mathrm{deg}$. The testing data and results are shown in Table 6.4. Data values were then plotted in CurveExpert as shown in Figure 6.7.

Table 6.3 Spatial spreading testing Tx and $\mathrm{Rx}$ in the vertical position (Z)

\begin{tabular}{|c|c|c|c|c|c|c|c|c|c|c|c|c|c|c|}
\hline \multicolumn{15}{|c|}{ Tx=60 Rx=60, File \# 1038-1065, Range 20(ns), Gain 15 (dB), Sv=5.6320, Sc=5858.7,0ffset -2.67(ns), February 5, 2007 } \\
\hline Rx Point & Distance, $\mathrm{ft}$ & Angle, deg & Memory & Max & time & Memory & Min & time & Ave. time & Abs & First Arrival & \begin{tabular}{|l|} 
Velocity \\
\end{tabular} & Air Volts & Normalized \\
\hline & receiver & & \begin{tabular}{|l} 
Location \\
\end{tabular} & Count & ns & Location & Count & ns & $\mathrm{ns}$ & & $\begin{array}{l}\mathrm{ns} \\
\end{array}$ & $\mathrm{ft} / \mathrm{ns}$ & (uV) & \\
\hline L1-A & 2.83 & -45 & 42 & 12928 & 1.65 & 28 & -9600 & 1.10 & 1.37 & 22528 & 2.63 & 1.08 & 3.8452 & 0.45 \\
\hline L1-B & 2.31 & -30 & 31 & 21632 & 1.22 & 18 & -16000 & 0.71 & 0.96 & 37632 & 2.24 & 1.03 & 6.4233 & 0.75 \\
\hline L1-C & 2.07 & -15 & 28 & 27776 & 1.10 & 15 & -18816 & 0.59 & 0.84 & 46592 & 2.12 & 0.98 & 7.9526 & 0.92 \\
\hline L1-D & 2.00 & 0 & 26 & 31104 & 1.02 & 12 & -19328 & 0.47 & 0.74 & 50432 & 2.00 & 1.00 & 8.6081 & 1.00 \\
\hline L1-E & 2.07 & 15 & 30 & 27216 & 1.18 & 15 & -17792 & 0.59 & 0.88 & 45008 & 2.12 & 0.98 & 7.6823 & 0.89 \\
\hline L1-F & 2.31 & 30 & 39 & 19000 & 1.53 & 25 & -14672 & 0.98 & 1.25 & 33672 & 2.51 & 0.92 & 5.7474 & 0.67 \\
\hline L1-G & 2.83 & 45 & 54 & 11904 & 2.12 & 39 & -9344 & 1.53 & 1.82 & 21248 & 3.06 & 0.93 & 3.6267 & 0.42 \\
\hline L2-A & 4.24 & -45 & 77 & 9344 & 3.02 & 64 & -6528 & 2.51 & 2.76 & 15872 & 4.04 & 1.05 & 2.7091 & 0.50 \\
\hline L2-B & 3.46 & -30 & 58 & 14208 & 2.27 & 43 & -11392 & 1.69 & 1.98 & 25600 & 3.22 & 1.08 & 4.3696 & 0.80 \\
\hline L2-C & 3.11 & -15 & 51 & 17536 & 2.00 & 38 & -12928 & 1.49 & 1.74 & 30464 & 3.02 & 1.03 & 5.1998 & 0.95 \\
\hline L2-D & 3.00 & 0 & 51 & 17536 & 2.00 & 37 & -14464 & 1.45 & 1.72 & 32000 & 2.98 & 1.01 & 5.4620 & 1.00 \\
\hline L2-E & 3.11 & 15 & 56 & 16488 & 2.20 & 42 & -12416 & 1.65 & 1.92 & 28904 & 3.18 & 0.98 & 4.9335 & 0.90 \\
\hline L2-F & 3.46 & 30 & 66 & 12160 & 2.59 & 52 & \begin{tabular}{|l|}
-9856 \\
\end{tabular} & 2.04 & 2.31 & 22016 & 3.57 & 0.97 & 3.7578 & 0.69 \\
\hline L2-G & 4.24 & 45 & 84 & 8448 & 3.29 & 69 & -6912 & 2.70 & 3.00 & 15360 & 4.23 & 1.00 & 2.6217 & 0.48 \\
\hline L3-A & 7.07 & -45 & 151 & 7040 & 5.92 & 137 & -5504 & 5.37 & 5.64 & 12544 & 6.90 & 1.02 & 2.1411 & 0.49 \\
\hline L3-B & 5.77 & -30 & 119 & 10880 & 4.66 & 105 & -8320 & 4.12 & 4.39 & 19200 & 5.65 & 1.02 & 3.2772 & 0.75 \\
\hline L3-C & 5.18 & -15 & 104 & 13952 & 4.08 & 92 & -9856 & 3.61 & 3.84 & 23808 & 5.14 & 1.01 & 4.0637 & 0.93 \\
\hline L3-D & 5.00 & 0 & 105 & \begin{tabular}{|l|l}
14976 \\
\end{tabular} & 4.12 & 92 & -10624 & 3.61 & 3.86 & 25600 & 5.14 & 0.97 & 4.3696 & 1.00 \\
\hline L3-E & 5.18 & 15 & 108 & 13720 & 4.23 & 95 & -10136 & 3.72 & 3.98 & 23856 & 5.25 & 0.99 & 4.0719 & 0.93 \\
\hline L3-F & 5.77 & 30 & 125 & 10112 & 4.90 & 113 & -9088 & 4.43 & 4.66 & 19200 & 5.96 & 0.97 & 3.2772 & 0.75 \\
\hline L3-G & 7.07 & 45 & 161 & \begin{tabular}{|l|}
6784 \\
\end{tabular} & 6.31 & 147 & -6016 & 5.76 & 6.04 & 12800 & 7.29 & 0.97 & 2.1848 & 0.50 \\
\hline L4-A & 14.14 & -45 & 340 & 3968 & 13.33 & 357 & -3712 & 13.99 & 13.66 & 7680 & 14.86 & 0.95 & 1.3109 & 0.56 \\
\hline L4-B & 11.55 & -30 & 278 & 5760 & 10.90 & 297 & -4992 & 11.64 & 11.27 & 10752 & 12.43 & 0.93 & 1.8352 & 0.78 \\
\hline L4-C & 10.35 & -15 & 243 & 7040 & 9.53 & 227 & -6016 & 8.90 & 9.21 & 13056 & 10.43 & 0.99 & 2.2285 & 0.94 \\
\hline L4-D & 10.00 & 0 & 238 & 7296 & 9.33 & 223 & -6528 & 8.74 & 9.04 & 13824 & 10.27 & 0.97 & 2.3596 & 1.00 \\
\hline L4-E & 10.35 & 15 & 248 & 6528 & 9.72 & 233 & -6016 & 9.13 & 9.43 & 12544 & 10.66 & 0.97 & 2.1411 & 0.91 \\
\hline L4-F & 11.55 & 30 & 284 & 6528 & 11.13 & 301 & -5248 & 11.80 & 11.47 & 11776 & 12.66 & 0.91 & 2.0100 & 0.85 \\
\hline L4-G & 14.14 & 45 & 348 & 4736 & 13.64 & 363 & -3712 & 14.23 & 13.94 & 8448 & 15.17 & 0.93 & 1.4420 & 0.61 \\
\hline
\end{tabular}


The equation developed for the $\mathrm{Z}$-axis is as follows.

$$
f\left(\phi_{z}\right)=a e^{\frac{-\phi_{z} 2}{2 c^{2}}}
$$

Where:

$$
\begin{aligned}
& a=1.000621 ; \\
& c=38.69559 .
\end{aligned}
$$

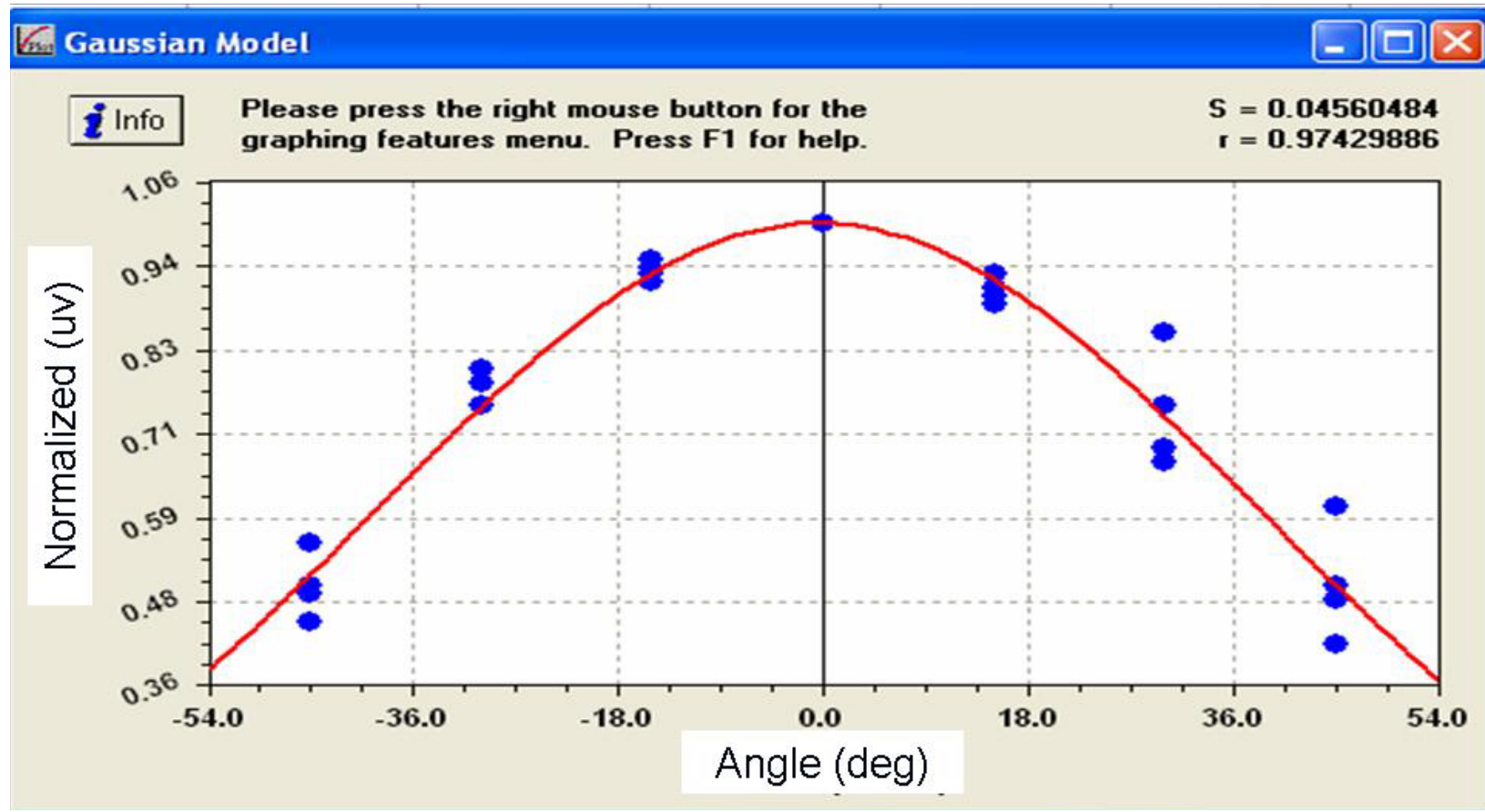

Figure 6.7 Curve fitting for $\mathrm{Z}$ equation development

\subsubsection{Measured Radiation Distribution in the Z Direction}

The measured radiation distributions for the $\mathrm{Z}$ direction are shown in Figure 6.8. It is noted that the signal strengths are slightly higher when the antennas are in the vertical positions. As mentioned before, numerical values in the contour mapping are volts that were derived from the absolute magnitude counts. 


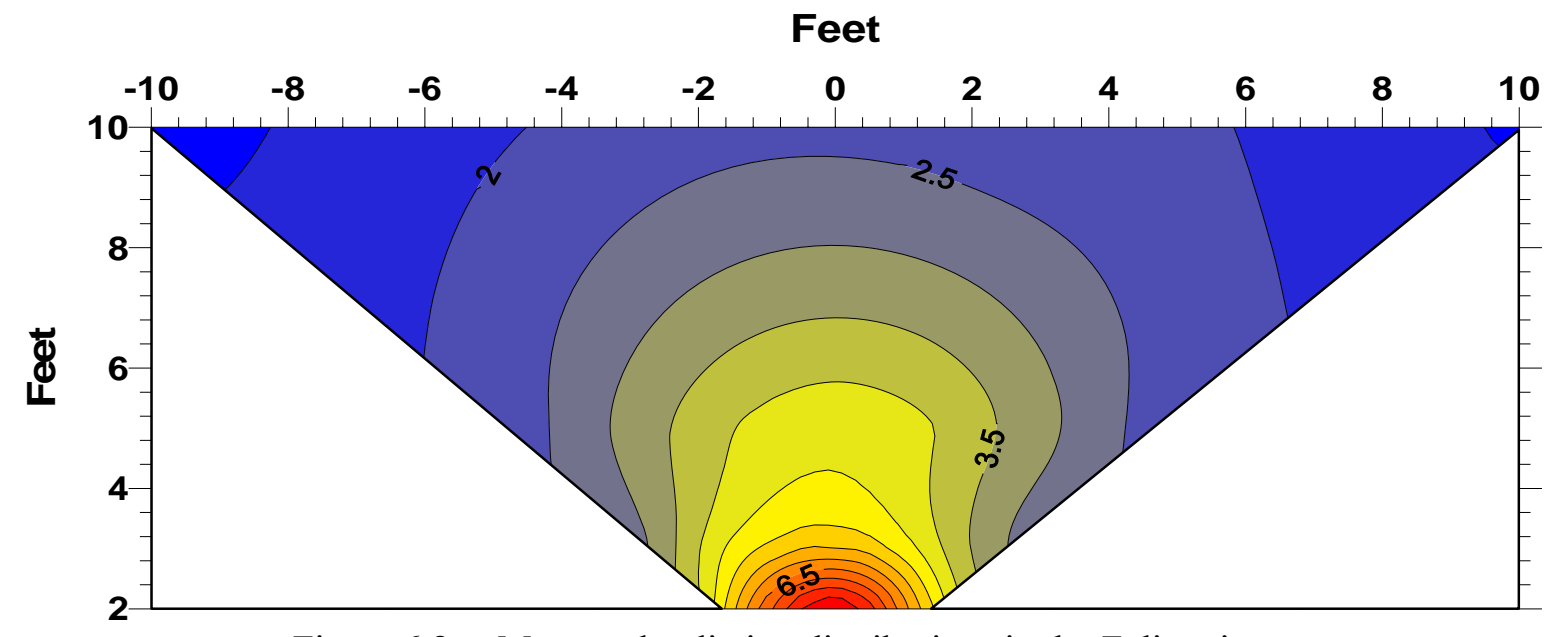

Figure 6.8 Measured radiation distributions in the $\mathrm{Z}$ direction

\subsection{Scaled Physical Model Data Analysis}

Reconnaissance EM surveys were performed on the scaled physical model at various times and under different conditions to understand how the roof, objects, coal seam and floor effect the received signal characteristics. Two examples of the EM reconnaissance surveys and data analysis are presented in this chapter. Additional data on the reconnaissance surveys are located in Appendix B. The first set of data presented is a series of surveys from a dry model. The second set of data presented is from the same model where the moisture content was approximately $7 \%$ by weight. The data are plotted in contour forms, and in individual line scans from the dry and wet model (a short summary is provided at the end of each paragraph), which are compared to the known geometry and geologic anomalies. The data presented are quantified as they are compared to the know geometry and physical properties of the model.

\subsubsection{Procedure to Determine the Voltage Attenuation Rate in the Scaled Physical Model}

The following procedure was used to determine the voltage attenuation rate of a single EM scan in the physical model. An example of this procedure is shown in Figure 6.9.

1. Determine the air volts V(a) by using Eqs. 6.3, 6.4, 6.5 and 6.6.

2. Determine the maximum and minimum counts of the EM model scan after the relaxation pulse as shown in Figure 5.2.

3. Determine the absolute count from the maximum and minimum count.

4. Determine the model voltage $(\mathrm{Vm})$ by taking the absolute count divided by the scaling count factor Eq. 5.6.

5. Determine the voltage attenuation $\left(\mathrm{V}_{\mathrm{i}}\right)$ caused by the media Eq. 6.1.

6. Determine the voltage attenuation rate Eq. 6.2. 
Step 1

Air volts at a distance

$$
\mathrm{Va}=8.759 \mathrm{uV}
$$

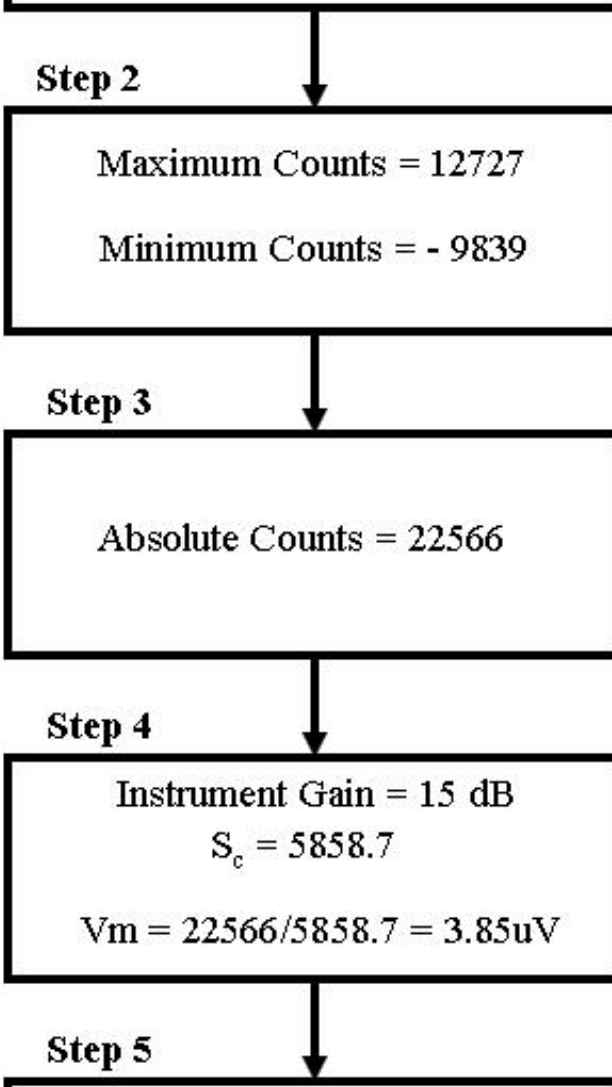

Voltage Attenuation $=\mathrm{Va}-\mathrm{Vm}=$ $8.759 \mathrm{uV}-3.85 \mathrm{uV}=4.91 \mathrm{uV}$

\begin{tabular}{|c|} 
Step 6 \\
Distance $=1.875 \mathrm{ft}$ \\
Attenuation Rate $=4.91 \mathrm{uV} / 1.875 \mathrm{ft}$ \\
Attenuation Rate $=2.62 \mathrm{uV} / \mathrm{ft}$
\end{tabular}

Figure 6.9 Example of determining signal attenuation rate in the scaled physical model 


\subsubsection{Reconnaissance Survey Scaled Physical Model}

In a reconnaissance survey, the Tx and Rx antenna are positioned with no offset angle in the $\mathrm{Y}$ or $\mathrm{Z}$ direction. The antennas are in line and in this testing separated by 22.5 inches, which is the width of the physical model as shown in Figure 4.8. The surveys were performed every 2 inches on 5 different lines as shown in Figure 4.10. The total number of data points generated is 155 (31 points per line) in the reconnaissance survey of the physical model.

\subsubsection{Distribution of EM Signal Attenuation of the Dry and Wet Physical Model}

After the reconnaissance data from the dry and wet model was analyzed, Surfer software was used to generate contour images of the EM attenuation distributions. Figure 6.10 and Figure 6.11 show examples of the contour plots of the attenuation rates. The unit for this attenuation rate is $\mathrm{uV} / \mathrm{ft}$. The unit of voltage was used since there is not a wide range of values in the data sets.

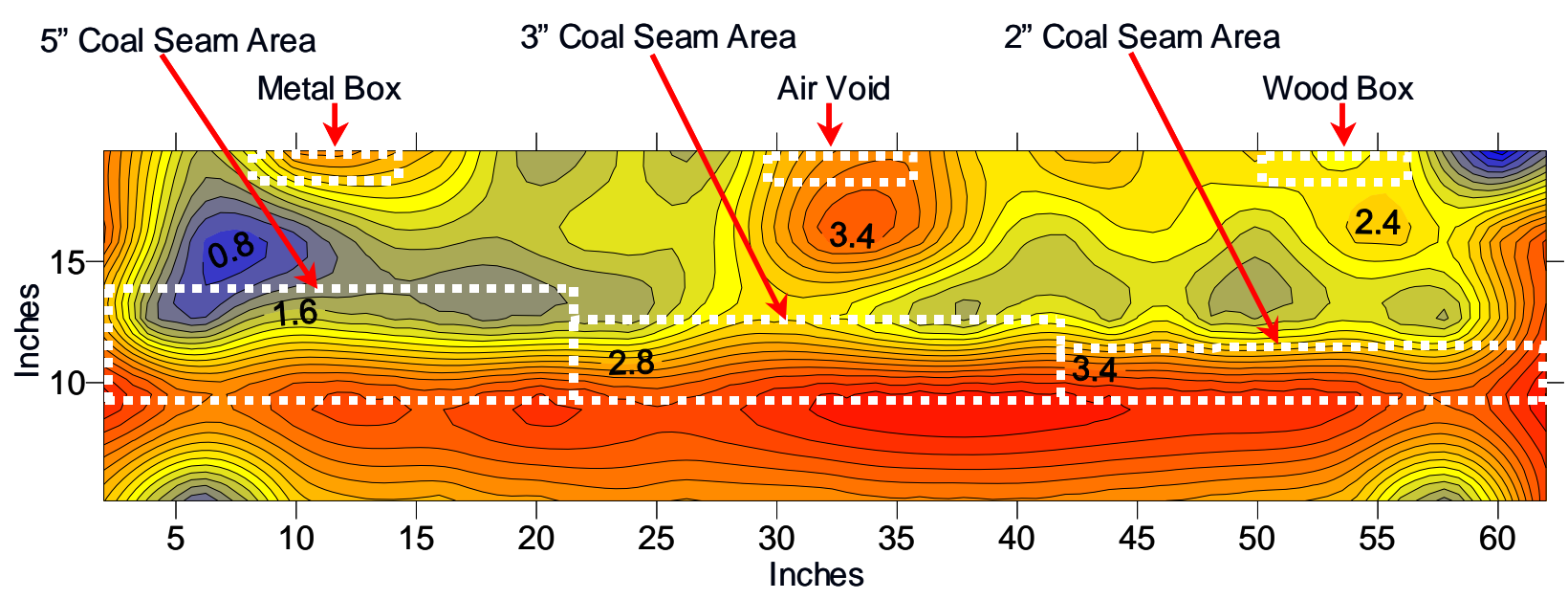

Figure 6.10 Total signal strength attenuation distribution in dry physical model 


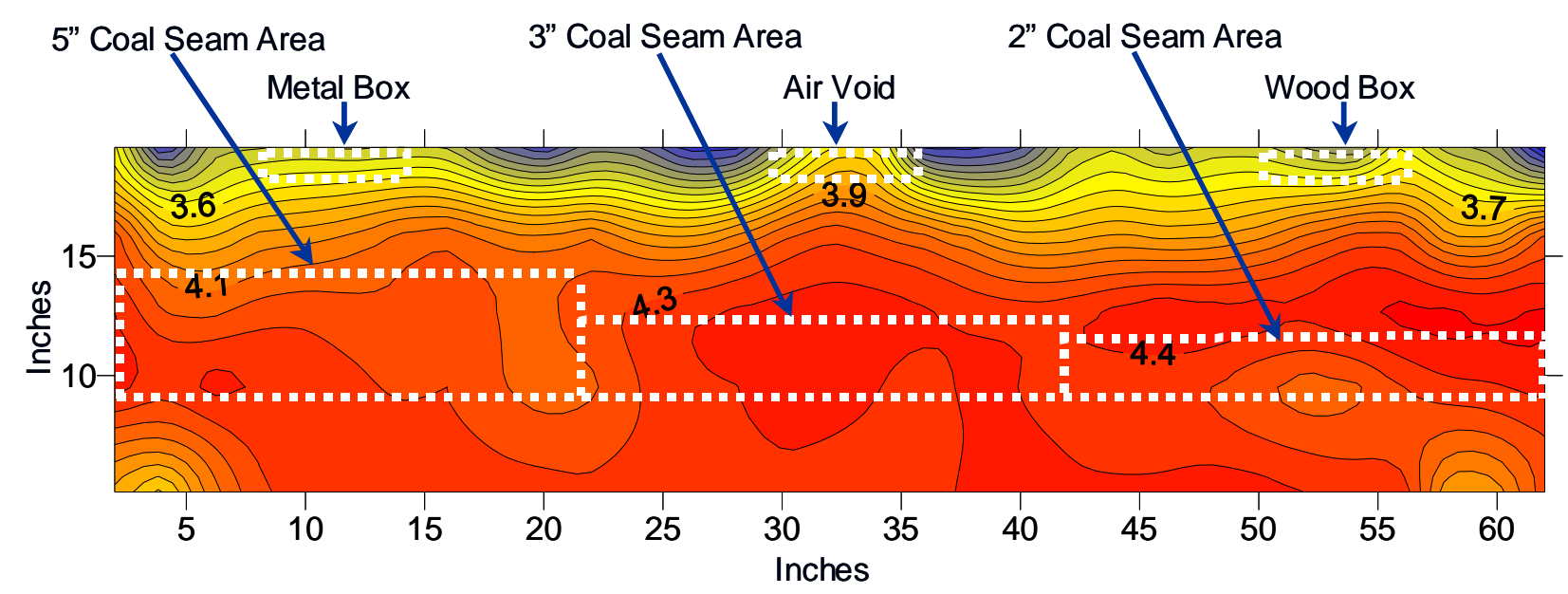

Figure 6.11 Total signal strength attenuation distribution in wet physical model

In Figures 6.10 and 6.11, in general the attenuation rate increases as the coal seam becomes thinner. The embedded objects in the model (metal box, air void (empty box), and wood box) as shown in Figure 4.8, are identified by the changes in the contour lines at the approximate locations in both the wet and dry models. In the wet model the overall attenuation rate increases compared to the dry model. In addition there are less contour lines in the wet model compared to that of the dry model. This reduction in contour lines is caused by the semi-homogeneous moisture distribution in the model. In the case of the wet model, there are fewer changes in the attenuation rate throughout the model. In general, in the wet physical model the attenuation rate is lower on the top (roof) and higher on the bottom (floor). This indicates drying of the model from the top to the bottom.

\subsubsection{Reconnaissance Survey of the Dry Physical Model}

To better understand the EM signal characteristics, line scans were compared to the known geologic anomalies in the model. As mentioned earlier, 31 data points were obtained on every line. The higher voltage signals represent lower attenuation rates while the lower voltage signals represent higher attenuation rates. The voltage attenuation rate as determined by equation 6.2 , ranged between $0.72 \mathrm{uV} / \mathrm{ft}$ to $4.22 \mathrm{uV} / \mathrm{ft}$ in the dry model.

It should be noted that in rare cases the manufacture of the instrumentation has observed model voltage signal higher than the air voltage signal while performing similar type of tests. These tests were performed on very dry fire bricks (composed of hard clay material and metal fines) used in high temperature kiln ovens. In these cases the attenuation would appear negative which is not possible. It 
was believed that the media material (hard clay and metal fines) focused the EM signal on the Rx antenna (GSSI, 2006).

As mentioned earlier the characteristics of interest are the EM signal attenuation rates caused from interfaces between the roof, seam, floor and objects (simulated geologic anomalies). The interfaces are those, which cause a significant reduction (attenuation) in the EM signal received at the Rx antenna. Attenuation rates for each line: L5 Objects, L4 Roof, L3 Coal Seam/Roof, L2 Coal Seam, L1 Floor and air voltage as determined by Eq. 6.3 are shown in the figures below. It is important to show the air voltage in these figures since the actual line attenuation is determined by subtracting the measured model voltage from the air voltage as determined by Eq. 6.1 As mention earlier, Eq. 6.2 determines the attenuation rate. In addition, each data table for these lines is presented. 
In Figure 6.12, the edge effect of the model is shown at approximately 6 inches at the beginning and end for both line 5 (L5 Objects) and line 4 (L4 Roof). The edge effect is caused by the physical geometry of the model and the wooden frame and metal lag bolts used to support the model as shown in Figure 4.11. Near the edge of the model the EM signal may find a multipath. As shown by L5, the first object (metal box) caused a voltage attenuation increase starting at approximately 7 inches and continuing until 14 inches. The second object (empty box) caused a voltage attenuation increase starting at approximately 28 inches and continuing until approximately 36 inches. It was expected to see a voltage attenuation decrease at the location of the empty box; however, the voltage attenuation increase may have been caused by moisture trapped inside the empty box. The third object (wood box) voltage attenuation rate changes are not as pronounced as the metal box and the empty box. A small voltage attenuation rate increase is observed at approximately 54 to approximately 57 inches then a larger voltage attenuation rate decrease is observed at approximately 57 inches.

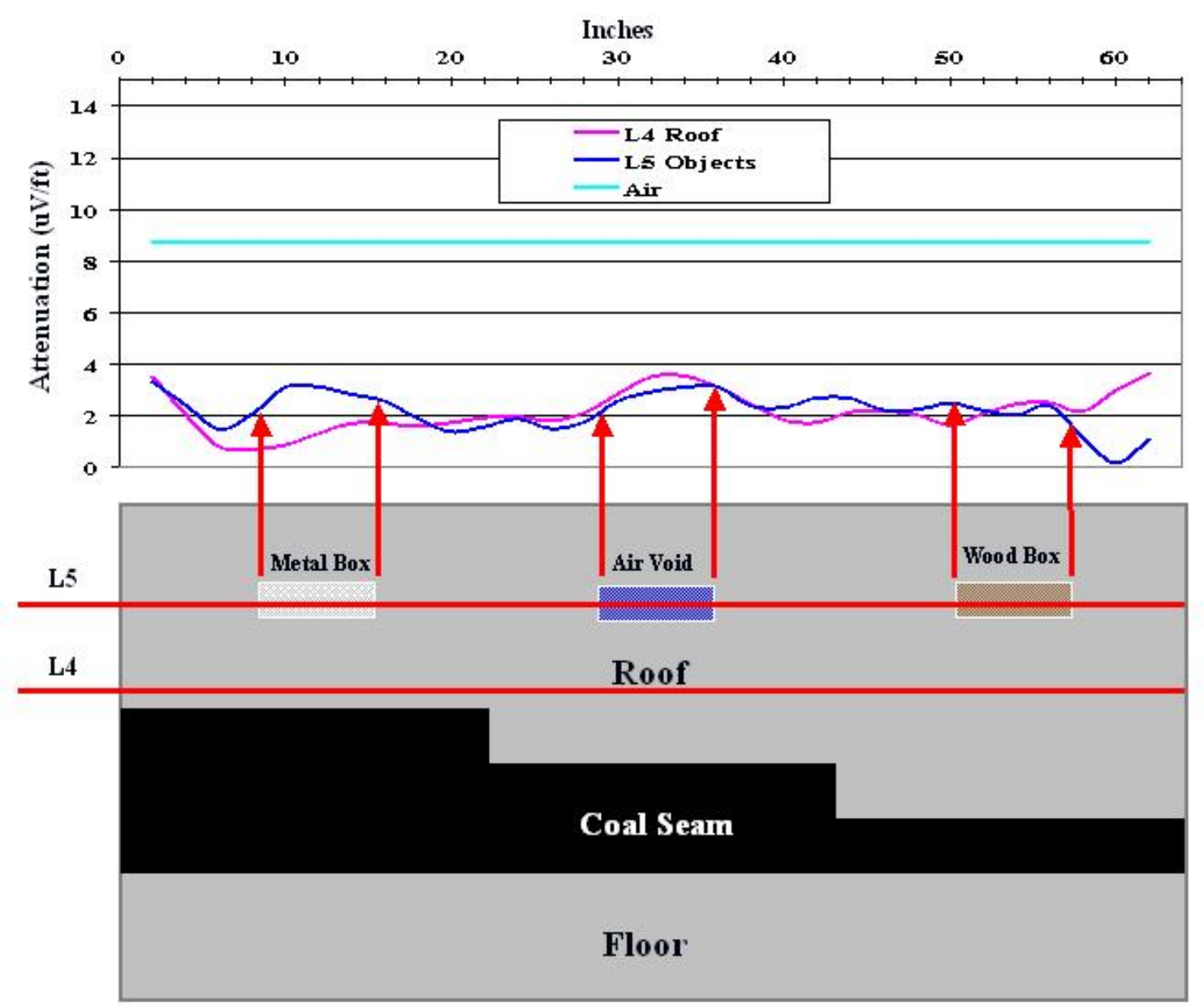

Figure 6.12 Dry model objects and roof lines 
Table 6.4 Reconnaissance survey dry physical model line 5 objects

\begin{tabular}{|c|c|c|c|c|c|c|c|c|c|c|c|c|c|}
\hline \multicolumn{14}{|c|}{$\begin{array}{l}\text { April 22, } 2007 \text { Dry Model, Line } 5 \text { Objects, File \# } 1017 \text { - 1019, X= } 22.5 \text { (in), Y= } 19.625 \text { (in), Range } 15 \text { (ns), } \\
\text { Gain } 15 \text { (dB), Sc=5858.7, Va = 8.759 (uV), Vm = model Volts }\end{array}$} \\
\hline$Z$ (in) & Max & Max & Max & Min & Min & Min & Abs & First & Velocity & $\mathrm{Vm}$ & $\mathrm{Va}-\mathrm{Vm}$ & & \\
\hline & \begin{tabular}{|l|} 
Count \\
\end{tabular} & Sample & Time (ns) & \begin{tabular}{|l|} 
Count \\
\end{tabular} & Sample & Time (ns) & & Arrival (ns) & $\mathrm{ft} / \mathrm{ns}$ & $\mathrm{uV}$ & $\mathrm{uV}$ & $\mathrm{uV} / \mathrm{ft}$ & $\mathrm{db} / \mathrm{ft}$ \\
\hline 2 & 6619 & 197 & 5.79 & -8213 & 215 & 6.32 & 14832 & \begin{tabular}{|l|}
3.29 \\
\end{tabular} & 1.76 & 2.53 & 6.23 & 3.32 & $\bar{~} 5.75$ \\
\hline 4 & 16819 & 201 & 5.91 & -8018 & 184 & 5.41 & 24837 & 3.41 & 1.82 & 4.24 & 4.52 & 2.41 & 3.36 \\
\hline 6 & 21310 & 206 & 6.06 & -13602 & 189 & 5.56 & 34912 & 3.56 & 1.90 & 5.96 & 2.80 & 1.49 & 1.78 \\
\hline 8 & 17074 & 212 & 6.23 & -11454 & 193 & 5.68 & 28528 & 3.73 & 1.99 & 4.87 & 3.89 & 2.07 & 2.72 \\
\hline 10 & 9670 & 212 & 6.23 & \begin{tabular}{|l|}
-7314 \\
\end{tabular} & 193 & 5.68 & 16984 & 3.73 & 1.99 & 2.90 & 5.86 & 3.13 & 5.12 \\
\hline 12 & 9663 & 210 & 6.18 & -7301 & 191 & 5.62 & 16964 & 3.68 & 1.96 & 2.90 & 5.86 & 3.13 & 5.13 \\
\hline 14 & 11269 & 209 & 6.15 & -8796 & 190 & 5.59 & 20065 & 3.65 & 1.94 & 3.42 & 5.33 & 2.84 & 4.35 \\
\hline 16 & 12820 & 209 & 6.15 & -10299 & 190 & 5.59 & 23119 & 3.65 & 1.94 & 3.95 & 4.81 & 2.57 & 3.69 \\
\hline 18 & 17794 & 209 & 6.15 & \begin{tabular}{|l|}
-12772 \\
\end{tabular} & 190 & 5.59 & 30566 & 3.65 & 1.94 & 5.22 & 3.54 & 1.89 & 2.40 \\
\hline 20 & 20690 & 209 & 6.15 & -15365 & 191 & 5.62 & 36055 & 3.65 & 1.94 & 6.15 & 2.60 & 1.39 & 1.64 \\
\hline 22 & 18489 & 210 & 6.18 & -15365 & 190 & 5.59 & 33854 & 3.68 & 1.96 & 5.78 & 2.98 & 1.59 & 1.93 \\
\hline 24 & 17478 & 210 & 6.18 & -13162 & 190 & 5.59 & 30640 & 3.68 & 1.96 & 5.23 & 3.53 & 1.88 & 2.39 \\
\hline 26 & 20346 & 209 & 6.15 & -14332 & 191 & 5.62 & 34678 & 3.65 & 1.94 & 5.92 & 2.84 & 1.51 & 1.82 \\
\hline 28 & 18526 & 206 & 6.06 & \begin{tabular}{|l|}
-13289 \\
\end{tabular} & 189 & 5.56 & 31815 & 3.56 & 1.90 & 5.43 & 3.33 & 1.78 & 2.21 \\
\hline 30 & 13740 & 204 & 6.00 & -9346 & 186 & 5.47 & 23086 & 3.50 & 1.87 & 3.94 & 4.82 & 2.57 & 3.70 \\
\hline 32 & 11112 & 201 & 5.91 & -7976 & 182 & 5.35 & 19088 & 3.41 & 1.82 & 3.26 & 5.50 & 2.93 & 4.58 \\
\hline 34 & 9993 & 202 & 5.94 & -7117 & 182 & 5.35 & 17110 & 3.44 & 1.84 & 2.92 & 5.84 & 3.11 & 5.09 \\
\hline 36 & 9948 & 206 & 6.06 & -6991 & 187 & 5.50 & 16939 & 3.56 & 1.90 & 2.89 & 5.87 & 3.13 & 5.13 \\
\hline 38 & 15379 & 210 & 6.18 & -9572 & 193 & 5.68 & 24951 & 3.68 & 1.96 & 4.26 & 4.50 & 2.40 & 3.34 \\
\hline 40 & 15438 & 212 & 6.23 & -10287 & 194 & 5.71 & 25725 & 3.73 & 1.99 & 4.39 & 4.37 & 2.33 & 3.20 \\
\hline 42 & 12244 & 213 & 6.26 & -9475 & 192 & 5.65 & 21719 & 3.76 & 2.01 & 3.71 & 5.05 & 2.69 & 3.98 \\
\hline 44 & 11813 & 210 & 6.18 & -10075 & 191 & 5.62 & 21888 & 3.68 & 1.96 & 3.74 & 5.02 & 2.68 & 3.95 \\
\hline 46 & 14992 & 209 & 6.15 & -11768 & 191 & 5.62 & 26760 & 3.65 & 1.94 & 4.57 & 4.19 & 2.24 & 3.02 \\
\hline 48 & 14942 & 210 & 6.18 & \begin{tabular}{|l|}
-11773 \\
\end{tabular} & 191 & 5.62 & 26715 & 3.68 & 1.96 & 4.56 & 4.20 & 2.24 & 3.02 \\
\hline 50 & 13884 & 212 & 6.23 & -10022 & 193 & 5.68 & 23906 & 3.73 & 1.99 & 4.08 & 4.68 & 2.50 & 3.54 \\
\hline 52 & 15540 & 212 & 6.23 & -11368 & 193 & 5.68 & 26908 & 3.73 & 1.99 & 4.59 & 4.17 & 2.22 & 2.99 \\
\hline 54 & 16872 & 210 & 6.18 & -12098 & 191 & 5.62 & 28970 & 3.68 & 1.96 & 4.94 & 3.81 & 2.03 & 2.65 \\
\hline 56 & 13705 & 210 & 6.18 & -11265 & 190 & 5.59 & 24970 & 3.68 & 1.96 & 4.26 & 4.50 & 2.40 & 3.34 \\
\hline 58 & 23501 & 209 & 6.15 & -14715 & 190 & 5.59 & 38216 & 3.65 & 1.94 & 6.52 & 2.24 & 1.19 & 1.37 \\
\hline 60 & 32767 & 202 & 5.94 & -16632 & 190 & 5.59 & 49399 & 3.44 & 1.84 & 8.43 & 0.33 & 0.17 & 0.18 \\
\hline 62 & 26342 & 202 & 5.94 & -13155 & 185 & 5.44 & 39497 & 3.44 & 1.84 & 6.74 & 2.02 & 1.08 & 1.21 \\
\hline
\end{tabular}


In Figure 6.13, the edge effect of the model is shown at approximately 6 inches at the beginning and at the end for both lines 4 (L4 Roof) and line 3 (L3 Coal Seam/Roof). As shown by L4, the area below the first object (metal box) causes a voltage attenuation decrease at approximately 5 inches and continues until approximately 13 inches. This attenuation may be caused from the EM signal finding a multipath. The area below the second object (empty box) causes a voltage attenuation increase starting at approximately 28 inches and continuing until 40 inches on L4. The area below the third object (wood box) causes a voltage increase starting at approximately 50 inches and continuing until 57 inches. It appears that the wood box target is more aligned with L4 then L5 since this voltage attenuation increase is appearing on L4 and the voltage attenuation increase was not obvious on L5.

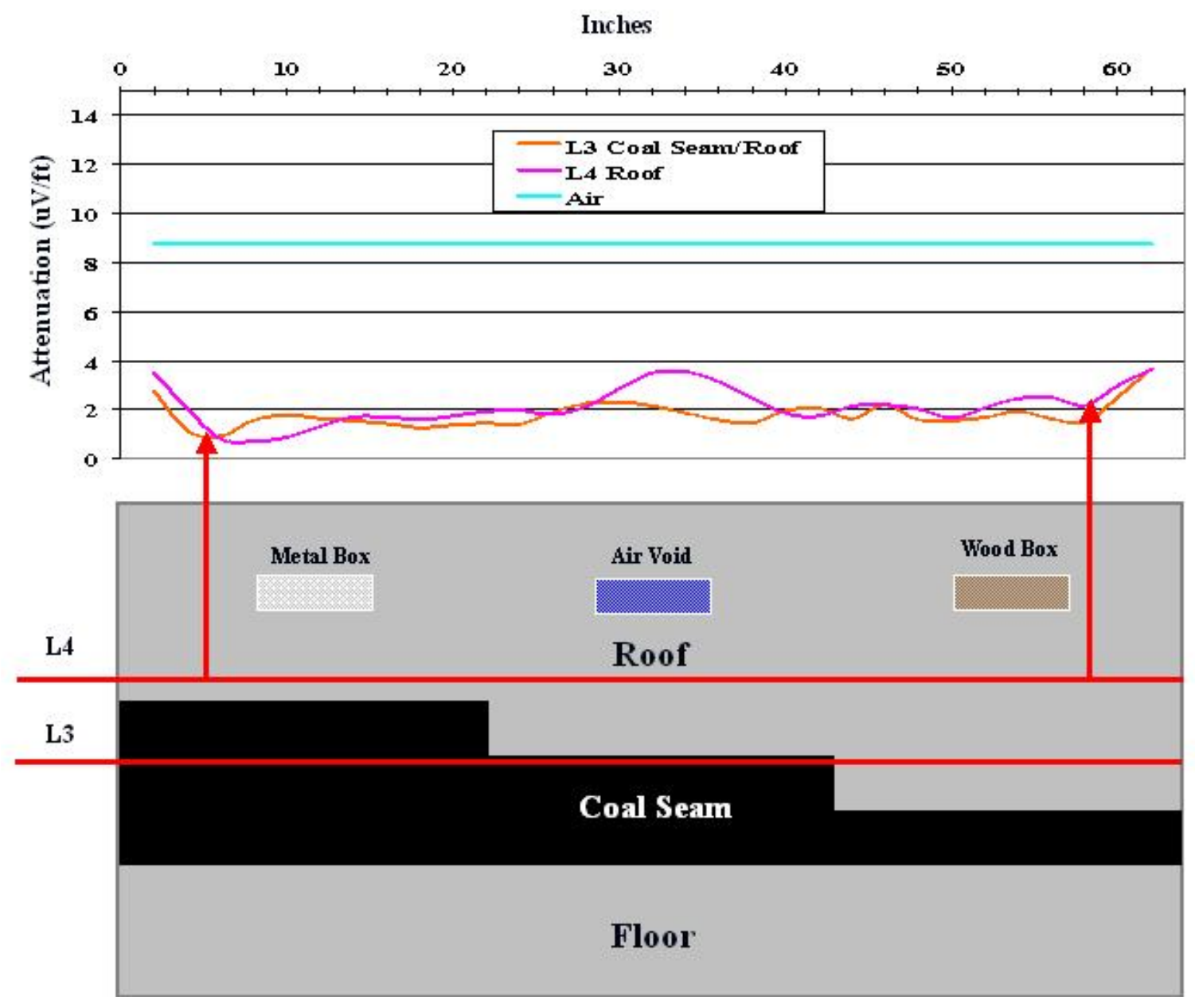

Figure 6.13 Dry model roof and coal seam/roof lines 
Table 6.5 Reconnaissance survey dry physical model line 4 roof

\begin{tabular}{|c|c|c|c|c|c|c|c|c|c|c|c|c|c|}
\hline \multicolumn{14}{|c|}{$\begin{array}{l}\text { April 22, } 2007 \text { Dry Model, Line } 4 \text { in Roof, \# } 10141016 \mathrm{X}=22.5 \text { (in), Y= } 16.125 \text { (in), Range } 15 \text { (ns) } \\
\text { Gain } 15(\mathrm{~dB}), \mathrm{Sc}=5858.7, \mathrm{Va}=8.759(\mathrm{uV}), \mathrm{Vm}=\text { model Volts }\end{array}$} \\
\hline Z (in) & $\operatorname{Max}$ & $\operatorname{Max}$ & $\operatorname{Max}$ & Min & Min & Min & Abs & First & Velocity & $\mathrm{Vm}$ & Va -Vm & \multicolumn{2}{|c|}{ Attentuation } \\
\hline & Count & Sample & Time (ns) & Count & Sample & Time (ns) & & Arrival (ns) & $\mathrm{ft} / \mathrm{ns}$ & $\mathrm{uV}$ & $\mathrm{uV}$ & $\mathrm{uV} / \mathrm{ft}$ & $\mathrm{db} / \mathrm{ft}$ \\
\hline 2 & 8040 & 206 & 6.06 & -4666 & \begin{tabular}{|l|}
186 \\
\end{tabular} & 5.47 & 12706 & 3.56 & 1.90 & 2.17 & 6.59 & 3.51 & 6.47 \\
\hline 4 & 18081 & 213 & 6.26 & -10793 & 194 & 5.71 & 28874 & 3.76 & 2.01 & 4.93 & 3.83 & 2.04 & 2.66 \\
\hline 6 & 31546 & 219 & 6.44 & -10793 & 198 & 5.82 & 42339 & 3.94 & 2.10 & 7.23 & 1.53 & 0.82 & 0.89 \\
\hline 8 & 32668 & 225 & 6.62 & -10793 & 204 & 6.00 & 43461 & 4.12 & 2.20 & 7.42 & 1.34 & 0.72 & 0.77 \\
\hline 10 & 22895 & 226 & 6.65 & -18672 & 204 & 6.00 & 41567 & 4.15 & 2.21 & 7.09 & 1.66 & 0.89 & 0.98 \\
\hline 12 & 19954 & 226 & 6.65 & -16722 & 205 & 6.03 & 36676 & 4.15 & 2.21 & 6.26 & 2.50 & 1.33 & 1.56 \\
\hline 14 & 17590 & 226 & 6.65 & -14929 & 204 & 6.00 & 32519 & 4.15 & 2.21 & 5.55 & 3.21 & 1.71 & 2.11 \\
\hline 16 & 17688 & 226 & 6.65 & -14848 & 204 & 6.00 & 32536 & 4.15 & 2.21 & 5.55 & 3.21 & 1.71 & 2.11 \\
\hline 18 & 18423 & 226 & 6.65 & -15222 & 204 & 6.00 & 33645 & 4.15 & 2.21 & 5.74 & 3.02 & 1.61 & 1.96 \\
\hline 20 & 17767 & 226 & 6.65 & -14327 & 204 & 6.00 & 32094 & 4.15 & 2.21 & 5.48 & 3.28 & 1.75 & 2.17 \\
\hline 22 & 16782 & 226 & 6.65 & -13239 & 204 & 6.00 & 30021 & 4.15 & 2.21 & 5.12 & 3.63 & 1.94 & 2.48 \\
\hline 24 & 16149 & 225 & 6.62 & -13438 & 204 & 6.00 & 29587 & 4.12 & 2.20 & 5.05 & 3.71 & 1.98 & 2.55 \\
\hline 26 & 16581 & 224 & 6.59 & -14758 & 204 & 6.00 & 31339 & 4.09 & 2.18 & 5.35 & 3.41 & 1.82 & 2.28 \\
\hline 28 & 15134 & 223 & 6.56 & -12793 & 202 & 5.94 & 27927 & 4.06 & 2.16 & 4.77 & 3.99 & 2.13 & 2.82 \\
\hline 30 & 11249 & 223 & 6.56 & -8719 & 202 & 5.94 & 19968 & 4.06 & 2.16 & 3.41 & 5.35 & 2.85 & 4.37 \\
\hline 32 & \begin{tabular}{c|}
7105 \\
\end{tabular} & 223 & 6.56 & -5629 & 201 & 5.91 & 12734 & 4.06 & 2.16 & 2.17 & 6.59 & 3.51 & 6.46 \\
\hline 34 & 6997 & 226 & 6.65 & -5314 & 203 & 5.97 & 12311 & 4.15 & 2.21 & 2.10 & 6.66 & 3.55 & 6.61 \\
\hline 36 & 9102 & 227 & 6.68 & -7696 & 204 & 6.00 & 16798 & 4.18 & 2.23 & 2.87 & 5.89 & 3.14 & 5.17 \\
\hline 38 & 12594 & 227 & 6.68 & -11483 & 206 & 6.06 & 24077 & 4.18 & 2.23 & 4.11 & 4.65 & 2.48 & 3.51 \\
\hline 40 & 16381 & 228 & 6.71 & -14492 & 208 & 6.12 & 30873 & 4.21 & 2.24 & 5.27 & 3.49 & 1.86 & 2.35 \\
\hline 42 & 16600 & 230 & 6.76 & -15559 & 210 & 6.18 & 32159 & 4.26 & 2.27 & 5.49 & 3.27 & 1.74 & 2.16 \\
\hline 44 & 14072 & 230 & 6.76 & -13645 & 210 & 6.18 & 27717 & 4.26 & 2.27 & 4.73 & 4.03 & 2.15 & 2.85 \\
\hline 46 & 13955 & 229 & 6.73 & -13150 & 210 & 6.18 & 27105 & 4.23 & 2.26 & 4.63 & 4.13 & 2.20 & 2.96 \\
\hline 48 & 14758 & 230 & 6.76 & -14101 & 210 & 6.18 & 28859 & 4.26 & 2.27 & 4.93 & 3.83 & 2.04 & 2.67 \\
\hline 50 & 17197 & 231 & 6.79 & -15884 & 211 & 6.21 & 33081 & 4.29 & 2.29 & 5.65 & 3.11 & 1.66 & 2.03 \\
\hline 52 & 15034 & 230 & 6.76 & -13362 & 210 & 6.18 & 28396 & 4.26 & 2.27 & 4.85 & 3.91 & 2.09 & 2.74 \\
\hline 54 & 12764 & 227 & 6.68 & -11484 & 205 & 6.03 & 24248 & 4.18 & 2.23 & 4.14 & 4.62 & 2.46 & 3.47 \\
\hline 56 & 12230 & 225 & 6.62 & -11501 & 202 & 5.94 & 23731 & 4.12 & 2.20 & 4.05 & 4.71 & 2.51 & 3.57 \\
\hline 58 & 15340 & 218 & 6.41 & -12020 & 196 & 5.76 & 27360 & 3.91 & 2.09 & 4.67 & 4.09 & 2.18 & 2.91 \\
\hline 60 & 10946 & 212 & 6.23 & -7535 & 191 & 5.62 & 18481 & 3.73 & 1.99 & 3.15 & 5.60 & 2.99 & 4.73 \\
\hline 62 & 5819 & 211 & 6.21 & -5389 & 235 & 6.91 & 11208 & 3.71 & 1.98 & 1.91 & 6.85 & 3.65 & 7.05 \\
\hline
\end{tabular}

In Figure 6.14, the edge effect of the model is shown at approximately 6 inches at the beginning and end for line 3 (L3 Coal Seam/Roof) and line 2 (L2 Coal Seam). As shown by L3, the voltage attenuation rate remains fairly constant until about 24 inches. The voltage attenuation rate then increases slightly between 24 inches -35 inches and again between 38 inches -47 inches. This increase may be caused by slightly higher moisture content in this area. 


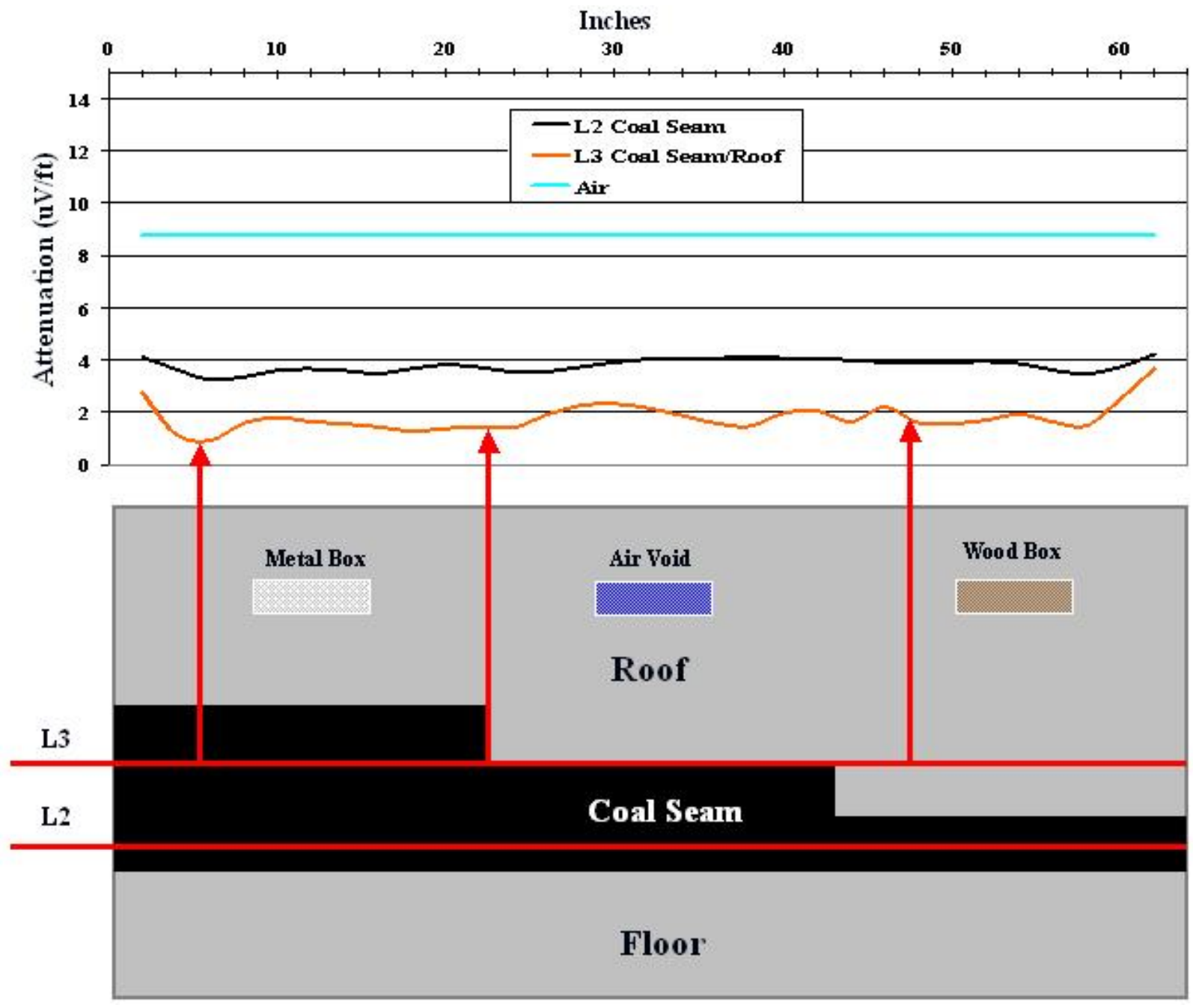

Figure 6.14 Dry model coal seam/roof and coal seam lines 
Table 6.6 Reconnaissance survey dry physical model line 3 coal seam/roof

\begin{tabular}{|c|c|c|c|c|c|c|c|c|c|c|c|c|c|}
\hline \multicolumn{14}{|c|}{$\begin{array}{l}\text { April 22, } 2007 \text { Dry Model, Line } 3 \text { in Coal Seam Roof \# 1011-1013, X = } 22.5 \text { (in), Y= } 12.625 \text { (in), Range } 15 \text { (ns), } \\
\text { Gain } 15 \text { (dB), Sc=5858.7, Va = 8.759 (uV), Vm = model Volts }\end{array}$} \\
\hline \multirow[t]{2}{*}{$Z$ (in) } & \multirow{2}{*}{\begin{tabular}{|c|} 
Max \\
Count \\
\end{tabular}} & \multirow{2}{*}{\begin{tabular}{|c|} 
Max \\
Sample \\
\end{tabular}} & \multirow{2}{*}{\begin{tabular}{|c|} 
Max \\
Time $(n s)$ \\
\end{tabular}} & \multirow{2}{*}{\begin{tabular}{|c|} 
Min \\
Count \\
\end{tabular}} & \multirow{2}{*}{\begin{tabular}{|c|} 
Min \\
Sample \\
\end{tabular}} & \multirow{2}{*}{ Min } & \multirow[t]{2}{*}{ Abs } & \multirow{2}{*}{\begin{tabular}{c|} 
First \\
Arrival (ns)
\end{tabular}} & \multirow{2}{*}{\begin{tabular}{c|} 
Velocity \\
$\mathrm{ft} / \mathrm{ns}$
\end{tabular}} & \multirow{2}{*}{\begin{tabular}{l|}
$\mathrm{Vm}$ \\
$\mathrm{uV}$
\end{tabular}} & \multirow{2}{*}{$\frac{\mathrm{Va}-\mathrm{Vm}}{\mathrm{uV}}$} & \multicolumn{2}{|c|}{ Attentuation } \\
\hline & & & & & & & & & & & & $\mathrm{uV} / \mathrm{ft}$ & $\mathrm{db} / \mathrm{ft}$ \\
\hline 2 & 12963 & \begin{tabular}{|r|}
207 \\
\end{tabular} & 6.09 & \begin{tabular}{|r|}
-8174 \\
\end{tabular} & 189 & 5.56 & 21137 & $\begin{array}{r}3.59 \\
\end{array}$ & 1.91 & 3.61 & 5.15 & 2.75 & 4.11 \\
\hline 4 & 22421 & 213 & 6.26 & -16168 & 194 & 5.71 & 38589 & 3.76 & 2.01 & 6.59 & 2.17 & 1.16 & 1.32 \\
\hline 6 & 23799 & 219 & 6.44 & -17304 & 199 & 5.85 & 41103 & 3.94 & 2.10 & 7.02 & 1.74 & 0.93 & 1.03 \\
\hline 8 & 18246 & 225 & 6.62 & -15732 & 204 & 6.00 & 33978 & 4.12 & 2.20 & 5.80 & 2.96 & 1.58 & 1.91 \\
\hline 10 & 16937 & 225 & 6.62 & -14606 & 205 & 6.03 & 31543 & 4.12 & 2.20 & 5.38 & 3.38 & 1.80 & 2.25 \\
\hline 12 & 18512 & 227 & 6.68 & -14743 & 207 & 6.09 & 33255 & 4.18 & 2.23 & 5.68 & 3.08 & 1.64 & 2.01 \\
\hline 14 & 18901 & 228 & 6.71 & -15300 & 210 & 6.18 & 34201 & 4.21 & 2.24 & 5.84 & 2.92 & 1.56 & 1.88 \\
\hline 16 & 19345 & 230 & 6.76 & -16130 & 211 & 6.21 & 35475 & 4.26 & 2.27 & 6.06 & 2.70 & 1.44 & 1.71 \\
\hline 18 & 20162 & 231 & 6.79 & -17063 & 211 & 6.21 & 37225 & 4.29 & 2.29 & 6.35 & 2.41 & 1.28 & 1.49 \\
\hline 20 & 19466 & 231 & 6.79 & -16696 & 211 & 6.21 & 36162 & 4.29 & 2.29 & 6.17 & 2.59 & 1.38 & 1.62 \\
\hline 22 & 18886 & 232 & 6.82 & -16413 & 212 & 6.23 & 35299 & 4.32 & 2.31 & 6.03 & 2.73 & 1.46 & 1.73 \\
\hline 24 & 19723 & 233 & 6.85 & -16022 & 212 & 6.23 & 35745 & 4.35 & 2.32 & 6.10 & 2.66 & 1.42 & 1.68 \\
\hline 26 & 16993 & 235 & 6.91 & -13314 & 213 & 6.26 & 30307 & 4.41 & 2.35 & 5.17 & 3.59 & 1.91 & 2.44 \\
\hline 28 & 14407 & 234 & 6.88 & -12082 & 213 & 6.26 & 26489 & 4.38 & 2.34 & 4.52 & 4.24 & 2.26 & 3.06 \\
\hline 30 & 14136 & 234 & 6.88 & -11667 & 213 & 6.26 & 25803 & 4.38 & 2.34 & 4.40 & 4.35 & 2.32 & 3.18 \\
\hline 32 & 15529 & 235 & 6.91 & -12086 & 214 & 6.29 & 27615 & 4.41 & 2.35 & 4.71 & 4.05 & 2.16 & 2.87 \\
\hline 34 & 17257 & 236 & 6.94 & -13411 & 216 & 6.35 & 30668 & 4.44 & 2.37 & 5.23 & 3.52 & 1.88 & 2.38 \\
\hline 36 & 19496 & 236 & 6.94 & -14362 & 216 & 6.35 & 33858 & 4.44 & 2.37 & 5.78 & 2.98 & 1.59 & 1.93 \\
\hline 38 & 19934 & 237 & 6.97 & -15222 & 218 & 6.41 & 35156 & 4.47 & 2.38 & 6.00 & 2.76 & 1.47 & 1.75 \\
\hline 40 & 16366 & 236 & 6.94 & -13402 & 216 & 6.35 & 29768 & 4.44 & 2.37 & 5.08 & 3.68 & 1.96 & 2.52 \\
\hline 42 & 15956 & 238 & 7.00 & -12790 & 218 & 6.41 & 28746 & 4.50 & 2.40 & 4.91 & 3.85 & 2.05 & 2.68 \\
\hline 44 & 18938 & 240 & 7.06 & -14264 & 219 & 6.44 & 33202 & 4.56 & 2.43 & 5.67 & 3.09 & 1.65 & 2.02 \\
\hline 46 & 15480 & 223 & 6.56 & -11722 & 243 & 7.15 & 27202 & 4.06 & 2.16 & 4.64 & 4.12 & 2.20 & 2.94 \\
\hline 48 & 19714 & 241 & 7.09 & -13999 & 219 & 6.44 & 33713 & 4.59 & 2.45 & 5.75 & 3.00 & 1.60 & 1.95 \\
\hline 50 & 19289 & 240 & 7.06 & -14755 & 219 & 6.44 & 34044 & 4.56 & 2.43 & 5.81 & 2.95 & 1.57 & 1.90 \\
\hline 52 & 18602 & 239 & 7.03 & \begin{tabular}{|l|}
-14073 \\
\end{tabular} & 219 & 6.44 & 32675 & 4.53 & 2.42 & 5.58 & 3.18 & 1.70 & 2.09 \\
\hline 54 & 16959 & 237 & 6.97 & -13160 & 217 & 6.38 & 30119 & 4.47 & 2.38 & 5.14 & 3.62 & 1.93 & 2.47 \\
\hline 56 & 19115 & 234 & 6.88 & -14201 & 213 & 6.26 & 33316 & 4.38 & 2.34 & 5.69 & 3.07 & 1.64 & 2.00 \\
\hline 58 & 21638 & 228 & 6.71 & -13241 & 209 & 6.15 & 34879 & 4.21 & 2.24 & 5.95 & 2.81 & 1.50 & 1.79 \\
\hline 60 & 15480 & 223 & 6.56 & \begin{tabular}{|l|}
-8100 \\
\end{tabular} & 204 & 6.00 & 23580 & 4.06 & 2.16 & 4.02 & 4.73 & 2.52 & 3.60 \\
\hline 62 & \begin{tabular}{|l|}
7808 \\
\end{tabular} & 218 & 6.41 & -3156 & 199 & 5.85 & 10964 & 3.91 & 2.09 & 1.87 & 6.89 & 3.67 & 7.15 \\
\hline
\end{tabular}


In Figure 6.15, the edge effect of the model is shown at approximately 6 inches at the beginning and end for line 2 (L2 Coal Seam) and line 1 (L1 floor). As shown by L2, the voltage attenuation rate is lower form approximately 2 inches up to approximately 24 inches. This is the area where the coal seam height is 5 inches and it was expected to see a lower voltage attenuation rate. At approximately 24 inches, the coal seam height decreases to 3 inches and the voltage attenuation rate increases slightly and remains constant until the end of the model with the exception of the edge effect. At approximately 44 inches the coal seam height decreases to 2 inches and there is not a noticeable change in the voltage attenuation rate. This change may not have been detected due to instrumentation limitations. As shown by L1, the voltage attenuation rate is fairly constant with the exception of the edge effects.

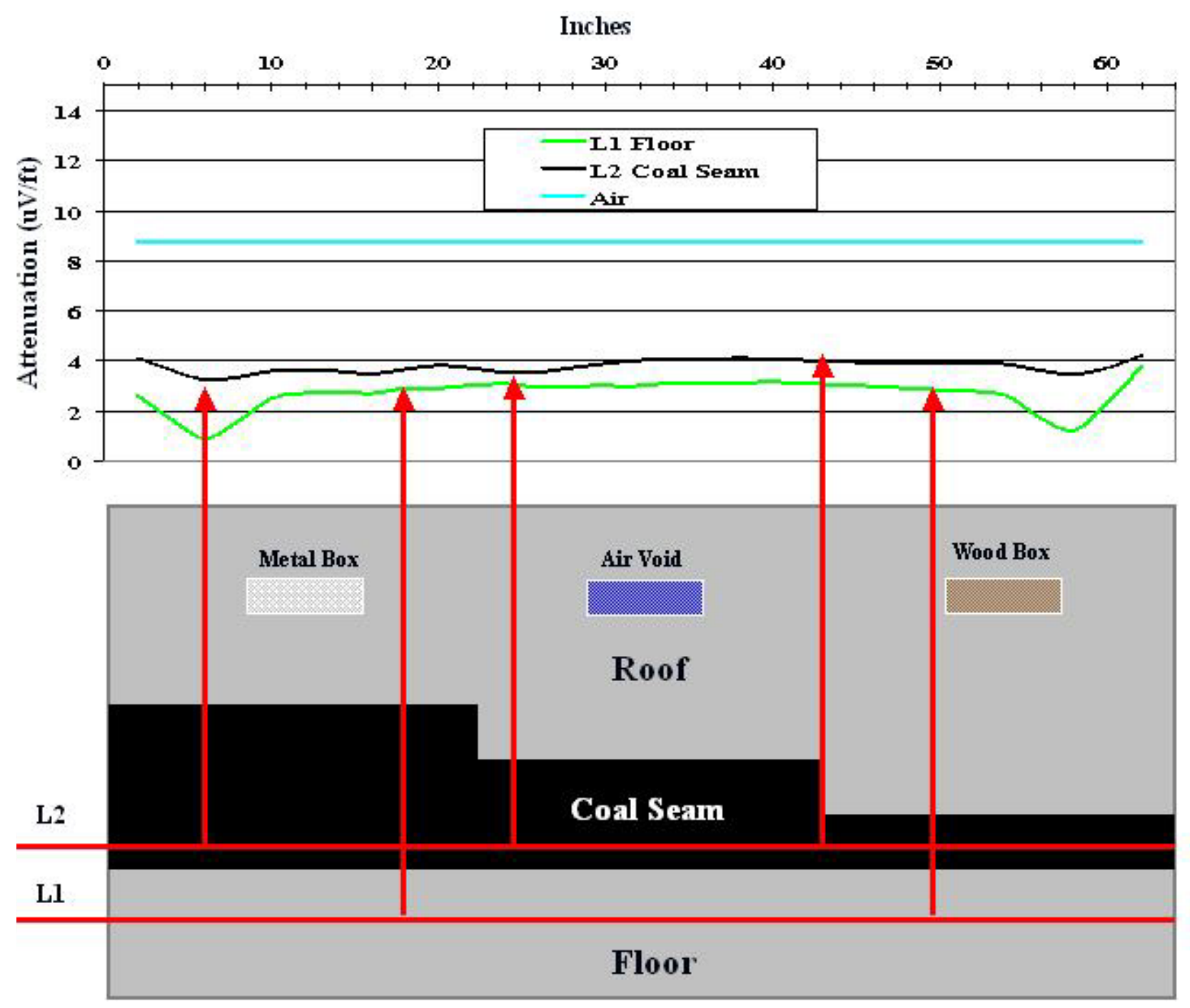

Figure 6.15 Dry model coal seam and floor lines 
Table 6.7 Reconnaissance survey dry physical model line 2 coal seam

\begin{tabular}{|c|c|c|c|c|c|c|c|c|c|c|c|c|c|}
\hline \multicolumn{14}{|c|}{$\begin{array}{l}\text { April 22, } 2007 \text { Dry Model, Line } 2 \text { in the Coal Seam File \# 1008-1010, X = } 22.5 \text { (in), Y= 9.625 (in), Range } 15 \text { (ns), } \\
\text { Gain } 15 \text { (dB), Sc=5858.7, Va = 8.759 (uV), Vm = model Volts }\end{array}$} \\
\hline Z (in) & Max & Max & Max & Min & Min & Min & Abs & First & Velocity & $\mathrm{Vm}$ & Va - Vm & \multicolumn{2}{|c|}{ Attentuation } \\
\hline & Count & Sample & Time (ns) & Count & Sample & Time (ns) & & Arrival (ns) & $\mathrm{ft} / \mathrm{ns}$ & $\mathrm{uV}$ & $\mathrm{uV}$ & $\mathrm{uV} / \mathrm{ft}$ & $\mathrm{db} / \mathrm{ft}$ \\
\hline 2 & 3496 & 196 & 5.76 & -2562 & 160 & 4.71 & 6058 & 3.26 & 1.74 & 1.03 & 7.72 & 4.12 & 9.90 \\
\hline 4 & 6422 & 203 & 5.97 & -4894 & 172 & 5.06 & 11316 & 3.47 & 1.85 & 1.93 & 6.83 & 3.64 & 7.00 \\
\hline 6 & 8246 & 207 & 6.09 & -7313 & 180 & 5.29 & 15559 & 3.59 & 1.91 & 2.66 & 6.10 & 3.26 & 5.53 \\
\hline 8 & 7770 & 213 & 6.26 & -6662 & 186 & 5.47 & 14432 & 3.76 & 2.01 & 2.46 & 6.30 & 3.36 & 5.88 \\
\hline 10 & 6412 & 218 & 6.41 & -5361 & 189 & 5.56 & 11773 & 3.91 & 2.09 & 2.01 & 6.75 & 3.60 & 6.82 \\
\hline 12 & 6296 & 218 & 6.41 & -4842 & 189 & 5.56 & 11138 & 3.91 & 2.09 & 1.90 & 6.86 & 3.66 & 7.08 \\
\hline 14 & 6462 & 218 & 6.41 & -5392 & 193 & 5.68 & 11854 & 3.91 & 2.09 & 2.02 & 6.74 & 3.59 & 6.79 \\
\hline 16 & 6992 & 218 & 6.41 & -6011 & 194 & 5.71 & 13003 & 3.91 & 2.09 & 2.22 & 6.54 & 3.49 & 6.36 \\
\hline 18 & 5991 & 219 & 6.44 & -4966 & 195 & 5.73 & 10957 & 3.94 & 2.10 & 1.87 & 6.89 & 3.67 & 7.15 \\
\hline 20 & 5283 & 226 & 6.65 & -4027 & 194 & 5.71 & 9310 & 4.15 & 2.21 & 1.59 & 7.17 & 3.82 & 7.91 \\
\hline 22 & 6740 & 227 & 6.68 & -3723 & 196 & 5.76 & 10463 & 4.18 & 2.23 & 1.79 & 6.97 & 3.72 & 7.37 \\
\hline 24 & 8919 & 227 & 6.68 & -3409 & 207 & 6.09 & 12328 & 4.18 & 2.23 & 2.10 & 6.65 & 3.55 & 6.61 \\
\hline 26 & 8842 & 228 & 6.71 & -3308 & 210 & 6.18 & 12150 & 4.21 & 2.24 & 2.07 & 6.69 & 3.57 & 6.67 \\
\hline 28 & 7526 & 228 & 6.71 & -2756 & 207 & 6.09 & 10282 & 4.21 & 2.24 & 1.75 & 7.00 & 3.74 & 7.45 \\
\hline 30 & 5867 & 228 & 6.71 & -2549 & 200 & 5.88 & 8416 & 4.21 & 2.24 & 1.44 & 7.32 & 3.91 & 8.37 \\
\hline 32 & 4536 & 232 & 6.82 & -2489 & 197 & 5.79 & 7025 & 4.32 & 2.31 & 1.20 & 7.56 & 4.03 & 9.21 \\
\hline 34 & 4103 & 234 & 6.88 & -2499 & 194 & 5.71 & 6602 & 4.38 & 2.34 & 1.13 & 7.63 & 4.07 & 9.50 \\
\hline 36 & 3895 & 233 & 6.85 & -2612 & 193 & 5.68 & 6507 & 4.35 & 2.32 & 1.11 & 7.65 & 4.08 & 9.57 \\
\hline 38 & 2956 & 234 & 6.88 & -3168 & 189 & 5.56 & 6124 & 4.38 & 2.34 & 1.05 & 7.71 & 4.11 & 9.85 \\
\hline 40 & 2788 & 235 & 6.91 & -3736 & 189 & 5.56 & 6524 & 4.41 & 2.35 & 1.11 & 7.65 & 4.08 & 9.55 \\
\hline 42 & 3333 & 235 & 6.91 & -3679 & 188 & 5.53 & 7012 & 4.41 & 2.35 & 1.20 & 7.56 & 4.03 & 9.22 \\
\hline 44 & 4007 & 236 & 6.94 & -3405 & 189 & 5.56 & 7412 & 4.44 & 2.37 & 1.27 & 7.49 & 4.00 & 8.96 \\
\hline 46 & 4831 & 237 & 6.97 & -3403 & 189 & 5.56 & 8234 & 4.47 & 2.38 & 1.41 & 7.35 & 3.92 & 8.48 \\
\hline 48 & 5087 & 238 & 7.00 & -3403 & 190 & 5.59 & 8490 & 4.50 & 2.40 & 1.45 & 7.31 & 3.90 & 8.33 \\
\hline 50 & 4868 & 238 & 7.00 & -3403 & 190 & 5.59 & 8271 & 4.50 & 2.40 & 1.41 & 7.35 & 3.92 & 8.46 \\
\hline 52 & 4223 & 235 & 6.91 & -3766 & 189 & 5.56 & 7989 & 4.41 & 2.35 & 1.36 & 7.40 & 3.94 & 8.62 \\
\hline 54 & 4934 & 234 & 6.88 & -3904 & 190 & 5.59 & 8838 & 4.38 & 2.34 & 1.51 & 7.25 & 3.87 & 8.15 \\
\hline 56 & 5769 & 227 & 6.68 & -5785 & 188 & 5.53 & 11554 & 4.18 & 2.23 & 1.97 & 6.79 & 3.62 & 6.91 \\
\hline 58 & 6221 & 218 & 6.41 & -6867 & 181 & 5.32 & 13088 & 3.91 & 2.09 & 2.23 & 6.53 & 3.48 & 6.33 \\
\hline 60 & 5154 & 213 & 6.26 & -5062 & 176 & 5.18 & 10216 & 3.76 & 2.01 & 1.74 & 7.02 & 3.74 & 7.48 \\
\hline 62 & 3252 & 204 & 6.00 & -1720 & -177 & -5.21 & 4972 & 3.50 & 1.87 & 0.85 & 7.91 & 4.22 & 10.81 \\
\hline
\end{tabular}


Table 6.8 Reconnaissance survey dry physical model line 1 floor

\begin{tabular}{|c|c|c|c|c|c|c|c|c|c|c|c|c|c|}
\hline \multicolumn{14}{|c|}{$\begin{array}{l}\text { April 22, } 2007 \text { Dry Model, Line } 1 \text { in the Floor, File \# 1005-1007, X = } 22.5 \text { (in), Y= } 5.125 \text { (in), Range } 15 \text { (ns), } \\
\text { Gain } 15 \text { (dB), Sc=5858.7, Va = 8.759 (uV), Vm = model Volts }\end{array}$} \\
\hline \multirow[t]{2}{*}{$Z$ (in) } & \multirow{2}{*}{\begin{tabular}{|c|} 
Max \\
Count \\
\end{tabular}} & \multirow{2}{*}{\begin{tabular}{|c|} 
Max \\
Sample
\end{tabular}} & \multirow{2}{*}{\begin{tabular}{|c|} 
Max \\
Time (ns) \\
\end{tabular}} & \multirow{2}{*}{\begin{tabular}{|c|} 
Min \\
Count
\end{tabular}} & \multirow{2}{*}{\begin{tabular}{|c|} 
Min \\
Sample
\end{tabular}} & \multirow{2}{*}{\begin{tabular}{|c|} 
Min \\
Time (ns) \\
\end{tabular}} & \multirow{2}{*}{ Abs } & \multirow{2}{*}{\begin{tabular}{|c|} 
First \\
Arrival (ns) \\
\end{tabular}} & \multirow{2}{*}{\begin{tabular}{c|} 
Velocity \\
$\mathrm{ft} / \mathrm{ns}$
\end{tabular}} & \multirow{2}{*}{$\begin{array}{l}\mathrm{Vm} \\
\mathrm{uV}\end{array}$} & \multirow{2}{*}{$\frac{\mathrm{Va}-\mathrm{Vm}}{\mathrm{uV}}$} & \multicolumn{2}{|c|}{ Attentuation } \\
\hline & & & & & & & & & & & & $\mathrm{uV} / \mathrm{ft}$ & $\mathrm{db} / \mathrm{ft}$ \\
\hline 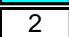 & 12727 & 180 & 5.29 & $\begin{array}{l}-9839 \\
\end{array}$ & 156 & \begin{tabular}{|l|}
4.59 \\
\end{tabular} & 22566 & 3.59 & 1.92 & 3.85 & 4.91 & 2.62 & 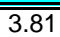 \\
\hline 4 & 19096 & 188 & 5.53 & -13913 & 165 & 4.85 & 33009 & 3.83 & 2.04 & 5.63 & 3.12 & 1.67 & 2.04 \\
\hline 6 & 25564 & 195 & 5.73 & -15681 & 175 & 5.15 & 41245 & 4.03 & 2.15 & 7.04 & 1.72 & 0.92 & 1.01 \\
\hline 8 & 21325 & 200 & 5.88 & -12571 & 179 & 5.26 & 33896 & 4.18 & 2.23 & 5.79 & 2.97 & 1.59 & 1.92 \\
\hline 10 & 14422 & 203 & 5.97 & \begin{tabular}{|l|}
-9332 \\
\end{tabular} & 179 & 5.26 & 23754 & 4.27 & 2.28 & 4.05 & 4.70 & 2.51 & 3.57 \\
\hline 12 & 12630 & 203 & 5.97 & -8817 & 176 & 5.18 & 21447 & 4.27 & 2.28 & 3.66 & 5.10 & 2.72 & 4.04 \\
\hline 14 & 12613 & 204 & 6.00 & -8174 & 180 & 5.29 & 20787 & 4.30 & 2.29 & 3.55 & 5.21 & 2.78 & 4.19 \\
\hline 16 & 12379 & 204 & 6.00 & -9135 & 179 & 5.26 & 21514 & 4.30 & 2.29 & 3.67 & 5.09 & 2.71 & 4.03 \\
\hline 18 & 10516 & 205 & 6.03 & -8760 & 179 & 5.26 & 19276 & 4.33 & 2.31 & 3.29 & 5.47 & 2.92 & 4.54 \\
\hline 20 & 10561 & 205 & 6.03 & -8701 & 179 & 5.26 & 19262 & 4.33 & 2.31 & 3.29 & 5.47 & 2.92 & 4.54 \\
\hline 22 & 9956 & 206 & 6.06 & -8010 & 178 & 5.23 & 17966 & 4.36 & 2.32 & 3.07 & 5.69 & 3.04 & 4.86 \\
\hline 24 & 9987 & 206 & 6.06 & -7443 & 179 & 5.26 & 17430 & 4.36 & 2.32 & 2.98 & 5.78 & 3.08 & 5.00 \\
\hline 26 & 10835 & 205 & 6.03 & -7921 & 179 & 5.26 & 18756 & 4.33 & 2.31 & 3.20 & 5.56 & 2.96 & 4.66 \\
\hline 28 & 10503 & 205 & 6.03 & -7813 & 179 & 5.26 & 18316 & 4.33 & 2.31 & 3.13 & 5.63 & 3.00 & 4.77 \\
\hline 30 & 10623 & 205 & 6.03 & -7681 & 179 & 5.26 & 18304 & 4.33 & 2.31 & 3.12 & 5.63 & 3.01 & 4.78 \\
\hline 32 & 10819 & 206 & 6.06 & -7405 & 181 & 5.32 & 18224 & 4.36 & 2.32 & 3.11 & 5.65 & 3.01 & 4.80 \\
\hline 34 & 10008 & 207 & 6.09 & -6872 & 181 & 5.32 & 16880 & 4.39 & 2.34 & 2.88 & 5.88 & 3.13 & 5.15 \\
\hline 36 & 9571 & 207 & 6.09 & -7266 & 179 & 5.26 & 16837 & 4.39 & 2.34 & 2.87 & 5.89 & 3.14 & 5.16 \\
\hline 38 & 9368 & 207 & 6.09 & -7434 & 179 & 5.26 & 16802 & 4.39 & 2.34 & 2.87 & 5.89 & 3.14 & 5.17 \\
\hline 40 & 9061 & 208 & 6.12 & -7541 & 180 & 5.29 & 16602 & 4.42 & 2.36 & 2.83 & 5.93 & 3.16 & 5.23 \\
\hline 42 & 9157 & 209 & 6.15 & -7963 & 180 & 5.29 & 17120 & 4.45 & 2.37 & 2.92 & 5.84 & 3.11 & 5.09 \\
\hline 44 & 9093 & 210 & 6.18 & -8900 & 181 & 5.32 & 17993 & 4.48 & 2.39 & 3.07 & 5.69 & 3.03 & 4.85 \\
\hline 46 & 9703 & 210 & 6.18 & -8711 & 182 & 5.35 & 18414 & 4.48 & 2.39 & 3.14 & 5.62 & 3.00 & 4.75 \\
\hline 48 & 10426 & 209 & 6.15 & -8891 & 183 & 5.38 & 19317 & 4.45 & 2.37 & 3.30 & 5.46 & 2.91 & 4.53 \\
\hline 50 & 11126 & 209 & 6.15 & -9008 & 184 & 5.41 & 20134 & 4.45 & 2.37 & 3.44 & 5.32 & 2.84 & 4.33 \\
\hline 52 & 11126 & 207 & 6.09 & -9532 & 184 & 5.41 & 20658 & 4.39 & 2.34 & 3.53 & 5.23 & 2.79 & 4.22 \\
\hline 54 & 11951 & 206 & 6.06 & -10842 & 182 & 5.35 & 22793 & 4.36 & 2.32 & 3.89 & 4.87 & 2.60 & 3.76 \\
\hline 56 & 18178 & 204 & 6.00 & \begin{tabular}{|l|}
-14379 \\
\end{tabular} & 181 & 5.32 & 32557 & 4.30 & 2.29 & 5.56 & 3.20 & 1.71 & 2.11 \\
\hline 58 & 21288 & 197 & 5.79 & -16347 & 177 & 5.21 & 37635 & 4.09 & 2.18 & 6.42 & 2.34 & 1.25 & 1.44 \\
\hline 60 & 15402 & 193 & 5.68 & -10084 & -174 & -5.12 & 25486 & 3.98 & 2.12 & 4.35 & 4.41 & 2.35 & 3.24 \\
\hline 62 & 7761 & 189 & 5.56 & -2039 & -174 & -5.12 & 9800 & 3.86 & 2.06 & 1.67 & 7.09 & 3.78 & 7.67 \\
\hline
\end{tabular}




\subsubsection{Reconnaissance Survey Wet Physical Model}

In order to study the effects of moisture, approximately 20 gallons of water was sprayed on the top and around the model. The model dried for 10 days prior to testing. In general, voltage attenuation rates of the wet model were higher than the voltage attenuation rate of the dry model. Voltage attenuation rates of the wet model ranged between $2.60 \mathrm{uV} / \mathrm{ft}$ to $4.53 \mathrm{uV} / \mathrm{ft}$ and as mentioned earlier the voltage attenuation rate of the dry model ranged between $0.72 \mathrm{uV} / \mathrm{ft}$ to $4.22 \mathrm{uV} / \mathrm{ft}$. In general, the wet model was driest at the top and wettest on the bottom. The water percolated from the top to the bottom. Figure 6.16 shows the wet motel with the survey lines (L1-L5).

From the data analysis it appears that the moisture did not distribute evenly through out the model. Cracks in the model appeared to provide channels for the water and allowed quicker drying around these areas. Wax paper was used between the roof, coal seam, and floor during construction that possibly formed a water barrier. Figure 6.17 shows the wax paper and one of the cracks between the 5 and 3-inch coal seam.

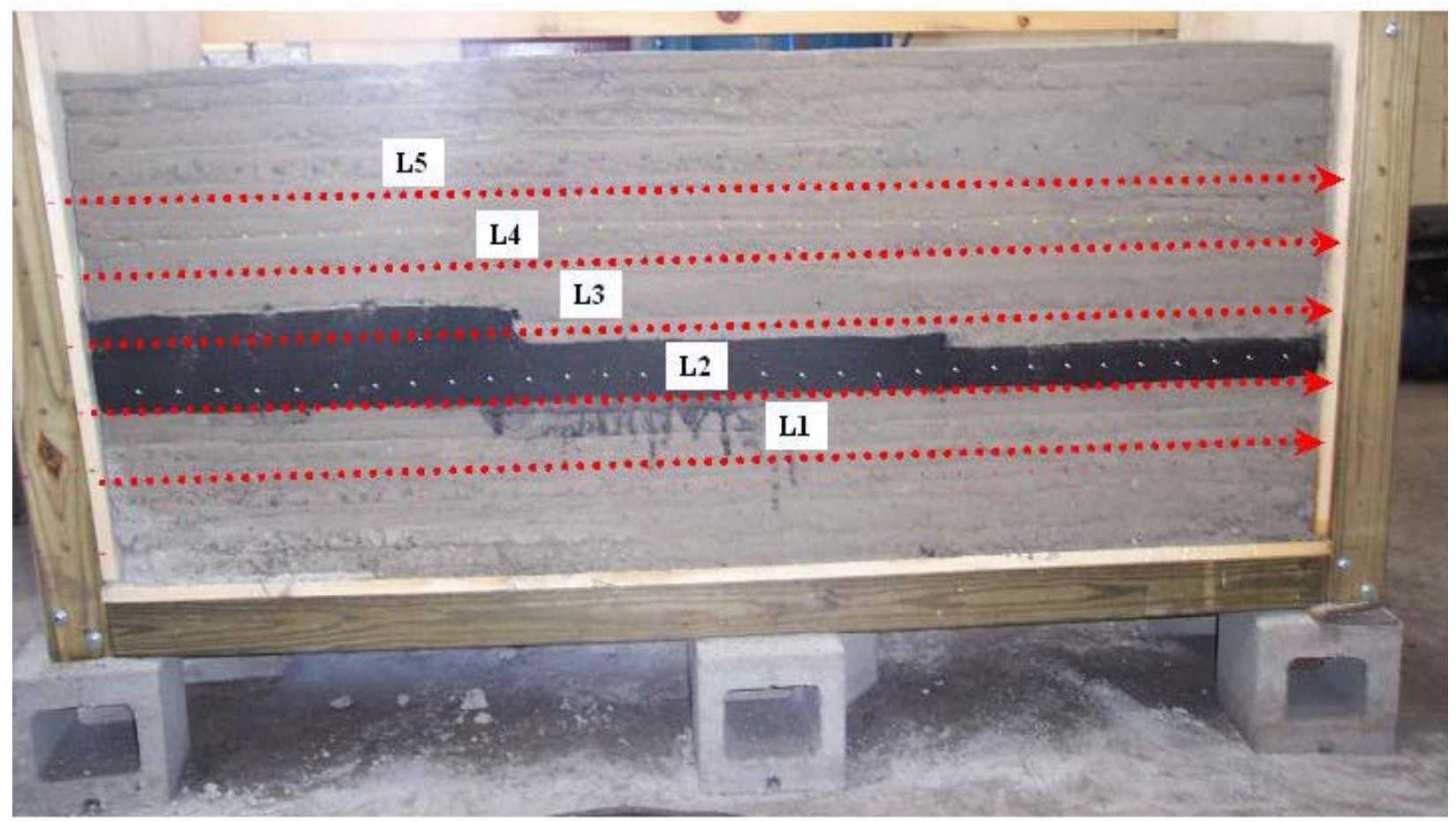

Figure 6.16 Image of wet physical model with survey lines (L1-L5) 


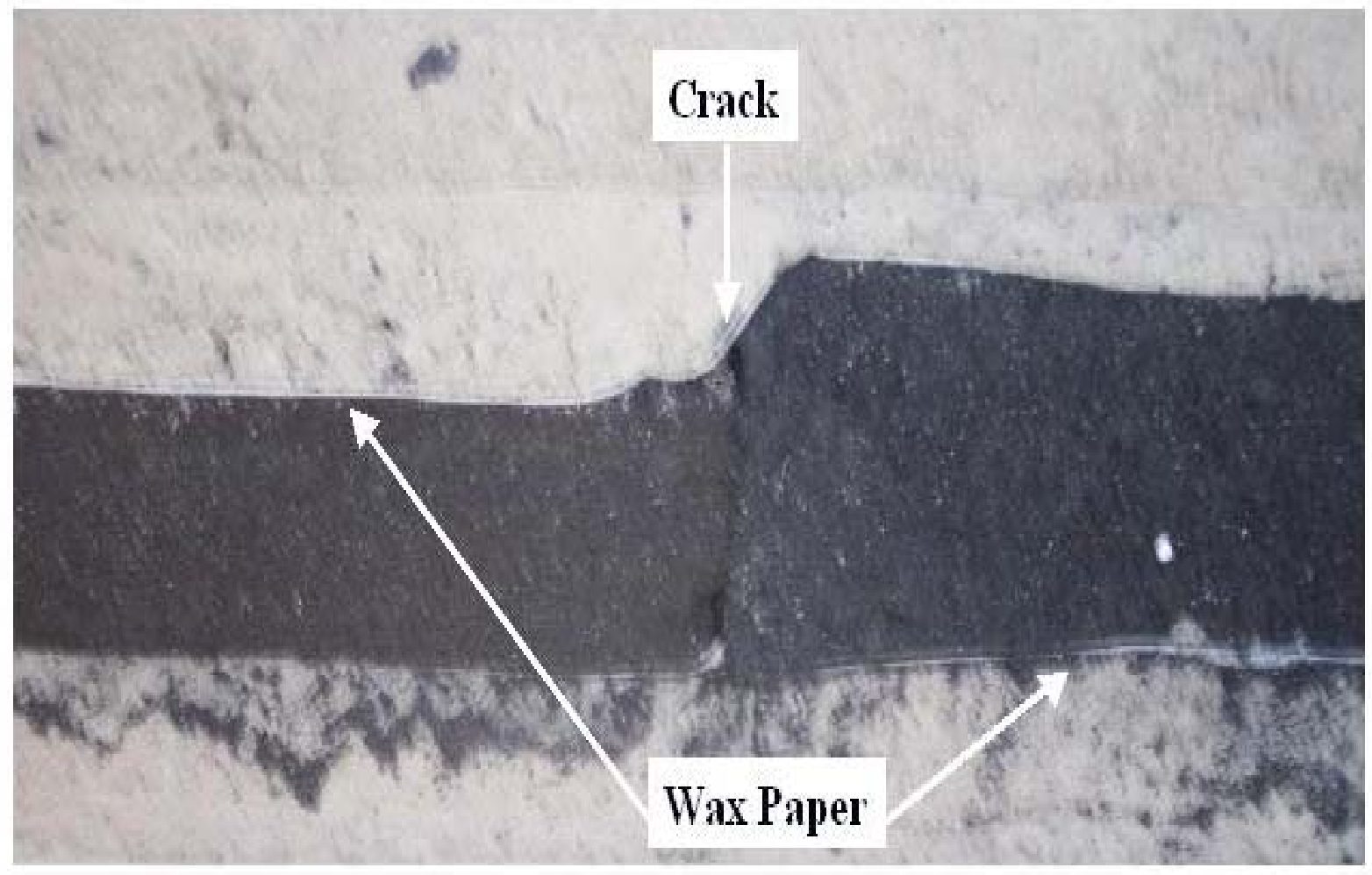

Figure 6.17 Image of wax paper and crack in wet physical model 
In Figure 6.18, the edge effect of the model is shown at approximately 4 inches at the beginning for line 5 (L5 Objects); however no edge effect is apparent at the end of L5. The voltage attenuation rate of L5 decreases slightly at the end of the line. As shown in Figure 6.16, the model appears to have a dry area from approximately 44 inches to the end of the model above L5. This voltage attenuation rate decrease at the end of L5 is possibly due to this drier area. For line 4 (L4 Roof) the edge effect of the model is shown at approximately 6 inches at the beginning and at approximately 4 inches at the end. As shown by L5, the first object (metal box) caused a voltage attenuation increase starting at approximately 5 inches and continuing until approximately 16 inches. The second object (empty box) caused a voltage attenuation increase starting at approximately 28 inches and continuing until 36 inches. Water may be trapped in this area that could cause this attenuation increase. The third object (wood box) voltage attenuation rate changes are not as pronounced as the metal box and the empty box. A small voltage attenuation increase is observed at approximately 54 inches then a larger voltage attenuation rate decrease is observed at approximately 57 inches. The voltage attenuation rate trend of the wet model follows a similar trend of the dry model for L5.

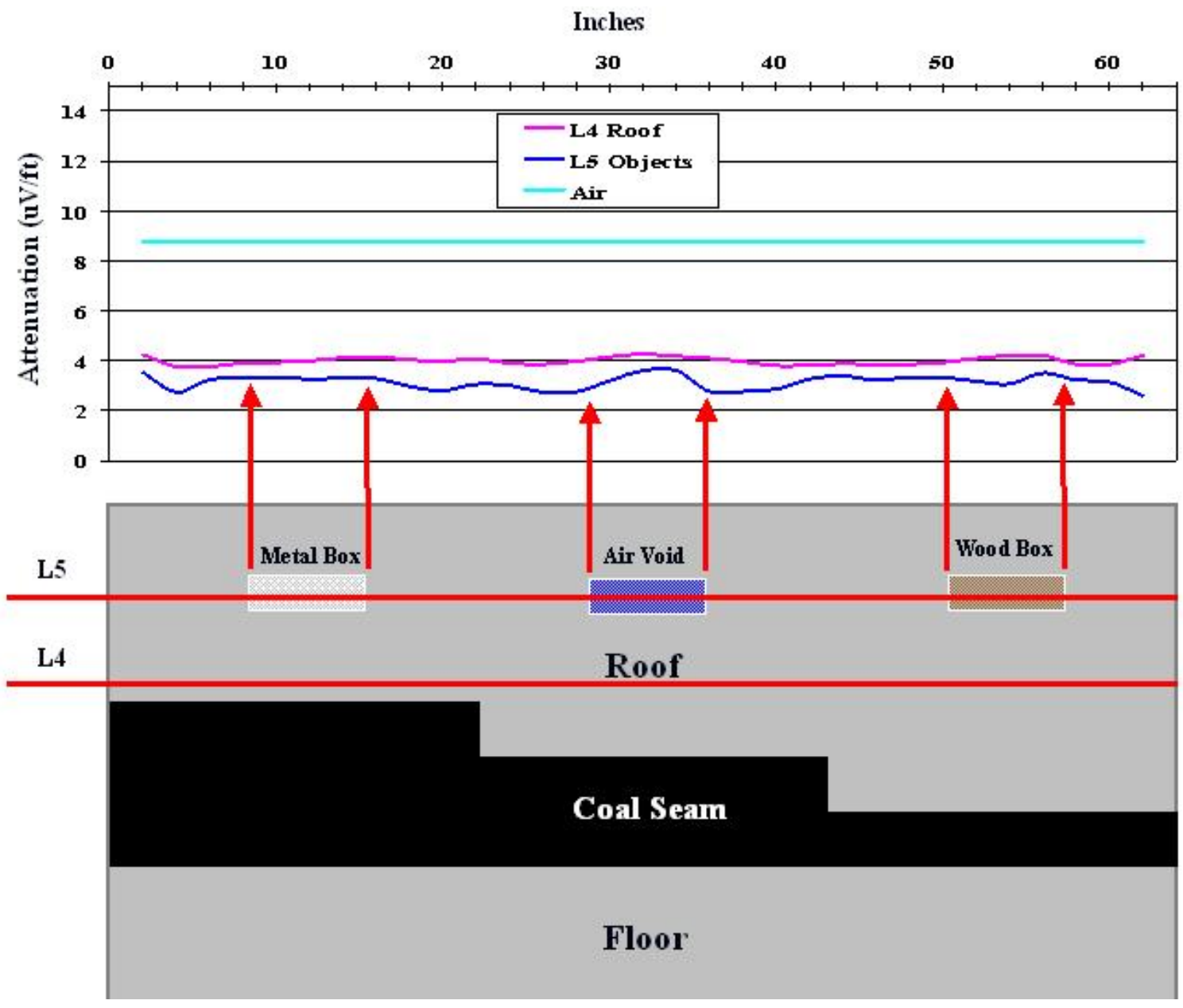

Figure 6.18 Wet model objects and roof lines 
Table 6.9 Reconnaissance survey wet physical model line 5 objects

\begin{tabular}{|c|c|c|c|c|c|c|c|c|c|c|c|c|c|}
\hline \multicolumn{14}{|c|}{$\begin{array}{c}\text { February 16, } 2007 \text { Wet Model, Line } 5 \text { in Objects, File \# 1030, X = } 22.5 \text { (in), Y= } 19.625 \text { (in), } \\
\text { Range } 15 \text { (ns), Gain } 20 \text { (dB), Sc=10418.35, Va = 8.759 (uV), Vm = model volts }\end{array}$} \\
\hline$\overline{\mid \bar{Z} \text { (in) }}$ & Max & Max & Max & Min & Min & Min & Abs & First & Velocity & Vm & $\overline{V a-V m}$ & \multicolumn{2}{|c|}{$\begin{array}{ll}\text { Attentuation } \\
\end{array}$} \\
\hline & Count & Sample & Time (ns) & Count & Sample & Time (ns) & & Arrival (ns) & \begin{tabular}{|l}
$\mathrm{ft} / \mathrm{ns}$ \\
\end{tabular} & $\mathrm{uV}$ & $\mathrm{uV}$ & $\mathrm{uV} / \mathrm{ft}$ & $\mathrm{dB}$ \\
\hline 2 & 11517 & 215 & 6.32 & -10832 & 234 & 6.88 & 22349.0 & 3.82 & 2.04 & 2.15 & 6.61 & 3.53 & $\overline{6.52}$ \\
\hline 4 & 21220 & 218 & 6.41 & -16425 & 245 & 7.21 & 37645.0 & 3.91 & 2.09 & 3.61 & 5.15 & 2.74 & 4.10 \\
\hline 6 & 16215 & 227 & 6.68 & -11568 & 209 & 6.15 & 27783.0 & 4.18 & 2.23 & 2.67 & 6.09 & 3.25 & 5.51 \\
\hline 8 & 15359 & 227 & 6.68 & -11653 & 249 & 7.32 & 27012.0 & 4.18 & 2.23 & 2.59 & 6.17 & 3.29 & 5.64 \\
\hline 10 & 15733 & 226 & 6.65 & -10835 & 247 & 7.26 & 26568.0 & 4.15 & 2.21 & 2.55 & 6.21 & 3.31 & 5.72 \\
\hline 12 & 15837 & 226 & 6.65 & -11420 & 204 & 6.00 & 27257.0 & 4.15 & 2.21 & 2.62 & 6.14 & 3.28 & 5.60 \\
\hline 14 & 15317 & 225 & 6.62 & -11544 & 204 & 6.00 & 26861.0 & 4.12 & 2.20 & 2.58 & 6.18 & 3.30 & 5.67 \\
\hline 16 & 15506 & 225 & 6.62 & -11519 & 204 & 6.00 & 27025.0 & 4.12 & 2.20 & 2.59 & 6.17 & 3.29 & 5.64 \\
\hline 18 & 19137 & 225 & 6.62 & -14074 & 242 & 7.12 & 33211.0 & 4.12 & 2.20 & 3.19 & 5.57 & 2.97 & 4.68 \\
\hline 20 & 20819 & 225 & 6.62 & -15645 & 242 & 7.12 & 36464.0 & 4.12 & 2.20 & 3.50 & 5.26 & 2.80 & 4.25 \\
\hline 22 & 17936 & 224 & 6.59 & -13608 & 203 & 5.97 & 31544.0 & 4.09 & 2.18 & 3.03 & 5.73 & 3.06 & 4.92 \\
\hline 24 & 18409 & 219 & 6.44 & -14100 & 242 & 7.12 & 32509.0 & 3.94 & 2.10 & 3.12 & 5.64 & 3.01 & 4.78 \\
\hline 26 & 21951 & 219 & 6.44 & -15768 & 241 & 7.09 & 37719.0 & 3.94 & 2.10 & 3.62 & 5.14 & 2.74 & 4.09 \\
\hline 28 & 22130 & 218 & 6.41 & -15226 & 238 & 7.00 & 37356.0 & 3.91 & 2.09 & 3.59 & 5.17 & 2.76 & 4.14 \\
\hline 30 & 15932 & 217 & 6.38 & -12945 & 234 & 6.88 & 28877.0 & 3.88 & 2.07 & 2.77 & 5.99 & 3.19 & 5.33 \\
\hline 32 & 11070 & 215 & 6.32 & -9688 & 234 & 6.88 & 20758.0 & 3.82 & 2.04 & 1.99 & 6.77 & 3.61 & 6.86 \\
\hline 34 & 11108 & 215 & 6.32 & $\begin{array}{l}-9702 \\
\end{array}$ & 234 & 6.88 & 20810.0 & 3.82 & 2.04 & 2.00 & 6.76 & 3.61 & 6.85 \\
\hline 36 & 21677 & 218 & 6.41 & -15637 & 237 & 6.97 & 37314.0 & 3.91 & 2.09 & 3.58 & 5.18 & 2.76 & 4.14 \\
\hline 38 & 21551 & 218 & 6.41 & -15626 & 238 & 7.00 & 37177.0 & 3.91 & 2.09 & 3.57 & 5.19 & 2.77 & 4.16 \\
\hline 40 & 20338 & 219 & 6.44 & -14827 & 240 & 7.06 & 35165.0 & 3.94 & 2.10 & 3.38 & 5.38 & 2.87 & 4.42 \\
\hline 42 & 16104 & 219 & 6.44 & -11284 & 241 & 7.09 & 27388.0 & 3.94 & 2.10 & 2.63 & 6.13 & 3.27 & 5.58 \\
\hline 44 & 14897 & 218 & 6.41 & -10033 & 201 & 5.91 & 24930.0 & 3.91 & 2.09 & 2.39 & 6.37 & 3.40 & 6.01 \\
\hline 46 & 17058 & 219 & 6.44 & -11161 & 202 & 5.94 & 28219.0 & 3.94 & 2.10 & 2.71 & 6.05 & 3.23 & 5.44 \\
\hline 48 & 15434 & 219 & 6.44 & \begin{tabular}{|l|}
-10531 \\
\end{tabular} & 241 & 7.09 & 25965.0 & 3.94 & 2.10 & 2.49 & 6.27 & 3.34 & 5.82 \\
\hline 50 & 15528 & 219 & 6.44 & -10542 & 241 & 7.09 & 26070.0 & 3.94 & 2.10 & 2.50 & 6.26 & 3.34 & 5.80 \\
\hline 52 & 16857 & 219 & 6.44 & \begin{tabular}{|l|}
-12273 \\
\end{tabular} & 241 & 7.09 & 29130.0 & 3.94 & 2.10 & 2.80 & 5.96 & 3.18 & 5.29 \\
\hline 54 & 17437 & 218 & 6.41 & -13809 & 241 & 7.09 & 31246.0 & 3.91 & 2.09 & 3.00 & 5.76 & 3.07 & 4.96 \\
\hline 56 & 13770 & 218 & 6.41 & -9057 & 201 & 5.91 & 22827.0 & 3.91 & 2.09 & 2.19 & 6.57 & 3.50 & 6.42 \\
\hline 58 & 15035 & 226 & 6.65 & -13020 & 242 & 7.12 & 28055.0 & 4.15 & 2.21 & 2.69 & 6.07 & 3.24 & 5.46 \\
\hline 60 & 29878 & 226 & 6.65 & -32768 & 242 & 7.12 & 29813.0 & 4.15 & 2.21 & 2.86 & 5.90 & 3.15 & 5.18 \\
\hline 62 & 19653 & 223 & 6.56 & \begin{tabular}{|l}
-20819 \\
\end{tabular} & 241 & 7.09 & 40472.0 & 4.06 & 2.16 & 3.88 & 4.87 & 2.60 & 3.77 \\
\hline
\end{tabular}


In Figure 6.19, line 4 (L4 Roof) the edge effect of the model is shown at approximately 6 inches at the beginning and at approximately 4 inches at the end. As shown by L4, the area below the first object (metal box) causes a slight voltage attenuation increase at approximately 8 inches and continues until approximately 15 inches. The area below the second object (empty box) causes a voltage attenuation increase starting at approximately 28 inches and continuing until approximately 35 inches. The area below the third object (wood box) causes a voltage increase starting at approximately 50 inches and continuing until 57 inches. Line 3 (Coal Seam/Roof) shows no edge effect. The voltage attenuation rate remains fairly constant through out the complete line scan.

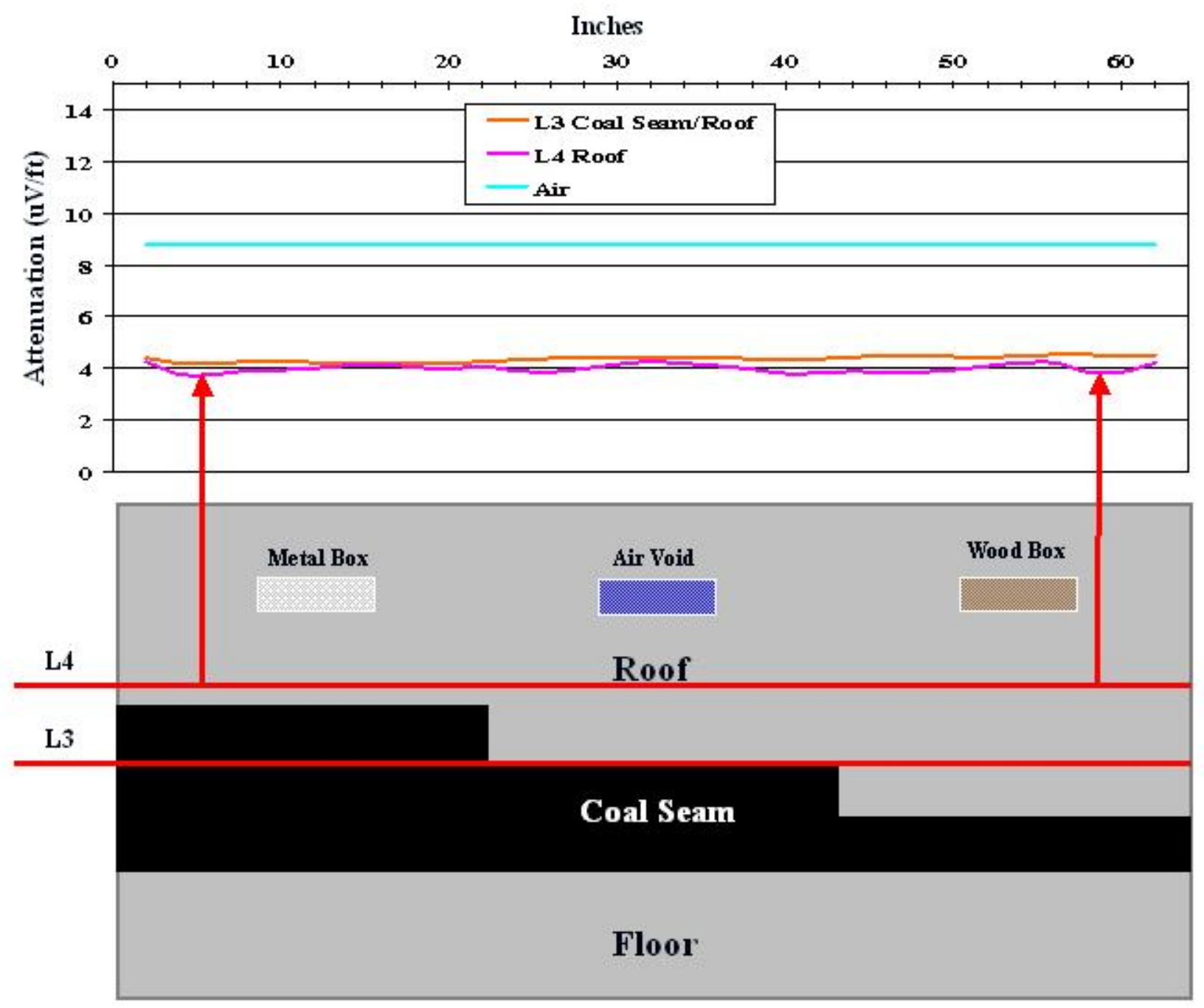

Figure 6.19 Wet model roof and coal seam/roof lines 
Table 6.10 Reconnaissance survey wet physical model line 4 roof

\begin{tabular}{|c|c|c|c|c|c|c|c|c|c|c|c|c|c|}
\hline \multicolumn{14}{|c|}{$\begin{array}{l}\text { Febuary 16, } 2007 \text { Wet Model, Line } 4 \text { in Roof, File \# 1031, X = } 22.5 \text { (in), Y= } 16.125 \text { (in), } \\
\text { Range } 15 \text { (ns), Gain } 20 \text { (dB), Sc=10418.35, Va = 8.759 (uV), Vm = model volts }\end{array}$} \\
\hline$\overline{Z Z \text { (in) }}$ & Max & Max & Max & Min & Min & Min & Abs & First & Velocity & $\mathrm{Vm}$ & Va -Vm & \multicolumn{2}{|c|}{ Attentuation } \\
\hline & Count & Sample & Time (ns) & Count & Sample & Time (ns) & & Arrival (ns) & $\mathrm{ft} / \mathrm{ns}$ & $\mathrm{uV}$ & $\mathrm{uV}$ & $\mathrm{uV} / \mathrm{ft}$ & $\mathrm{dB}$ \\
\hline 2 & 4758 & 226 & 6.65 & -3503 & 249 & 7.32 & 8261.0 & 4.15 & 2.21 & 0.79 & $\overline{77.97}$ & 4.25 & 111.13 \\
\hline 4 & 9997 & 241 & 7.09 & -7614 & 216 & 6.35 & 17611.0 & 4.59 & 2.45 & 1.69 & 7.07 & 3.77 & 7.62 \\
\hline 6 & 10073 & 241 & 7.09 & -7638 & 217 & 6.38 & 17711.0 & 4.59 & 2.45 & 1.70 & 7.06 & 3.76 & 7.59 \\
\hline 8 & 7715 & 241 & 7.09 & -7108 & 218 & 6.41 & 14823.0 & 4.59 & 2.45 & 1.42 & 7.34 & 3.91 & 8.42 \\
\hline 10 & 7542 & 241 & 7.09 & -6812 & 218 & 6.41 & 14354.0 & 4.59 & 2.45 & 1.38 & 7.38 & 3.94 & 8.57 \\
\hline 12 & 7132 & 241 & 7.09 & -5988 & 218 & 6.41 & 13120.0 & 4.59 & 2.45 & 1.26 & 7.50 & 4.00 & 8.98 \\
\hline 14 & 5773 & 241 & 7.09 & -5188 & 215 & 6.32 & 10961.0 & 4.59 & 2.45 & 1.05 & 7.71 & 4.11 & 9.82 \\
\hline 16 & 5120 & 241 & 7.09 & -4960 & 215 & 6.32 & 10080.0 & 4.59 & 2.45 & 0.97 & 7.79 & 4.16 & 10.21 \\
\hline 18 & 6455 & 239 & 7.03 & -5905 & 215 & 6.32 & 12360.0 & 4.53 & 2.42 & 1.19 & 7.57 & 4.04 & 9.26 \\
\hline 20 & 7364 & 235 & 6.91 & -6002 & 214 & 6.29 & 13366.0 & 4.41 & 2.35 & 1.28 & 7.48 & 3.99 & 8.90 \\
\hline 22 & 6361 & 238 & 7.00 & -5334 & 213 & 6.26 & 11695.0 & 4.50 & 2.40 & 1.12 & 7.64 & 4.07 & 9.52 \\
\hline 24 & 8222 & 234 & 6.88 & -6682 & 212 & 6.23 & 14904.0 & 4.38 & 2.34 & 1.43 & 7.33 & 3.91 & 8.39 \\
\hline 26 & 8494 & 233 & 6.85 & -7295 & 210 & 6.18 & 15789.0 & 4.35 & 2.32 & 1.52 & 7.24 & 3.86 & 8.13 \\
\hline 28 & 7111 & 233 & 6.85 & -6421 & 256 & 7.53 & 13532.0 & 4.35 & 2.32 & 1.30 & 7.46 & 3.98 & 8.84 \\
\hline 30 & 4977 & 233 & 6.85 & -5180 & 256 & 7.53 & 10157.0 & 4.35 & 2.32 & 0.97 & 7.78 & 4.15 & 10.17 \\
\hline 32 & 4207 & 233 & 6.85 & -3826 & 255 & 7.50 & 8033.0 & 4.35 & 2.32 & 0.77 & 7.99 & 4.26 & 11.26 \\
\hline 34 & 4767 & 234 & 6.88 & -4857 & 256 & 7.53 & 9624.0 & 4.38 & 2.34 & 0.92 & 7.84 & 4.18 & 10.42 \\
\hline 36 & 5566 & 234 & 6.88 & -5687 & 256 & 7.53 & 11253.0 & 4.38 & 2.34 & 1.08 & 7.68 & 4.10 & 9.70 \\
\hline 38 & 7918 & 233 & 6.85 & -5893 & 210 & 6.18 & 13811.0 & 4.35 & 2.32 & 1.33 & 7.43 & 3.96 & 8.75 \\
\hline 40 & 9366 & 213 & 6.26 & -7596 & 213 & 6.26 & 16962.0 & 3.76 & 2.01 & 1.63 & 7.13 & 3.80 & 7.79 \\
\hline 42 & 8779 & 235 & 6.91 & -7858 & 215 & 6.32 & 16637.0 & 4.41 & 2.35 & 1.60 & 7.16 & 3.82 & 7.88 \\
\hline 44 & 8048 & 238 & 7.00 & -7302 & 217 & 6.38 & 15350.0 & 4.50 & 2.40 & 1.47 & 7.29 & 3.89 & 8.26 \\
\hline 46 & 8491 & 239 & 7.03 & -7843 & 218 & 6.41 & 16334.0 & 4.53 & 2.42 & 1.57 & 7.19 & 3.84 & 7.97 \\
\hline 48 & 8303 & 240 & 7.06 & -7644 & 218 & 6.41 & 15947.0 & 4.56 & 2.43 & 1.53 & 7.23 & 3.86 & 8.08 \\
\hline 50 & 7444 & 240 & 7.06 & -6843 & 218 & 6.41 & 14287.0 & 4.56 & 2.43 & 1.37 & 7.39 & 3.94 & 8.59 \\
\hline 52 & 6441 & 240 & 7.06 & -4922 & 216 & 6.35 & 11363.0 & 4.56 & 2.43 & 1.09 & 7.67 & 4.09 & 9.65 \\
\hline 54 & 5080 & 238 & 7.00 & -4034 & 213 & 6.26 & 9114.0 & 4.50 & 2.40 & 0.87 & 7.88 & 4.20 & 10.67 \\
\hline 56 & 3972 & 234 & 6.88 & -5057 & 211 & 6.21 & 9029.0 & 4.38 & 2.34 & 0.87 & 7.89 & 4.21 & 10.72 \\
\hline 58 & 8207 & 234 & 6.88 & -7626 & 211 & 6.21 & 15833.0 & 4.38 & 2.34 & 1.52 & 7.24 & 3.86 & 8.11 \\
\hline 60 & 8386 & 233 & 6.85 & -7570 & 257 & 7.56 & 15956.0 & 4.35 & 2.32 & 1.53 & 7.23 & 3.85 & 8.08 \\
\hline 62 & 3524 & 233 & 6.85 & -5495 & 257 & 7.56 & 9019.0 & 4.35 & 2.32 & 0.87 & 7.89 & 4.21 & 10.72 \\
\hline
\end{tabular}


Table 6.11 Reconnaissance survey wet physical model line 3 coal seam/roof

\begin{tabular}{|c|c|c|c|c|c|c|c|c|c|c|c|c|c|}
\hline \multicolumn{14}{|c|}{$\begin{array}{c}\text { February 16, } 2007 \text { Wet Model, Line } 3 \text { in Coal Seam Roof, File \# 1033, X = } 22.5 \text { (in), Y= } 12.625 \text { (in), } \\
\text { Range } 15 \text { (ns), Gain } 20 \text { (dB), Sc=10418.35, Va = 8.759 (uV), Vm = model volts }\end{array}$} \\
\hline \multirow[t]{2}{*}{$Z$ (in) } & \multirow{2}{*}{$\begin{array}{c}\text { Max } \\
\text { Count }\end{array}$} & \multirow{2}{*}{ 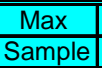 } & \multirow{2}{*}{\begin{tabular}{c|c|} 
Max & \\
Time $(n s)$ &
\end{tabular}} & \multirow{2}{*}{\begin{tabular}{c|c|} 
Min \\
Count
\end{tabular}} & \multirow{2}{*}{\begin{tabular}{|c|} 
Min \\
Sample
\end{tabular}} & \multirow{2}{*}{\begin{tabular}{|c|} 
Min \\
Time (ns)
\end{tabular}} & \multirow[t]{2}{*}{ Abs } & \multirow{2}{*}{\begin{tabular}{|c|} 
First \\
Arrival (ns) \\
\end{tabular}} & \multirow{2}{*}{$\begin{array}{ll}\text { Velocity } \\
\mathrm{ft} / \mathrm{ns} \\
\end{array}$} & \multirow{2}{*}{$\begin{array}{lll}\mathrm{Vm} \\
\mathrm{uV}\end{array}$} & \multirow{2}{*}{$\frac{\mathrm{Va}-\mathrm{Vm}}{\mathrm{uV}}$} & \multicolumn{2}{|c|}{ "Attentuation } \\
\hline & & & & & & & & & & & & $\mathrm{uV} / \mathrm{ft}$ & $\mathrm{dB}$ \\
\hline 2 & 2721 & 264 & 7.76 & $2-2551$ & 294 & 8.65 & 5272.0 & 5.26 & 2.81 & 0.51 & 8.25 & 4.40 & 13.21 \\
\hline 4 & 4545 & 264 & 7.76 & -4677 & 302 & 8.88 & 9222.0 & 5.26 & 2.81 & 0.89 & 7.87 & 4.20 & 10.62 \\
\hline 6 & 5028 & 272 & 8.00 & -4642 & 241 & 7.09 & 9670.0 & 5.50 & 2.93 & 0.93 & 7.83 & 4.18 & 10.40 \\
\hline 8 & 3682 & 277 & 8.15 & -4480 & 241 & 7.09 & 8162.0 & 5.65 & 3.01 & 0.78 & 7.98 & 4.25 & 11.18 \\
\hline 10 & 3415 & 272 & 8.00 & -4432 & 241 & 7.09 & 7847.0 & 5.50 & 2.93 & 0.75 & 8.01 & 4.27 & 11.37 \\
\hline 12 & 4255 & 279 & 8.21 & -4403 & 242 & 7.12 & 8658.0 & 5.71 & 3.04 & 0.83 & 7.93 & 4.23 & 10.91 \\
\hline 14 & 4539 & 279 & 8.21 & -4565 & 310 & 9.12 & 9104.0 & 5.71 & 3.04 & 0.87 & 7.89 & 4.21 & 10.68 \\
\hline 16 & 4440 & 279 & 8.21 & -4312 & 242 & 7.12 & 8752.0 & 5.71 & 3.04 & 0.84 & 7.92 & 4.22 & 10.86 \\
\hline 18 & 4826 & 278 & 8.18 & -4402 & 248 & 7.29 & 9228.0 & 5.68 & 3.03 & 0.89 & 7.87 & 4.20 & 10.61 \\
\hline 20 & 5240 & 272 & 8.00 & -4437 & 242 & 7.12 & 9677.0 & 5.50 & 2.93 & 0.93 & 7.83 & 4.18 & 10.39 \\
\hline 22 & 4220 & 272 & 8.00 & -3790 & 309 & 9.09 & 8010.0 & 5.50 & 2.93 & 0.77 & 7.99 & 4.26 & 11.27 \\
\hline 24 & 3623 & 279 & 8.21 & -3201 & 310 & 9.12 & 6824.0 & 5.71 & 3.04 & 0.66 & 8.10 & 4.32 & 12.01 \\
\hline 26 & 3067 & 279 & 8.21 & -2614 & 303 & 8.91 & 5681.0 & 5.71 & 3.04 & 0.55 & 8.21 & 4.38 & 12.86 \\
\hline 28 & 2728 & 279 & 8.21 & -2269 & 303 & 8.91 & 4997.0 & 5.71 & 3.04 & 0.48 & 8.28 & 4.42 & 13.46 \\
\hline 30 & 2704 & 279 & 8.21 & -2000 & 310 & 9.12 & 4704.0 & 5.71 & 3.04 & 0.45 & 8.31 & 4.43 & 13.74 \\
\hline 32 & 2722 & 279 & 8.21 & -2019 & 310 & 9.12 & 4741.0 & 5.71 & 3.04 & 0.46 & 8.30 & 4.43 & 13.70 \\
\hline 34 & 2594 & 279 & 8.21 & -2028 & 249 & 7.32 & 4622.0 & 5.71 & 3.04 & 0.44 & 8.32 & 4.43 & 13.82 \\
\hline 36 & 2927 & 279 & 8.21 & -2147 & 249 & 7.32 & 5074.0 & 5.71 & 3.04 & 0.49 & 8.27 & 4.41 & 13.39 \\
\hline 38 & 3583 & 279 & 8.21 & -2341 & 249 & 7.32 & 5924.0 & 5.71 & 3.04 & 0.57 & 8.19 & 4.37 & 12.67 \\
\hline 40 & 3710 & 278 & 8.18 & -2562 & 249 & 7.32 & 6272.0 & 5.68 & 3.03 & 0.60 & 8.16 & 4.35 & 12.40 \\
\hline 42 & 3122 & 275 & 8.09 & -2788 & 249 & 7.32 & 5910.0 & 5.59 & 2.98 & 0.57 & 8.19 & 4.37 & 12.68 \\
\hline 44 & 2155 & 275 & 8.09 & -2437 & 249 & 7.32 & 4592.0 & 5.59 & 2.98 & 0.44 & 8.32 & 4.44 & 13.85 \\
\hline 46 & 1314 & 295 & 8.68 & -2112 & 248 & 7.29 & 3426.0 & 6.18 & 3.29 & 0.33 & 8.43 & 4.50 & 15.20 \\
\hline 48 & 1801 & 265 & 7.79 & -2508 & 246 & 7.23 & 4309.0 & 5.29 & 2.82 & 0.41 & 8.35 & 4.45 & 14.14 \\
\hline 50 & 1782 & 265 & 7.79 & -2499 & 247 & 7.26 & 4281.0 & 5.29 & 2.82 & 0.41 & 8.35 & 4.45 & 14.17 \\
\hline 52 & 2288 & 265 & 7.79 & -2619 & 248 & 7.29 & 4907.0 & 5.29 & 2.82 & 0.47 & 8.29 & 4.42 & 13.54 \\
\hline 54 & 1671 & 271 & 7.97 & -1895 & 249 & 7.32 & 3566.0 & 5.47 & 2.92 & 0.34 & 8.42 & 4.49 & 15.02 \\
\hline 56 & 1648 & 310 & 9.12 & -1195 & 335 & 9.85 & 2843.0 & 6.62 & 3.53 & 0.27 & 8.49 & 4.53 & 16.07 \\
\hline 58 & 1645 & 310 & 9.12 & -1203 & 336 & 9.88 & 2848.0 & 6.62 & 3.53 & 0.27 & 8.49 & 4.53 & 16.06 \\
\hline 60 & 1701 & 303 & 8.91 & -1938 & 326 & 9.59 & 3639.0 & 6.41 & 3.42 & 0.35 & 8.41 & 4.49 & 14.93 \\
\hline 62 & 1275 & 295 & 8.68 & -1734 & 318 & 9.35 & 3009.0 & 6.18 & 3.29 & 0.29 & 8.47 & 4.52 & 15.81 \\
\hline
\end{tabular}


In Figure 6.20, line 2 (Coal Seam) shows no edge effect. As shown by L2, the voltage attenuation rate is lower from approximately 2 inches up to approximately 22 inches. This is the area where the coal seam height is 5 inches and it was expected to see lower voltage attenuation rate. At approximately 24 inches as mentioned before the coal seam height decreases to 3 inches and the voltage attenuation rate increases slightly and remains fairly constant until approximately 46 inches. As mentioned before, the voltage attenuation rate was expected to increase along this section of L2 due to the thinner coal seam. The voltage attenuation then decreases slightly from approximately 46 inches till approximately 56 inches. It was expected to see a slight voltage attenuation increase starting at 46 inches and continuing to the end of L2. The voltage attenuation decrease may have been caused by a drier media, in this case the 2-inch coal seam, was drier. From approximately 56 inches to approximately 62 inches the attenuation rate increases slightly.

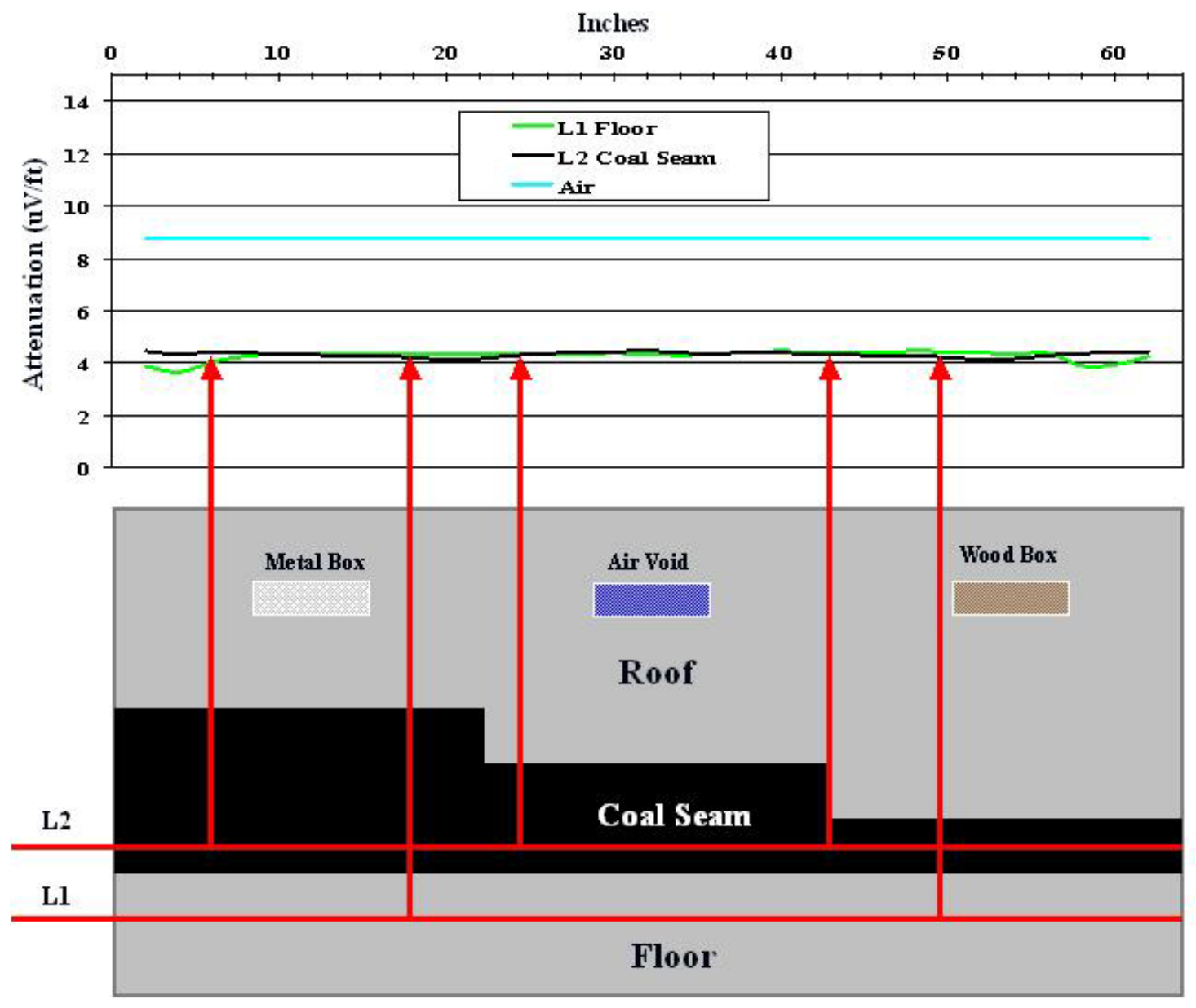

Figure 6.20 Wet model coal and floor 
Table 6.12 Reconnaissance survey wet physical model line 2 coal seam

\begin{tabular}{|c|c|c|c|c|c|c|c|c|c|c|c|c|c|}
\hline & & Febru & $\begin{array}{r}\text { Iary } 16,2 \\
\text { Range } 1\end{array}$ & $\begin{array}{l}007 \mathrm{We} \\
.5 \text { (ns), }\end{array}$ & $\begin{array}{l}\text { t Model } \\
\text { Gain } 2 C\end{array}$ & $\begin{array}{l}\text {, Line } 2 \text { in } \\
0 \text { (dB), Sc }\end{array}$ & $\begin{array}{l}\text { Coal Se } \\
=10418.3\end{array}$ & $\begin{array}{l}\mathrm{am}, \text { File \# } \\
5, \mathrm{Va}=8.75\end{array}$ & $\begin{array}{l}035, X= \\
59(u V),\end{array}$ & $\begin{array}{l}22.5 \\
m=r\end{array}$ & $\begin{array}{l}\text { I), } Y=9 . \\
\text { odel vol }\end{array}$ & (in), & \\
\hline Z (in) & Max & Max & Max & Min & Min & Min & Abs & First & Velocity & $\overline{V m}$ & $\overline{V a-V m}$ & & tion \\
\hline & Count & Sample & Time (ns) & Count & Sample & Time (ns) & & Arrival (ns) & $\mathrm{ft} / \mathrm{ns}$ & uV & $u V$ & $\mathrm{uV} / \mathrm{ft}$ & $d B$ \\
\hline 2 & 2199 & 277 & 8.15 & \begin{tabular}{|l|l|}
-1859 \\
\end{tabular} & 301 & 8.85 & 4058.0 & 5.65 & 3.01 & 0.39 & 8.37 & 4.46 & 14.42 \\
\hline 4 & 3716 & 279 & 8.21 & -2942 & 303 & 8.91 & 6658.0 & 5.71 & 3.04 & 0.64 & 8.12 & 4.33 & 12.13 \\
\hline 6 & 2780 & 279 & 8.21 & -1775 & 302 & 8.88 & 4555.0 & 5.71 & 3.04 & 0.44 & 8.32 & 4.44 & 13.89 \\
\hline 8 & 3438 & 279 & 8.21 & -1957 & 303 & 8.91 & 5395.0 & 5.71 & 3.04 & 0.52 & 8.24 & 4.40 & 13.10 \\
\hline 10 & 3836 & 279 & 8.21 & -2274 & 303 & 8.91 & 6110.0 & 5.71 & 3.04 & 0.59 & 8.17 & 4.36 & 12.52 \\
\hline 12 & 4312 & 280 & 8.23 & -2462 & 308 & 9.06 & 6774.0 & 5.73 & 3.06 & 0.65 & 8.11 & 4.32 & 12.05 \\
\hline 14 & 4897 & 280 & 8.23 & -2824 & 310 & 9.12 & 7721.0 & 5.73 & 3.06 & 0.74 & 8.02 & 4.28 & 11.44 \\
\hline 16 & 4452 & 280 & 8.23 & -2809 & 310 & 9.12 & 7261.0 & 5.73 & 3.06 & 0.70 & 8.06 & 4.30 & 11.73 \\
\hline 18 & 5519 & 279 & 8.21 & -3439 & 303 & 8.91 & 8958.0 & 5.71 & 3.04 & 0.86 & 7.90 & 4.21 & 10.75 \\
\hline 20 & 6324 & 279 & 8.21 & -3937 & 302 & 8.88 & 10261.0 & 5.71 & 3.04 & 0.98 & 7.77 & 4.15 & 10.12 \\
\hline 22 & 5761 & 280 & 8.23 & -3893 & 306 & 9.00 & 9654.0 & 5.73 & 3.06 & 0.93 & 7.83 & 4.18 & 10.41 \\
\hline 24 & 4324 & 280 & 8.23 & -2928 & 304 & 8.94 & 7252.0 & 5.73 & 3.06 & 0.70 & 8.06 & 4.30 & 11.73 \\
\hline 26 & 3632 & 279 & 8.21 & -2140 & 303 & 8.91 & 5772.0 & 5.71 & 3.04 & 0.55 & 8.20 & 4.38 & 12.79 \\
\hline 28 & 3204 & 279 & 8.21 & -2170 & 303 & 8.91 & 5374.0 & 5.71 & 3.04 & 0.52 & 8.24 & 4.40 & 13.12 \\
\hline 30 & 2887 & 279 & 8.21 & -1641 & 257 & 7.56 & 4528.0 & 5.71 & 3.04 & 0.43 & 8.32 & 4.44 & 13.91 \\
\hline 32 & 2487 & 280 & 8.23 & -1369 & 260 & 7.65 & 3856.0 & 5.73 & 3.06 & 0.37 & 8.39 & 4.47 & 14.66 \\
\hline 34 & 2200 & 279 & 8.21 & -2961 & 302 & 8.88 & 5161.0 & 5.71 & 3.04 & 0.50 & 8.26 & 4.41 & 13.31 \\
\hline 36 & 3709 & 277 & 8.15 & -2939 & 303 & 8.91 & 6648.0 & 5.65 & 3.01 & 0.64 & 8.12 & 4.33 & 12.13 \\
\hline 38 & 2780 & 279 & 8.21 & -1775 & 303 & 8.91 & 4555.0 & 5.71 & 3.04 & 0.44 & 8.32 & 4.44 & 13.89 \\
\hline 40 & 3447 & 279 & 8.21 & -1957 & 302 & 8.88 & 5404.0 & 5.71 & 3.04 & 0.52 & 8.24 & 4.39 & 13.09 \\
\hline 42 & 3837 & 279 & 8.21 & -2279 & 303 & 8.91 & 6116.0 & 5.71 & 3.04 & 0.59 & 8.17 & 4.36 & 12.52 \\
\hline 44 & 4299 & 279 & 8.21 & -2477 & 308 & 9.06 & 6776.0 & 5.71 & 3.04 & 0.65 & 8.11 & 4.32 & 12.05 \\
\hline 46 & 4442 & 280 & 8.23 & -2783 & 310 & 9.12 & 7225.0 & 5.73 & 3.06 & 0.69 & 8.07 & 4.30 & 11.75 \\
\hline 48 & 4422 & 280 & 8.23 & -2794 & 310 & 9.12 & 7216.0 & 5.73 & 3.06 & 0.69 & 8.07 & 4.30 & 11.75 \\
\hline 50 & 5519 & 279 & 8.21 & -3439 & 303 & 8.91 & 8958.0 & 5.71 & 3.04 & 0.86 & 7.90 & 4.21 & 10.75 \\
\hline 52 & 6324 & 279 & 8.21 & -3877 & 304 & 8.94 & 10201.0 & 5.71 & 3.04 & 0.98 & 7.78 & 4.15 & 10.15 \\
\hline 54 & 5761 & 280 & 8.23 & -3893 & 304 & 8.94 & 9654.0 & 5.73 & 3.06 & 0.93 & 7.83 & 4.18 & 10.41 \\
\hline 56 & 4324 & 280 & 8.23 & -2928 & 307 & 9.03 & 7252.0 & 5.73 & 3.06 & 0.70 & 8.06 & 4.30 & 11.73 \\
\hline 58 & 3632 & 280 & 8.23 & -2140 & 303 & 8.91 & 5772.0 & 5.73 & 3.06 & 0.55 & 8.20 & 4.38 & 12.79 \\
\hline 60 & 3204 & 279 & 8.21 & -2170 & 257 & 7.56 & 5374.0 & 5.71 & 3.04 & 0.52 & 8.24 & 4.40 & 13.12 \\
\hline 62 & 2887 & 279 & 8.21 & -1641 & 257 & 7.56 & 4528.0 & 5.71 & 3.04 & 0.43 & 8.32 & 4.44 & 13.91 \\
\hline
\end{tabular}


Table 6.13 Reconnaissance survey wet physical model line 1 floor

\begin{tabular}{|c|c|c|c|c|c|c|c|c|c|c|c|c|c|}
\hline \multicolumn{14}{|c|}{$\begin{array}{l}\text { Febuary 16, } 2007 \text { Wet Model, Line } 1 \text { Floor, File \# 1040, X = } 22.5 \text { (in), Y= } 5.125 \text { (in), } \\
\text { Range } 15 \text { (ns), Gain } 20 \text { (dB), Sc=10418.35, Va = 8.759 (uV), Vm = model volts }\end{array}$} \\
\hline$Z$ (in) & Max & Max & Max & Min & Min & Min & Abs & \begin{tabular}{|c|} 
First \\
\end{tabular} & Velocity & $\mathrm{Vm}$ & Va-Vm & \multicolumn{2}{|c|}{ Attentuation } \\
\hline & Count & \begin{tabular}{|l|} 
Sample \\
\end{tabular} & Time (ns) & Count & Sample & Time (ns) & & Arrival (ns) & $\mathrm{ft} / \mathrm{ns}$ & $\mathrm{uV}$ & $\mathrm{uV}$ & $\mathrm{uV} / \mathrm{ft}$ & $\mathrm{db} / \mathrm{ft}$ \\
\hline 2 & 6818 & \begin{tabular}{|l|}
188 \\
\end{tabular} & \begin{tabular}{|l|}
5.53 \\
\end{tabular} & -8734 & 166 & 4.88 & 15552.0 & \begin{tabular}{|c|}
3.03 \\
\end{tabular} & 1.62 & 1.49 & 7.27 & 3.88 & 8.20 \\
\hline 4 & 6889 & 196 & 5.76 & -12873 & 178 & 5.23 & 19762.0 & 3.26 & 1.74 & 1.90 & 6.86 & 3.66 & 7.09 \\
\hline 6 & 4832 & 233 & 6.85 & \begin{tabular}{|l|}
-7390 \\
\end{tabular} & 186 & 5.47 & 12222.0 & 4.35 & 2.32 & 1.17 & 7.59 & 4.05 & 9.31 \\
\hline 8 & 2937 & 238 & 7.00 & -4827 & 188 & 5.53 & 7764.0 & 4.50 & 2.40 & 0.75 & 8.01 & 4.27 & 11.42 \\
\hline 10 & 2005 & 215 & 6.32 & -4276 & 193 & 5.68 & 6281.0 & 3.82 & 2.04 & 0.60 & 8.16 & 4.35 & 12.40 \\
\hline 12 & 2049 & 218 & 6.41 & -4149 & 196 & 5.76 & 6198.0 & 3.91 & 2.09 & 0.59 & 8.16 & 4.35 & 12.46 \\
\hline 14 & 2161 & 255 & 7.50 & -3985 & 196 & 5.76 & 6146.0 & 5.00 & 2.67 & 0.59 & 8.17 & 4.36 & 12.50 \\
\hline 16 & 2015 & 254 & 7.47 & -3812 & 201 & 5.91 & 5827.0 & 4.97 & 2.65 & 0.56 & 8.20 & 4.37 & 12.74 \\
\hline 18 & 2106 & 223 & 6.56 & -4323 & 202 & 5.94 & 6429.0 & 4.06 & 2.16 & 0.62 & 8.14 & 4.34 & 12.29 \\
\hline 20 & 2105 & 223 & 6.56 & -4361 & 202 & 5.94 & 6466.0 & 4.06 & 2.16 & 0.62 & 8.14 & 4.34 & 12.26 \\
\hline 22 & 2473 & 220 & 6.47 & -4478 & 201 & 5.91 & 6951.0 & 3.97 & 2.12 & 0.67 & 8.09 & 4.32 & 11.93 \\
\hline 24 & 2086 & 218 & 6.41 & -4044 & 195 & 5.73 & 6130.0 & 3.91 & 2.09 & 0.59 & 8.17 & 4.36 & 12.51 \\
\hline 26 & 2098 & 216 & 6.35 & -4056 & 195 & 5.73 & 6154.0 & 3.85 & 2.05 & 0.59 & 8.17 & 4.36 & 12.49 \\
\hline 28 & 2098 & 216 & 6.35 & -4053 & 195 & 5.73 & 6151.0 & 3.85 & 2.05 & 0.59 & 8.17 & 4.36 & 12.49 \\
\hline 30 & 1945 & 214 & 6.29 & -3482 & 192 & 5.65 & 5427.0 & 3.79 & 2.02 & 0.52 & 8.24 & 4.39 & 13.07 \\
\hline 32 & 2294 & 211 & 6.21 & -3957 & 189 & 5.56 & 6251.0 & 3.71 & 1.98 & 0.60 & 8.16 & 4.35 & 12.42 \\
\hline 34 & 2723 & 211 & 6.21 & -4449 & 192 & 5.65 & 7172.0 & 3.71 & 1.98 & 0.69 & 8.07 & 4.30 & 11.78 \\
\hline 36 & 2331 & 212 & 6.23 & -3853 & 192 & 5.65 & 6184.0 & 3.73 & 1.99 & 0.59 & 8.17 & 4.35 & 12.47 \\
\hline 38 & 1681 & 216 & 6.35 & -3133 & 195 & 5.73 & 4814.0 & 3.85 & 2.05 & 0.46 & 8.30 & 4.43 & 13.63 \\
\hline 40 & 1342 & 257 & 7.56 & -2775 & 196 & 5.76 & 4117.0 & 5.06 & 2.70 & 0.40 & 8.36 & 4.46 & 14.35 \\
\hline 42 & 1871 & 232 & 6.82 & -3069 & 211 & 6.21 & 4940.0 & 4.32 & 2.31 & 0.47 & 8.28 & 4.42 & 13.51 \\
\hline 44 & 1859 & 232 & 6.82 & -3070 & 211 & 6.21 & 4929.0 & 4.32 & 2.31 & 0.47 & 8.29 & 4.42 & 13.52 \\
\hline 46 & 1849 & 233 & 6.85 & -2961 & 212 & 6.23 & 4810.0 & 4.35 & 2.32 & 0.46 & 8.30 & 4.43 & 13.63 \\
\hline 48 & 1612 & 234 & 6.88 & -2478 & 211 & 6.21 & 4090.0 & 4.38 & 2.34 & 0.39 & 8.37 & 4.46 & 14.38 \\
\hline 50 & 1795 & 233 & 6.85 & -2675 & 211 & 6.21 & 4470.0 & 4.35 & 2.32 & 0.43 & 8.33 & 4.44 & 13.97 \\
\hline 52 & 2555 & 234 & 6.88 & -2736 & 211 & 6.21 & 5291.0 & 4.38 & 2.34 & 0.51 & 8.25 & 4.40 & 13.19 \\
\hline 54 & 3376 & 233 & 6.85 & -2988 & 210 & 6.18 & 6364.0 & 4.35 & 2.32 & 0.61 & 8.15 & 4.35 & 12.34 \\
\hline 56 & 2914 & 236 & 6.94 & -2671 & 211 & 6.21 & 5585.0 & 4.44 & 2.37 & 0.54 & 8.22 & 4.39 & 12.94 \\
\hline 58 & 8726 & 233 & 6.85 & -6312 & 255 & 7.50 & 15038.0 & 4.35 & 2.32 & 1.44 & 7.32 & 3.90 & 8.35 \\
\hline 60 & 8540 & 226 & 6.65 & -5510 & 249 & 7.32 & 14050.0 & 4.15 & 2.21 & 1.35 & 7.41 & 3.95 & 8.67 \\
\hline 62 & 4376 & 219 & 6.44 & -3758 & 242 & 7.12 & 8134.0 & 3.94 & 2.10 & 0.78 & 7.98 & 4.26 & 11.20 \\
\hline
\end{tabular}




\section{CHAPTER 7}

\section{CONCLUSIONS}

The Radio Imaging Method (RIM), which uses electromagnetic wave propagation, was developed about twenty years ago and shows promise in being able to identify geologic anomalies ahead of the longwall face. In coal seams, geologic anomalies can cause difficult mining conditions, unsafe working conditions, and loss of production. These geologic anomalies may be caused from sandstone intrusion, faults, dykes, fracture zones, gas well pipelines, sudden thinning and severe undulation of coal seams. Geologic anomalies affect the EM signal attenuation rate (the rate of reduction of the EM signal strength) and phase angle $(\theta)$ with respect to distance along a transmitting path. From the attenuation rate changes it is possible to generate mapped images such as contour maps and tomographic imaging. It is then possible to see the geologic anomalies within the coal seam prior to mining.

The overall objective of this research was to increase the accuracy of the RIM technology by studying the EM wave properties on a scaled physical model of a longwall panel and quantifying the data collected. The properties of interest were the EM signal attenuation rates caused from interfaces between the roof, seam, floor and objects. This object was accomplished by modifying an off-the-shelf GPR system, performing spatial spreading testing in air, and performing EM reconnaissance testing on a scaled physical model under different moisture conditions, and using signal discrimination.

The GPR system was modified to allow the separation between the Tx and Rx antennas. This separation was necessary since the GPR system works on the reflective principle and uses one antenna that houses both the Tx and Rx antennas. The RIM system works on the penetrative principle with two antennas separated by a distance.

The signal strength measured at the Rx antenna will depend on the relative position of that antenna with respect to the Tx antenna. It should be noted that the signal received at a point (xyz) from the transmitter is weaker than that at the emitting point. The difference in signal strength is due to two parts: the signal spatial spreading and the attenuation by media on the path. After analyzing the data from the spatial spreading testing in air, an understanding was gained on the voltage attenuation rate in the $\mathrm{X}$, $\mathrm{Y}$, and $\mathrm{Z}$ directions in air and an equation was developed.

In the scaled physical model, the geometry of the area being survey was known, locations of geologic anomalies and objects (small metal box, small empty box and solid wood box) were known, the thickness of the roof, coal seam and floor were known, and the contact points of the transmitting and receiving antenna were known. Different ratios of sand, gypsum, and cement were used to build the floor and roof strata. A mixture of coal powder gypsum and iron powder was used to simulate the coal seam. Due to the small size of the physical model, a high-frequency $900 \mathrm{MHz}$ EM signal was used in the model 
testing to ensure the "similarity" between the actual longwall panels and the scaled model. EM reconnaissance surveys of the physical model were performed at different times to gain an understanding of how the moisture content and aging affect the voltage attenuation rate. Signal discrimination techniques were used to obtain the information needed from the EM waveform. Voltage attenuation rates of the EM waveforms in the scaled physical model were determined by taking the difference of the signal strength measured in air and the signal strength measured in the physical model then divided by the distance along the transmitting path. The data is presented in waveforms, graphs, radiation distribution maps, flow chart, data tables, contour images, and individual line scans from both the dry and wet model. These individual line scans are compared to the known geometry and geologic anomalies of the scaled physical model.

From the individual line scans on the physical modeling testing, the drier model roof, coal seam, floor and objects, were easier to identify than in the wet model. The wet model roof, coal seam, floor and objects were identifiable; however, one must know the condition of the physical composition and understand how the moisture traveled through the model. As quantified by the comparisons of data collected from the dry and wet physical model, moisture content plays a significant role in EM waveforms. In an actual RIM survey, knowing the surrounding geological conditions will help improve the data analysis in the post processing and reconstruction phases. Moisture is a problem and careful post processing of the data must be done.

This research can be used to further: define the characteristics of the attenuation rate during an actual longwall panel RIM survey, provide insight on the spatial spreading of the EM signal, provide insight on how moisture content effect the EM signal, provide insight in the design and development for software programs used for post processing, and provide insight in the design and development for software programs used for tomographic reconstruction. The testing procedures and data results are presented and quantified. 


\section{CHAPTER 8}

\section{RECOMMENDATIONS FOR FUTURE RESEARCH}

It is recommended to increase the size of future physical models taking into consideration the wavelength of the EM system. For example, if using a $900 \mathrm{MHz}$ system, one wavelength as determined by Eq. 2.2, is approximately 13.0 inches (using an EM velocity of $3 \times 10^{8} \mathrm{~m} / \mathrm{s}$ ). The minimum width of physical model is recommended to be 2 wavelengths. As seen from these experiments, start scanning at least one wavelength from the edge of the physical model to avoid the edge affects. Another suggestion is to remove the forms that are used during the construction of the physical model. The geologic anomalies should be a minimum of $1 / 4$ wavelength, since this is typically the minimum detectable size. If using a $900 \mathrm{MHz}$ system, it is recommended that the minimum size of the embedded object be a 3.5-inch cube. Placement of the geologic anomalies inside the model should be one wavelength from the outer boundaries of the physical model.

A better method of surveying future physical models is needed. One suggestion, use a device similar to a computer controlled Raster scanner. In an actual longwall EM survey, a robotic device that positions the antenna in the exact locations using laser-surveying techniques is suggested. In addition, it is suggested to set up the survey marking stations every 5 feet in an actual longwall EM survey to increase the resolution of the area survey and to perform 2 EM surveys of the same area for comparison purposes.

It is recommended to develop better software processing methods for data analysis. For example, software processing to handle large quantities of data and software processing for single scan data. Software processing for signal discrimination will be needed to identify the maximum and minimum signal strength of the first reflected pulse. Software processing should be used for signal discrimination to identify first relaxation pulse to determine the first arrival time. Software processing to convert digital data counts into the user-friendly units such as of volts will be needed. The author also suggests software

processing to determine the attenuation rate, taking into consideration the spatial spreading formulae developed, and software processing for tomographic reconstruction.

The moisture content of the material significantly affects the attenuation rate of the EM waveform and signal strength. This study showed that additional research is needed to fully understand the effect of moisture on the EM signal characteristics. One suggestion is to place a scaled physical model in a controlled environmental chamber where the moisture content can be precisely controlled. It is also recommended to determine a non-invasive method to measure the moisture content within the model.

A few suggested future scaled physical model designs are: a model with a rock parting, a model with a fault, and a model with a seam undulation. 


\section{REFERENCES}

1. Boykov N.B., 2006, "Measurements of the Electrical Properties of Coal Measure Rock", Master of Science in Mining Engineering, Thesis, West Virginia University.

2. Cook, J.C., 1960, "Proposed monocycle-pulse VHF RADAR for airborne ice and snow measurements",:AIEE Trans.Commun. and Electron., pp. 588-594.

3. Commonwealth of Pennsylvania, 2002, "Governor's Commission on Abandoned Mine Voids and Mine Safety, Executive Order No. 2002-10”, September 4, pp. 3.

4. GSSI, 2006,Geophysical Survey Systems Inc, http://www.geophysical com

5. Monaghan, W.D., 2003, "Recent National Institute for Occupational Safety and Health Research Using Ground Penetrating RADAR for Detection of Mine Voids", Proceedings of Geophysical Technologies for Detecting Underground Coal Mine Voids, Lexington, KY.

6. Olhoeft, G.R., 1980, "Electrical properties of rocks: in Physical properties rock and minerals", Y.S. Touloukian, W.R. Judd, and R.F. Roy, eds, McGraw-Hill, NY pp.257-330.

7. Olhoeft, G.R., 1981 "Electrical properties of rocks, in Physical Properties of Rocks and Minerals", in Touloukian, Y.S., Judd, W.R., and Roy, R.F., eds.: New York, McGraw-Hill, pp. 257-330.

8. Olhoeft, G.R., 1993, "Velocity, Attenuation, dispersion and diffraction hole-to-hole RADAR processing, in Proceeding of the Fourth Tunnel Detection Symposium on Subsurface Exploration Technology", Colorado School of Mines, Golden, CO, 26-29 April, Miller, R., ed: US Army Belvoir Research, Development and Engineering Center pp. 309-322.

9. Olhoeft, G.R., 2003, “Ground Penetrating Radar, Home Page”, July 5, 2006, http://www.g-pr.com/introduc.htm.

10. Pennsylvania Department of Environmental Protection, 2002, "Report of Commission on Abandoned Mine Voids and Mine Safety”, November 15, pp. 46.

11. Parkhomenko, E, I, 1967, “Electrical Properties of Rocks”, Plenum Press, New York.

12. Reynolds, J., 2004, “An Introduction to Applied and Environmental Geophysics", Willey Pub, West Sussex, England.

13. Roberts, P., 1988, "Electrical and Magnetic Properties of Materials", Artech House, pp. 458.

14. Stillman, D.E., "2006, Electromagnetic Properties of Martian Analog Minerals At RADAR Frequencies and Martian Temperature", Colorado School of Mines, 1500 Illinois St., Golden, CO 80401, Lunar and Planetary Science XXXVII pp.1-2.

15. Stern, W., 1929, "Versuch einer elektrodynamischen Dickenmessung von Gletschereis", Ger. Beitr. zur Geophysik, v.23, pp. 292-333. 


\section{REFERENCES (CONTINUED)}

16. Stern, W., 1930, "Uber Grundlagen, Methodik und bisherige Ergebnisse elektrodynamischer Dickenmessung von Gletschereis", Z. Gletscherkunde, v.15, pp. 24-42.

17. Stolarczyk, L.G. and R.C. Fry, 1990, "Radio Imaging Method (RIM) or Diagnostic Imaging of Anomalous Geologic Structures in Coal Seam Waveguides", SME Transactions, Vol. 288, pp. 1806-1814.

18. UNSW, 2007, "The University New South Wales, Sydney Australia" http://www.phys.unsw.edu.au/jw/dB.html\#definition.

19. Wait, J, 1976, "Note on the theory of transmission of electromagnetic waves in a coal seam", Radio Science, Volume 11, Number 4, April pages 263-265.

20. Wait, J, 1963, "The possibility of guided electromagnetic waves in the earth's crust", IEEE Transactions on Antenna and Propagation, Vol. 11, Issue 3 May, pp. 330-335. 


\section{APPENDIX A: RESULTS FROM SIGNAL STRENGTH REDUCTION AS SPATIAL SPREADING STUDIES}

The first signal strength reduction as spatial spreading testing was performed near the fitness center at West Virginia University in July of 2005. Figure A-1 shows the test arrangement. The persons in this figure are William D. Monaghan (author of this Thesis), Jun Lu, Ph.D. graduate student and Yi Luo, Ph.D. Associate Professor Department of Mining Engineering. Additional testing was performed in August 2005, December 2005 and February 2007. Figure A-2 show the antenna grid array used in these tests.

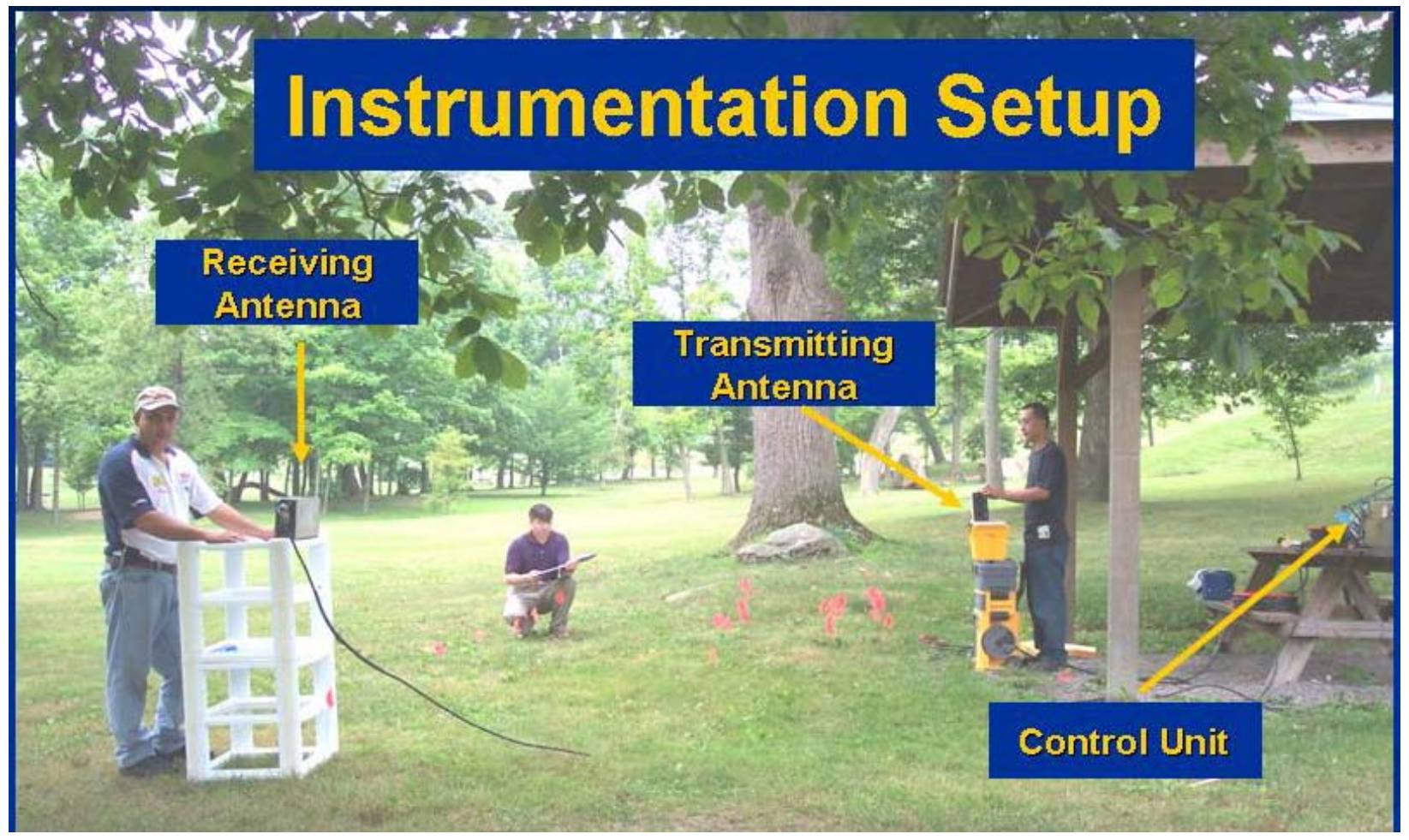

Figure A-1. Initial spatial spreading testing at WVU, July 2005 


\section{Spatial Spreading Testing}

Line 4

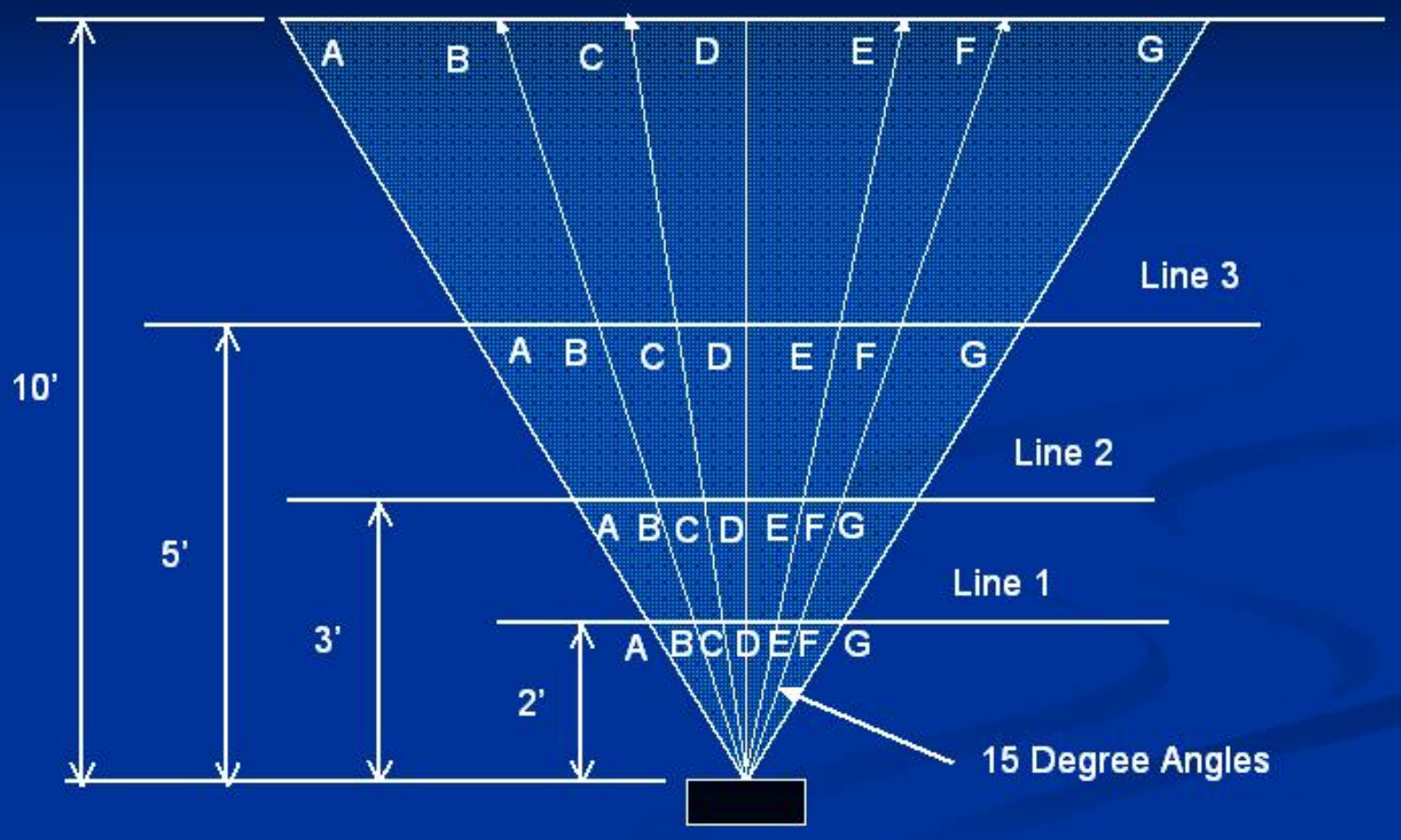

TX Antenna

Figure A-2 Antenna grid array 


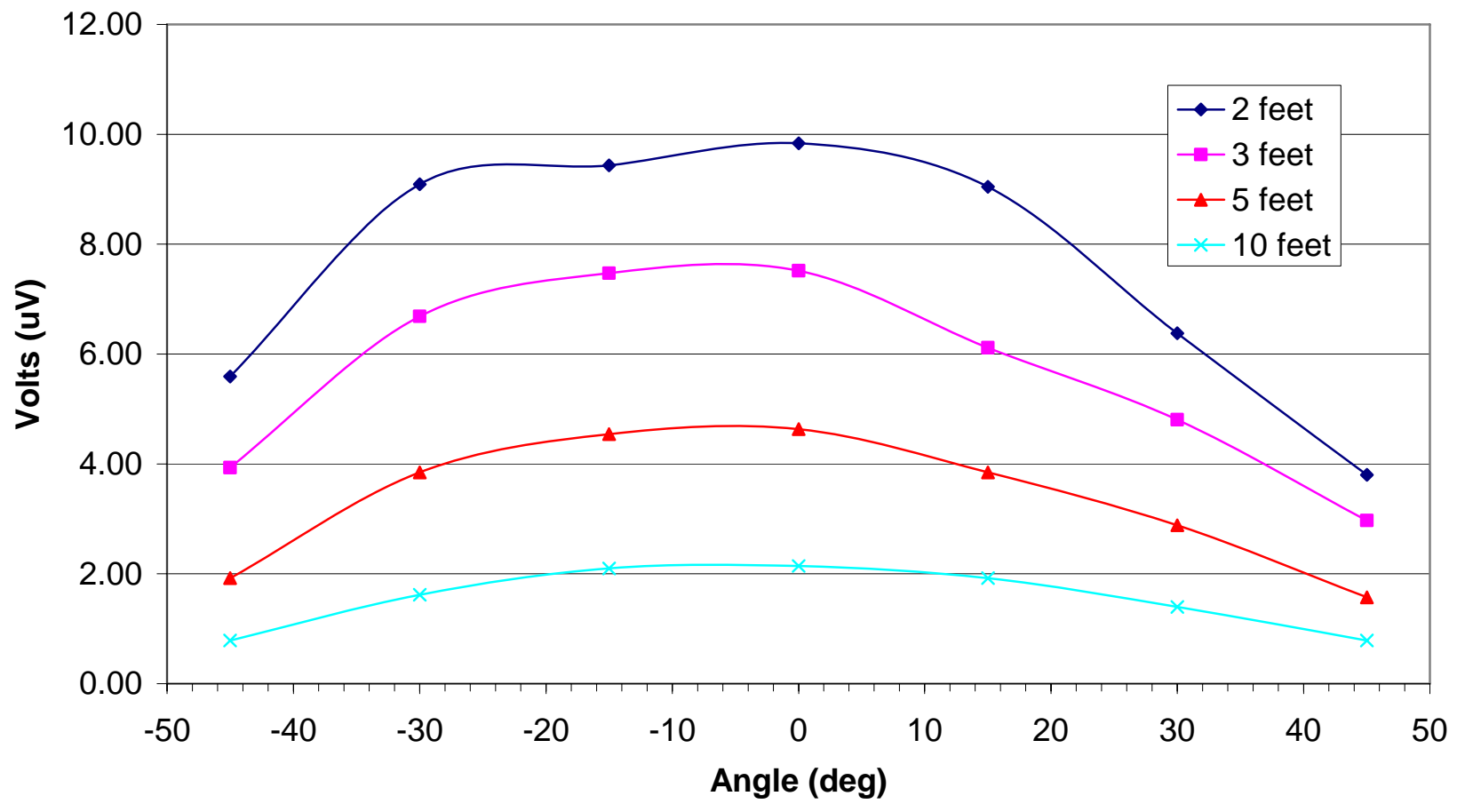

Figure A-3 Spatial spreading air attenuation test 001 - antennas Y position - July 2005

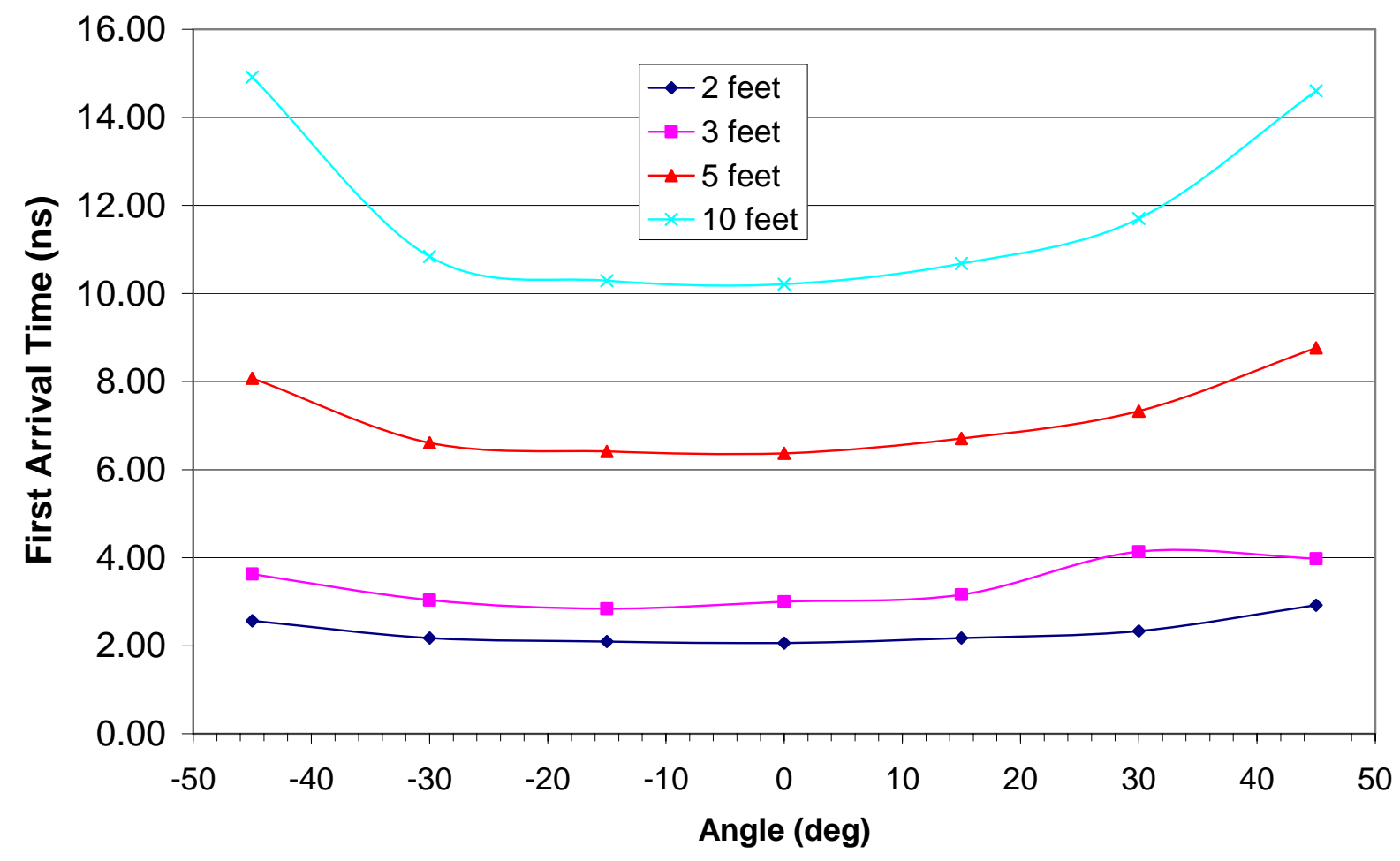

Figure A-4 Spatial spreading air attenuation test 001 - first arrival - antennas Y position - July 2005 


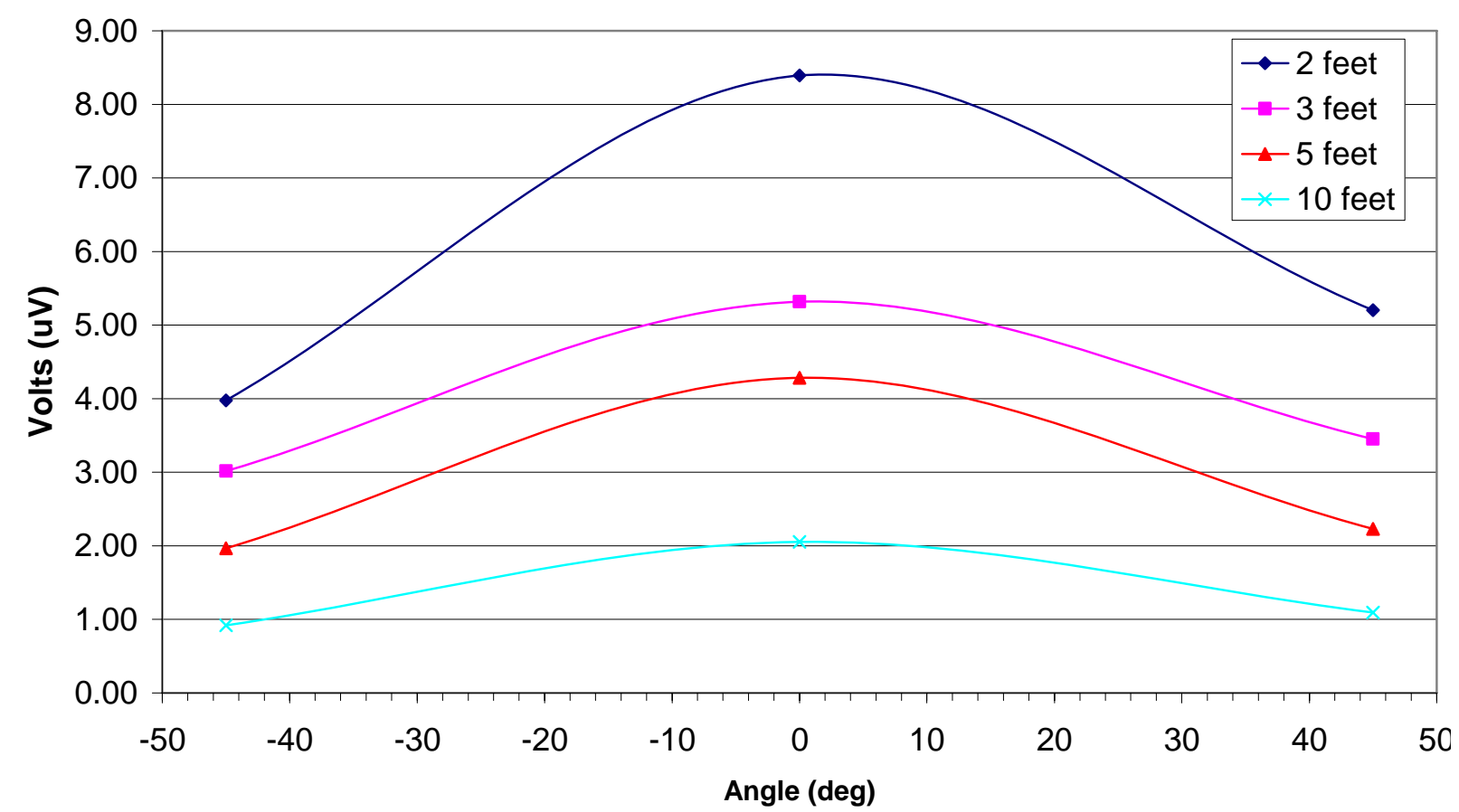

Figure A-5 Spatial spreading air attenuation test 002 - antennas Y position - July 2005

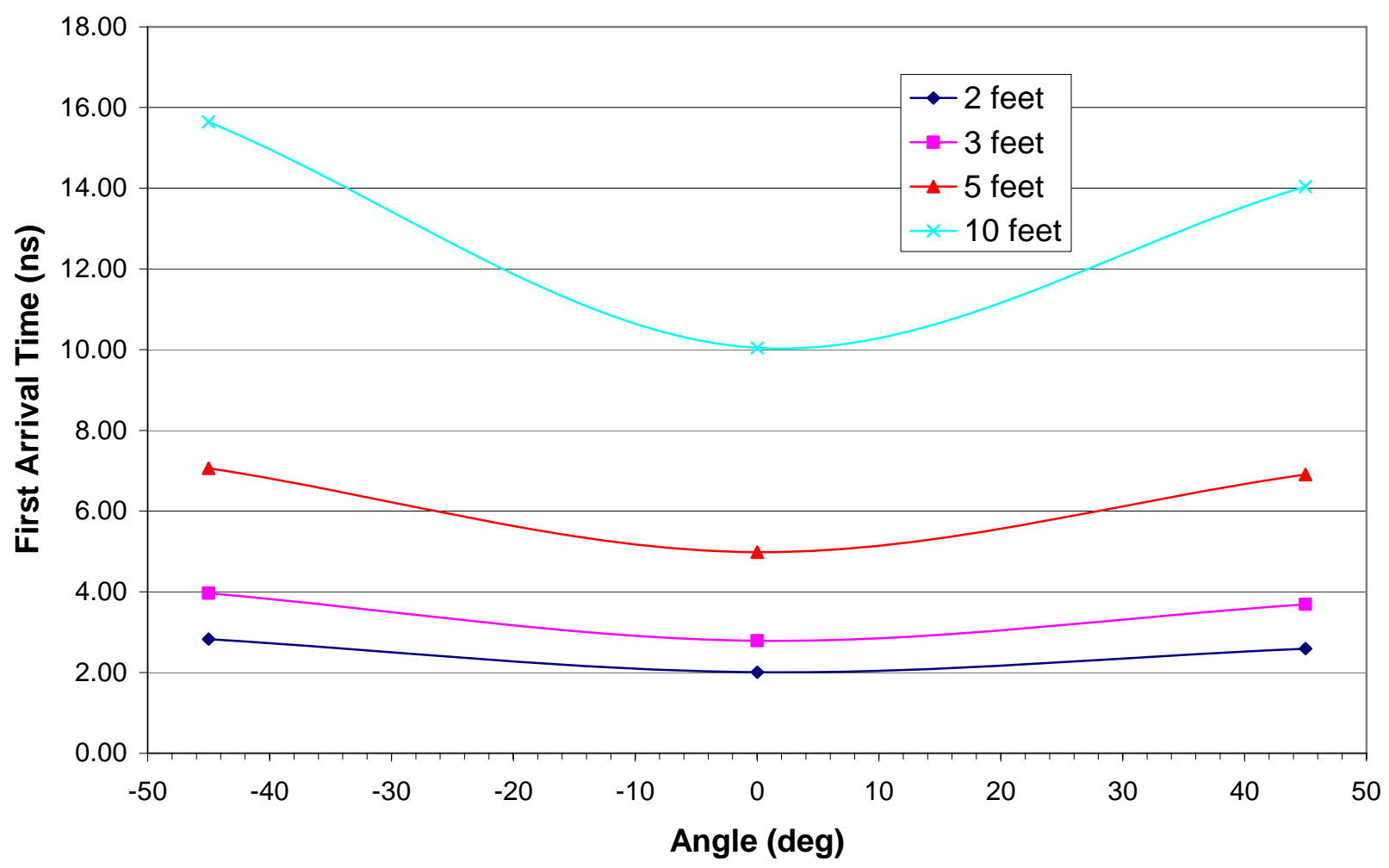

Figure A-6 Spatial spreading air attenuation test 002 - first arrival - antennas Y position - July 2005 


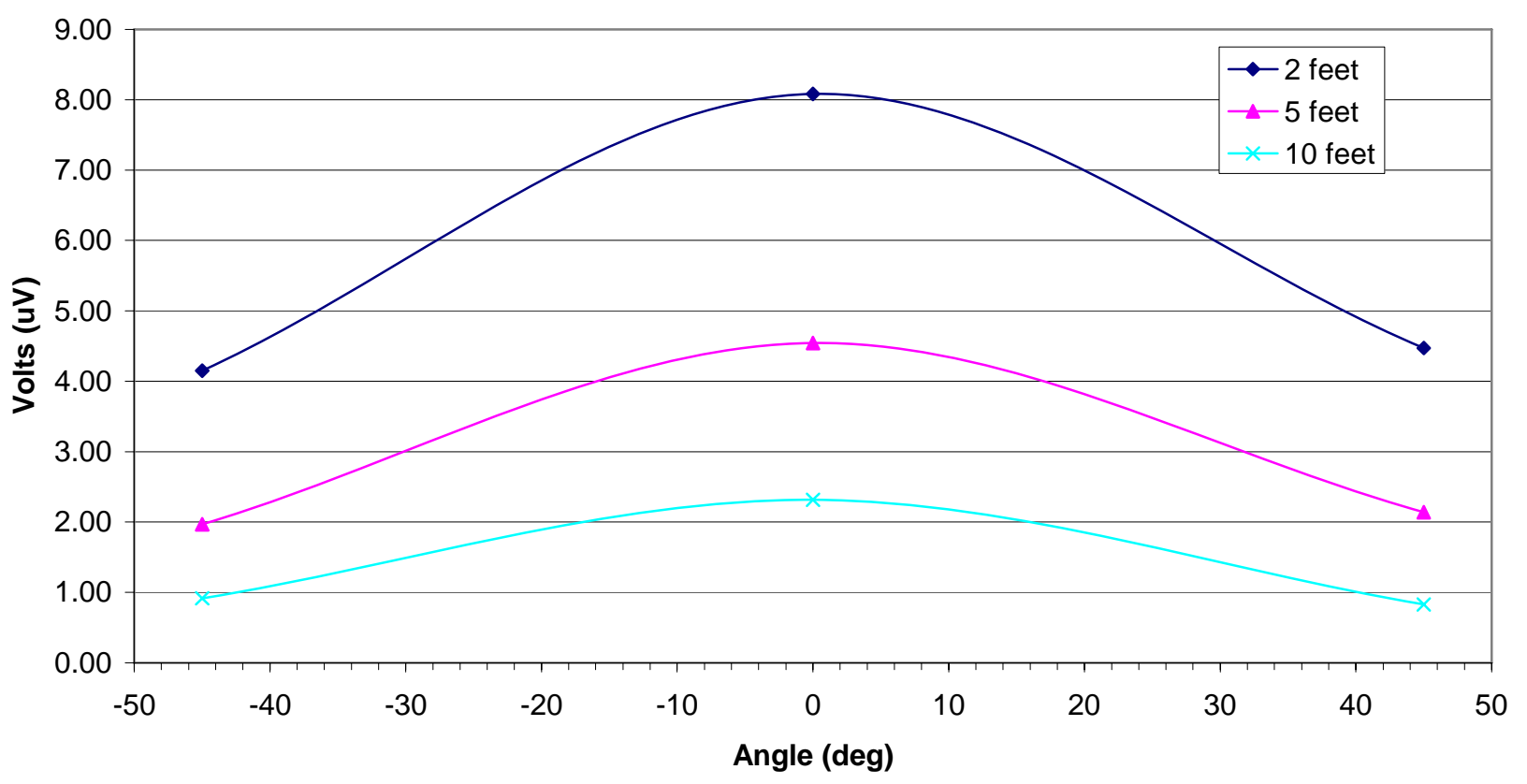

Figure A-7 Spatial spreading air attenuation test 003 - antennas Z position - Aug. 2005

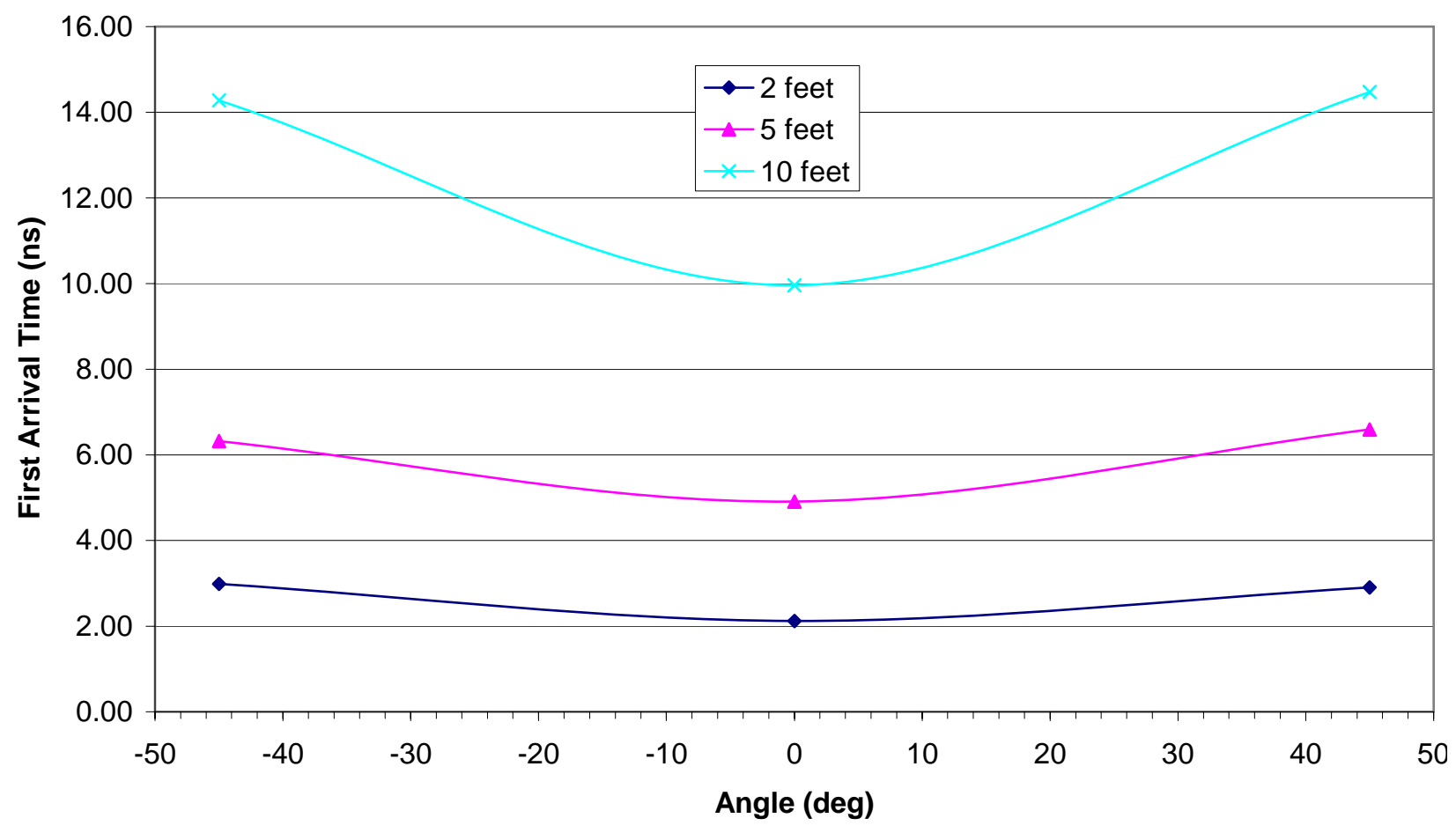

Figure A-8 Spatial spreading air attenuation test 003 - first arrival - antennas Z position - Aug. 2005 
Table A-1 Test 001 spatial spreading air attenuation testing antennas in Y position July 2005

\begin{tabular}{|c|c|c|c|c|c|c|c|c|c|c|c|c|c|c|c|}
\hline \multicolumn{16}{|c|}{ Tx=90 Rx=90, Range 20(ns), Gain 15 (dB), Sv=5.6320, Sc=5858.7 } \\
\hline File \# & Rx Point & Distance, $\mathrm{ft}$ & Angle, deg & Memory & $\operatorname{Max}$ & time & Memory & Min & time & Ave. time & First Inflection & Abs & Velocity & Air Volts & \begin{tabular}{|l|} 
Normalized \\
\end{tabular} \\
\hline & & receiver & & Location & Count & $\mathrm{ns}$ & Location & Count & ns & ns & \begin{tabular}{|l|l} 
Arrival (ns) & \\
\end{tabular} & & $\mathrm{ft} / \mathrm{ns}$ & $(\mathrm{uV})$ & \\
\hline 531 & L1-A & 2.83 & -45 & 91 & 14464 & 3.57 & 105 & -18304 & 4.12 & 3.84 & 2.57 & 32768 & 1.10 & 5.5930 & 0.569 \\
\hline 529 & L1-B & 2.31 & -30 & 81 & 24192 & 3.18 & 96 & -29056 & 3.76 & 3.47 & 2.18 & 53248 & 1.06 & 9.0887 & 0.924 \\
\hline 527 & L1-C & 2.07 & -15 & 79 & 27264 & 3.10 & 93 & -28000 & 3.65 & 3.37 & 2.10 & 55264 & 0.99 & 9.4328 & 0.959 \\
\hline 525 & L1-D & 2.00 & 0 & 78 & 26496 & 3.06 & 92 & -31128 & 3.61 & 3.33 & 2.06 & 57624 & 0.97 & 9.8356 & 1.000 \\
\hline 523 & L1-E & 2.07 & 15 & 81 & 24192 & 3.18 & 94 & -28800 & 3.68 & 3.43 & 2.18 & 52992 & 0.95 & 9.0450 & 0.920 \\
\hline 521 & L1-F & 2.31 & 30 & 85 & 20352 & 3.33 & 100 & \begin{tabular}{|l|}
-17024 \\
\end{tabular} & 3.92 & 3.63 & 2.33 & 37376 & 0.99 & 6.3796 & 0.649 \\
\hline 519 & L1-G & 2.83 & 45 & 100 & 9600 & 3.92 & 115 & $\mid-12672$ & 4.51 & 4.21 & 2.92 & 22272 & 0.97 & 3.8015 & 0.387 \\
\hline 504 & L2-A & 4.24 & -45 & 118 & 10368 & 4.63 & 134 & \begin{tabular}{|l|}
-12672 \\
\end{tabular} & 5.25 & 4.94 & 3.63 & 23040 & 1.17 & 3.9326 & 0.523 \\
\hline 506 & L2-B & 3.46 & -30 & 103 & 17792 & 4.04 & 118 & -21376 & 4.63 & 4.33 & 3.04 & 39168 & 1.14 & 6.6854 & 0.890 \\
\hline 508 & L2-C & 3.11 & -15 & 98 & 19584 & 3.84 & 113 & -24192 & 4.43 & 4.14 & 2.84 & 43776 & 1.09 & 7.4720 & 0.994 \\
\hline 510 & L2-D & 3.00 & 0 & 102 & 19584 & 4.00 & 116 & -24448 & 4.55 & 4.27 & 3.00 & 44032 & 1.00 & 7.5157 & 1.000 \\
\hline 513 & L2-E & 3.11 & 15 & 106 & 16000 & 4.16 & 121 & -19840 & 4.74 & 4.45 & 3.16 & 35840 & 0.99 & 6.1174 & 0.814 \\
\hline 515 & L2-F & 3.46 & 30 & 131 & 15744 & 5.14 & 115 & -12416 & 4.51 & 4.82 & 4.14 & 28160 & 0.84 & 4.8065 & 0.640 \\
\hline 517 & L2-G & 4.24 & 45 & 127 & 10112 & 4.98 & 143 & -7296 & 5.61 & 5.29 & 3.98 & 17408 & 1.07 & 2.9713 & 0.395 \\
\hline 502 & L3-A & 7.07 & -45 & 199 & 5248 & 7.80 & 213 & -6016 & 8.35 & 8.08 & 6.80 & 11264 & 1.04 & 1.9226 & 0.415 \\
\hline 500 & L3-B & 5.77 & -30 & 161 & 12416 & 6.31 & 176 & -10112 & 6.90 & 6.61 & 5.31 & 22528 & 1.09 & 3.8452 & 0.830 \\
\hline 498 & L3-C & 5.18 & -15 & 156 & 14720 & 6.12 & 171 & -11904 & 6.70 & 6.41 & 5.12 & 26624 & 1.01 & 4.5444 & 0.981 \\
\hline 496 & L3-D & 5.00 & 0 & 155 & 12160 & 6.08 & 170 & \begin{tabular}{|c|}
-14976 \\
\end{tabular} & 6.66 & 6.37 & 5.08 & 27136 & 0.99 & 4.6317 & 1.000 \\
\hline 494 & L3-E & 5.18 & 15 & 163 & 9856 & 6.39 & 179 & -12672 & 7.02 & 6.70 & 5.39 & 22528 & 0.96 & 3.8452 & 0.830 \\
\hline 492 & L3-F & 5.77 & 30 & 179 & 7296 & 7.02 & 195 & -9600 & 7.64 & 7.33 & 6.02 & 16896 & 0.96 & 2.8839 & 0.623 \\
\hline 490 & L3-G & 7.07 & 45 & 216 & 3968 & 8.47 & 231 & -5248 & 9.06 & 8.76 & 7.47 & 9216 & 0.95 & 1.5730 & 0.340 \\
\hline 475 & L4-A & 14.14 & -45 & 406 & 2688 & 15.92 & 390 & -1920 & 15.29 & 15.60 & 14.92 & 4608 & 0.95 & 0.7865 & 0.367 \\
\hline 478 & L4-B & 11.55 & -30 & 302 & 4224 & 11.84 & 317 & \begin{tabular}{|c|}
-5248 \\
\end{tabular} & 12.43 & 12.13 & 10.84 & 9472 & 1.07 & 1.6167 & 0.755 \\
\hline 480 & L4-C & 10.35 & -15 & 288 & 5504 & 11.29 & 302 & -6784 & 11.84 & 11.56 & 10.29 & 12288 & 1.01 & 2.0974 & 0.980 \\
\hline 482 & L4-D & 10.00 & 0 & 286 & 5504 & 11.21 & 300 & -7040 & 11.76 & 11.49 & 10.21 & 12544 & 0.98 & 2.1411 & 1.000 \\
\hline 484 & L4-E & 10.35 & 15 & 298 & 4992 & 11.68 & 311 & -6272 & 12.19 & 11.94 & 10.68 & 11264 & 0.97 & 1.9226 & 0.898 \\
\hline 486 & L4-F & 11.55 & 30 & 324 & 3456 & 12.70 & 339 & -4736 & 13.29 & 12.99 & 11.70 & 8192 & 0.99 & 1.3983 & 0.653 \\
\hline 488 & L4-G & 14.14 & 45 & 398 & 1920 & 15.60 & 413 & -2688 & \begin{tabular}{|l|}
16.19 \\
\end{tabular} & 15.90 & 14.60 & 4608 & 0.97 & 0.7865 & 0.367 \\
\hline
\end{tabular}

Table A-2 Test 002 spatial spreading air attenuation testing antennas in Y position July 2005

\begin{tabular}{|c|c|c|c|c|c|c|c|c|c|c|c|c|c|c|c|}
\hline \multicolumn{16}{|c|}{ Tx=60 Rx=60, Range 20(ns), Gain 15 (dB), Sv=5.6320, Sc=5858.7 } \\
\hline File \# & Rx Point & Distance, $\mathrm{ft}$ & Angle, deg & Memory & Max & time & Memory & Min & time & Ave time & First Inflection & Abs & Velocity & Air Volts & Normalized \\
\hline & & receiver & & Location & Count & ns & Location & Count & ns & ns & Arrival (ns) & & $\mathrm{ft} / \mathrm{ns}$ & (uV) & \\
\hline "534 & L1-A & 2.83 & -45 & 103 & 10368 & 4.04 & 118 & -12928 & 4.63 & 2.83 & 2.83 & 23296 & 1.00 & 4.0 & 0.47 \\
\hline 536 & L1-D & 2.00 & 0 & 82 & 21888 & 3.21 & 97 & -27264 & 3.80 & 2.01 & 2.00 & 49152 & 1.00 & 8.4 & 1.00 \\
\hline 538 & L1-G & 2.83 & 45 & 97 & 13440 & 3.80 & 112 & -17024 & 4.39 & 2.60 & 2.59 & 30464 & 1.09 & 5.2 & 0.62 \\
\hline 544 & L1-A & 4.24 & -45 & 132 & 7552 & 5.17 & 148 & -10112 & 5.80 & 3.99 & 3.96 & 17664 & 1.07 & 3.0 & 0.57 \\
\hline 542 & L1-D & 3.00 & 0 & 102 & 13888 & 4.00 & 117 & \begin{tabular}{|l|}
-17264 \\
\end{tabular} & 4.59 & 2.79 & 2.79 & 31152 & 1.08 & 5.3 & 1.00 \\
\hline 540 & L1-G & 4.24 & 45 & 125 & 8832 & 4.90 & 140 & -11392 & 5.49 & 3.69 & 3.69 & 20224 & 1.15 & 3.5 & 0.65 \\
\hline 546 & L1-A & 7.07 & -45 & 211 & 4992 & 8.27 & 226 & \begin{tabular}{|l|}
-6528 \\
\end{tabular} & 8.86 & 7.07 & 7.06 & 11520 & 1.00 & 2.0 & 0.46 \\
\hline 548 & L1-D & 5.00 & 0 & 158 & 11136 & 6.19 & 173 & -13952 & 6.78 & 4.99 & 4.98 & 25088 & 1.00 & 4.3 & 1.00 \\
\hline 550 & L1-G & 7.07 & 45 & 207 & 5760 & 8.11 & 222 & \begin{tabular}{|l|}
-7296 \\
\end{tabular} & 8.70 & 6.91 & 6.90 & 13056 & 1.02 & 2.2 & 0.52 \\
\hline 556 & L1-A & 14.14 & -45 & 430 & 2432 & 16.86 & 411 & -2944 & 16.11 & 14.98 & 15.65 & 5376 & 0.90 & 0.9 & 0.45 \\
\hline 554 & L1-D & 10.00 & 0 & 287 & 5248 & \begin{tabular}{|l|}
11.25 \\
\end{tabular} & 302 & -6784 & 11.84 & 10.04 & 10.04 & 12032 & 1.00 & 2.1 & 1.00 \\
\hline 552 & L1-G & 14.14 & 45 & 389 & 2688 & \begin{tabular}{|l|}
15.25 \\
\end{tabular} & 405 & -3712 & 15.88 & 14.06 & 14.04 & 6400 & 1.01 & 1.1 & 0.53 \\
\hline
\end{tabular}

Table A-3 Test 003 spatial spreading air attenuation testing antennas-Z position Aug. 2005

\begin{tabular}{|c|c|c|c|c|c|c|c|c|c|c|c|c|c|c|c|}
\hline \multicolumn{16}{|c|}{ Tx=60 Rx=60, Range 20(ns), Gain 15 (dB), Sv=5.6320, Sc=5858.7 } \\
\hline File \# & Rx Point & Distance, $\mathrm{ft}$ & Angle, deg & Memory & Max & time & Memory & Min & time & Ave. time & First Inflection & Abs & Velocity & Air Volts & Normalized \\
\hline & & receiver & & Location & Count & $\mathrm{ns}$ & Location & Count & ns & ns & Arrival (ns) & & $\mathrm{ft} / \mathrm{ns}$ & $(\mathrm{uV})$ & \\
\hline "652 & L1-A & 2.83 & -45 & 110 & 14464 & $\begin{array}{l}4.31 \\
\end{array}$ & $\begin{array}{l}106 \\
\end{array}$ & $\begin{array}{l}-9856 \\
\end{array}$ & 4.16 & 4.23 & 2.99 & 24320 & 0.95 & 4.2 & 0.51 \\
\hline 651 & L1-D & 2.00 & 0 & 98 & 26240 & 3.84 & 84 & -21120 & 3.29 & 3.57 & 2.12 & 47360 & 0.94 & 8.1 & 1.00 \\
\hline 650 & L1-G & 2.83 & 45 & 119 & \begin{tabular}{|l|}
16048 \\
\end{tabular} & 4.66 & 104 & 10160 & 4.08 & 4.37 & 2.91 & 26208 & 0.97 & 4.5 & 0.55 \\
\hline 649 & L2-A & 3.00 & 0 & 120 & 17216 & 4.70 & 105 & -13120 & 4.12 & 4.41 & 2.95 & 30336 & 1.02 & 5.2 & 1.00 \\
\hline 646 & L3-A & 7.07 & -45 & 206 & 6528 & 8.08 & 191 & \begin{tabular}{|l|}
-4992 \\
\end{tabular} & 7.49 & 7.78 & 6.32 & 11520 & 0.47 & 2.0 & 0.43 \\
\hline 647 & L3-B & 5.00 & 0 & 169 & 14208 & 6.62 & 155 & -12416 & 6.08 & 6.35 & 4.91 & 26624 & 1.02 & 4.5 & 1.00 \\
\hline 648 & L3-C & 7.07 & 45 & 213 & 6912 & 8.35 & 198 & -5632 & 7.76 & 8.06 & 6.59 & 12544 & 1.07 & 2.1 & 0.47 \\
\hline 644 & L4-A & 14.14 & -45 & 408 & 2944 & 15.99 & 394 & -2432 & 15.44 & 15.72 & 14.27 & 5376 & 0.99 & 0.9 & 0.40 \\
\hline 643 & L4-D & 10.00 & 0 & 299 & 7552 & 11.72 & 284 & -6016 & 11.13 & 11.43 & 9.96 & 13568 & 1.00 & 2.3 & 1.00 \\
\hline 645 & L1-G & 14.14 & 45 & 414 & 2688 & 16.23 & 399 & -2176 & \begin{tabular}{|l|}
15.64 \\
\end{tabular} & 15.93 & 14.47 & 4864 & 0.98 & 0.8 & 0.36 \\
\hline
\end{tabular}




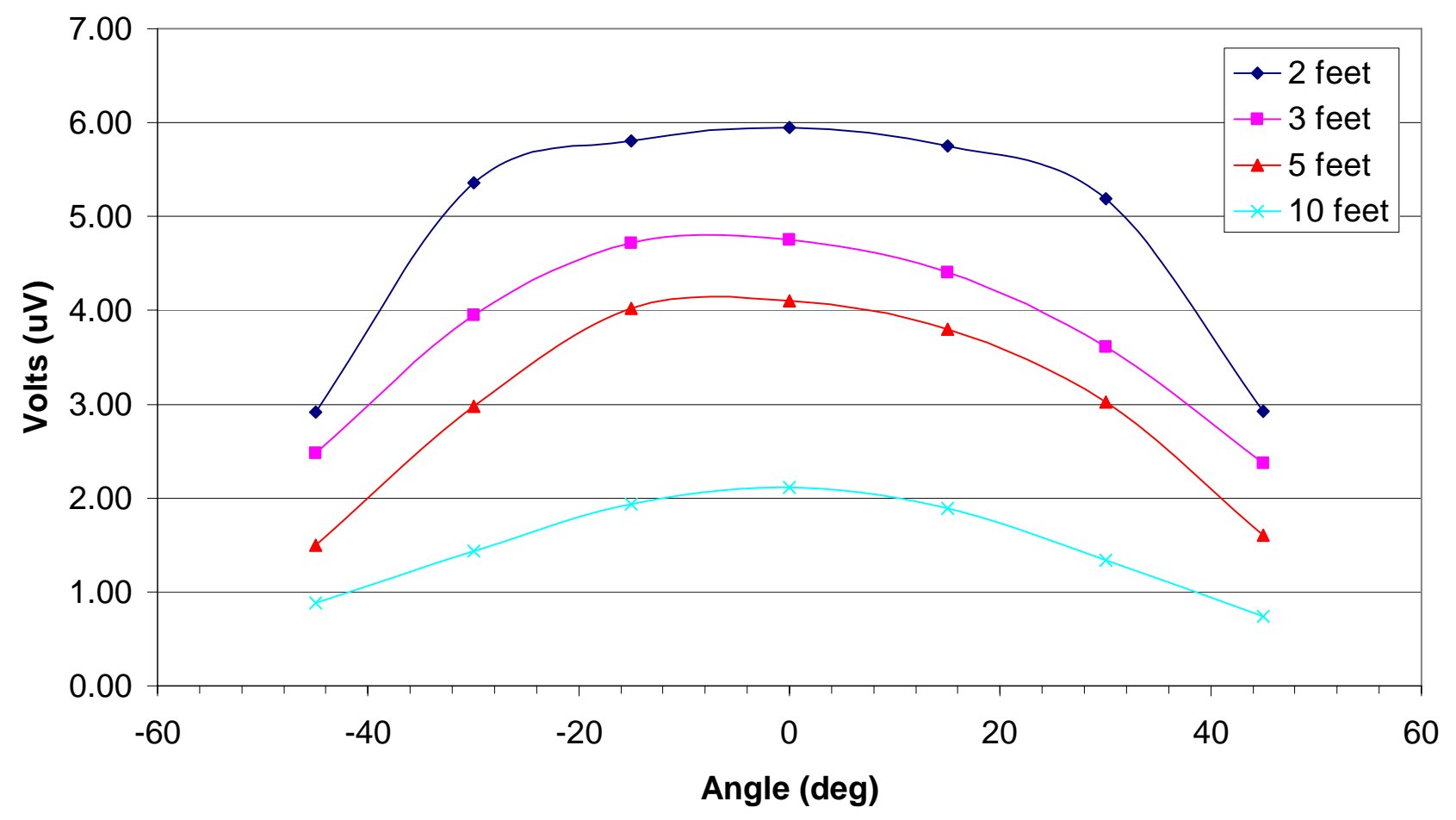

Figure A-9 Spatial spreading air attenuation test 004 - antenna in Y position - Dec. 2005

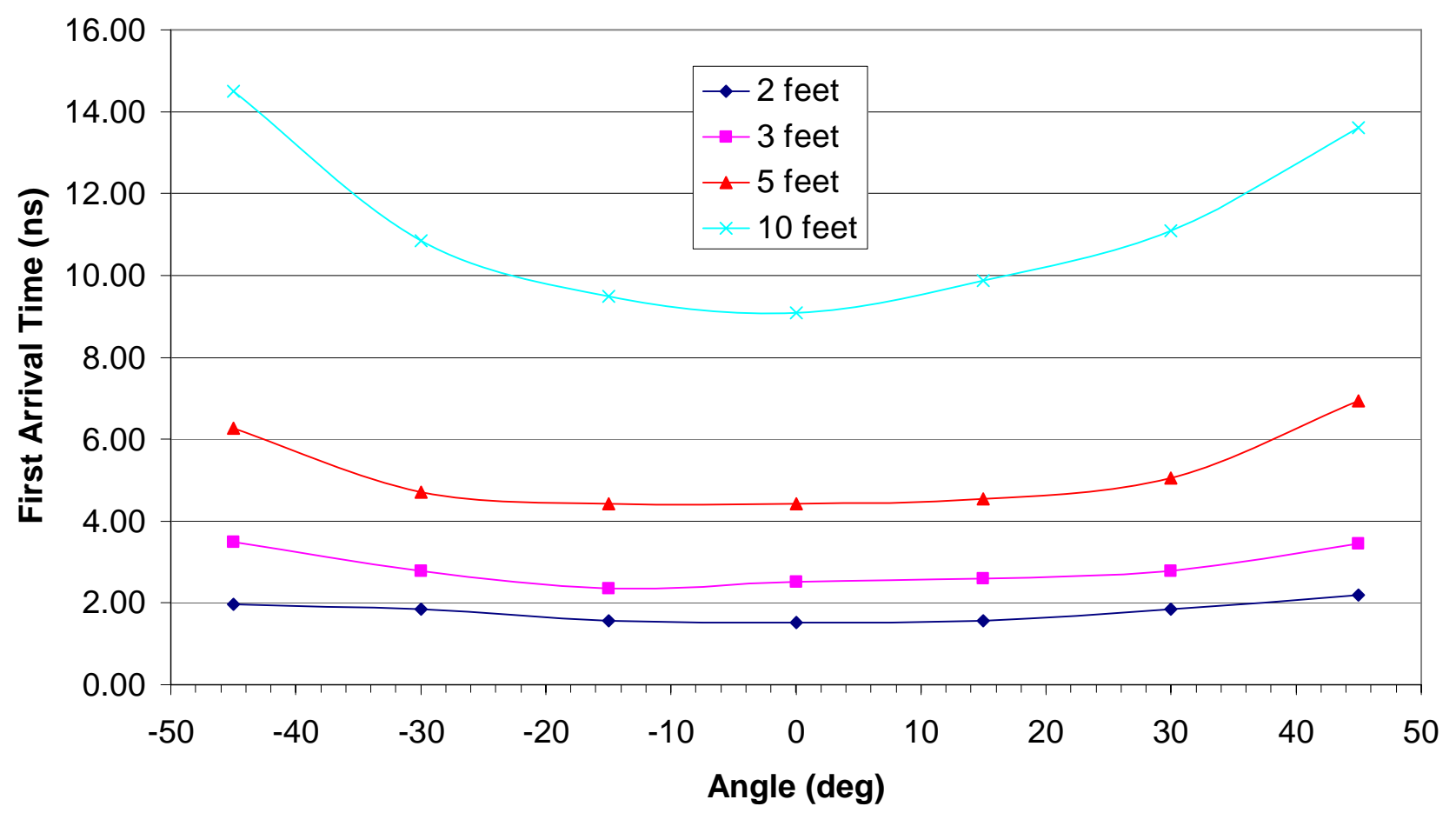

Figure A-10 Spatial spreading air attenuation test 004 - first arrival time - antenna in Y position Dec. 2005 


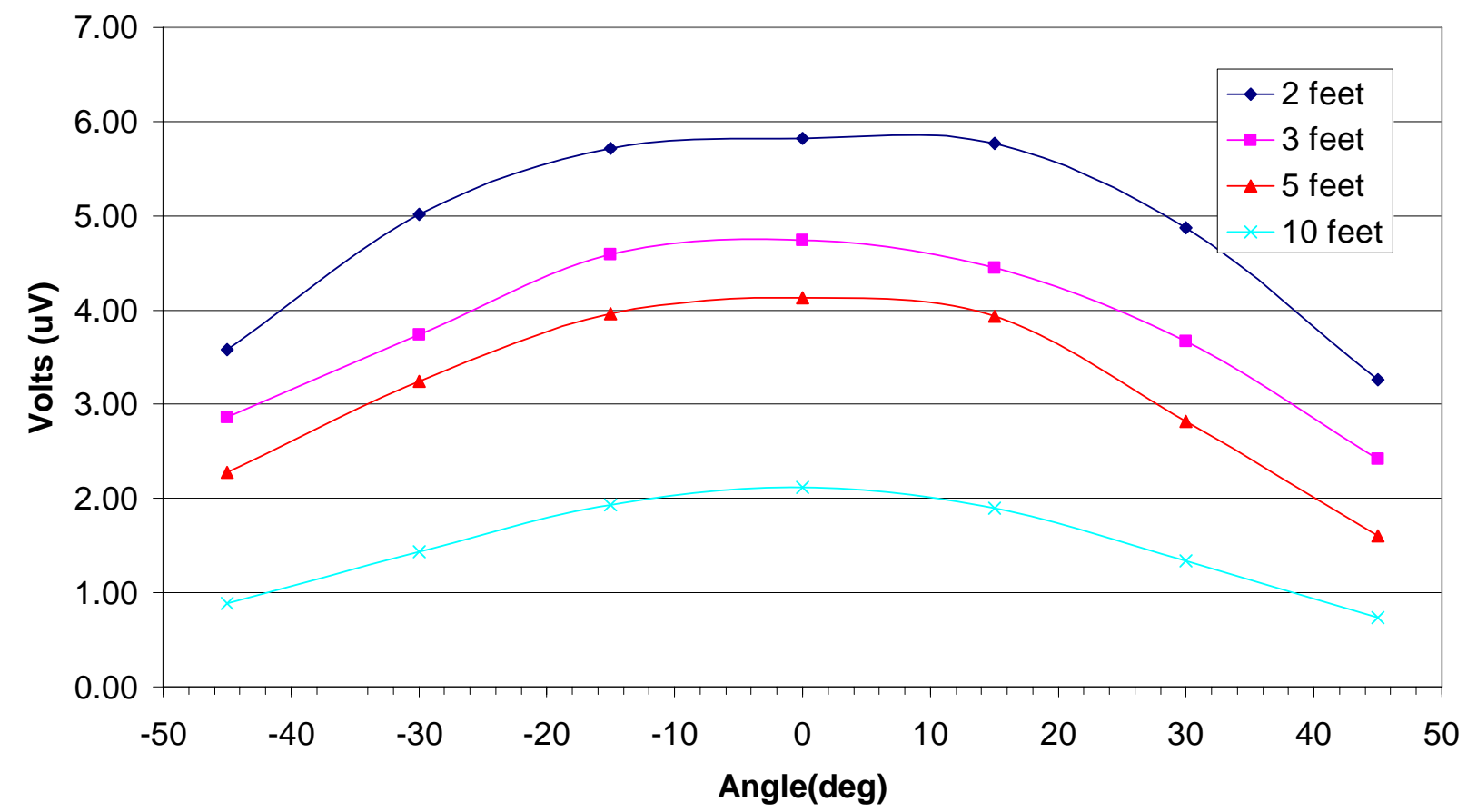

Figure A-11 Spatial spreading air attenuation test 004 - antenna in Z position - Dec. 2005

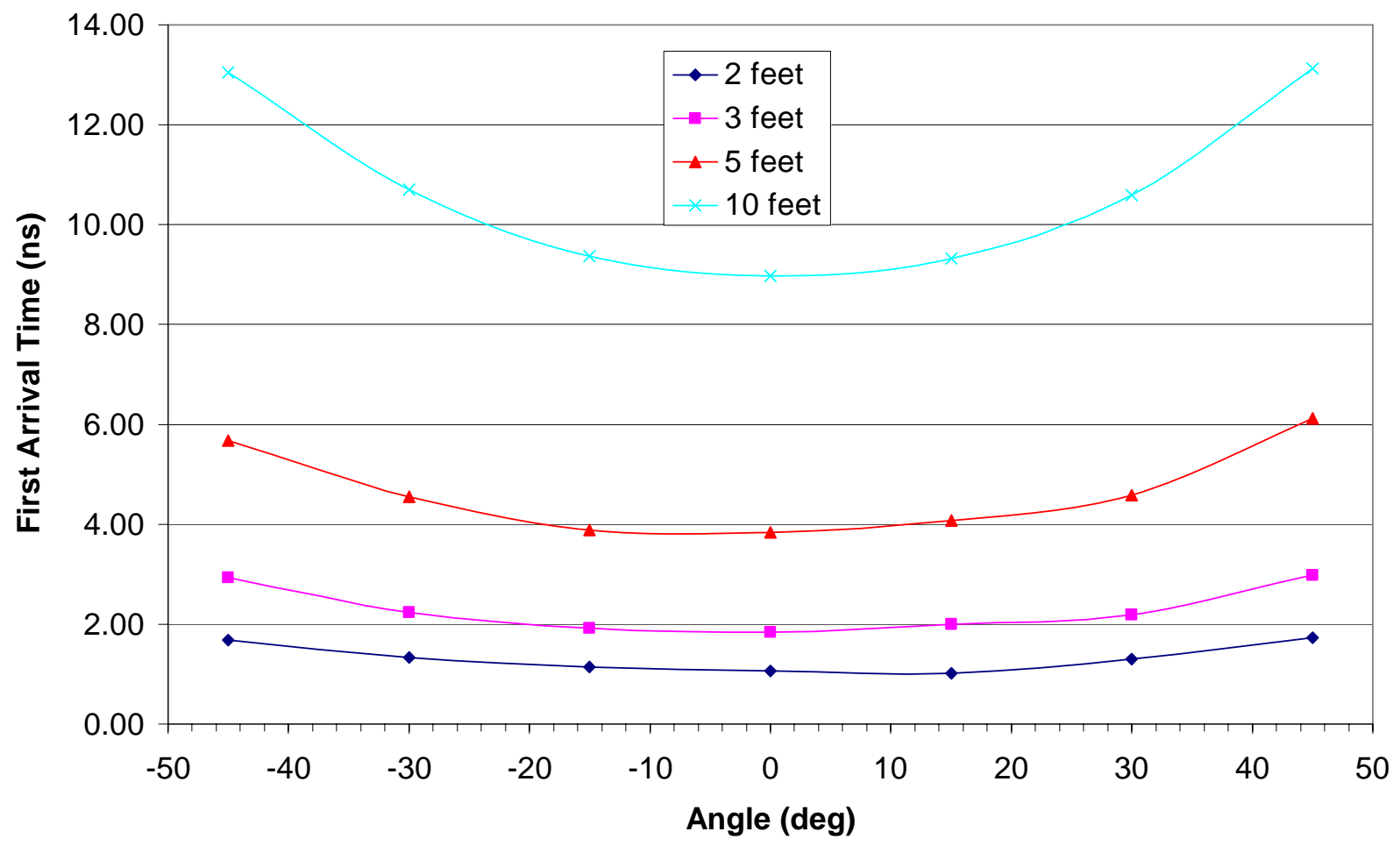

Figure A-12 Spatial spreading air attenuation test 004 - first arrival time - antenna in Z position -

Dec. 2005 
Table A-4 Test 004 spatial spreading air attenuation testing antennas in Y position Dec. 2005

\begin{tabular}{|c|c|c|c|c|c|c|c|c|c|c|c|c|c|c|c|}
\hline \multirow[b]{2}{*}{ File } & \multicolumn{15}{|c|}{ Tx=90 Rx=90, Range 20(ns), Gain 25 (dB), Sv=10.0152, Sc=10418.3, Offset=-1.94(ns), Dec 17, 2005} \\
\hline & Rx Point & Distance, $\mathrm{ft}$ & Angle, deg & Memory & Max & time & Memory & Min & time & Ave. time & Abs & First Arrival & Velocity & Air Volts & Normalized \\
\hline & & \begin{tabular}{|l|} 
receiver \\
\end{tabular} & & Location & Count & $\mathrm{ns}$ & Location & Count & $\mathrm{ns}$ & \begin{tabular}{|l|}
$\mathrm{ns}$ \\
\end{tabular} & & $\mathrm{ns}$ & $\mathrm{ft} / \mathrm{ns}$ & $(\mathrm{uV})$ & \\
\hline 739 & L1-A & 2.83 & -45 & 50 & 12794 & 1.96 & 2063 & -17627 & 2.47 & 2.21 & 30421 & 22.90 & $\bar{~} 0.98$ & 2.9200 & 0.49 \\
\hline 741 & L1-B & 2.31 & -30 & 47 & 30825 & 1.84 & 33 & -25050 & 1.29 & 1.57 & 55875 & 2.23 & 1.03 & 5.3632 & 0.90 \\
\hline 743 & L1-C & 2.07 & -15 & 40 & 32767 & 1.57 & 28 & -27715 & \begin{tabular}{|l|}
1.10 \\
\end{tabular} & 1.33 & 60482 & 2.04 & 1.02 & 5.8054 & 0.98 \\
\hline 745 & L1-D & 2.00 & 0 & 39 & 32767 & 1.53 & 27 & $\mid-29206$ & 1.06 & 1.29 & 61973 & 2.00 & 1.00 & 5.9485 & 1.00 \\
\hline 747 & L1-E & 2.07 & 15 & 40 & 32767 & 1.57 & 27 & $\mid-27143$ & 1.06 & 1.31 & 59910 & 2.00 & 1.04 & 5.7505 & 0.97 \\
\hline 749 & L1-F & 2.31 & 30 & 47 & 30408 & 1.84 & 34 & -23672 & 1.33 & 1.59 & 54080 & 2.27 & 1.02 & 5.1909 & 0.87 \\
\hline 751 & L1-G & 2.83 & 45 & 56 & 17465 & 2.20 & 42 & -13023 & 1.65 & 1.92 & 30488 & 2.59 & 1.09 & 2.9264 & 0.49 \\
\hline 724 & L2-A & 4.24 & -45 & 89 & 15175 & 3.49 & 103 & $\mid-10667$ & \begin{tabular}{|l|}
4.04 \\
\end{tabular} & 3.76 & 25842 & 4.98 & 0.85 & 2.4804 & 0.52 \\
\hline 726 & L2-B & 3.46 & -30 & 71 & 24015 & 2.78 & 57 & $\mid-17178$ & \begin{tabular}{|l|}
2.23 \\
\end{tabular} & 2.51 & 41193 & 3.17 & 1.09 & 3.9539 & 0.83 \\
\hline 728 & L2-C & 3.11 & -15 & 60 & 28071 & 2.35 & 47 & -21062 & \begin{tabular}{|l|}
1.84 \\
\end{tabular} & 2.10 & 49133 & 2.78 & 1.12 & 4.7160 & 0.99 \\
\hline 730 & L2-D & 3.00 & 0 & 64 & 28807 & 2.51 & 51 & \begin{tabular}{|l|}
-20738 \\
\end{tabular} & 2.00 & 2.25 & 49545 & 2.94 & 1.02 & 4.7556 & 1.00 \\
\hline 732 & L2-E & 3.11 & 15 & 66 & 26497 & 2.59 & 53 & \begin{tabular}{|c|}
-19408 \\
\end{tabular} & 2.08 & 2.33 & 45905 & 3.02 & 1.03 & 4.4062 & 0.93 \\
\hline 734 & L2-F & 3.46 & 30 & 71 & 21543 & 2.78 & 57 & $\mid-16079$ & 2.23 & 2.51 & 37622 & 3.17 & 1.09 & 3.6111 & 0.76 \\
\hline 736 & L2-G & 4.24 & 45 & 88 & 14592 & 3.45 & 103 & $\mid$\begin{tabular}{|l|}
-10151 \\
\end{tabular} & \begin{tabular}{|l|}
4.04 \\
\end{tabular} & 3.74 & 24743 & 4.98 & 0.85 & 2.3750 & 0.50 \\
\hline 710 & L3-A & 7.07 & -45 & 160 & 13094 & \begin{tabular}{|l|}
6.27 \\
\end{tabular} & 147 & \begin{tabular}{|l|}
-2503 \\
\end{tabular} & 5.76 & 6.02 & 15597 & 6.70 & 1.05 & 1.4971 & 0.36 \\
\hline 712 & L3-B & 5.77 & -30 & 120 & 13531 & 4.70 & 133 & $\mid-17471$ & 5.21 & 4.96 & 31002 & 6.15 & 0.94 & 2.9757 & 0.73 \\
\hline 714 & L3-C & 5.18 & -15 & 113 & 23928 & 4.43 & 100 & -18008 & 3.92 & 4.17 & 41936 & 4.86 & 1.07 & 4.0252 & 0.98 \\
\hline 716 & L3-D & 5.00 & 0 & 113 & 24358 & 4.43 & 99 & $\mid-18381$ & 3.88 & 4.16 & 42739 & 4.82 & 1.04 & 4.1023 & 1.00 \\
\hline 718 & L3-E & 5.18 & 15 & 116 & 22273 & 4.55 & 103 & $\mid-17272$ & \begin{tabular}{|l|}
4.04 \\
\end{tabular} & 4.29 & 39545 & 4.98 & 1.04 & 3.7957 & 0.93 \\
\hline 720 & L3-F & 5.77 & 30 & 129 & 17610 & 5.06 & 116 & $\mid-13912$ & 4.55 & 4.80 & 31522 & 5.49 & 1.05 & 3.0256 & 0.74 \\
\hline 722 & L3-G & 7.07 & 45 & 177 & 9675 & 6.94 & 163 & \begin{tabular}{|l|}
-7079 \\
\end{tabular} & \begin{tabular}{|l|}
6.39 \\
\end{tabular} & 6.66 & 16754 & 7.33 & 0.96 & 1.6081 & 0.39 \\
\hline 696 & L4-A & 14.14 & -45 & 370 & 3875 & 14.50 & 355 & -5345 & 13.92 & 14.21 & 9220 & 14.86 & 0.95 & 0.8850 & 0.42 \\
\hline 698 & L4-B & 11.55 & -30 & 277 & 6073 & 10.86 & 291 & \begin{tabular}{|l|}
-8888 \\
\end{tabular} & 11.41 & 11.13 & 14961 & 12.35 & 0.94 & 1.4360 & 0.68 \\
\hline 700 & L4-C & 10.35 & -15 & 242 & 8250 & 9.49 & 257 & -11866 & 10.07 & 9.78 & 20116 & 11.01 & 0.94 & 1.9308 & 0.91 \\
\hline 702 & L4-D & 10.00 & 0 & 232 & 8764 & 9.09 & 246 & -13257 & \begin{tabular}{|l|}
9.64 \\
\end{tabular} & 9.37 & 22021 & 10.58 & 0.94 & 2.1137 & 1.00 \\
\hline 704 & L4-E & 10.35 & 15 & 252 & 11293 & \begin{tabular}{|l|}
9.88 \\
\end{tabular} & 238 & \begin{tabular}{|l|}
-8437 \\
\end{tabular} & \begin{tabular}{|l|}
9.33 \\
\end{tabular} & 9.60 & 19730 & 10.27 & 1.01 & 1.8938 & 0.90 \\
\hline 706 & L4-F & 11.55 & 30 & 283 & 8021 & 11.09 & 269 & -5874 & 10.54 & 10.82 & 13895 & 11.48 & 1.01 & 1.3337 & 0.63 \\
\hline 708 & L4-G & 14.14 & 45 & 347 & 4352 & 13.60 & 365 & -3343 & 14.31 & 13.96 & 7695 & 15.25 & 0.93 & 0.7386 & 0.35 \\
\hline
\end{tabular}

Table A-5 Test 004 spatial spreading air attenuation testing antennas in Z position Dec. 2005

\begin{tabular}{|c|c|c|c|c|c|c|c|c|c|c|c|c|c|c|c|}
\hline \multirow[b]{2}{*}{ File } & \multicolumn{15}{|c|}{ Tx=60 Rx=60, Range 20(ns), Gain 20 (dB), Sv=5.6320, Sc=5858.7, Offset=-1.94(ns), Dec 17, 2005} \\
\hline & Rx Point & Distance, $\mathrm{ft}$ & Angle, deg & Memory & Max & time & Memory & Min & \begin{tabular}{|l|l|l} 
time \\
\end{tabular} & Ave. time & Abs & First Arrival & Velocity & Air Volts & Normalized \\
\hline & & receiver & & Location & Count & ns & Location & Count & \begin{tabular}{l|l}
$\mathrm{ns}$ \\
\end{tabular} & ns & & ns & $\mathrm{ft} / \mathrm{ns}$ & $(\mathrm{uV})$ & \\
\hline 740 & L1-A & 2.83 & -45 & 43 & 16018 & 1.69 & 57 & -21302 & 2.23 & 1.96 & 37320 & 2.63 & 1.08 & 3.5822 & 0.62 \\
\hline 742 & L1-B & 2.31 & -30 & 34 & 23135 & 1.33 & 48 & -29091 & \begin{tabular}{|l|}
1.88 \\
\end{tabular} & 1.61 & 52226 & 2.27 & 1.02 & 5.0129 & 0.86 \\
\hline 744 & L1-C & 2.07 & -15 & 29 & 26794 & 1.14 & 41 & -32768 & 1.61 & 1.37 & 59562 & 2.08 & 1.00 & 5.7171 & 0.98 \\
\hline 746 & L1-D & 2.00 & 0 & 27 & 27852 & 1.06 & 39 & -32768 & 1.53 & 1.29 & 60620 & 2.00 & 1.00 & 5.8186 & 1.00 \\
\hline 748 & L1-E & 2.07 & 15 & 26 & 27331 & 1.02 & 38 & -32768 & 1.49 & 1.25 & 60099 & 1.96 & 1.06 & 5.7686 & 0.99 \\
\hline 750 & L1-F & 2.31 & 30 & 33 & 22030 & 1.29 & 47 & -28765 & 1.84 & 1.57 & 50795 & 2.23 & 1.03 & 4.8756 & 0.84 \\
\hline 752 & L1-G & 2.83 & 45 & 44 & 14730 & 1.72 & 59 & -19254 & 2.31 & 2.02 & 33984 & 2.66 & 1.06 & 3.2620 & 0.56 \\
\hline 725 & L2-A & 4.24 & -45 & 75 & 11808 & 2.94 & 90 & -18021 & 3.53 & 3.23 & 29829 & 3.88 & 1.09 & 2.8631 & 0.60 \\
\hline 727 & L2-B & 3.46 & -30 & 57 & 16366 & 2.23 & 71 & -22624 & 2.78 & 2.51 & 38990 & 3.17 & 1.09 & 3.7425 & 0.79 \\
\hline 729 & L2-C & 3.11 & -15 & 49 & 20481 & 1.92 & 63 & -27368 & 2.47 & 2.20 & 47849 & 2.86 & 1.09 & 4.5928 & 0.97 \\
\hline 731 & L2-D & 3.00 & 0 & 47 & 21391 & 1.84 & 61 & -28009 & 2.39 & 2.12 & 49400 & 2.78 & 1.08 & 4.7417 & 1.00 \\
\hline 733 & L2-E & 3.11 & 15 & 51 & 19667 & 2.00 & 65 & -26693 & 2.55 & 2.27 & 46360 & 2.94 & 1.06 & 4.4499 & 0.94 \\
\hline 735 & L2-F & 3.46 & 30 & 56 & 16341 & 2.20 & 70 & -21908 & 2.74 & 2.47 & 38249 & 3.14 & 1.10 & 3.6713 & 0.77 \\
\hline 737 & L2-G & 4.24 & 45 & 76 & 9847 & 2.98 & 91 & -15315 & 3.57 & 3.27 & 25162 & 3.92 & 1.08 & 2.4152 & 0.51 \\
\hline 711 & L3-A & 7.07 & -45 & 145 & 10212 & 5.68 & 159 & -13558 & 6.23 & 5.96 & 23770 & 6.62 & 1.07 & 2.2816 & 0.55 \\
\hline 713 & L3-B & 5.77 & -30 & 116 & 14503 & 4.55 & 130 & -19285 & 5.10 & 4.82 & 33788 & 5.49 & 1.05 & 3.2431 & 0.79 \\
\hline 715 & L3-C & 5.18 & -15 & 99 & 17891 & 3.88 & 112 & -23334 & 4.39 & 4.14 & 41225 & 4.82 & 1.07 & 3.9570 & 0.96 \\
\hline 717 & L3-D & 5.00 & 0 & 98 & 18666 & 3.84 & 111 & -24363 & 4.35 & 4.10 & 43029 & 4.78 & 1.05 & 4.1301 & 1.00 \\
\hline 719 & L3-E & 5.18 & 15 & 104 & 17672 & 4.08 & 117 & -23298 & 4.59 & 4.33 & 40970 & 5.02 & 1.03 & 3.9325 & 0.95 \\
\hline 721 & L3-F & 5.77 & 30 & 117 & 12607 & 4.59 & 130 & -16733 & 5.10 & 4.84 & 29340 & 5.53 & 1.04 & 2.8162 & 0.68 \\
\hline 723 & L3-G & 7.07 & 45 & 156 & 7105 & 6.12 & 181 & -9592 & 7.10 & 6.61 & 16697 & 7.06 & 1.00 & 1.6027 & 0.39 \\
\hline 697 & L4-A & 14.14 & -45 & 333 & 4372 & 13.05 & 346 & -5684 & 13.56 & 13.31 & 10056 & 13.99 & 1.01 & 0.9652 & 0.47 \\
\hline 699 & L4-B & 11.55 & -30 & 273 & 6928 & 10.70 & 286 & -8872 & 11.21 & 10.96 & 15800 & 11.64 & 0.99 & 1.5166 & 0.75 \\
\hline 701 & L4-C & 10.35 & -15 & 239 & 8836 & 9.37 & 253 & -11069 & \begin{tabular}{|l|}
9.92 \\
\end{tabular} & 9.64 & 19905 & 10.31 & 1.00 & 1.9106 & 0.94 \\
\hline 703 & L4-D & 10.00 & 0 & 229 & 8914 & 8.98 & 224 & -12264 & 8.78 & 8.88 & 21178 & 9.92 & 1.01 & 2.0328 & 1.00 \\
\hline 705 & L4-E & 10.35 & 15 & 238 & 8569 & 9.33 & 252 & -10957 & \begin{tabular}{|l|}
9.88 \\
\end{tabular} & 9.60 & 19526 & 10.27 & 1.01 & 1.8742 & 0.92 \\
\hline 707 & L4-F & 11.55 & 30 & 270 & 5616 & 10.58 & 283 & -7757 & \begin{tabular}{|l|}
11.09 \\
\end{tabular} & 10.84 & 13373 & 11.52 & 1.00 & 1.2836 & 0.63 \\
\hline 709 & L4-G & 14.14 & 45 & 335 & 3401 & 13.13 & 348 & -4593 & \begin{tabular}{|l|}
13.64 \\
\end{tabular} & 13.39 & 7994 & 14.07 & 1.00 & 0.7673 & 0.38 \\
\hline
\end{tabular}


Examples of test results for EM waveforms in the spatial spreading studies are shown in the Figures below.

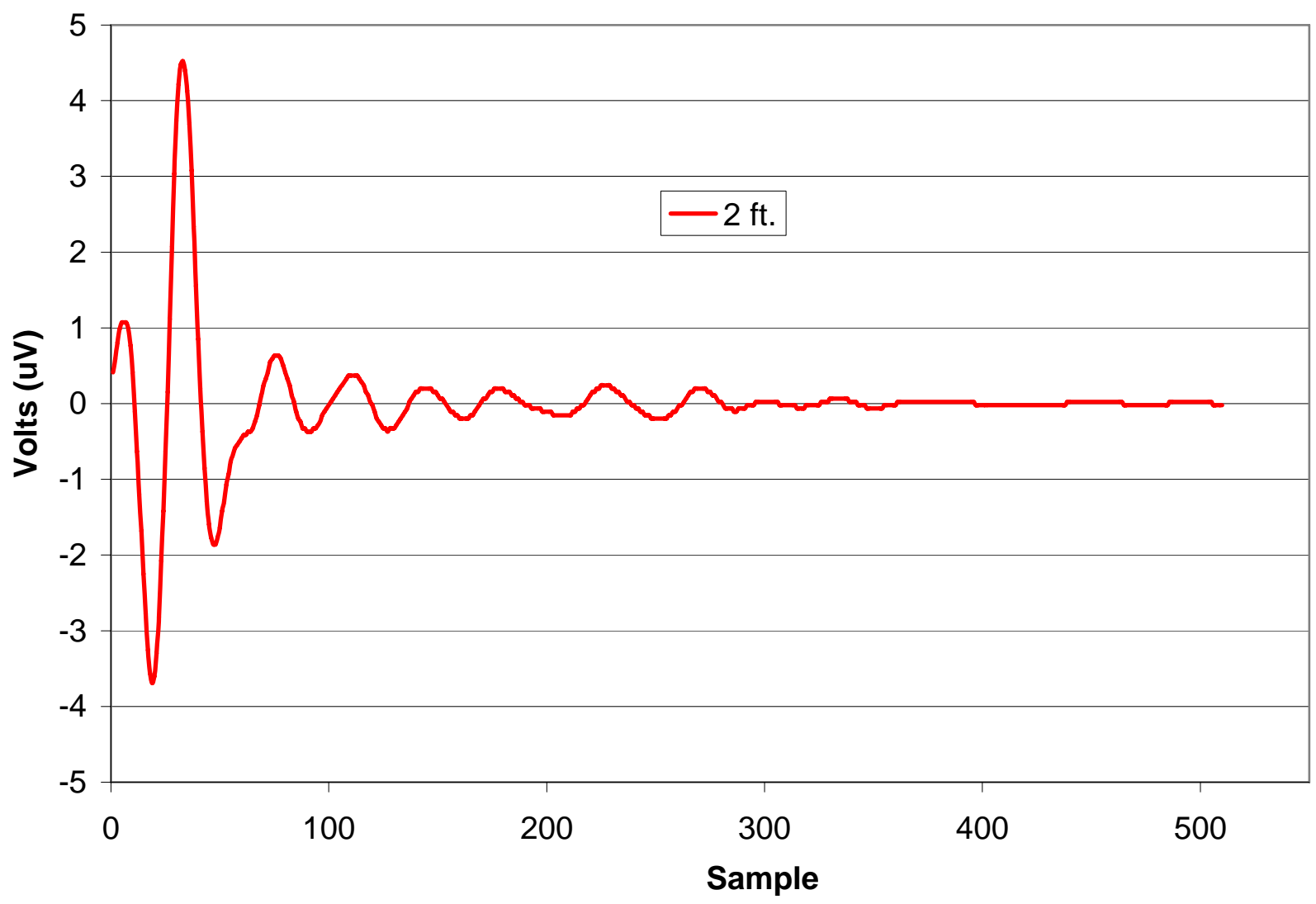

Figure A-14 Air attenuation test 005 - EM waveform - location $2 \mathrm{ft}$. point D - Feb. 2007 


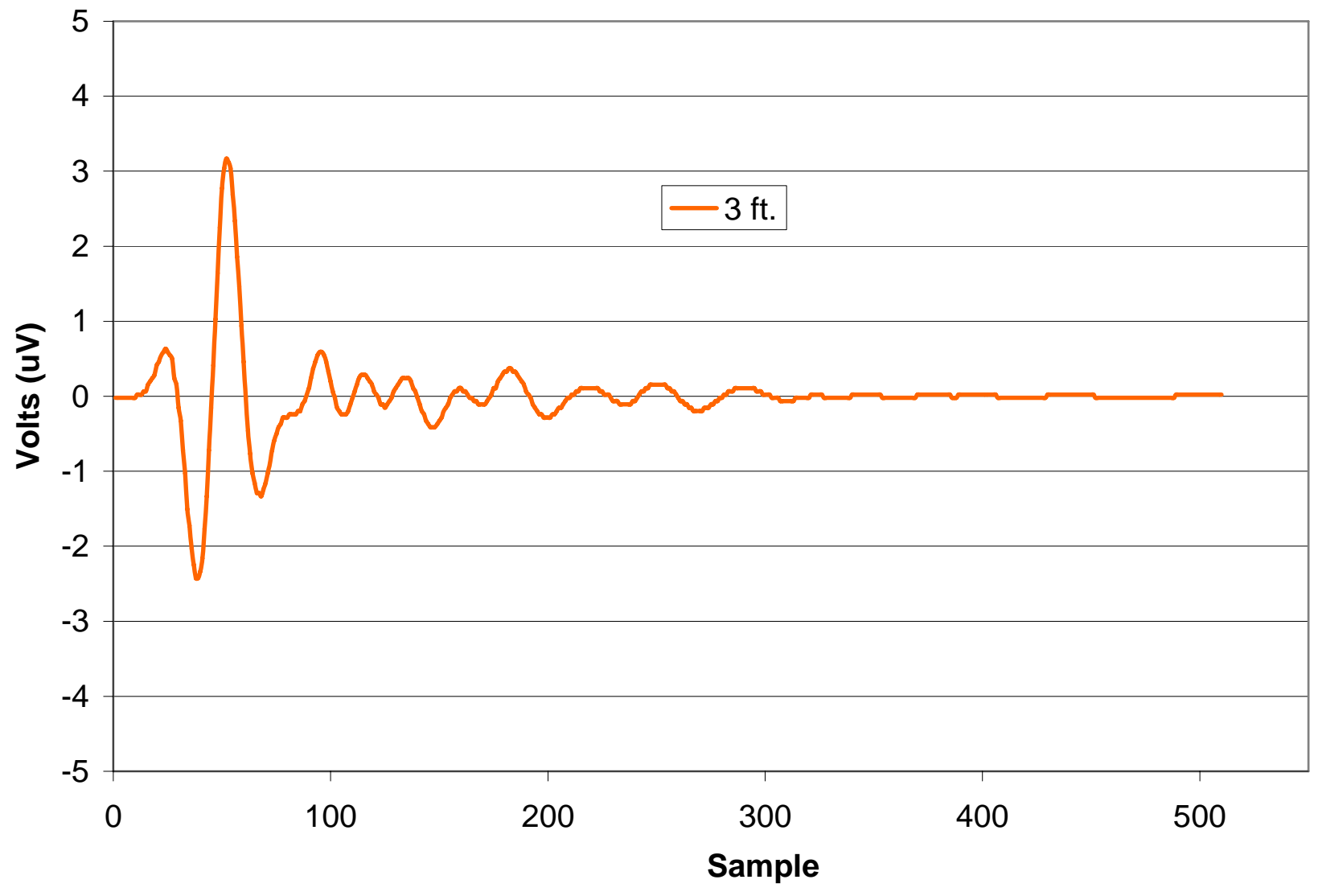

Figure A-15 Air attenuation test 005 - EM waveform - location $3 \mathrm{ft}$. point D - Feb. 2007 


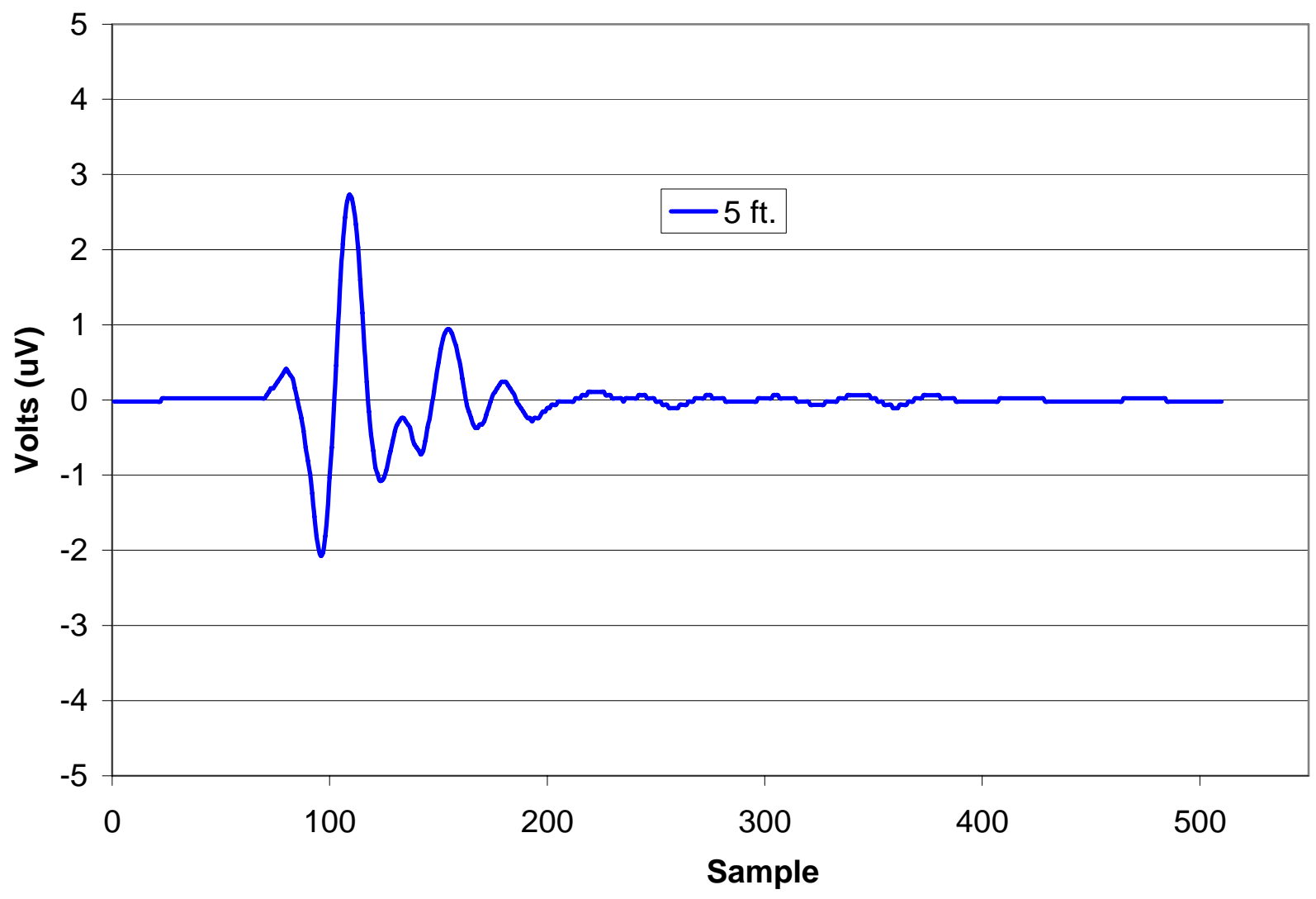

Figure A-16 Air attenuation test 005 - EM waveform - location $5 \mathrm{ft}$. point D -- Feb. 2007 


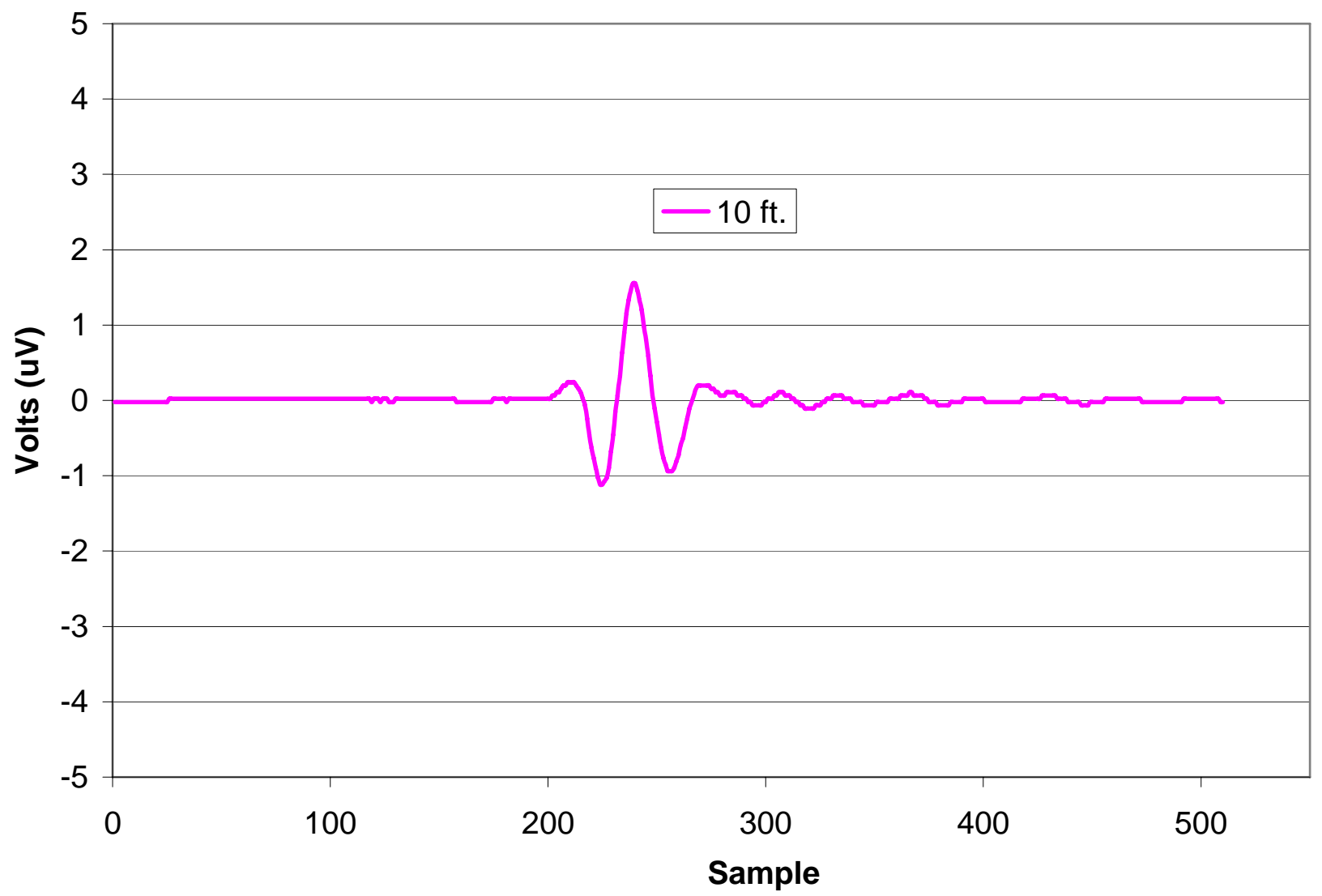

Figure A-17 Air attenuation test 005 - EM waveform - location $10 \mathrm{ft}$. point D - Feb. 2007 
Example of test results for lines (L1-2 ft., L2 - $3 \mathrm{ft}$., L3 - $5 \mathrm{ft}$., L4 - $10 \mathrm{ft}$.) for the EM waveforms in the spatial spreading studies are shown below.

740-point A, 742-point B, 744-point C, 746-point D, 748-point E, 750-point F, 752-point G,

740-752

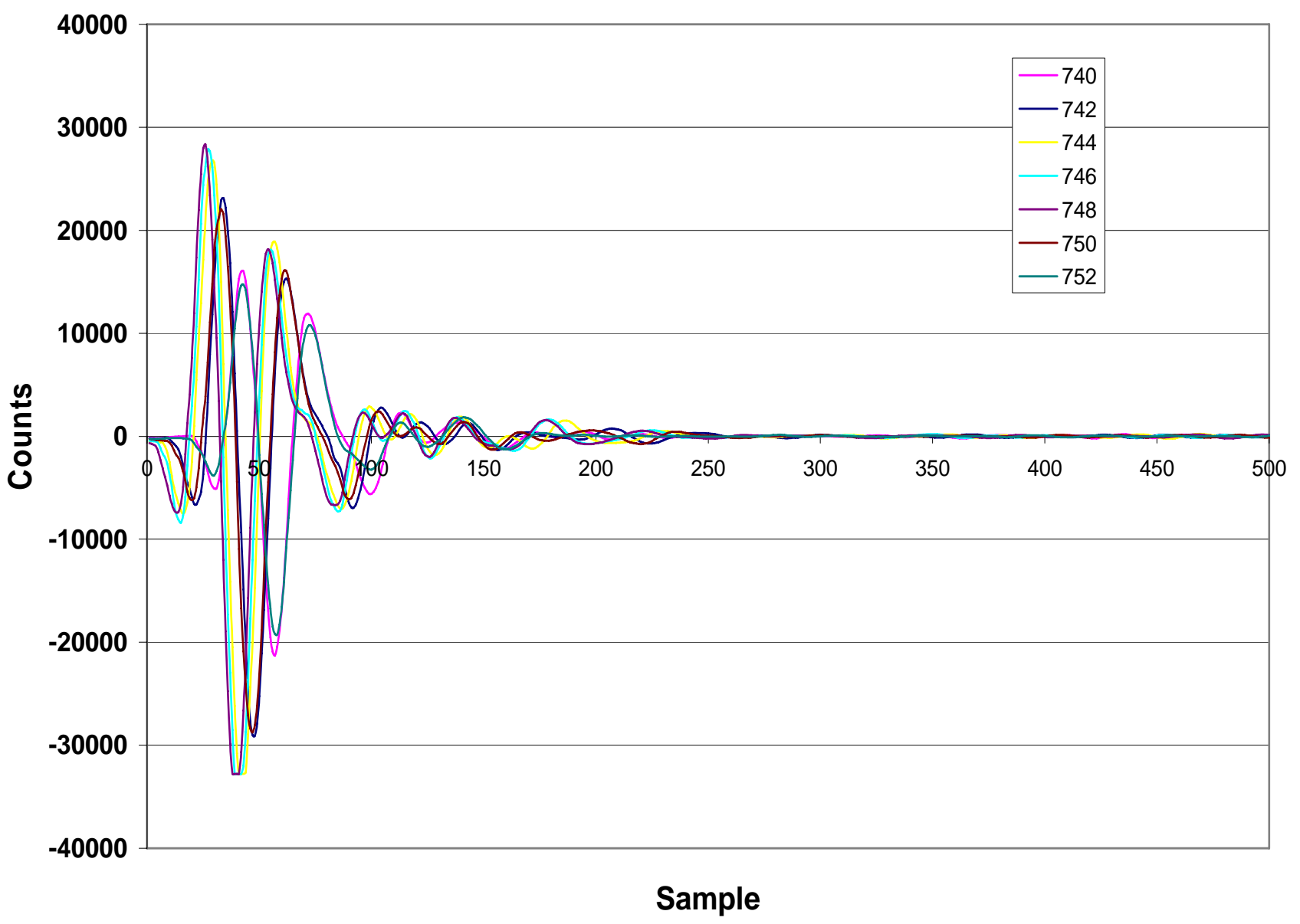

Figure A-18 Spatial spreading air attenuation test $003-\mathrm{L} 1-2 \mathrm{ft}$ - antennas in Y position - Dec. 2005 
725-point A, 727-point B, 729-point C, 731-point D, 733-point E, 735-point F, 737-point G,

725-737

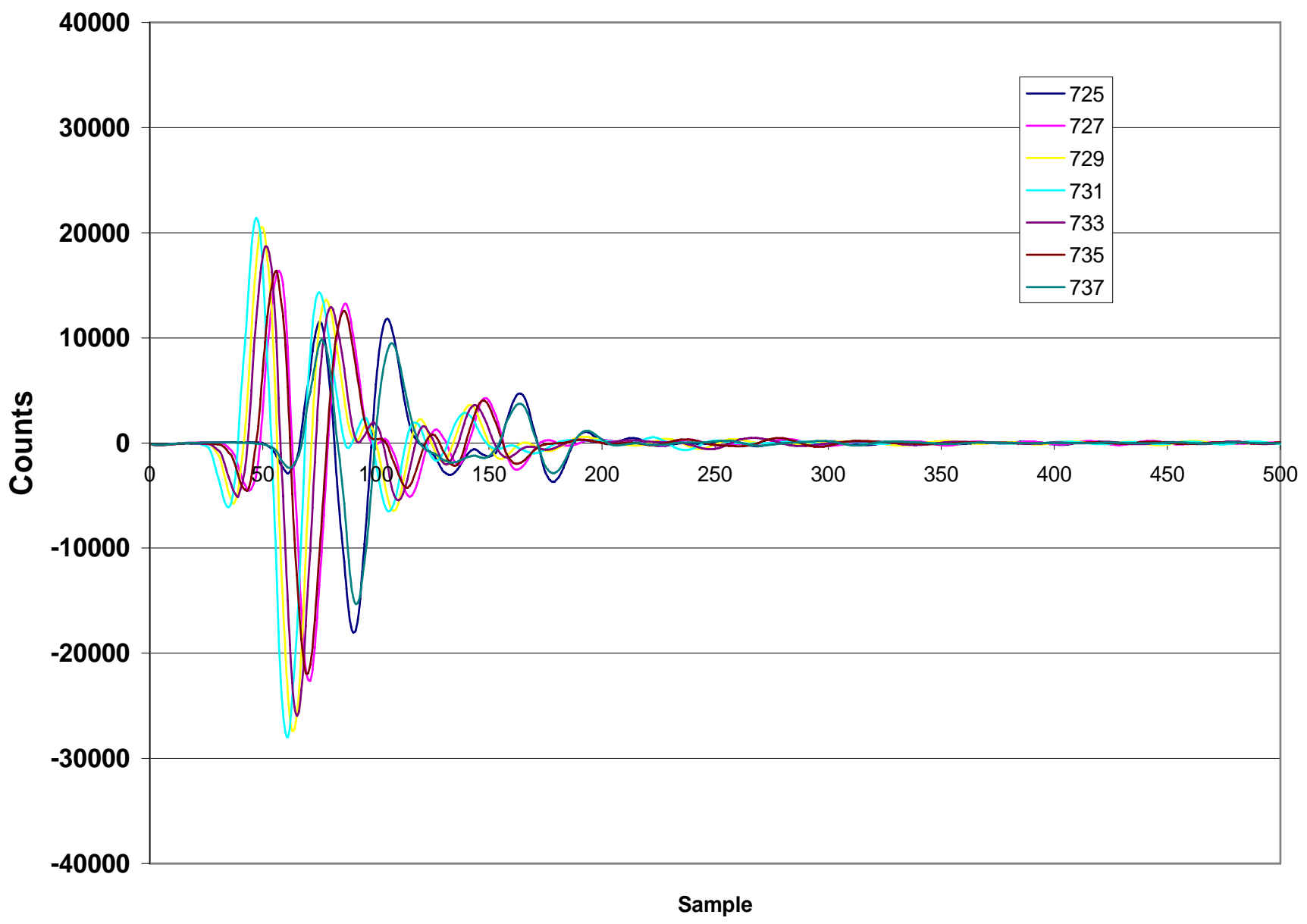

Figure A-19 Spatial spreading air attenuation test 003 - L2 - $3 \mathrm{ft}$ - - antennas in Y position - Dec. 2005 
711-point A, 713-point B, 715-point C, 717-point D, 719-point E, 721-point F, 723-point G,

711-723

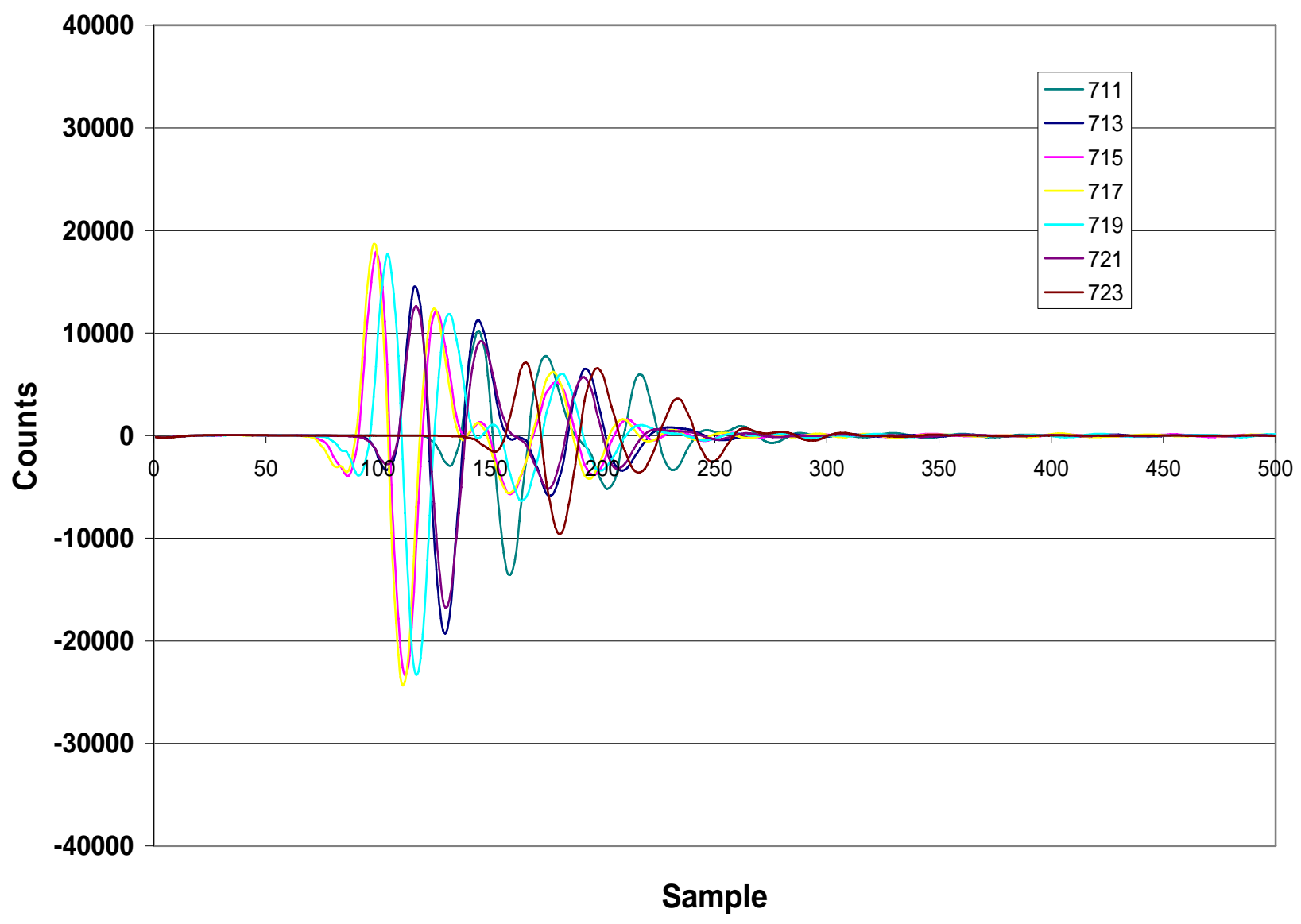

Figure A-20 Spatial spreading air attenuation test 003 - L3 - $5 \mathrm{ft}$ - antennas in Y position - Dec. 2005 
697-point A, 699-point B, 701-point C, 703-point D, 705-point E, 707-point F, 709-point G,

\section{7-709}

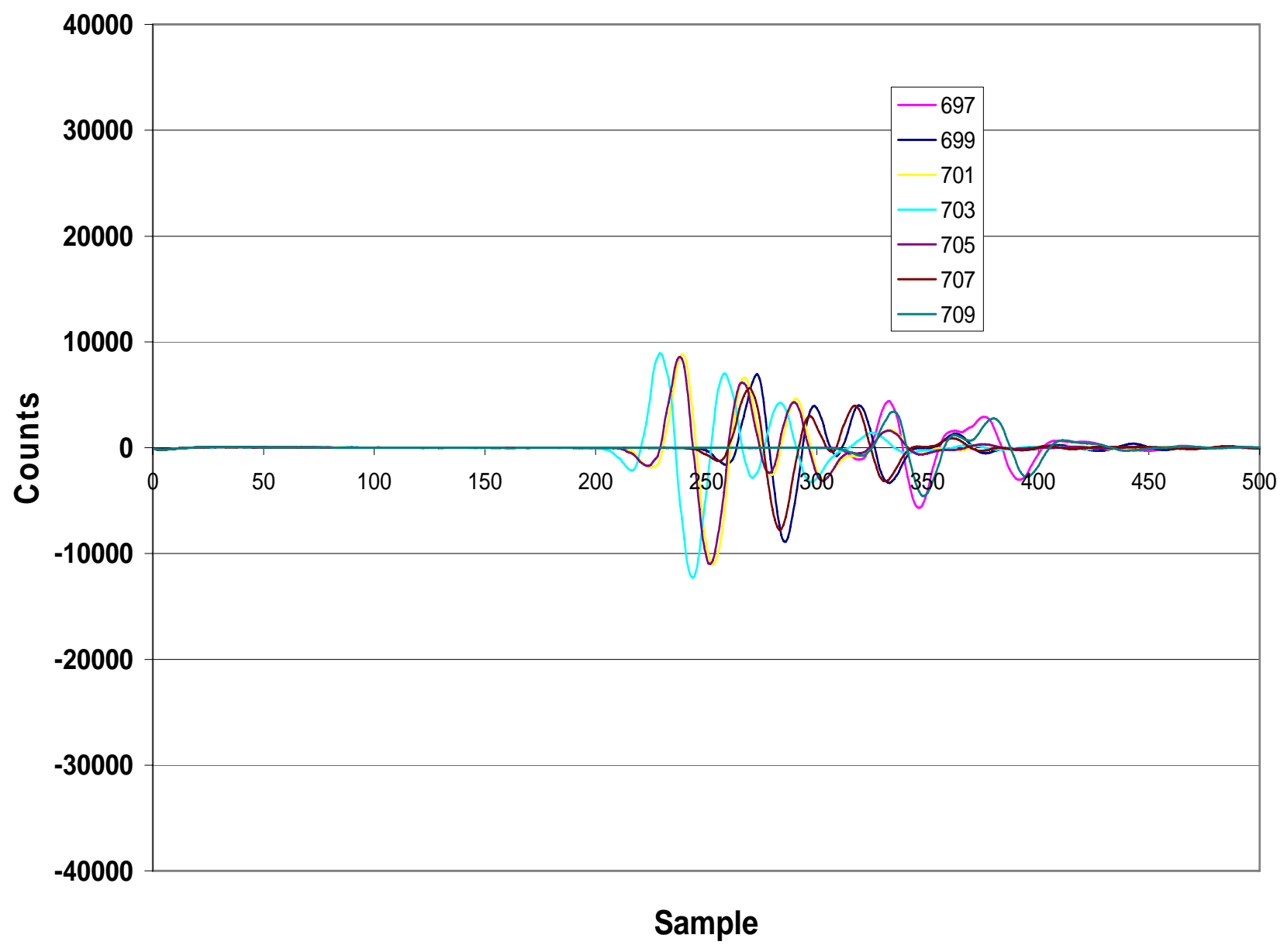

Figure A-21 Spatial spreading air attenuation test 003 - L 4 - $10 \mathrm{ft}$ - antennas in Y position - Dec. 2005 


\section{APPENDIX B: RESULTS FROM EM RECONNAISSANCE STUDIES}

The graphs contained in this appendix show additional EM reconnaissance testing data on the scaled physical mode at different times.

It should be noted that in the reconnaissance survey tests performed on the dry physical model in February 2007, the voltage signals in the model were higher then air voltage signal at the same distance. The author of this Thesis spoke to the manufacture of the instrumentation about these higher voltage signals. The manufacture has also observed higher voltages in a media while performing similar tests on very dry firebrick used in kiln ovens. The results of the tests performed in February 2007 are shown below.

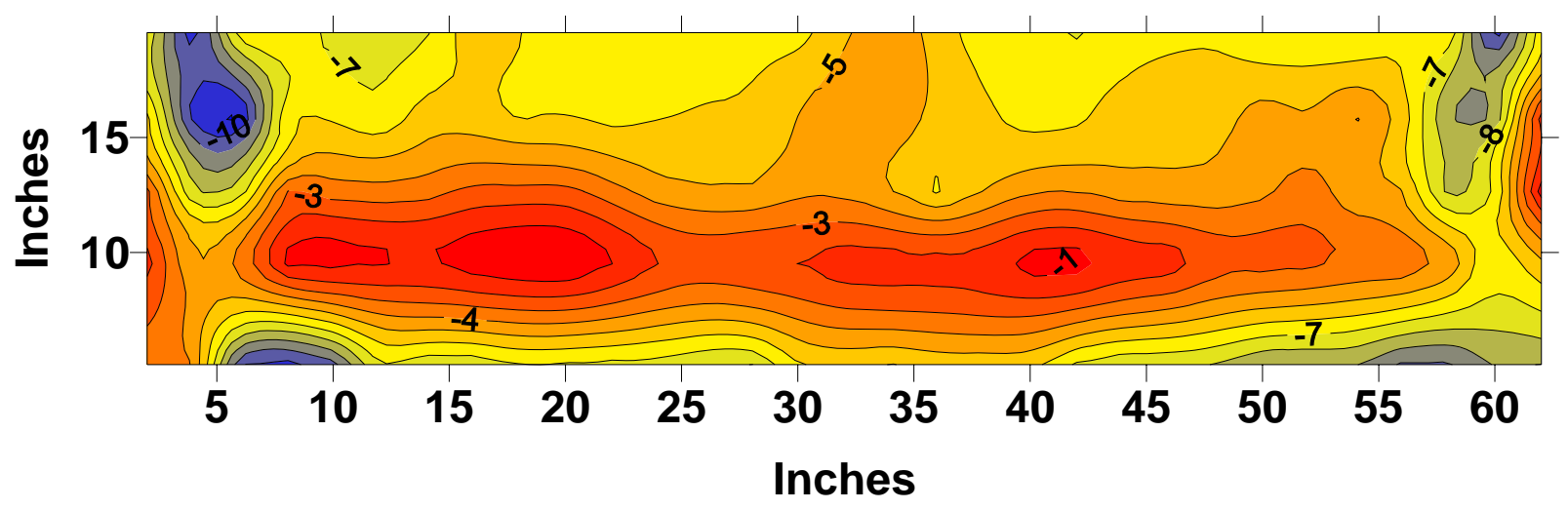

Figure B-1 Total signal attenuation distribution in dry physical model - Feb. 2007 


\section{Reconnaissance Tests Results from February 2007}

Table B-1 Reconnaissance survey test 003 - dry physical model - line 1 floor - Feb. 2007

\begin{tabular}{|c|c|c|c|c|c|c|c|c|c|c|c|c|c|}
\hline \multicolumn{14}{|c|}{$\begin{array}{c}\text { February 11, } 2007 \text { Dry Model, Line } 1 \text { in the Floor, File \# 1007, X = 22.5 (in), Y= } 5.125 \text { (in), Range } 15 \text { (ns), } \\
\text { Gain } 4 \text { (dB), Sv=1.5873,Sc=1651.2, Va = 8.759 (uV), Vm = model volts }\end{array}$} \\
\hline$\overline{Z \text { (in) }}$ & Max & Max & Max & \begin{tabular}{|l|} 
Min \\
\end{tabular} & Min & \begin{tabular}{|l|} 
Min \\
\end{tabular} & Abs & \begin{tabular}{|l|} 
First \\
\end{tabular} & Velocity & $\mathrm{Vm}$ & $\mathrm{Va}-\mathrm{Vm}$ & \multicolumn{2}{|c|}{ Attentuation } \\
\hline & Count & Sample & Time (ns) & \begin{tabular}{|l|} 
Count \\
\end{tabular} & Sample & Time (ns) & & Arrival (ns) & $\mathrm{ft} / \mathrm{ns}$ & $\mathrm{uV}$ & $\mathrm{uV}$ & $\mathrm{uV} / \mathrm{ft}$ & $\mathrm{db} / \mathrm{ft}$ \\
\hline 2 & 14622 & 219 & 6.44 & $\mid-12169$ & 243 & 7.15 & 26791 & 3.94 & 2.10 & 16.23 & -7.47 & -3.98 & -2.86 \\
\hline 4 & 14478 & 219 & 6.44 & \begin{tabular}{|l|}
-12184 \\
\end{tabular} & 243 & 7.15 & 26662 & 3.94 & 2.10 & 16.15 & -7.39 & -3.94 & -2.83 \\
\hline 6 & 28255 & 225 & 6.62 & \begin{tabular}{|l|}
-20352 \\
\end{tabular} & 248 & 7.29 & 48607 & 4.12 & 2.20 & 29.44 & -20.68 & -11.03 & -5.62 \\
\hline 8 & 32551 & 229 & 6.73 & \begin{tabular}{|l|}
-17263 \\
\end{tabular} & 252 & 7.41 & 49814 & 4.23 & 2.26 & 30.17 & -21.41 & -11.42 & -5.73 \\
\hline 10 & 26033 & 230 & 6.76 & \begin{tabular}{|l|}
-20909 \\
\end{tabular} & 255 & 7.50 & 46942 & 4.26 & 2.27 & 28.43 & -19.67 & -10.49 & -5.45 \\
\hline 12 & 21286 & 229 & 6.73 & \begin{tabular}{|l|}
-14826 \\
\end{tabular} & 253 & 7.44 & 36112 & 4.23 & 2.26 & 21.87 & -13.11 & -6.99 & -4.24 \\
\hline 14 & 21352 & 229 & 6.73 & \begin{tabular}{|l|}
-17103 \\
\end{tabular} & 254 & 7.47 & 38455 & 4.23 & 2.26 & 23.29 & -14.53 & -7.75 & -4.53 \\
\hline 16 & 21411 & 229 & 6.73 & \begin{tabular}{|l|}
-17018 \\
\end{tabular} & 254 & 7.47 & 38429 & 4.23 & 2.26 & 23.27 & -14.51 & -7.74 & -4.53 \\
\hline 18 & \begin{tabular}{|l|}
19747 \\
\end{tabular} & 229 & 6.73 & \begin{tabular}{|l|}
-16630 \\
\end{tabular} & 254 & 7.47 & 36377 & 4.23 & 2.26 & 22.03 & -13.27 & -7.08 & -4.27 \\
\hline 20 & 20110 & 230 & 6.76 & $|-16583|$ & 254 & 7.47 & 36693 & 4.26 & 2.27 & 22.22 & -13.46 & -7.18 & -4.31 \\
\hline 22 & 20538 & 230 & 6.76 & \begin{tabular}{|l|}
-16559 \\
\end{tabular} & 255 & 7.50 & 37097 & 4.26 & 2.27 & 22.47 & -13.71 & -7.31 & -4.36 \\
\hline 24 & 20723 & 230 & 6.76 & \begin{tabular}{|l|}
-16680 \\
\end{tabular} & 255 & 7.50 & 37403 & 4.26 & 2.27 & 22.65 & -13.89 & -7.41 & -4.40 \\
\hline 26 & 22203 & 231 & 6.79 & \begin{tabular}{|l|}
-16678 \\
\end{tabular} & 254 & 7.47 & 38881 & 4.29 & 2.29 & 23.55 & -14.79 & -7.89 & -4.58 \\
\hline 28 & 22721 & 231 & 6.79 & \begin{tabular}{|l|}
-16757 \\
\end{tabular} & 254 & 7.47 & 39478 & 4.29 & 2.29 & 23.91 & -15.15 & $\begin{array}{l}-8.08 \\
\end{array}$ & -4.65 \\
\hline 30 & 19887 & 230 & 6.76 & \begin{tabular}{|l|}
-13395 \\
\end{tabular} & 254 & 7.47 & 33282 & 4.26 & 2.27 & 20.16 & -11.40 & -6.08 & -3.86 \\
\hline 32 & 19133 & 230 & 6.76 & $\mid-13230$ & 255 & 7.50 & 32363 & 4.26 & 2.27 & 19.60 & -10.84 & -5.78 & -3.73 \\
\hline 34 & \begin{tabular}{|l}
19516 \\
\end{tabular} & 231 & 6.79 & \begin{tabular}{|l|}
-13775 \\
\end{tabular} & 255 & 7.50 & 33291 & 4.29 & 2.29 & 20.16 & -11.40 & -6.08 & -3.86 \\
\hline 36 & 18988 & 230 & 6.76 & \begin{tabular}{|l|}
-12931 \\
\end{tabular} & 255 & 7.50 & 31919 & 4.26 & 2.27 & 19.33 & -10.57 & -5.64 & -3.67 \\
\hline 38 & 18986 & 230 & 6.76 & \begin{tabular}{|l|}
-13043 \\
\end{tabular} & 255 & 7.50 & 32029 & 4.26 & 2.27 & 19.40 & -10.64 & -5.67 & -3.68 \\
\hline 40 & \begin{tabular}{|l|}
18523 \\
\end{tabular} & 231 & 6.79 & \begin{tabular}{|l|}
-13560 \\
\end{tabular} & 255 & 7.50 & 32083 & 4.29 & 2.29 & 19.43 & -10.67 & -5.69 & -3.69 \\
\hline 42 & \begin{tabular}{|l|}
20551 \\
\end{tabular} & 231 & 6.79 & \begin{tabular}{|l|}
-16124 \\
-1610
\end{tabular} & 256 & 7.53 & 36675 & 4.29 & 2.29 & 22.21 & -13.45 & -7.17 & -4.31 \\
\hline 44 & 21936 & 232 & 6.82 & \begin{tabular}{|c|}
-16711 \\
\end{tabular} & 256 & 7.53 & 38647 & 4.32 & 2.31 & 23.41 & -14.65 & -7.81 & -4.55 \\
\hline 46 & \begin{tabular}{|l|}
21795 \\
\end{tabular} & 232 & 6.82 & \begin{tabular}{|l|}
-16737 \\
\end{tabular} & 256 & 7.53 & 38532 & 4.32 & 2.31 & 23.34 & -14.58 & -7.77 & -4.54 \\
\hline 48 & 23056 & 233 & 6.85 & \begin{tabular}{|l|}
-16421 \\
-164
\end{tabular} & 256 & 7.53 & 39477 & 4.35 & 2.32 & 23.91 & -15.15 & -8.08 & -4.65 \\
\hline 50 & 24804 & 233 & 6.85 & \begin{tabular}{|l|}
-17482 \\
\end{tabular} & 257 & 7.56 & 42286 & 4.35 & 2.32 & 25.61 & -16.85 & -8.99 & -4.97 \\
\hline 52 & \begin{tabular}{|l}
24682 \\
\end{tabular} & 233 & 6.85 & \begin{tabular}{|l|}
-17589 \\
\end{tabular} & 257 & 7.56 & 42271 & 4.35 & 2.32 & 25.60 & -16.84 & -8.98 & -4.97 \\
\hline 54 & 25003 & 233 & 6.85 & \begin{tabular}{|l|}
-17180 \\
\end{tabular} & 255 & 7.50 & 42183 & 4.35 & 2.32 & 25.55 & -16.79 & -8.95 & -4.96 \\
\hline 56 & \begin{tabular}{|l|}
26268 \\
\end{tabular} & 231 & 6.79 & \begin{tabular}{|l|l|}
-19711 \\
\end{tabular} & 255 & 7.50 & 45979 & 4.29 & 2.29 & 27.85 & -19.09 & -10.18 & -5.36 \\
\hline 58 & 26500 & 232 & 6.82 & \begin{tabular}{|l|}
-19520 \\
\end{tabular} & 256 & 7.53 & 46020 & 4.32 & 2.31 & 27.87 & -19.11 & -10.19 & -5.36 \\
\hline 60 & 23535 & 224 & 6.59 & \begin{tabular}{|l|}
-18352 \\
\end{tabular} & 247 & 7.26 & 41887 & 4.09 & 2.18 & 25.37 & -16.61 & -8.86 & -4.93 \\
\hline 62 & \begin{tabular}{|l|}
23784 \\
\end{tabular} & 224 & 6.59 & \begin{tabular}{|l|}
-18613 \\
\end{tabular} & 247 & 7.26 & 42397 & 4.09 & 2.18 & 25.68 & -16.92 & -9.02 & -4.98 \\
\hline
\end{tabular}

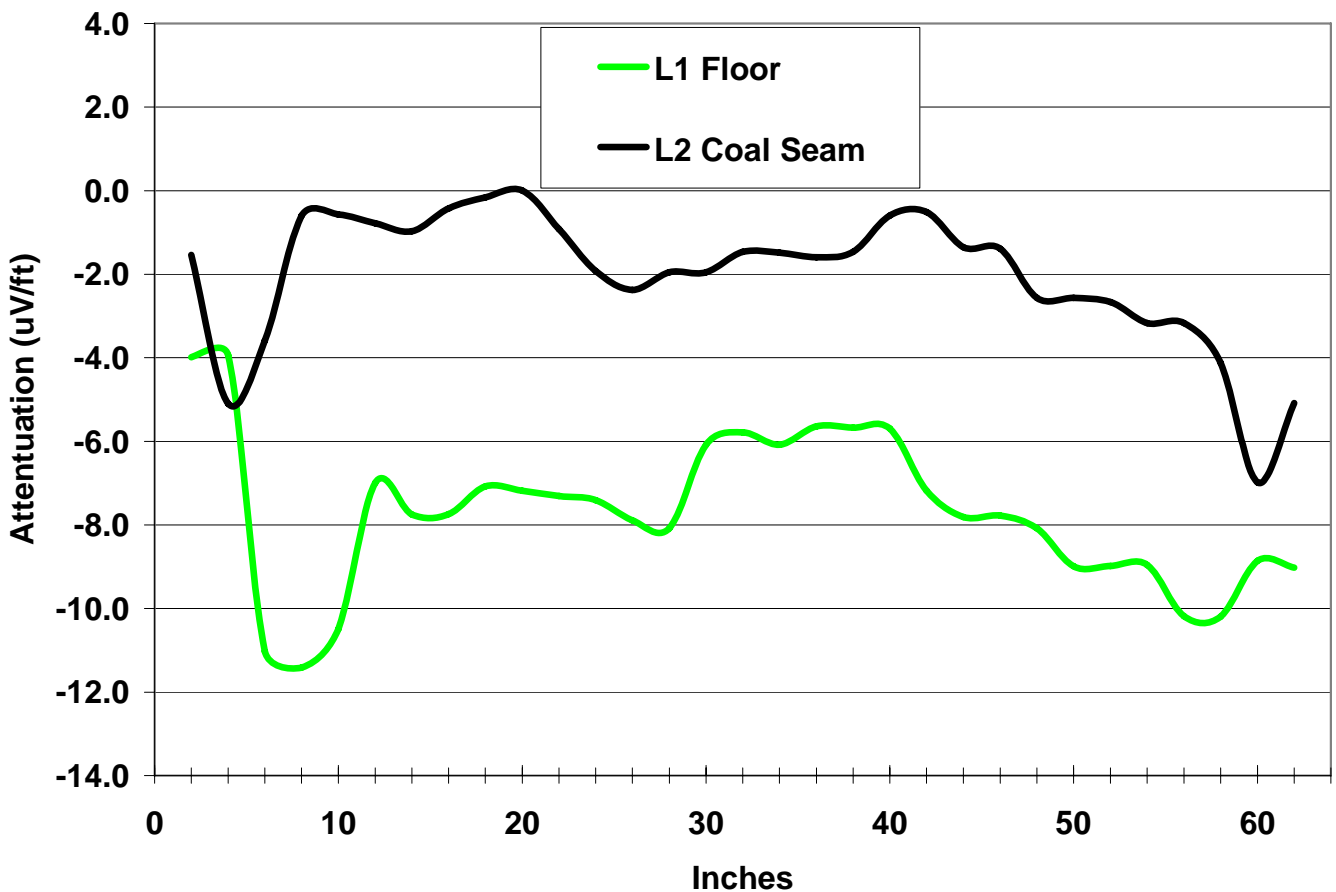

Figure B-2 Dry physical model coal seam and floor lines - Feb. 2007 
Table B-2 Reconnaissance survey test 003 - dry physical model - line 2 - -coal seam - Feb. 2007

\begin{tabular}{|c|c|c|c|c|c|c|c|c|c|c|c|c|c|}
\hline \multicolumn{14}{|c|}{$\begin{array}{l}\text { February 11, } 2007 \text { Dry Model, Line } 2 \text { in Coal Seam, File \# 1010, X = 22.5 (in), Y= 9.625 (in), Range } 15 \text { (ns), } \\
\text { Gain } 4 \text { (dB), Sv=1.5873,Sc=1651.2, Va = 8.759 (uV), Vm = model volts }\end{array}$} \\
\hline$Z$ (in) & $\operatorname{Max}$ & Max & Max & Min & Min & \begin{tabular}{|l|} 
Min \\
\end{tabular} & Abs & \begin{tabular}{|l|} 
First \\
\end{tabular} & Velocity & $\mathrm{Vm}$ & $\mathrm{Va}-\mathrm{Vm}$ & \multicolumn{2}{|c|}{ Attentuation } \\
\hline & Count & Sample & Time (ns) & Count & Sample & Time (ns) & & Arrival (ns) & $\mathrm{ft} / \mathrm{ns}$ & $\mathrm{uV}$ & $\mathrm{uV}$ & $\mathrm{uV} / \mathrm{ft}$ & $\mathrm{db} / \mathrm{ft}$ \\
\hline 2 & 12270 & 214 & 6.29 & -6959 & 196 & 5.76 & 19229.0 & 3.79 & 2.02 & 11.65 & -2.89 & -1.54 & -1.32 \\
\hline 4 & 18629 & 219 & 6.44 & -11616 & 202 & 5.94 & 30245.0 & 3.94 & 2.10 & 18.32 & -9.56 & -5.10 & -3.42 \\
\hline 6 & 15984 & 222 & 6.53 & -9591 & 205 & 6.03 & 25575.0 & 4.03 & 2.15 & 15.49 & -6.73 & -3.59 & -2.64 \\
\hline 8 & 9584 & 221 & 6.50 & -6738 & 199 & 5.85 & 16322.0 & 4.00 & 2.13 & 9.88 & -1.13 & -0.60 & -0.56 \\
\hline 10 & 9568 & 221 & 6.50 & -6660 & 199 & 5.85 & 16228.0 & 4.00 & 2.13 & 9.83 & -1.07 & -0.57 & -0.53 \\
\hline 12 & 10026 & 219 & 6.44 & -6855 & 199 & 5.85 & 16881.0 & 3.94 & 2.10 & 10.22 & -1.46 & -0.78 & -0.72 \\
\hline 14 & 10545 & 219 & 6.44 & -6920 & 199 & 5.85 & 17465.0 & 3.94 & 2.10 & 10.58 & -1.82 & -0.97 & -0.87 \\
\hline 16 & 9319 & 219 & 6.44 & -6448 & 198 & 5.82 & 15767.0 & 3.94 & 2.10 & 9.55 & -0.79 & -0.42 & -0.40 \\
\hline 18 & 8652 & 220 & 6.47 & -6311 & 198 & 5.82 & 14963.0 & 3.97 & 2.12 & 9.06 & -0.30 & -0.16 & -0.16 \\
\hline 20 & 8520 & 220 & 6.47 & -5932 & 198 & 5.82 & 14452.0 & 3.97 & 2.12 & 8.75 & 0.01 & 0.00 & 0.00 \\
\hline 22 & 10527 & 221 & 6.50 & -6781 & 202 & 5.94 & 17308.0 & 4.00 & 2.13 & 10.48 & -1.72 & -0.92 & -0.83 \\
\hline 24 & 12397 & 222 & 6.53 & -8018 & 205 & 6.03 & 20415.0 & 4.03 & 2.15 & 12.36 & -3.60 & -1.92 & -1.60 \\
\hline 26 & 13250 & 223 & 6.56 & -8562 & 205 & 6.03 & \begin{tabular}{|l|}
21812.0 \\
\end{tabular} & 4.06 & 2.16 & 13.21 & -4.45 & -2.37 & -1.90 \\
\hline 28 & 12418 & 223 & 6.56 & -8101 & 206 & 6.06 & \begin{tabular}{|l|}
20519.0 \\
\end{tabular} & 4.06 & 2.16 & 12.43 & -3.67 & -1.96 & -1.62 \\
\hline 30 & 12399 & 223 & 6.56 & -8123 & 206 & 6.06 & 20522.0 & 4.06 & 2.16 & 12.43 & -3.67 & -1.96 & -1.62 \\
\hline 32 & 11407 & 224 & 6.59 & -7603 & 205 & 6.03 & 19010.0 & 4.09 & 2.18 & 11.51 & -2.75 & -1.47 & -1.27 \\
\hline 34 & 11528 & 224 & 6.59 & -7532 & 206 & 6.06 & 19060.0 & 4.09 & 2.18 & 11.54 & -2.78 & -1.48 & -1.28 \\
\hline 36 & 11703 & 224 & 6.59 & -7677 & 206 & 6.06 & 19380.0 & 4.09 & 2.18 & 11.74 & -2.98 & -1.59 & -1.36 \\
\hline 38 & 11443 & 223 & 6.56 & -7557 & 204 & 6.00 & 19000.0 & 4.06 & 2.16 & 11.51 & -2.75 & -1.47 & -1.26 \\
\hline 40 & 9683 & 223 & 6.56 & -6616 & 204 & 6.00 & 16299.0 & 4.06 & 2.16 & 9.87 & -1.11 & -0.59 & -0.55 \\
\hline 42 & 9525 & 223 & 6.56 & -6514 & 204 & 6.00 & 16039.0 & 4.06 & 2.16 & 9.71 & -0.95 & -0.51 & -0.48 \\
\hline 44 & 11183 & 225 & 6.62 & -7481 & 206 & 6.06 & 18664.0 & 4.12 & 2.20 & 11.30 & -2.54 & -1.36 & -1.18 \\
\hline 46 & 11280 & 225 & 6.62 & -7486 & 207 & 6.09 & 18766.0 & 4.12 & 2.20 & 11.37 & -2.61 & -1.39 & -1.21 \\
\hline 48 & 13599 & 227 & 6.68 & -8818 & 208 & 6.12 & 22417.0 & 4.18 & 2.23 & 13.58 & -4.82 & -2.57 & -2.03 \\
\hline 50 & 13599 & 227 & 6.68 & -8818 & 208 & 6.12 & 22417.0 & 4.18 & 2.23 & 13.58 & -4.82 & -2.57 & -2.03 \\
\hline 52 & 13907 & 229 & 6.73 & -8801 & 210 & 6.18 & 22708.0 & 4.23 & 2.26 & 13.75 & -4.99 & -2.66 & -2.09 \\
\hline 54 & 14913 & 228 & 6.71 & -9350 & 210 & 6.18 & 24263.0 & 4.21 & 2.24 & 14.69 & -5.94 & -3.17 & -2.40 \\
\hline 56 & 14847 & 228 & 6.71 & -9412 & 210 & 6.18 & 24259.0 & 4.21 & 2.24 & 14.69 & -5.93 & -3.16 & -2.40 \\
\hline 58 & 17109 & 228 & 6.71 & -10111 & 210 & 6.18 & 27220.0 & 4.21 & 2.24 & 16.48 & -7.73 & -4.12 & -2.93 \\
\hline 60 & 21892 & 225 & 6.62 & -14193 & 207 & 6.09 & 36085.0 & 4.12 & 2.20 & 21.85 & -13.09 & -6.98 & -4.24 \\
\hline 62 & 18737 & 222 & 6.53 & $\mid-11470$ & 205 & 6.03 & 30207.0 & 4.03 & 2.15 & 18.29 & -9.53 & -5.09 & -3.41 \\
\hline
\end{tabular}

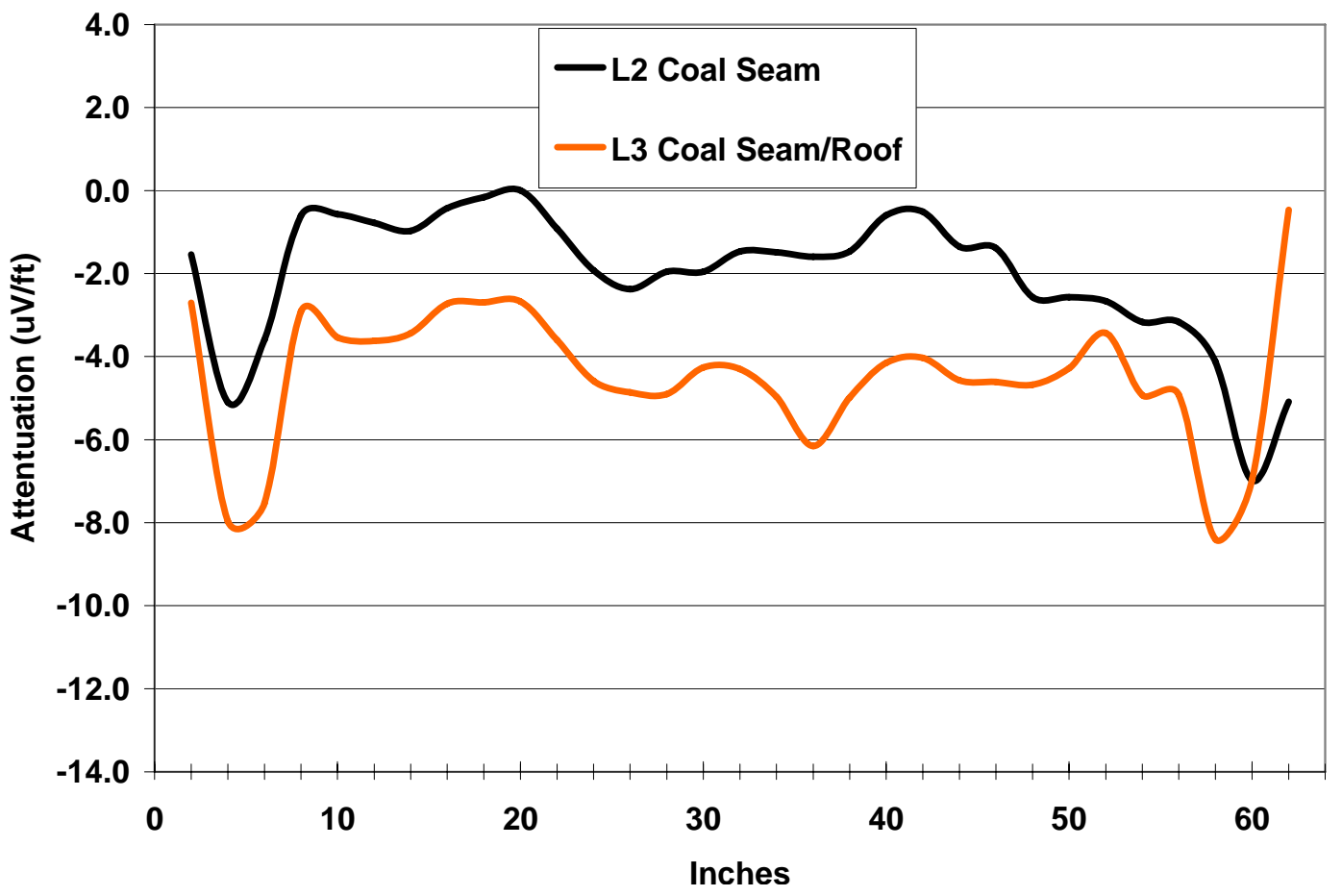

Figure B-3 Dry physical model coal seam and coal seam/roof lines - Feb. 2007 
Table B-3 Reconnaissance survey test 003 - dry physical model - line 3 - coal seam roof - Feb. 2007

\begin{tabular}{|c|c|c|c|c|c|c|c|c|c|c|c|c|c|}
\hline \multicolumn{14}{|c|}{$\begin{array}{c}\text { February 11, } 2007 \text { Dry Model, Line } 3 \text { in Coal Seam Roof, File \# 1011, X= } 22.5 \text { (in), Y= } 12.625 \text { (in), } \\
\text { Range } 15 \text { (ns), Gain } 4 \text { (dB), Sv=1.5873,Sc=1651.2, Va = 8..759 (uV), Vm = model volts }\end{array}$} \\
\hline Z (in) & Max & Max & Max & Min & Min & Min & Abs & First & Velocity & $\mathrm{Vm}$ & $\mathrm{Va}-\mathrm{Vm}$ & & \\
\hline & Count & Sample & Time (ns) & Count & Sample & Time (ns) & & Arrival (ns) & $\mathrm{ft} / \mathrm{ns}$ & $\mathrm{uV}$ & $\mathrm{uV}$ & $\mathrm{uV} / \mathrm{ft}$ & $\mathrm{db} / \mathrm{ft}$ \\
\hline 2 & 14273 & 215 & 6.32 & -8574 & 236 & 6.94 & 22847.0 & 3.82 & 2.04 & 13.84 & -5.08 & -2.71 & -2.12 \\
\hline 4 & 24016 & 220 & 6.47 & -15109 & 202 & 5.94 & 39125.0 & 3.97 & 2.12 & 23.69 & -14.94 & -7.97 & -4.61 \\
\hline 6 & 23480 & 224 & 6.59 & -14278 & 206 & 6.06 & 37758.0 & 4.09 & 2.18 & 22.87 & -14.11 & -7.52 & -4.45 \\
\hline 8 & 14462 & 224 & 6.59 & \begin{tabular}{|l|}
-9003 \\
\end{tabular} & 205 & 6.03 & 23465.0 & 4.09 & 2.18 & 14.21 & -5.45 & -2.91 & -2.24 \\
\hline 10 & 15884 & 222 & 6.53 & -9528 & 204 & 6.00 & 25412.0 & 4.03 & 2.15 & 15.39 & -6.63 & -3.54 & -2.61 \\
\hline 12 & 15961 & 223 & 6.56 & -9714 & 204 & 6.00 & 25675.0 & 4.06 & 2.16 & 15.55 & -6.79 & -3.62 & -2.66 \\
\hline 14 & 15651 & 222 & 6.53 & -9448 & 205 & 6.03 & 25099.0 & 4.03 & 2.15 & 15.20 & -6.44 & -3.44 & -2.55 \\
\hline 16 & 14309 & 221 & 6.50 & -8592 & 203 & 5.97 & 22901.0 & 4.00 & 2.13 & 13.87 & -5.11 & -2.73 & -2.13 \\
\hline 18 & 14138 & 221 & 6.50 & -8670 & 202 & 5.94 & 22808.0 & 4.00 & 2.13 & 13.81 & -5.05 & -2.70 & -2.11 \\
\hline 20 & 14066 & 221 & 6.50 & -8667 & 202 & 5.94 & 22733.0 & 4.00 & 2.13 & 13.77 & -5.01 & -2.67 & -2.09 \\
\hline 22 & 15850 & 221 & 6.50 & \begin{tabular}{|l|}
-9768 \\
\end{tabular} & 205 & 6.03 & 25618.0 & 4.00 & 2.13 & 15.51 & -6.76 & -3.60 & -2.65 \\
\hline 24 & 17461 & 223 & 6.56 & -11200 & 206 & 6.06 & 28661.0 & 4.06 & 2.16 & 17.36 & -8.60 & -4.59 & -3.17 \\
\hline 26 & 18023 & 223 & 6.56 & -11497 & 206 & 6.06 & 29520.0 & 4.06 & 2.16 & 17.88 & -9.12 & -4.86 & -3.31 \\
\hline 28 & 18034 & 223 & 6.56 & -11595 & 206 & 6.06 & 29629.0 & 4.06 & 2.16 & 17.94 & -9.18 & -4.90 & -3.32 \\
\hline 30 & 16857 & 223 & 6.56 & -10800 & 206 & 6.06 & 27657.0 & 4.06 & 2.16 & 16.75 & -7.99 & -4.26 & -3.00 \\
\hline 32 & 16970 & 223 & 6.56 & -10810 & 206 & 6.06 & 27780.0 & 4.06 & 2.16 & 16.82 & -8.07 & -4.30 & -3.02 \\
\hline 34 & 18110 & 224 & 6.59 & -11726 & 207 & 6.09 & 29836.0 & 4.09 & 2.18 & 18.07 & -9.31 & -4.97 & -3.35 \\
\hline 36 & 20678 & 225 & 6.62 & \begin{tabular}{|l|}
-12844 \\
\end{tabular} & 207 & 6.09 & 33522.0 & 4.12 & 2.20 & 20.30 & -11.54 & -6.16 & -3.89 \\
\hline 38 & 18034 & 224 & 6.59 & -11868 & 207 & 6.09 & 29902.0 & 4.09 & 2.18 & 18.11 & -9.35 & -4.99 & -3.36 \\
\hline 40 & 16559 & 224 & 6.59 & -10755 & 207 & 6.09 & 27314.0 & 4.09 & 2.18 & 16.54 & -7.78 & -4.15 & -2.95 \\
\hline 42 & 16373 & 224 & 6.59 & -10566 & 207 & 6.09 & 26939.0 & 4.09 & 2.18 & 16.31 & -7.56 & -4.03 & -2.88 \\
\hline 44 & 17408 & 225 & 6.62 & \begin{tabular}{|l|}
-11201 \\
\end{tabular} & 207 & 6.09 & 28609.0 & 4.12 & 2.20 & 17.33 & -8.57 & -4.57 & -3.16 \\
\hline 46 & 17785 & 226 & 6.65 & \begin{tabular}{|l|}
-10962 \\
\end{tabular} & 208 & 6.12 & 28747.0 & 4.15 & 2.21 & 17.41 & -8.65 & -4.61 & -3.18 \\
\hline 48 & 18014 & 226 & 6.65 & -10925 & 208 & 6.12 & 28939.0 & 4.15 & 2.21 & 17.53 & -8.77 & -4.68 & -3.21 \\
\hline 50 & 17100 & 226 & 6.65 & -10626 & 208 & 6.12 & 27726.0 & 4.15 & 2.21 & 16.79 & -8.03 & -4.28 & -3.01 \\
\hline 52 & 15043 & 226 & 6.65 & \begin{tabular}{|l|}
-10039 \\
\end{tabular} & 207 & 6.09 & 25082.0 & 4.15 & 2.21 & 15.19 & -6.43 & -3.43 & -2.55 \\
\hline 54 & 18258 & 227 & 6.68 & -11453 & 250 & 7.35 & 29711.0 & 4.18 & 2.23 & 17.99 & -9.23 & -4.93 & -3.34 \\
\hline 56 & 18402 & 228 & 6.71 & -11287 & 250 & 7.35 & 29689.0 & 4.21 & 2.24 & 17.98 & -9.22 & -4.92 & -3.33 \\
\hline 58 & 25006 & 225 & 6.62 & \begin{tabular}{|l|}
-15463 \\
\end{tabular} & 208 & 6.12 & 40469.0 & 4.12 & 2.20 & 24.51 & -15.75 & -8.40 & -4.77 \\
\hline 60 & 22516 & 222 & 6.53 & -13501 & 205 & 6.03 & 36017.0 & 4.03 & 2.15 & 21.81 & -13.05 & -6.96 & -4.23 \\
\hline 62 & 9229 & 217 & 6.38 & -6665 & 239 & 7.03 & 15894.0 & 3.88 & 2.07 & 9.63 & -0.87 & -0.46 & -0.44 \\
\hline
\end{tabular}

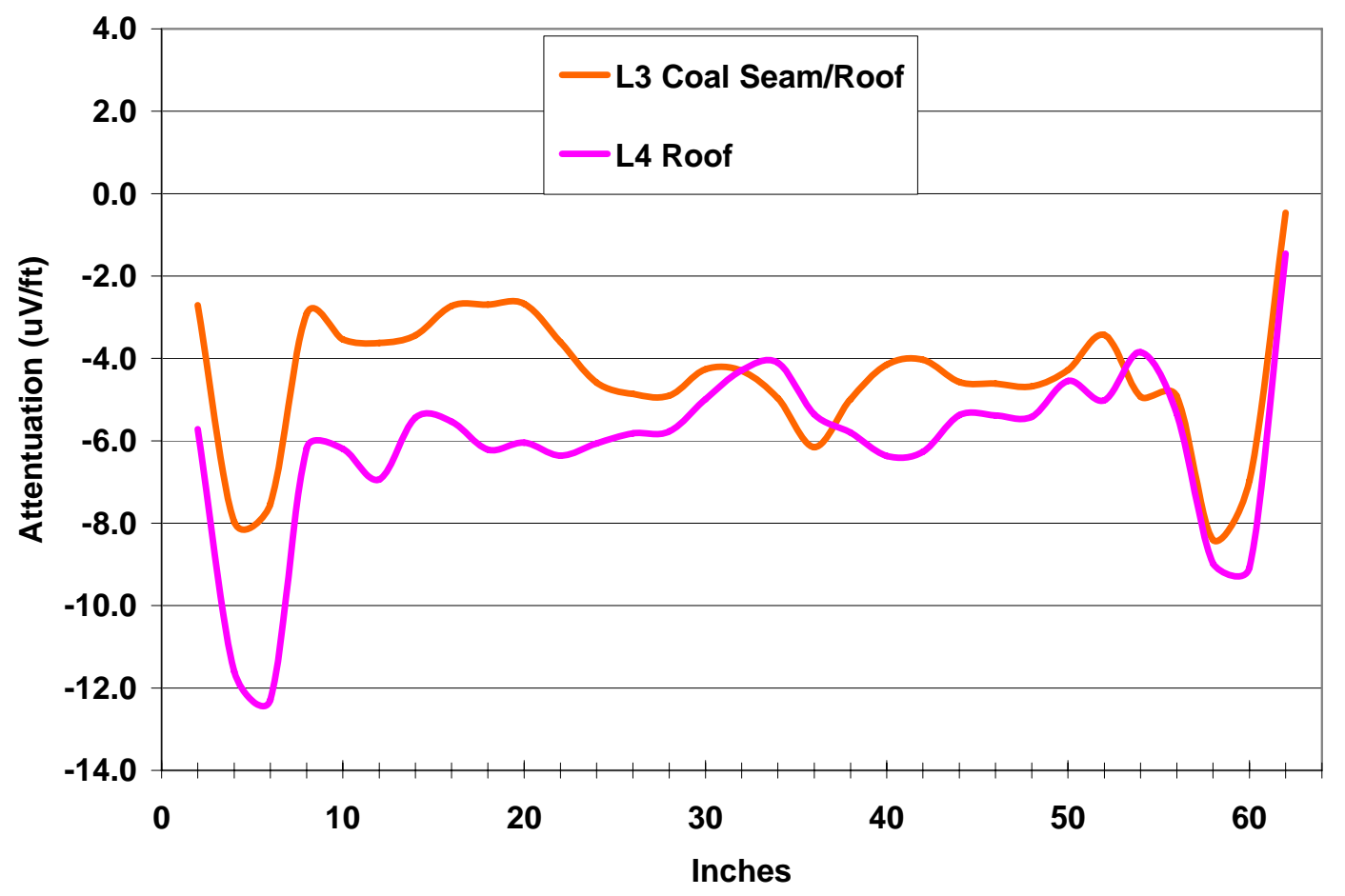

Figure B-4 Dry physical model coal seam/roof and roof lines - Feb. 2007 
Table B-4 Reconnaissance survey test 003 - dry physical model - line 4 - roof - Feb. 2007

\begin{tabular}{|c|c|c|c|c|c|c|c|c|c|c|c|c|c|}
\hline & & Februa & iry 11,200 & $\begin{array}{l}07 \text { Dry } \\
\text { ain } 4 \text { (d }\end{array}$ & $\begin{array}{l}\text { Model, L } \\
\text { B), Sv= }\end{array}$ & $\begin{array}{l}\text { ine } 4 \text { in F } \\
1.5873, \mathrm{Sc}\end{array}$ & $\begin{array}{l}\text { Roof, File } \\
=1651.2 \text {, }\end{array}$ & $\begin{array}{l}\# 1012, X \\
V a=8.759\end{array}$ & $\begin{array}{r}=22.5 \text { (i } \\
\text { (uV), Vn }\end{array}$ & $\begin{array}{l}\text { I), } Y=1 \\
1=\mathrm{mo}\end{array}$ & $\begin{array}{l}\text { (in), } R a \\
\text { el volts }\end{array}$ & 5 & \\
\hline Z (in) & Max & Max & Max & Min & Min & Min & Abs & First & \begin{tabular}{|l} 
Velocity \\
\end{tabular} & $\mathrm{Vm}$ & Va -Vm & & \\
\hline & Count & Sample & Time (ns) & Count & Sample & Time (ns) & & Arrival (ns) & $\mathrm{ft} / \mathrm{ns}$ & $\mathrm{uV}$ & $\mathrm{uV}$ & $\mathrm{uV} / \mathrm{ft}$ & $\mathrm{db} / \mathrm{ft}$ \\
\hline 2 & 18251 & 218 & 6.41 & -13911 & 242 & $\begin{array}{l}7.12 \\
\end{array}$ & 32162.0 & 3.91 & 2.09 & 19.48 & -10.72 & -5.72 & -3.70 \\
\hline 4 & 30061 & 223 & 6.56 & \begin{tabular}{|l|}
-20318 \\
\end{tabular} & 246 & 7.23 & 50379.0 & 4.06 & 2.16 & 30.51 & -21.75 & -11.60 & -5.78 \\
\hline 6 & 31407 & 227 & 6.68 & \begin{tabular}{|l|}
-21084 \\
\end{tabular} & 250 & 7.35 & 52491.0 & 4.18 & 2.23 & 31.79 & -23.03 & -12.28 & -5.97 \\
\hline 8 & 19321 & 227 & 6.68 & -14266 & 253 & 7.44 & 33587.0 & 4.18 & 2.23 & 20.34 & -11.58 & -6.18 & -3.90 \\
\hline 10 & 19308 & 227 & 6.68 & -14334 & 253 & 7.44 & 33642.0 & 4.18 & 2.23 & 20.37 & -11.62 & -6.19 & -3.91 \\
\hline 12 & 21314 & 225 & 6.62 & -14627 & 248 & 7.29 & 35941.0 & 4.12 & 2.20 & 21.77 & -13.01 & -6.94 & -4.22 \\
\hline 14 & 19084 & 225 & 6.62 & -12216 & 249 & 7.32 & 31300.0 & 4.12 & 2.20 & 18.96 & -10.20 & -5.44 & -3.58 \\
\hline 16 & 19279 & 225 & 6.62 & -12317 & 249 & 7.32 & 31596.0 & 4.12 & 2.20 & 19.14 & -10.38 & -5.53 & -3.62 \\
\hline 18 & 20677 & 224 & 6.59 & -13028 & 207 & 6.09 & 33705.0 & 4.09 & 2.18 & 20.41 & -11.65 & -6.22 & -3.92 \\
\hline 20 & 20299 & 224 & 6.59 & -12869 & 247 & 7.26 & 33168.0 & 4.09 & 2.18 & 20.09 & -11.33 & -6.04 & -3.84 \\
\hline 22 & 20741 & 224 & 6.59 & \begin{tabular}{|l|}
-13413 \\
\end{tabular} & 248 & 7.29 & 34154.0 & 4.09 & 2.18 & 20.68 & -11.93 & -6.36 & -3.98 \\
\hline 24 & 19840 & 225 & 6.62 & -13395 & 248 & 7.29 & 33235.0 & 4.12 & 2.20 & 20.13 & -11.37 & -6.06 & -3.85 \\
\hline 26 & 19549 & 224 & 6.59 & -12935 & 248 & 7.29 & 32484.0 & 4.09 & 2.18 & 19.67 & -10.91 & -5.82 & -3.75 \\
\hline 28 & 19603 & 224 & 6.59 & -12722 & 248 & 7.29 & 32325.0 & 4.09 & 2.18 & 19.58 & -10.82 & -5.77 & -3.73 \\
\hline 30 & 18263 & 224 & 6.59 & -11644 & 247 & 7.26 & 29907.0 & 4.09 & 2.18 & 18.11 & -9.35 & -4.99 & -3.37 \\
\hline 32 & 16893 & 223 & 6.56 & -10845 & 246 & 7.23 & 27738.0 & 4.06 & 2.16 & 16.80 & -8.04 & -4.29 & -3.02 \\
\hline 34 & 16720 & 223 & 6.56 & -10454 & 246 & 7.23 & 27174.0 & 4.06 & 2.16 & 16.46 & -7.70 & -4.11 & -2.92 \\
\hline 36 & 19056 & 224 & 6.59 & -11984 & 247 & 7.26 & 31040.0 & 4.09 & 2.18 & 18.80 & -10.04 & -5.35 & -3.54 \\
\hline 38 & 19944 & 224 & 6.59 & -12462 & 207 & 6.09 & 32406.0 & 4.09 & 2.18 & 19.63 & -10.87 & -5.80 & -3.74 \\
\hline 40 & 21115 & 225 & 6.62 & -13051 & 206 & 6.06 & 34166.0 & 4.12 & 2.20 & 20.69 & -11.93 & -6.36 & -3.98 \\
\hline 42 & 20905 & 225 & 6.62 & -12949 & 207 & 6.09 & 33854.0 & 4.12 & 2.20 & 20.50 & -11.74 & -6.26 & -3.94 \\
\hline 44 & 18918 & 225 & 6.62 & -12179 & 207 & 6.09 & 31097.0 & 4.12 & 2.20 & 18.83 & -10.07 & -5.37 & -3.55 \\
\hline 46 & 18973 & 225 & 6.62 & -12162 & 207 & 6.09 & 31135.0 & 4.12 & 2.20 & 18.86 & -10.10 & -5.39 & -3.55 \\
\hline 48 & 19211 & 225 & 6.62 & -12017 & 206 & 6.06 & 31228.0 & 4.12 & 2.20 & 18.91 & -10.15 & -5.42 & -3.57 \\
\hline 50 & 17480 & 225 & 6.62 & -11059 & 206 & 6.06 & 28539.0 & 4.12 & 2.20 & 17.28 & -8.52 & -4.55 & -3.15 \\
\hline 52 & 18163 & 225 & 6.62 & -11815 & 206 & 6.06 & 29978.0 & 4.12 & 2.20 & 18.16 & -9.40 & -5.01 & -3.38 \\
\hline 54 & 15689 & 223 & 6.56 & -10687 & 206 & 6.06 & 26376.0 & 4.06 & 2.16 & 15.97 & -7.21 & -3.85 & -2.78 \\
\hline 56 & 17985 & 226 & 6.65 & -13031 & 251 & 7.38 & 31016.0 & 4.15 & 2.21 & 18.78 & -10.02 & -5.35 & -3.53 \\
\hline 58 & 25556 & 224 & 6.59 & -16691 & 248 & 7.29 & 42247.0 & 4.09 & 2.18 & 25.59 & -16.83 & -8.97 & -4.97 \\
\hline 60 & 25995 & 224 & 6.59 & -16558 & 248 & 7.29 & 42553.0 & 4.09 & 2.18 & 25.77 & -17.01 & -9.07 & -5.00 \\
\hline 62 & 10248 & 216 & 6.35 & -8720 & 240 & 7.06 & 18968.0 & 3.85 & 2.05 & 11.49 & -2.73 & -1.46 & -1.26 \\
\hline
\end{tabular}

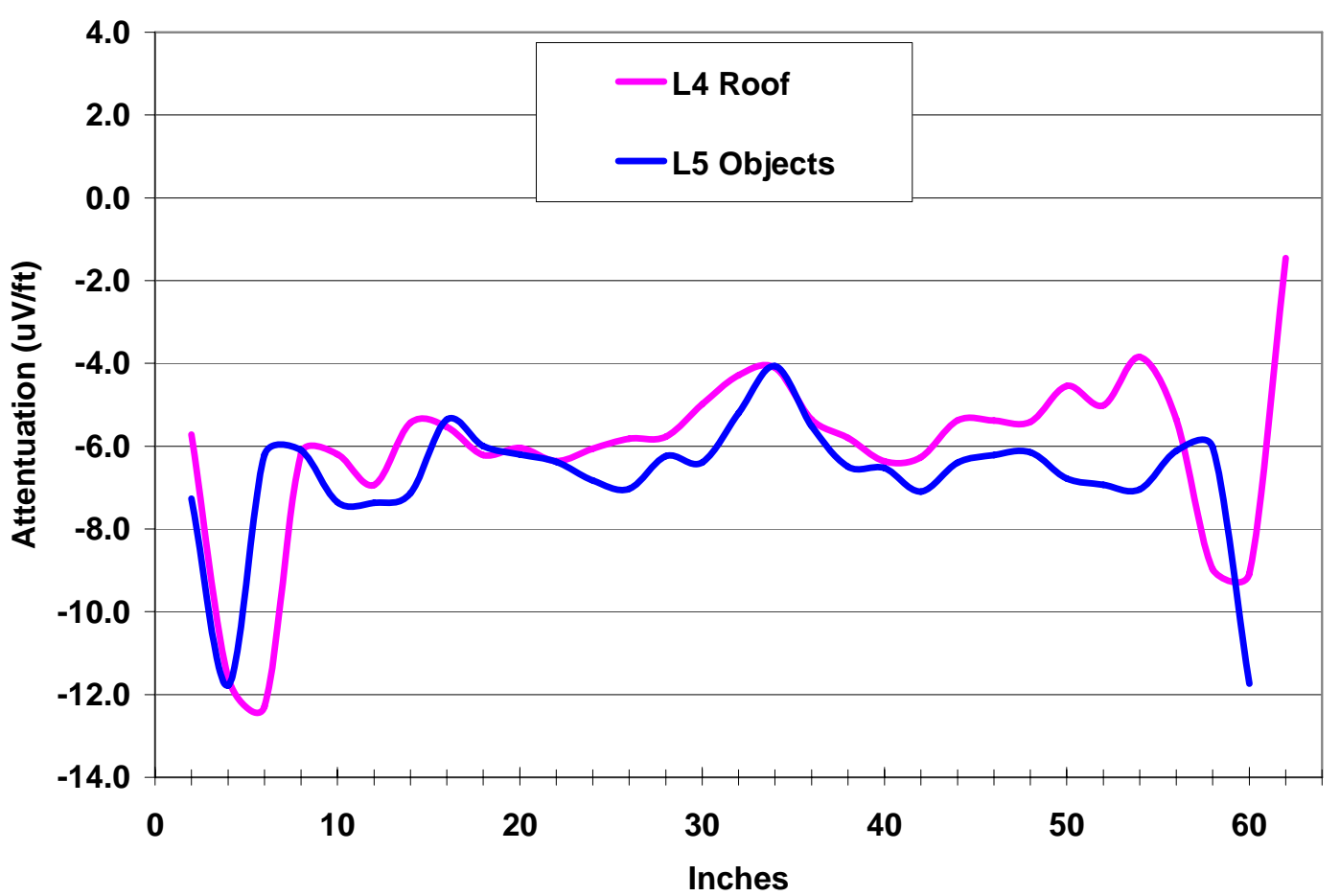

Figure B-5 Dry physical model coal seam and roof lines - Feb. 2007 
Table B-5 Reconnaissance survey test 003 - dry physical model - line 5-objects - Feb. 2007

\begin{tabular}{|c|c|c|c|c|c|c|c|c|c|c|c|c|c|}
\hline \multicolumn{14}{|c|}{$\begin{array}{c}\text { February 11, } 2007 \text { Dry Model, Line } 5 \text { Objects, File \# 1013, X= } 22.5 \text { (in), Y= } 19.56 \text { (in), Range } 15 \text { (ns), } \\
\text { Gain } 4 \text { (dB), Sv=1.5873,Sc=1651.2, Va = 8.759 (uV), Vm = model volts }\end{array}$} \\
\hline$\overline{Z \text { (in) }}$ & Max & Max & Max & Min & Min & Min & Abs & \begin{tabular}{|l|} 
First \\
\end{tabular} & Velocity & $\mathrm{Vm}$ & $\mathrm{Va}-\mathrm{Vm}$ & Att & \\
\hline & Count & Sample & Time (ns) & Count & Sample & Time (ns) & & Arrival (ns) & $\mathrm{ft} / \mathrm{ns}$ & $\mathrm{uV}$ & $\mathrm{uV}$ & $\mathrm{uV} / \mathrm{ft}$ & $\mathrm{db} / \mathrm{ft}$ \\
\hline 2 & 22140 & 214 & 6.29 & -14832 & 236 & 6.94 & 36972.0 & 3.79 & 2.02 & 22.39 & -13.63 & $\begin{array}{l}-7.27 \\
\end{array}$ & -4.35 \\
\hline 4 & 31056 & 219 & 6.44 & -19875 & 201 & 5.91 & 50931.0 & 3.94 & 2.10 & 30.84 & -22.09 & -11.78 & -5.83 \\
\hline 6 & 20360 & 221 & 6.50 & -13317 & 245 & 7.21 & \begin{tabular}{|l|}
33677.0 \\
\end{tabular} & 4.00 & 2.13 & 20.40 & -11.64 & -6.21 & -3.92 \\
\hline 8 & 20142 & 221 & 6.50 & -13197 & 245 & 7.21 & 33339.0 & 4.00 & 2.13 & 20.19 & -11.43 & -6.10 & -3.87 \\
\hline 10 & 22924 & 220 & 6.47 & -14305 & 202 & 5.94 & 37229.0 & 3.97 & 2.12 & 22.55 & -13.79 & -7.35 & -4.38 \\
\hline 12 & 22886 & 220 & 6.47 & -14383 & 202 & 5.94 & 37269.0 & 3.97 & 2.12 & 22.57 & -13.81 & -7.37 & -4.38 \\
\hline 14 & 21796 & 220 & 6.47 & -14764 & 242 & 7.12 & 36560.0 & 3.97 & 2.12 & 22.14 & -13.38 & -7.14 & -4.30 \\
\hline 16 & 19021 & 219 & 6.44 & -12020 & 201 & 5.91 & 31041.0 & 3.94 & 2.10 & 18.80 & -10.04 & -5.35 & -3.54 \\
\hline 18 & 20004 & 219 & 6.44 & -13025 & 201 & 5.91 & 33029.0 & 3.94 & 2.10 & 20.00 & -11.24 & -6.00 & -3.83 \\
\hline 20 & 20339 & 218 & 6.41 & -13309 & 201 & 5.91 & 33648.0 & 3.91 & 2.09 & 20.38 & -11.62 & -6.20 & -3.91 \\
\hline 22 & 20779 & 218 & 6.41 & -13439 & 201 & 5.91 & 34218.0 & 3.91 & 2.09 & 20.72 & -11.96 & -6.38 & -3.99 \\
\hline 24 & 21683 & 219 & 6.44 & -13919 & 201 & 5.91 & 35602.0 & 3.94 & 2.10 & 21.56 & -12.80 & -6.83 & -4.17 \\
\hline 26 & 22104 & 218 & 6.41 & -14119 & 201 & 5.91 & 36223.0 & 3.91 & 2.09 & 21.94 & -13.18 & -7.03 & -4.25 \\
\hline 28 & 20427 & 216 & 6.35 & -13363 & 199 & 5.85 & 33790.0 & 3.85 & 2.05 & 20.46 & -11.70 & -6.24 & -3.93 \\
\hline 30 & 20697 & 216 & 6.35 & -13549 & 199 & 5.85 & 34246.0 & 3.85 & 2.05 & 20.74 & -11.98 & -6.39 & -3.99 \\
\hline 32 & 18706 & 216 & 6.35 & -11867 & 199 & 5.85 & 30573.0 & 3.85 & 2.05 & 18.52 & -9.76 & -5.20 & -3.47 \\
\hline 34 & 16474 & 216 & 6.35 & -10577 & 199 & 5.85 & \begin{tabular}{|l|}
27051.0 \\
\end{tabular} & 3.85 & 2.05 & 16.38 & -7.62 & -4.07 & -2.90 \\
\hline 36 & 19319 & 217 & 6.38 & -12224 & 200 & 5.88 & 31543.0 & 3.88 & 2.07 & 19.10 & -10.34 & -5.52 & -3.61 \\
\hline 38 & 20948 & 218 & 6.41 & -13636 & 201 & 5.91 & 34584.0 & 3.91 & 2.09 & 20.94 & -12.19 & -6.50 & -4.04 \\
\hline 40 & 21191 & 218 & 6.41 & -13484 & 240 & 7.06 & 34675.0 & 3.91 & 2.09 & 21.00 & -12.24 & -6.53 & -4.05 \\
\hline 42 & 22332 & 218 & 6.41 & -14100 & 201 & 5.91 & 36432.0 & 3.91 & 2.09 & 22.06 & -13.30 & -7.10 & -4.28 \\
\hline 44 & 21002 & 218 & 6.41 & -13264 & 201 & 5.91 & 34266.0 & 3.91 & 2.09 & 20.75 & -11.99 & -6.40 & -4.00 \\
\hline 46 & 20301 & 217 & 6.38 & -13391 & 200 & 5.88 & 33692.0 & 3.88 & 2.07 & 20.40 & -11.65 & -6.21 & -3.92 \\
\hline 48 & 20167 & 217 & 6.38 & -13327 & 200 & 5.88 & 33494.0 & 3.88 & 2.07 & 20.28 & -11.53 & -6.15 & -3.89 \\
\hline 50 & 21828 & 219 & 6.44 & -13618 & 201 & 5.91 & 35446.0 & 3.94 & 2.10 & 21.47 & -12.71 & -6.78 & -4.15 \\
\hline 52 & 21993 & 218 & 6.41 & -13924 & 201 & 5.91 & \begin{tabular}{|l|}
35917.0 \\
\end{tabular} & 3.91 & 2.09 & 21.75 & -12.99 & -6.93 & -4.21 \\
\hline 54 & 22244 & 218 & 6.41 & -14024 & 201 & 5.91 & 36268.0 & 3.91 & 2.09 & 21.96 & -13.21 & -7.04 & -4.26 \\
\hline 56 & 20001 & 217 & 6.38 & -13400 & 201 & 5.91 & 33401.0 & 3.88 & 2.07 & 20.23 & -11.47 & -6.12 & -3.88 \\
\hline 58 & 19519 & 220 & 6.47 & -13591 & 244 & 7.18 & 33110.0 & 3.97 & 2.12 & 20.05 & -11.29 & -6.02 & -3.84 \\
\hline 60 & 30912 & 217 & 6.38 & -19893 & 200 & 5.88 & 50805.0 & 3.88 & 2.07 & 30.77 & -22.01 & -11.74 & -5.82 \\
\hline 62 & 19600 & 213 & 6.26 & -14611 & 235 & 6.91 & 34211.0 & 3.76 & 2.01 & 20.72 & -11.96 & -6.38 & -3.99 \\
\hline
\end{tabular}


Reconnaissance Tests Results from April 2006

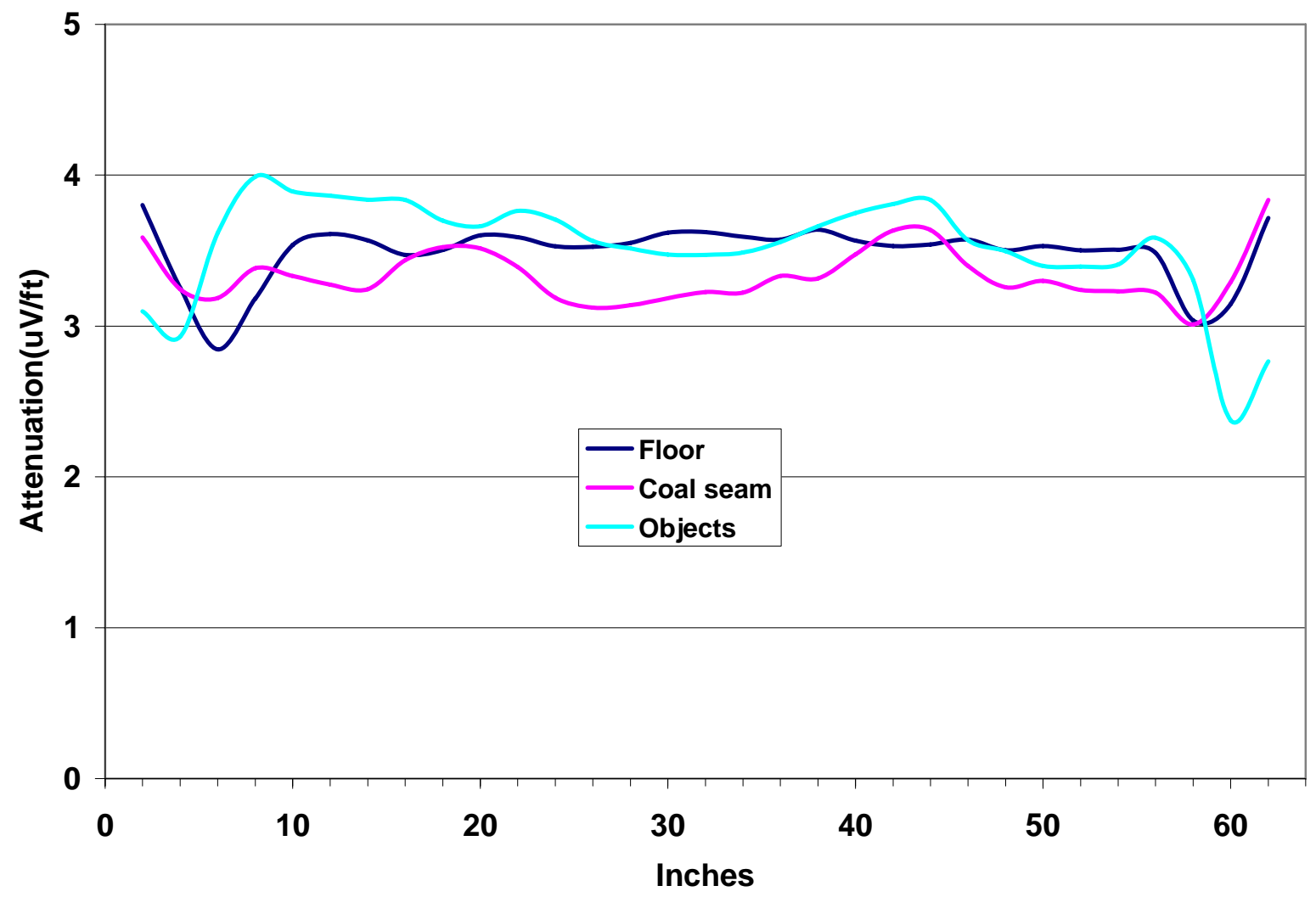

Figure B-6 Reconnaissance test 002 - floor, coal seam and objects - Apr. 2006 
Table B-6 Reconnaissance survey test 002 - physical model - floor - Apr. 2006

\begin{tabular}{||c|c|c|c|c|c|c|c||}
\hline \multicolumn{7}{|c|}{ April 2006, Model, in the Floor, $\mathrm{X}=22.5$ (in), Y=4.25 (in), Range 15 (ns) } \\
\hline \hline Gain 22 (dB), Sc=13115.92, Va $=8.759(\mathrm{uV}), \mathrm{Vm}=$ model volts \\
\hline \hline & Max & Min & Abs & Vm & Va -Vm & \multicolumn{2}{|c||}{ Attentuation } \\
\hline \hline 2 & 9651 & -11734 & 21385 & 1.63 & 7.13 & 3.80 & 7.79 \\
\hline 4 & 15525 & -19362 & 34887 & 2.66 & 6.10 & 3.25 & 5.52 \\
\hline 6 & 21061 & -23859 & 44920 & 3.42 & 5.33 & 2.84 & 4.35 \\
\hline 8 & 15831 & -20802 & 36633 & 2.79 & 5.97 & 3.18 & 5.29 \\
\hline 10 & 11455 & -16422 & 27877 & 2.13 & 6.63 & 3.54 & 6.56 \\
\hline 12 & 11107 & -14987 & 26094 & 1.99 & 6.77 & 3.61 & 6.87 \\
\hline 14 & 11571 & -15577 & 27148 & 2.07 & 6.69 & 3.57 & 6.68 \\
\hline 16 & 12727 & -16793 & 29520 & 2.25 & 6.51 & 3.47 & 6.29 \\
\hline 18 & 12518 & -16196 & 28714 & 2.19 & 6.57 & 3.50 & 6.42 \\
\hline 20 & 11394 & -14933 & 26327 & 2.01 & 6.75 & 3.60 & 6.83 \\
\hline 22 & 11395 & -15220 & 26615 & 2.03 & 6.73 & 3.59 & 6.77 \\
\hline 24 & 11884 & -16241 & 28125 & 2.14 & 6.61 & 3.53 & 6.52 \\
\hline 26 & 11813 & -16372 & 28185 & 2.15 & 6.61 & 3.53 & 6.51 \\
\hline 28 & 11457 & -16089 & 27546 & 2.10 & 6.66 & 3.55 & 6.62 \\
\hline 30 & 10577 & -15321 & 25898 & 1.97 & 6.78 & 3.62 & 6.90 \\
\hline 32 & 10921 & -14883 & 25804 & 1.97 & 6.79 & 3.62 & 6.92 \\
\hline 34 & 11102 & -15454 & 26556 & 2.02 & 6.73 & 3.59 & 6.78 \\
\hline 36 & 11400 & -15611 & 27011 & 2.06 & 6.70 & 3.57 & 6.71 \\
\hline 38 & 10787 & -14595 & 25382 & 1.94 & 6.82 & 3.64 & 6.99 \\
\hline 40 & 11768 & -15401 & 27169 & 2.07 & 6.69 & 3.57 & 6.68 \\
\hline 42 & 12016 & -16039 & 28055 & 2.14 & 6.62 & 3.53 & 6.53 \\
\hline 44 & 11837 & -15975 & 27812 & 2.12 & 6.64 & 3.54 & 6.57 \\
\hline 46 & 11402 & -15601 & 27003 & 2.06 & 6.70 & 3.57 & 6.71 \\
\hline 48 & 11861 & -16895 & 28756 & 2.19 & 6.57 & 3.50 & 6.42 \\
\hline 50 & 11523 & -16525 & 28048 & 2.14 & 6.62 & 3.53 & 6.53 \\
\hline 52 & 11851 & -16900 & 28751 & 2.19 & 6.57 & 3.50 & 6.42 \\
\hline 54 & 11851 & -16834 & 28685 & 2.19 & 6.57 & 3.51 & 6.43 \\
\hline 56 & 12091 & -17062 & 29153 & 2.22 & 6.54 & 3.49 & 6.35 \\
\hline 58 & 18433 & -21761 & 40194 & 3.06 & 5.69 & 3.04 & 4.86 \\
\hline 60 & 17755 & -19785 & 37540 & 2.86 & 5.90 & 3.14 & 5.18 \\
\hline 62 & 12119 & -11377 & 23496 & 1.79 & 6.97 & 3.72 & 7.35 \\
\hline
\end{tabular}


Table B-7 Reconnaissance survey test 002 - physical model - coal seam - Apr. 2006

\begin{tabular}{|c|c|c|c|c|c|c|c|}
\hline \multicolumn{8}{|c|}{$\begin{array}{l}\text { April 2006, Model, Line in the Coal Seam, X }=22.5 \text { (in), Y= } 11.5 \text { (in), Range } 15 \text { (ns), } \\
\text { Gain } 22(\mathrm{~dB}), \mathrm{Sc}=13115.92, \mathrm{Va}=8.759(\mathrm{uV}), \mathrm{Vm}=\text { model volts }\end{array}$} \\
\hline$\overline{\overline{Z \text { Z (in) }}}$ & Max & Min & Abs & Vm & Va-Vm & Attentuation & \\
\hline & Count & Count & & uV & $\mathrm{uV}$ & $\mathrm{uV} / \mathrm{ft}$ & $\mathrm{dB} / \mathrm{ft}$ \\
\hline$\overline{2}$ & $\bar{~} 10086$ & $\overline{-1-16567}$ & 26653 & $\overline{2.03}$ & (26.73 & 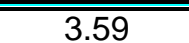 & 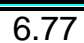 \\
\hline 4 & 13535 & -21573 & 35108 & 2.68 & 6.08 & 3.24 & 5.49 \\
\hline 6 & 14733 & $\begin{array}{l}-21798 \\
\end{array}$ & 36531 & 2.79 & 5.97 & 3.19 & 5.31 \\
\hline 8 & 13166 & -18540 & 31706 & 2.42 & 6.34 & 3.38 & 5.96 \\
\hline 10 & 12992 & -19943 & 32935 & 2.51 & 6.25 & 3.33 & 5.79 \\
\hline 12 & 13796 & -20564 & 34360 & 2.62 & 6.14 & 3.27 & 5.59 \\
\hline 14 & 14532 & -20547 & 35079 & 2.67 & 6.08 & 3.25 & 5.50 \\
\hline 16 & 12328 & -18031 & 30359 & 2.31 & 6.44 & 3.44 & 6.16 \\
\hline 18 & 11179 & -17070 & 28249 & 2.15 & 6.61 & 3.52 & 6.50 \\
\hline 20 & 11704 & -16758 & 28462 & 2.17 & 6.59 & 3.51 & 6.46 \\
\hline 22 & 13164 & -18288 & 31452 & 2.40 & 6.36 & 3.39 & 6.00 \\
\hline 24 & 14547 & -21954 & 36501 & 2.78 & 5.98 & 3.19 & 5.31 \\
\hline 26 & 14831 & -23260 & 38091 & 2.90 & 5.85 & 3.12 & 5.11 \\
\hline 28 & 14870 & -22859 & 37729 & 2.88 & 5.88 & 3.14 & 5.16 \\
\hline 30 & 14620 & -21942 & 36562 & 2.79 & 5.97 & 3.18 & 5.30 \\
\hline 32 & 14384 & -21166 & 35550 & 2.71 & 6.05 & 3.23 & 5.43 \\
\hline 34 & 14946 & -20715 & 35661 & 2.72 & 6.04 & 3.22 & 5.42 \\
\hline 36 & 13540 & -19400 & 32940 & 2.51 & 6.25 & 3.33 & 5.79 \\
\hline 38 & 14335 & -19031 & 33366 & 2.54 & 6.22 & 3.31 & 5.73 \\
\hline 40 & 13355 & -16057 & 29412 & 2.24 & 6.52 & 3.48 & 6.31 \\
\hline 42 & 11334 & -14200 & 25534 & 1.95 & 6.81 & 3.63 & 6.97 \\
\hline 44 & 11097 & -14326 & 25423 & 1.94 & 6.82 & 3.64 & 6.99 \\
\hline 46 & 13241 & -18043 & 31284 & 2.39 & 6.37 & 3.40 & 6.03 \\
\hline 48 & 14423 & -20366 & 34789 & 2.65 & 6.11 & 3.26 & 5.53 \\
\hline 50 & 14029 & -19709 & 33738 & 2.57 & 6.19 & 3.30 & 5.68 \\
\hline 52 & 14853 & -20363 & 35216 & 2.68 & 6.07 & 3.24 & 5.48 \\
\hline 54 & 14748 & -20690 & 35438 & 2.70 & 6.06 & 3.23 & 5.45 \\
\hline 56 & 15352 & -20298 & 35650 & 2.72 & 6.04 & 3.22 & 5.42 \\
\hline 58 & 17577 & -23260 & 40837 & 3.11 & 5.65 & 3.01 & 4.79 \\
\hline 60 & 12299 & -21653 & 33952 & 2.59 & 6.17 & 3.29 & 5.65 \\
\hline 62 & 7456 & -13111 & 20567 & 1.57 & 7.19 & 3.84 & 7.97 \\
\hline
\end{tabular}


Table B-8 Reconnaissance survey test 002 - physical model - objects - Apr. 2006

\begin{tabular}{|c|c|c|c|c|c|c|c|}
\hline \multicolumn{8}{|c|}{$\begin{array}{c}\text { April 2006, Model, Line in the Objects, } X=22.5(\mathrm{in}), \mathrm{Y}=21 \text { (in), Range } 15 \text { (ns) } \\
\text { Gain } 22(\mathrm{~dB}), \mathrm{Sc}=13115.92, \mathrm{Va}=8.759(\mathrm{uV}), \mathrm{Vm}=\text { model volts }\end{array}$} \\
\hline$Z$ Z (in) & $\operatorname{Max}$ & Min & Abs & Vm & $\mathrm{Va}-\mathrm{Vm}$ & \multicolumn{2}{|c|}{ Attentuation } \\
\hline & Count & Count & & $\mathrm{uV}$ & $\mathrm{uV}$ & $\mathrm{uV} / \mathrm{ft}$ & $\mathrm{dB} / \mathrm{ft}$ \\
\hline 2 & 17364 & -21333 & 38697 & 2.95 & $\overline{5.81}$ & 3.10 & $\overline{5.04}$ \\
\hline 4 & 18027 & -24809 & 42836 & 3.27 & 5.49 & 2.93 & 4.57 \\
\hline 6 & 11449 & -14491 & 25940 & 1.98 & 6.78 & 3.62 & 6.89 \\
\hline 8 & 9022 & -7732 & 16754 & 1.28 & 7.48 & 3.99 & 8.92 \\
\hline 10 & 9412 & -9745 & 19157 & 1.46 & 7.30 & 3.89 & 8.30 \\
\hline 12 & 9220 & -10653 & 19873 & 1.52 & 7.24 & 3.86 & 8.13 \\
\hline 14 & 9198 & -11328 & 20526 & 1.56 & 7.19 & 3.84 & 7.98 \\
\hline 16 & 8940 & -11603 & 20543 & 1.57 & 7.19 & 3.84 & 7.97 \\
\hline 18 & 10570 & -13336 & 23906 & 1.82 & 6.94 & 3.70 & 7.27 \\
\hline 20 & 10640 & -14210 & 24850 & 1.89 & 6.86 & 3.66 & 7.09 \\
\hline 22 & 9617 & -12710 & 22327 & 1.70 & 7.06 & 3.76 & 7.59 \\
\hline 24 & 9937 & -13796 & 23733 & 1.81 & 6.95 & 3.71 & 7.31 \\
\hline 26 & 11376 & -15879 & 27255 & 2.08 & 6.68 & 3.56 & 6.66 \\
\hline 28 & 12234 & -16235 & 28469 & 2.17 & 6.59 & 3.51 & 6.46 \\
\hline 30 & 13261 & -16189 & 29450 & 2.25 & 6.51 & 3.47 & 6.31 \\
\hline 32 & 14109 & -15412 & 29521 & 2.25 & 6.51 & 3.47 & 6.29 \\
\hline 34 & 13942 & -15162 & 29104 & 2.22 & 6.54 & 3.49 & 6.36 \\
\hline 36 & 12907 & -14520 & 27427 & 2.09 & 6.67 & 3.56 & 6.64 \\
\hline 38 & 11159 & -13653 & 24812 & 1.89 & 6.87 & 3.66 & 7.10 \\
\hline 40 & 10521 & -12179 & 22700 & 1.73 & 7.03 & 3.75 & 7.51 \\
\hline 42 & 9962 & -11263 & 21225 & 1.62 & 7.14 & 3.81 & 7.82 \\
\hline 44 & 10000 & -10547 & 20547 & 1.57 & 7.19 & 3.84 & 7.97 \\
\hline 46 & 12679 & -14445 & 27124 & 2.07 & 6.69 & 3.57 & 6.69 \\
\hline 48 & 13214 & -15694 & 28908 & 2.20 & 6.55 & 3.50 & 6.39 \\
\hline 50 & 13925 & -17349 & 31274 & 2.38 & 6.37 & 3.40 & 6.03 \\
\hline 52 & 13857 & -17573 & 31430 & 2.40 & 6.36 & 3.39 & 6.00 \\
\hline 54 & 13840 & -17215 & 31055 & 2.37 & 6.39 & 3.41 & 6.06 \\
\hline 56 & 12646 & -14063 & 26709 & 2.04 & 6.72 & 3.59 & 6.76 \\
\hline 58 & 14083 & -19509 & 33592 & 2.56 & 6.20 & 3.31 & 5.70 \\
\hline 60 & 23728 & -32768 & 56496 & 4.31 & 4.45 & 2.37 & 3.29 \\
\hline 62 & 19615 & -27265 & 46880 & 3.57 & 5.18 & 2.77 & 4.15 \\
\hline
\end{tabular}


Reconnaissance Tests Results from February 2006

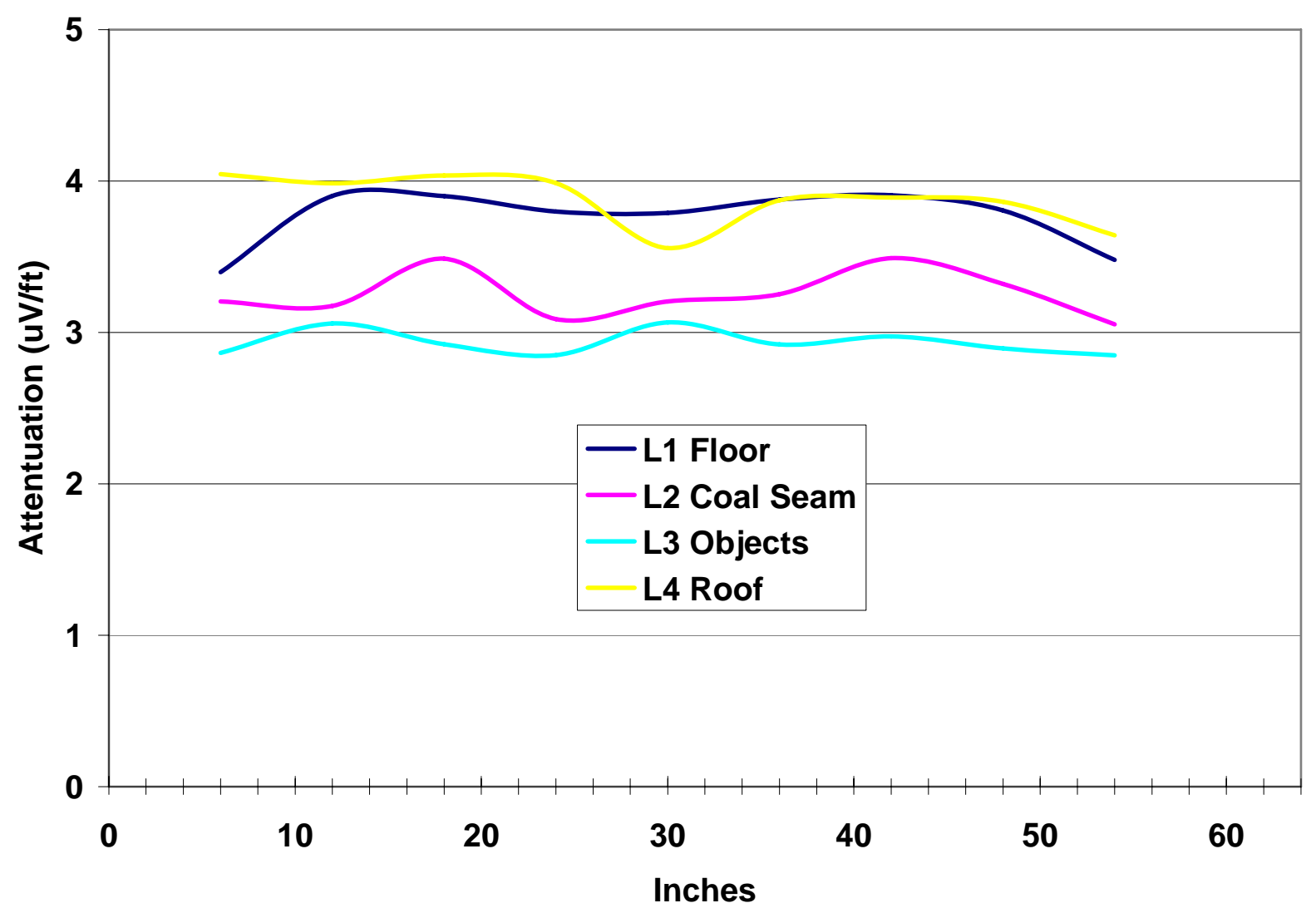

Figure B-7 Reconnaissance test 001 floor, coal seam, objects, and roof - Feb. 2006 
Table B-9 Reconnaissance survey test 001 - physical model -floor - Feb. 2006

\begin{tabular}{|c|c|c|c|c|c|c|c|c|c|c|c|c|c|}
\hline \multicolumn{14}{|c|}{$\begin{array}{l}\text { February 7, } 2006 \text { Line } 1 \text { in the Floor, File \# 830, X = } 22.5 \text { (in), Y= 4.25 (in), } \\
\text { Range } 6 \text { (ns), Gain } 25 \text { (dB), Sc=18526.73, Va = 8.759 (uV), Vm = model volts }\end{array}$} \\
\hline$Z$ (in) & $\operatorname{Max}$ & Max & Max & Min & Min & Min & Abs & First & Velocity & $\mathrm{Vm}$ & $\mathrm{Va}-\mathrm{Vm}$ & Atte & tion \\
\hline & Count & Sample & Time (ns) & Count & Sample & Time (ns) & & Arrival (ns) & $\mathrm{ft} / \mathrm{ns}$ & $\mathrm{uV}$ & $\mathrm{uV}$ & $\mathrm{uV} / \mathrm{ft}$ & $\mathrm{db} / \mathrm{ft}$ \\
\hline 6 & 14852 & 306 & 3.60 & -29393 & 362 & 4.26 & 44245 & 4.26 & 2.27 & 2.4 & 6.4 & 3.40 & 6.02 \\
\hline 12 & 9691 & 304 & 3.58 & -17019 & 364 & 4.28 & 26710 & 4.28 & 2.28 & 1.4 & 7.3 & 3.90 & 8.36 \\
\hline 18 & 9172 & 305 & 3.59 & $\begin{array}{l}-17639 \\
\end{array}$ & 364 & 4.28 & 26811 & 4.28 & 2.28 & 1.4 & 7.3 & 3.90 & 8.34 \\
\hline 24 & 10713 & 318 & 3.74 & -19583 & 365 & 4.29 & 30296 & 4.29 & 2.29 & 1.6 & 7.1 & 3.80 & 7.77 \\
\hline 30 & 11537 & 305 & 3.59 & \begin{tabular}{|l|}
-19101 \\
\end{tabular} & 360 & 4.24 & 30638 & 4.24 & 2.26 & 1.7 & 7.1 & 3.79 & 7.72 \\
\hline 36 & 9770 & 304 & 3.58 & -17778 & 363 & 4.27 & 27548 & 4.27 & 2.28 & 1.5 & 7.3 & 3.88 & 8.22 \\
\hline 42 & 9499 & 321 & 3.78 & -17088 & 371 & 4.37 & 26587 & 4.37 & 2.33 & 1.4 & 7.3 & 3.91 & 8.38 \\
\hline 48 & 11812 & 322 & 3.79 & -18225 & 372 & 4.38 & 30037 & 4.38 & 2.34 & 1.6 & 7.1 & 3.81 & 7.81 \\
\hline 54 & 16037 & 302 & 3.55 & -25339 & 360 & 4.24 & 41376 & 4.24 & 2.26 & 2.2 & 6.5 & 3.48 & 6.33 \\
\hline
\end{tabular}

Table B-10 Reconnaissance survey test $001-$ physical model - coal seam - Feb. 2006

\begin{tabular}{|c|c|c|c|c|c|c|c|c|c|c|c|c|c|}
\hline \multicolumn{14}{|c|}{$\begin{array}{l}\text { February 7, } 2006 \text { Line } 2 \text { in Coal Seam, File \# 831, X = 22.5 (in), Y= } 11.5 \text { (in), } \\
\text { Range } 6 \text { (ns), Gain } 25 \text { (dB), Sc=18526.73, Va = 8.759 (uV), Vm = model volts }\end{array}$} \\
\hline$\overline{\bar{Z} \text { (in) }}$ & Max & Max & Max & Min & Min & Min & Abs & First & Velocity & $\overline{V m}$ & $\overline{V a-V m}$ & Atte & tion \\
\hline & Count & Sample & Time (ns) & Count & Sample & Time (ns) & & Arrival (ns) & $\mathrm{ft} / \mathrm{ns}$ & $\mathrm{uV}$ & $\mathrm{uV}$ & $\mathrm{uV} / \mathrm{ft}$ & $\mathrm{db} / \mathrm{ft}$ \\
\hline 6 & 21375 & 305 & 3.59 & -29588 & 361 & 4.25 & 50963 & 3.59 & 1.91 & 2.8 & 6.0 & 3.20 & 5.37 \\
\hline 12 & 21886 & 303 & 3.57 & -30097 & 360 & 4.24 & 51983 & 3.57 & 1.90 & 2.8 & 6.0 & 3.18 & 5.27 \\
\hline 18 & 17176 & 303 & 3.57 & -23998 & 357 & 4.2 & 41174 & 3.57 & 1.90 & 2.2 & 6.5 & 3.49 & 6.35 \\
\hline 24 & 22242 & 306 & 3.60 & -32768 & 358 & 4.21 & 55010 & 3.60 & 1.92 & 3.0 & 5.8 & 3.09 & 5.01 \\
\hline 30 & 21969 & 305 & 3.59 & -28963 & 357 & 4.2 & 50932 & 3.59 & 1.91 & 2.7 & 6.0 & 3.21 & 5.37 \\
\hline 36 & 21989 & 302 & 3.55 & -27280 & 350 & 4.12 & 49269 & 3.55 & 1.89 & 2.7 & 6.1 & 3.25 & 5.52 \\
\hline 42 & 18604 & 302 & 3.55 & -22413 & 353 & 4.15 & 41017 & 3.55 & 1.89 & 2.2 & 6.5 & 3.49 & 6.37 \\
\hline 48 & 19700 & 305 & 3.59 & -27229 & 361 & 4.25 & 46929 & 3.59 & 1.91 & 2.5 & 6.2 & 3.32 & 5.75 \\
\hline 54 & 25020 & 304 & 3.58 & -31164 & 354 & 4.16 & 56184 & 3.58 & 1.91 & 3.0 & 5.7 & 3.05 & 4.91 \\
\hline
\end{tabular}

Table B-11 Reconnaissance survey test 001 - physical model - roof - Feb. 2006

\begin{tabular}{|c|c|c|c|c|c|c|c|c|c|c|c|c|c|}
\hline \multicolumn{14}{|c|}{$\begin{array}{l}\text { February 7, } 2006 \text { Line } 3 \text { in Roof, File } \# 835, X=22.5 \text { (in), Y= } 16 \text { (in), } \\
\text { Range } 6 \text { (ns), Gain } 25 \text { (dB), Sc=18526.73, Va = 8.759 (uV), Vm = model volts }\end{array}$} \\
\hline$Z$ (in) & $\operatorname{Max}$ & $\operatorname{Max}$ & Max & Min & Min & Min & Abs & First & Velocity & $\mathrm{Vm}$ & Va-Vm & Atte & tion \\
\hline & Count & Sample & Time (ns) & Count & Sample & Time (ns) & & Arrival (ns) & $\mathrm{ft} / \mathrm{ns}$ & $\mathrm{uV}$ & $\mathrm{uV}$ & $\mathrm{uV} / \mathrm{ft}$ & $\mathrm{db} / \mathrm{ft}$ \\
\hline 6 & 29994 & 290.7 & \begin{tabular}{r|}
3.42 \\
\end{tabular} & -32768 & 346 & $\begin{array}{l}4.07 \\
\end{array}$ & 62762 & \begin{tabular}{|l|}
3.42 \\
\end{tabular} & 1.82 & 3.4 & 5.4 & 2.86 & 4.40 \\
\hline 12 & 24780 & 287.3 & 3.38 & -31235 & 339 & 3.99 & 56015 & 3.38 & 1.80 & 3.0 & 5.7 & 3.06 & 4.93 \\
\hline 18 & 27992 & 287.3 & 3.38 & -32768 & 333 & 3.92 & 60760 & 3.38 & 1.80 & 3.3 & 5.5 & 2.92 & 4.55 \\
\hline 24 & 30497 & 285.6 & 3.36 & -32768 & 339 & 3.99 & 63265 & 3.36 & 1.79 & 3.4 & 5.3 & 2.85 & 4.36 \\
\hline 30 & 23920 & 283.05 & 3.33 & -31841 & 326 & 3.84 & 55761 & 3.33 & 1.78 & 3.0 & 5.7 & 3.07 & 4.95 \\
\hline 36 & 28052 & 287.3 & 3.38 & -32768 & 340 & 4.00 & 60820 & 3.38 & 1.80 & 3.3 & 5.5 & 2.92 & 4.55 \\
\hline 42 & 26188 & 288.15 & 3.39 & -32768 & 339 & 3.99 & 58956 & 3.39 & 1.81 & 3.2 & 5.6 & 2.97 & 4.69 \\
\hline 48 & 28979 & 285.6 & 3.36 & -32768 & 338 & 3.98 & 61747 & 3.36 & 1.79 & 3.3 & 5.4 & 2.89 & 4.48 \\
\hline 54 & 30566 & 285.6 & 3.36 & -32768 & 339 & 3.99 & 63334 & 3.36 & 1.79 & 3.4 & 5.3 & 2.85 & 4.36 \\
\hline
\end{tabular}

Table B-12 Reconnaissance survey test 001 - physical model - objects - Feb. 2006

\begin{tabular}{|c|c|c|c|c|c|c|c|c|c|c|c|c|c|}
\hline \multicolumn{14}{|c|}{$\begin{array}{l}\text { February 6, } 2006 \text { Line } 4 \text { in Objects, File \# 836, X = 22.5 (in), Y= } 21 \text { (in), } \\
\text { Range } 6 \text { (ns), Gain } 25 \text { (dB), Sc=18526.73, Va = 8.759 (uV), Vm = model volts }\end{array}$} \\
\hline Z (in) & Max & Max & Max & Min & Min & Min & Abs & First & Velocity & $\mathrm{Vm}$ & $\mathrm{Va}-\mathrm{Vm}$ & Atte & tion \\
\hline & Count & Sample & Time (ns) & Count & Sample & Time (ns) & & Arrival (ns) & $\mathrm{ft} / \mathrm{ns}$ & $\mathrm{uV}$ & $\mathrm{uV}$ & $\mathrm{uV} / \mathrm{ft}$ & $\mathrm{db} / \mathrm{ft}$ \\
\hline$\overline{c 6}$ & 10222 & 228 & 2.68 & -11484 & 283 & 3.33 & 21706 & \begin{tabular}{|l|}
2.68 \\
\end{tabular} & 1.43 & 1.2 & $\overline{77.6}$ & 4.05 & 9.32 \\
\hline 12 & 10643 & 226 & 2.66 & -13166 & 281 & 3.31 & 23809 & 2.66 & 1.42 & 1.3 & 7.5 & 3.99 & 8.89 \\
\hline 18 & 9091 & 225 & 2.65 & -12931 & 284 & 3.34 & 22022 & 2.65 & 1.41 & 1.2 & 7.6 & 4.04 & 9.25 \\
\hline 24 & 10350 & 225 & 2.65 & -13406 & 285 & 3.35 & 23756 & 2.65 & 1.41 & 1.3 & 7.5 & 3.99 & 8.90 \\
\hline 30 & 16838 & 225 & 2.65 & -21873 & 266 & 3.13 & 38711 & 2.65 & 1.41 & 2.1 & 6.7 & 3.56 & 6.64 \\
\hline 36 & 13385 & 227 & 2.67 & -14349 & 279 & 3.28 & 27734 & 2.67 & 1.42 & 1.5 & 7.3 & 3.87 & 8.18 \\
\hline 42 & 13055 & 229 & 2.69 & -14024 & 281 & 3.31 & 27079 & 2.69 & 1.43 & 1.5 & 7.3 & 3.89 & 8.29 \\
\hline 48 & 12304 & 231 & 2.72 & -15794 & 286 & 3.36 & 28098 & 2.72 & 1.45 & 1.5 & 7.2 & 3.86 & 8.12 \\
\hline 54 & 14913 & 230 & 2.71 & -20868 & 288 & 3.39 & 35781 & 2.71 & 1.45 & 1.9 & 6.8 & 3.64 & 7.00 \\
\hline
\end{tabular}




\section{APPENDIX C: EXAMPLE OF CONTROL UNIT SETUP PARAMETERS}

A modified SIR-2 ground penetrating radar built by Geophysical Survey Systems, Inc was used in these studies. The SIR-2 a lightweight, portable, general-purpose radar system and is available as an intrinsically safe unit. Prior to an EM surveys, the control unit requires setup parameters. An example of the set-up parameters is shown in the Table C-1 below.

Table C-1 Example of set parameters for the EM control unit

\begin{tabular}{|l|c|}
\hline \multicolumn{1}{|c|}{ Parameter } & 900-MHz Antenna \\
\hline Data collection mode & Continuous \\
\hline Range, ns & 15 \\
\hline Samples per scan & 512 \\
\hline Resolution, bits & 16 \\
\hline Gain Points & $20,20,20,20$ \\
\hline Vertical high pass filter, MHz & 100 \\
\hline Vertical low pass filter, MHz & 1800 \\
\hline Scans per second & 32 \\
\hline Horizontal Smoothing, scans & 4 \\
\hline Transmit Rate, KHz & 32 \\
\hline
\end{tabular}




\section{APPENDIX D: ANTENNAS}

The antennas used in this study were $900 \mathrm{MHz}$. The Figures below show additional antennas.

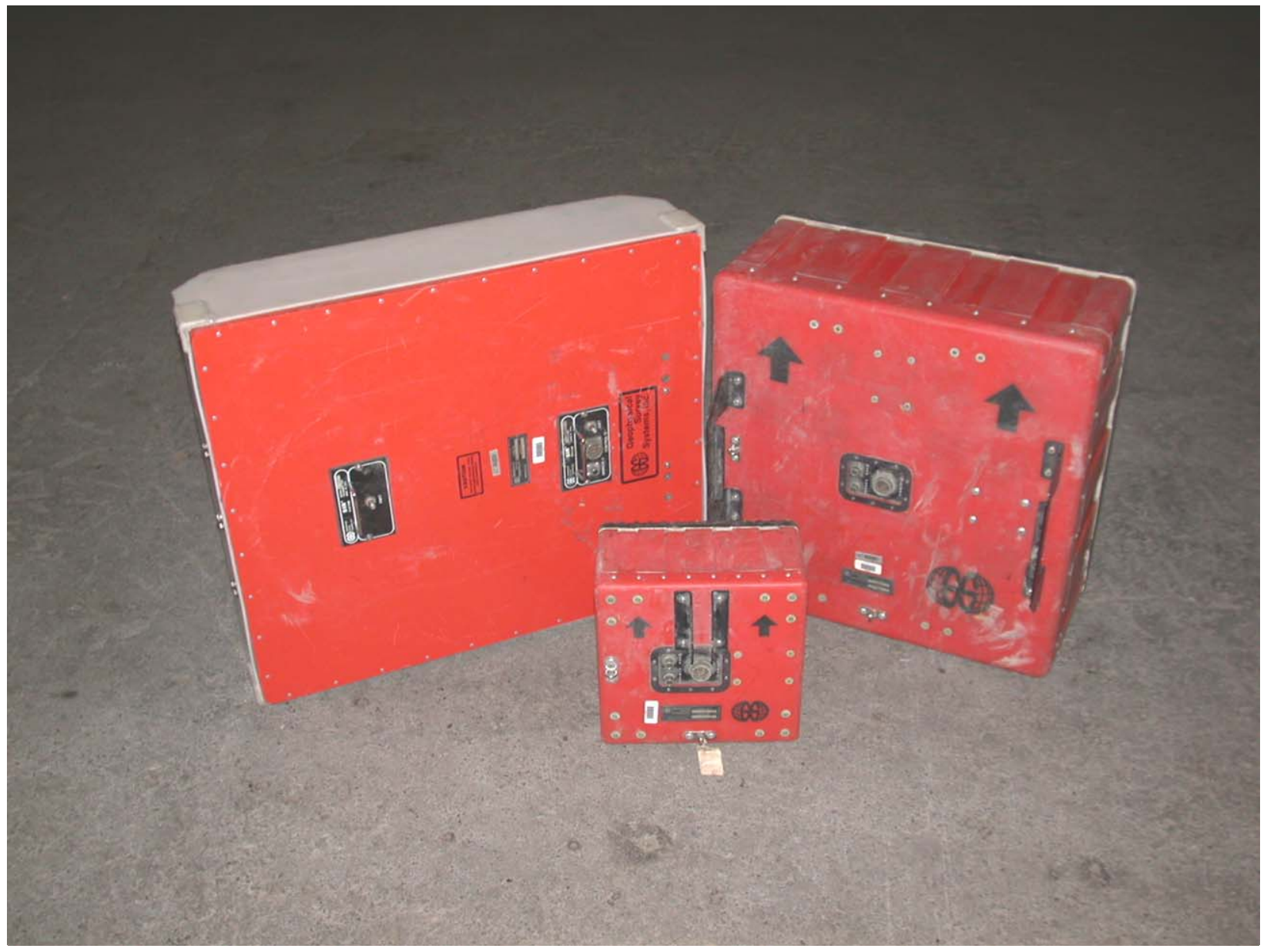

Figure C-1 300 - (antenna size 27 in by 31 in), 200 - (antenna size 24 in by 24 in) and 400 - (antenna size 12 in by 12 in) MHz antennas 


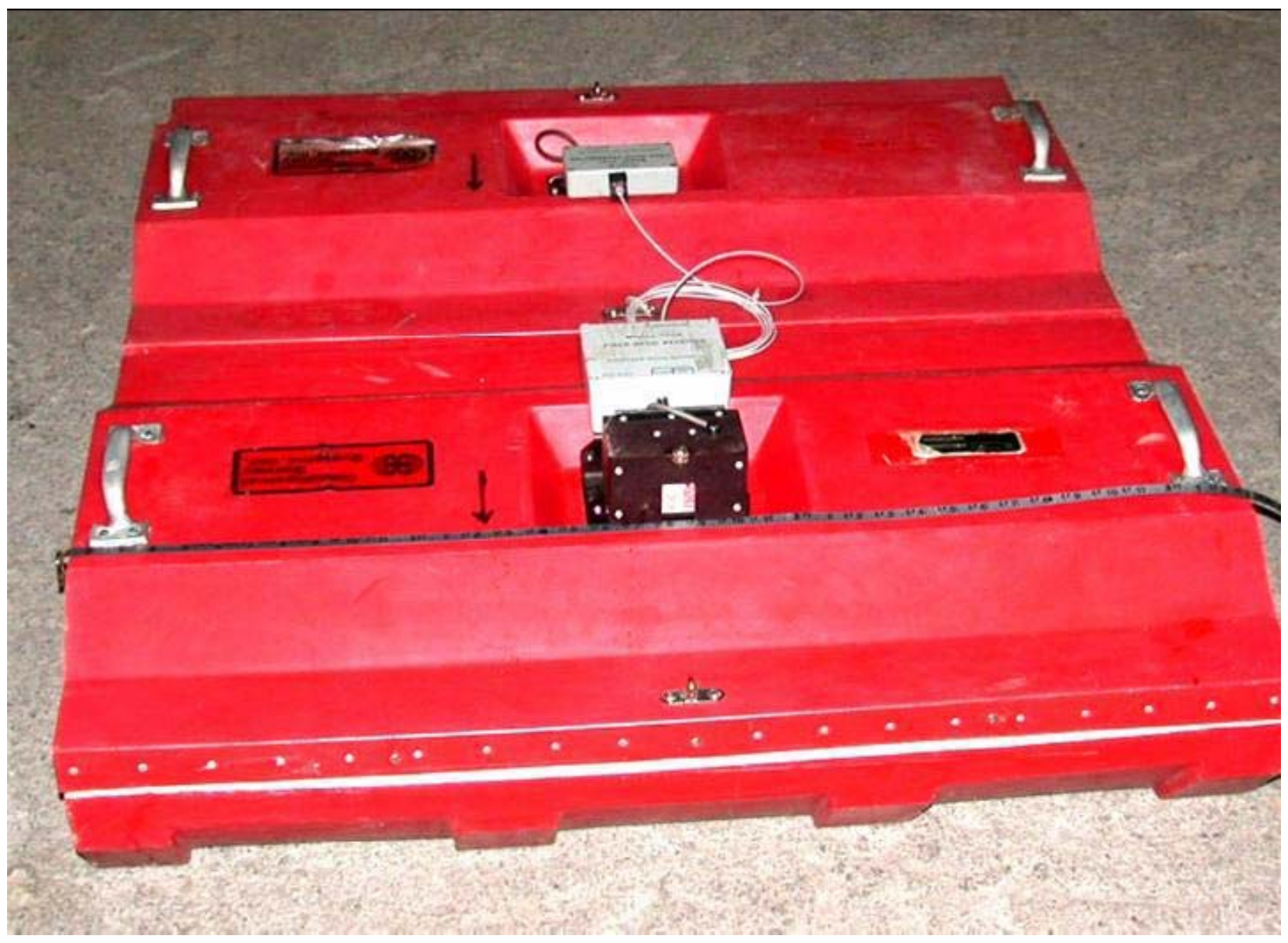

Figure C-2 100-MHz antenna (as configured antenna size 33 in by 44 in). 


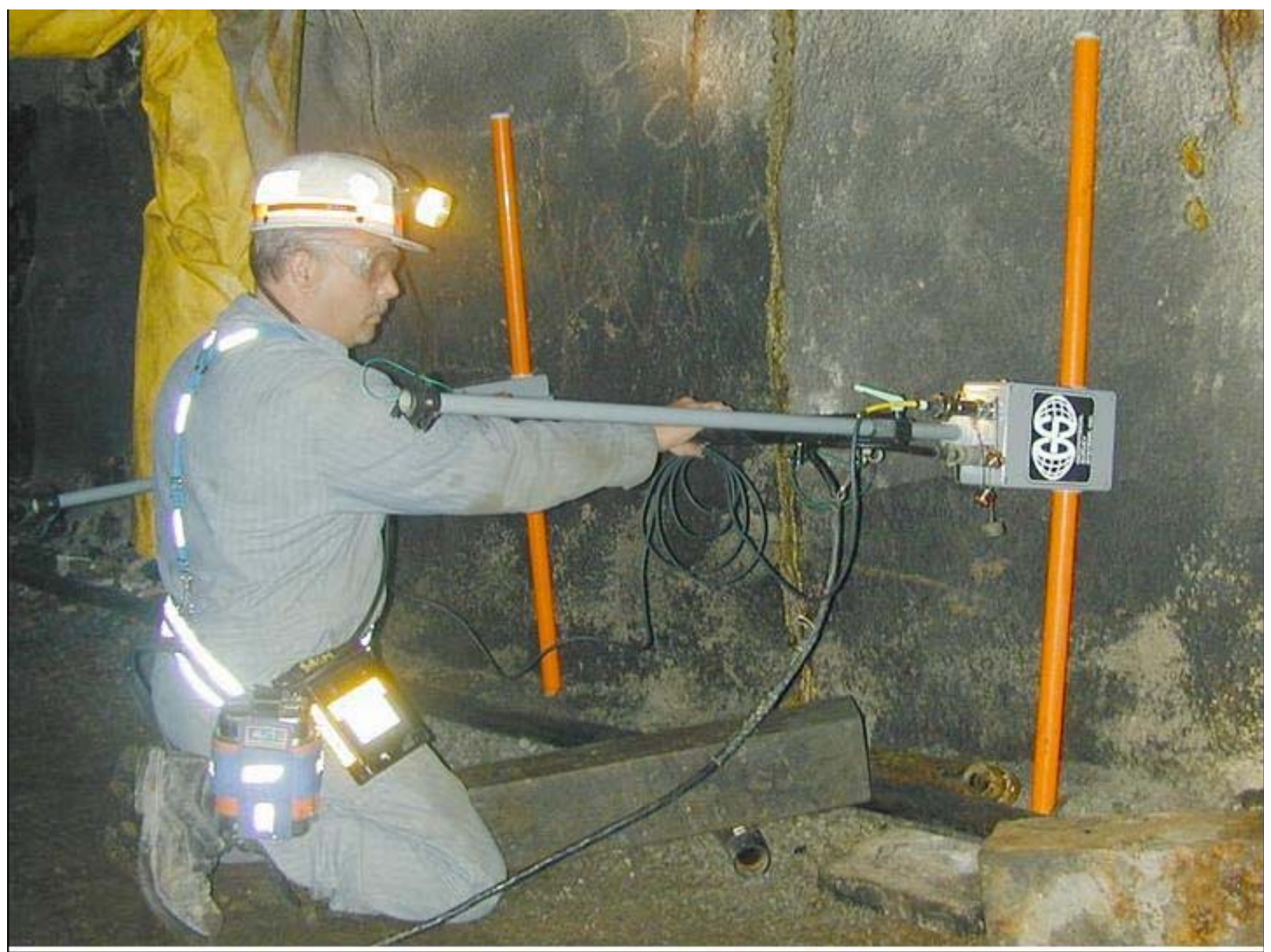

Figure C-3 80-MHz antenna 


\section{CURRICULUM VITAE}

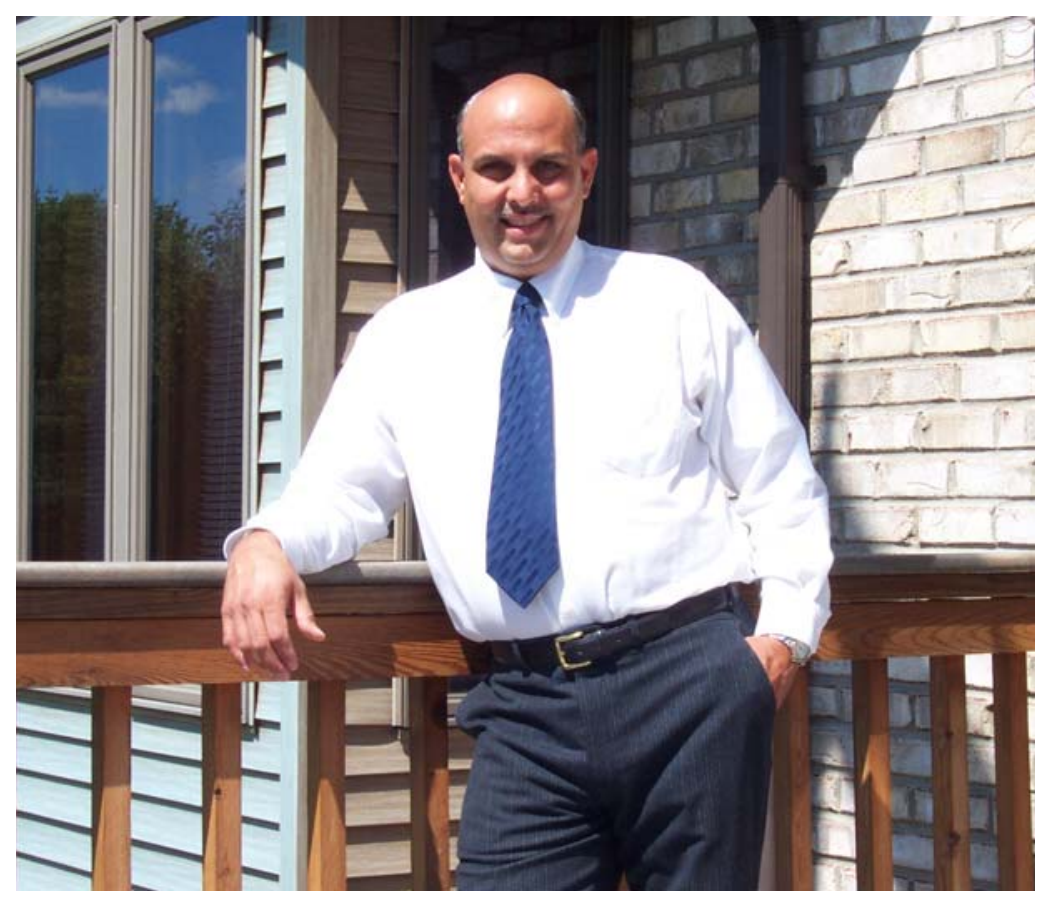

William D. Monaghan was born on December 16, 1961, in McKeesport, Pennsylvania, USA. He is the son of Patrick David Monaghan and Grace Antionette Monaghan and has a brother Patrick James Monaghan. He obtained a Bachelor of Science in Electrical Engineering in 1984 from The Pennsylvania State University

After graduation, he worked from 1984 - 1987, at Westinghouse Defense and Electronic Center, in Baltimore, Maryland. His primary duties included: design, debug and integration of sophisticated electromagnetic equipment.

In 1987, he transferred to Westinghouse Transportation System Inc. Pittsburgh, Pennsylvania. From the 1987 - 1990, he served as an Electronic Design Engineer designing analog/digital control printed circuit boards, automatic test equipment and customer training. He received his first patent, "Online Processor Based Diagnostic System” while working for Westinghouse Transportation System Inc.

In 1990, he accepted a position as Research Electrical Engineer with the U.S. Bureau of Mines (USBM) in Pittsburgh, Pennsylvania, at the Pittsburgh Research Laboratory. In 1996, he transferred to the National Institute for Occupational Safety and Health (NIOSH). His primary research duties include: fire prevention, ground penetrating radar, teleoperated control systems, proximity detection systems, and infrared detection. He received his second patent, "A Method and Apparatus for Monitoring Coal Rib Thickness on a Highwall Mining Operation" while working for the USBM. 